Carlos Alberto de Mattos Scaramuzza

\title{
Flora e ecologia dos campos de Itararé, São Paulo, Brasil.
}

São Paulo

2006 


\title{
Carlos Alberto de Mattos Scaramuzza
}

\section{Flora e ecologia dos campos de Itararé, São Paulo, Brasil.}

\author{
Versão revisada
}

Tese apresentada ao Instituto de Biociências da Universidade de São Paulo, para obtenção de Título de Doutor em Ciências, na Área de Ecologia.

Orientador: Prof. Dr. Waldir Mantovani

São Paulo

2006 
Scaramuzza, Carlos Alberto de Mattos

Flora e ecologia dos campos de Itararé, São

Paulo, Brasil.

Número de páginas: 153

Tese (Doutorado) - Instituto de Biociências da Universidade de São Paulo. Departamento de Ecologia.

1. Ecologia de vegetação - estatística multivariada 2. Fitogeografia 3. Campo de planalto I. Universidade de São Paulo. Instituto de Biociências. Departamento de Ecologia.

\section{Comissão Julgadora:}

Profa. Dra. Vânia R. Pivello

Dr. Ricardo J. F. Garcia
Dr. Alexandre C. Coutinho

Dr. Eduardo P. C. Gomes

Prof. Dr. Waldir Mantovani

Orientador 
A Solange, Maria Amália e Alberto Hélio 
Transmutação das formas e suas mudanças e movimentos em signos imóveis: escritura; dissipação dos signos: leitura. Pela escritura abolimos as coisas, as convertemos em sentido e, quase imediatamente, o dissipamos: o sentido volta à massa primordial. $\mathrm{O}$ arvoredo não tem nome e estas árvores não são signos: são árvores. São reais e são ilegíveis. Ainda que me refira a elas quando digo: estas árvores são ilegíveis, elas não podem ser aludidas. Não dizem, não significam: estão ali, apenas estão. Eu posso derrubá-las, queimá-las, cortá-las, convertê-las em mastros, cadeiras, barcos, casas, cinzas; posso pintá-las, esculpi-las, descrevê-las, convertê-las em símbolos disto ou daquilo (inclusive delas mesmas) e fazer com que elas um outro arvoredo, real ou imaginário; posso classificá-las, analisálas, reduzi-las a uma fórmula química ou a uma proporção matemática e, assim, traduzi-las, convertê-las em linguagem - mas estas árvores, estas que assinalo e que estão além, sempre além, de seus signos e de minhas palavras, intocáveis inalcançáveis impenetráveis, são o que são e nenhum nome, nenhuma combinação de signos pode dizêlas. E são irrepitíveis: nunca voltarão a ser o que são agora.

Octavio Paz. O Mono Gramático. Rio de Janeiro, Guanabara, 1974. cap. 18 


\section{Agradecimentos}

Não teria concluído, mesmo com todas as suas limitações, esta tese sem o auxílio inestimável de muitos professores, funcionários, colegas, instituições, amigos e familiares aos quais agradeço profundamente, destacando, entre outros:

- ao Dr. Waldir Mantovani pelo apoio constante à consecução desta tese;

- aos Drs. Vinícius C. Souza, Eduardo P. Cabral Gomes e Luiz E. Mantovani, pelo inestimável apoio e principalmente pela amizade;

- a Ms. Mônica Takako Shimabukuro, por seu apoio crucial em diversas fases dessa tese;

- a Dra Rosa Lemos de Sá, Dr. Gilberto F. Xavier, Ms. Sidney T. Rodrigues, Ekena R. Pinagé e ao WWF-Brasil por seu apoio irrestrito à conclusão deste trabalho;

- aos taxonomistas pelo inestimável apoio: Drs. Adriano Bida, Alan Sciamarelli, Alexandre Salino, Ana M. Giullietti, Angela B. Martins, D. C. Zappi, Eneida Martins, Fábio A. Vitta, Fábio de Barros, Fatima R. Salimena-Pires, G. P. Lewis, Genise V. Sommer, Gerlene L. Esteves, Hermogenes F. Leitão-Filho, in memorian, Hilda M. Longui-Wagner, Ilse I. Boldrini, Inez Cordeiro, Ingrid Koch, Jefferson Prado, João L. A. Moreira, João R. Stehmann, João Semir, José F. M. Valls, José R. Pirani, Julie Dutill, Kikyo Yamomoto, Lara P. Di Lazzari, Les Landrum, Lucia Rossi, Lynn G. Clark, M. Alice Correia, M. Candida H. Mamede, M. das Graças L. Wanderley, M. de Carmo Amaral, M. Lucia Kawasaki, Maria Luiza Kinoshita, Marie Sugiyama, Nadia Chukr, Paulo T. Sano, R. M. Harley, Regina C. de Oliveira, Renato Goldemberg, Renato Mello e Silva, Rosangela Simão-Bianchinni, Sandra Atkins, Sigrid L. JungMendaçolli, Sonja de C. Boechat, Taciana Cavalcanti, Tania R. S. Silva, Tarciso S. Filgueiras, Tatiana Sendulsky e Volker Bittrich;

- a Ms. Alessandra Fidelis, Denise Sasaki e Mariana R. Fantinati e aos Drs. Abel Conceição, Alexandre C. Coutinho, Alexandre Ulhmann, Cássia B. R. Munhoz, Cássia M. Sakuragui, D.C. Zappi, Evaristo E. de Miranda, Jean P. W. Metzger, Jean F. Duranton, Marcos A. Batalha, Mariko Meguro, Marisa D. B. Pereira, Michel Godron; Michel Lecoq, Ricardo B. Machado, Ricardo J. F. Garcia, Sérgio T. Meirelles, Vânia Pivello, Valério de P. Pillar pelas valiosas contribuições e orientações em diferentes momentos desse projeto;

- a André Gurgel, Bruna G. Fina, Fernando F. Paternost, Glauco Rolim, Jean Gigault, Juliana de P. Souza, Liliana C. Marino, Larissa Ferraro, Márcia S. F. Carneiro, Marcos R. Rosa, M. Angela M. Amparo, Marina Deur, Moacir A. Cornetti e Paulo H. Miyagui cuja colaboração em diferentes fases tornaram esse projeto possível;

- à Carlos Lima, Jefferson Camargo, M. Luiza Cortes-Cavazzotti, Dr. Armando Pettinelli Jr., Dr. Valdir J. Ramos, João B. de Oliveira, Elzira D. de Lima, José F. Ferreira (Zé Flora), Sebastião F. Lima, pelo suporte logístico nas etapas de campo;

- ao CNPq-MCT e à CAPES pela concessão de bolsa de pós-graduação e apoio financeiro e à EMBRAPA Monitoramento por Satélite, Depto de Biologia da ESALQUSP, PETROBRAS, Faz. Sta Maria do Espinho e Saco Grande, Instituto Agronômico IAC-SA-SP, Instituto de Botânica-SMA-SP, Instituto Florestal-SMA-SP, Prefeitura de Itararé, Pisa, Ripasa e Suzano, por apoios diversos ao longo desse projeto;

- à Maria Amália, Alberto Hélio e Solange, colaboradores em diversas etapas deste projeto e sobremaneira por serem sempre uma Família; 


\section{Índice}

$\begin{array}{ll}\text { Introdução geral } & 1\end{array}$

Capítulo 1. Cartografia morfopedológica e de ocupação das terras como subsídio à avaliação ecológica: o caso dos campos do planalto em Itararé, SP.

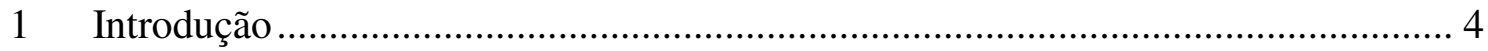

1.1 Abordagem morfopedológica ............................................................... 5

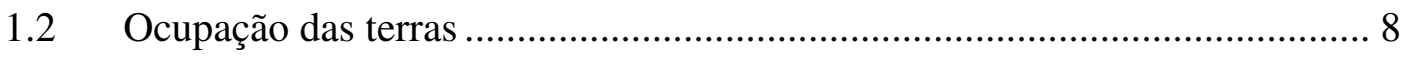

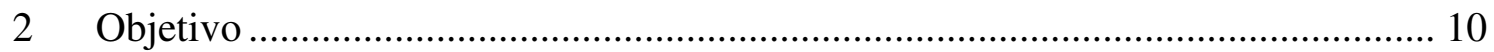

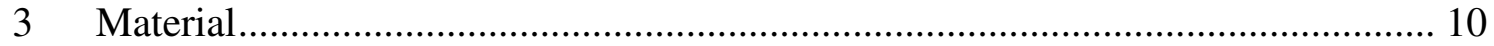

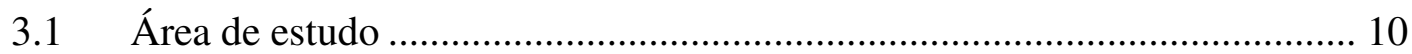

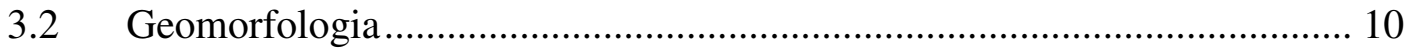

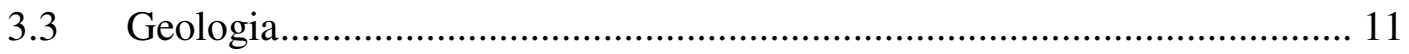

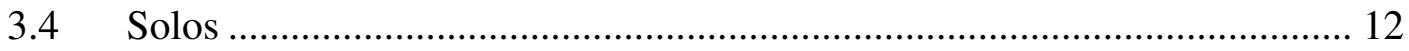

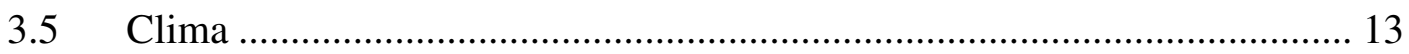

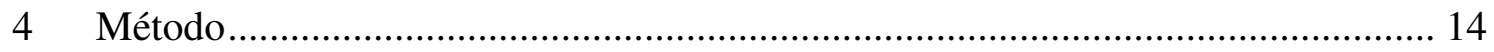

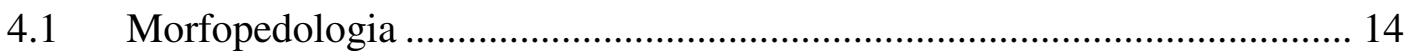

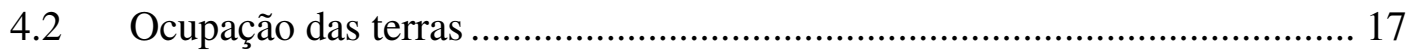

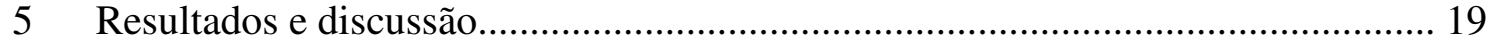

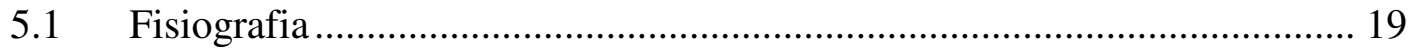

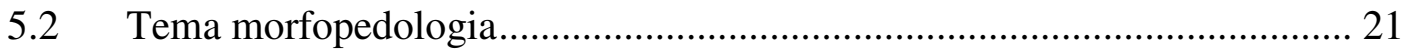

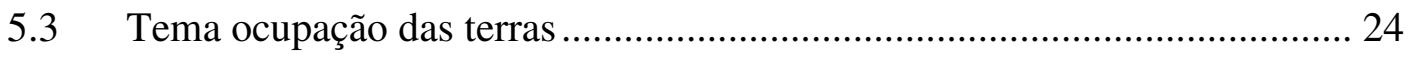

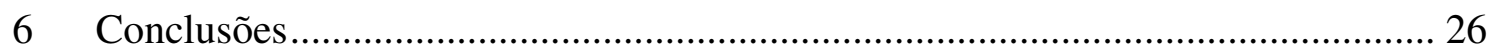

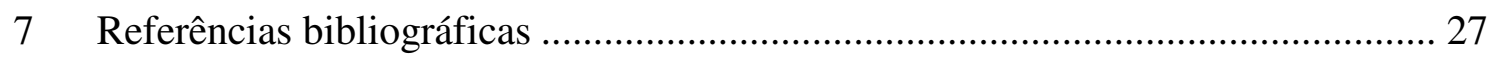

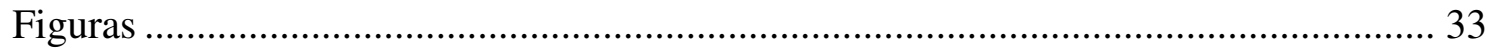

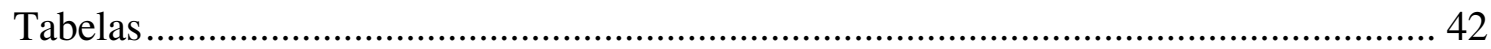

Capítulo 2. Análise florística e fitogeográfica dos campos de Itararé, SP.

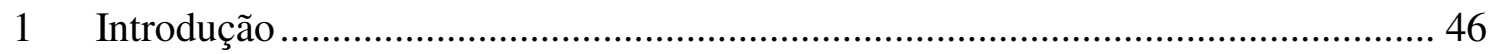

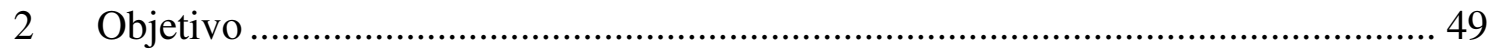

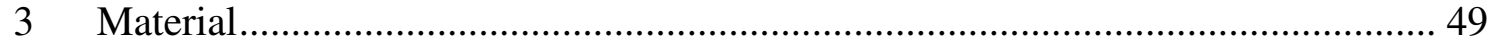

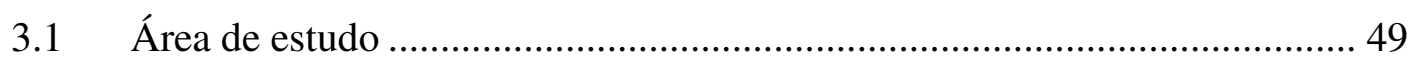

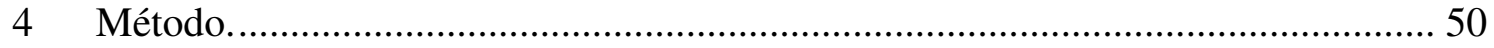

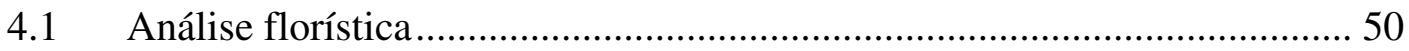

4.2 Análise fitogeográfica ............................................................... 51

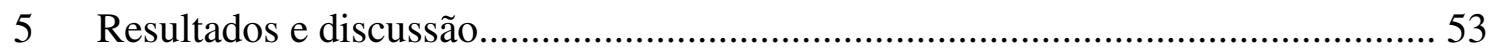

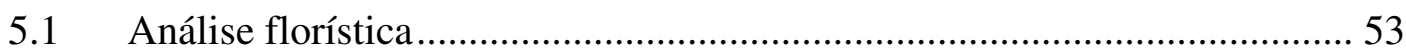




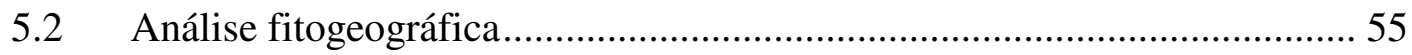

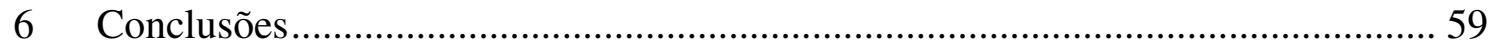

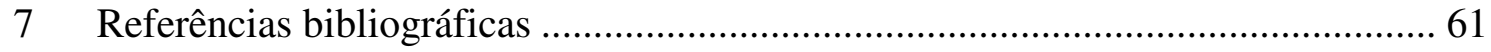

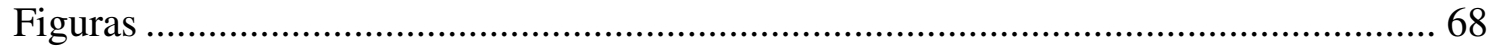

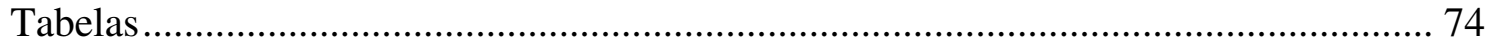

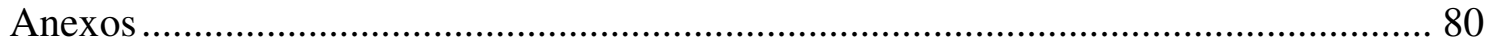

Capítulo 3. Estrutura dos campos e suas relações com o ambiente em Itararé, SP.

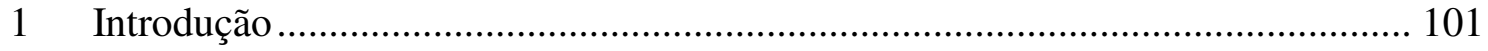

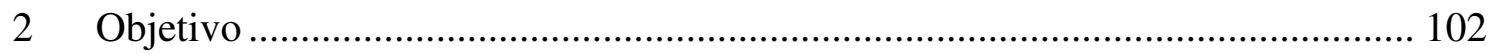

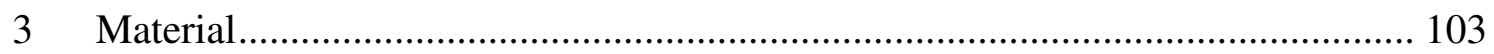

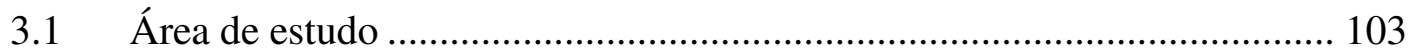

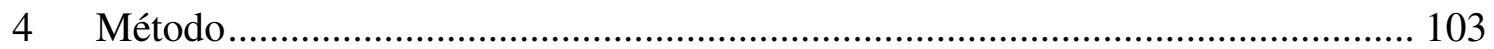

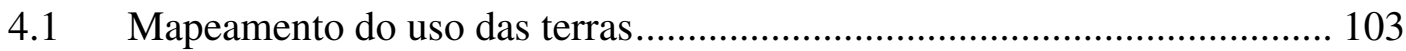

4.2 Plano de amostragem e campanha de levantamento..................................... 103

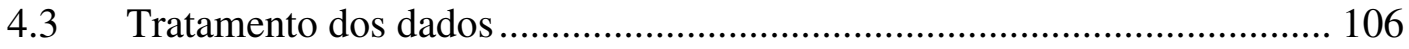

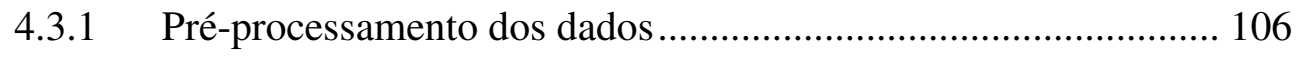

4.3.2 Análise exploratória............................................................................. 108

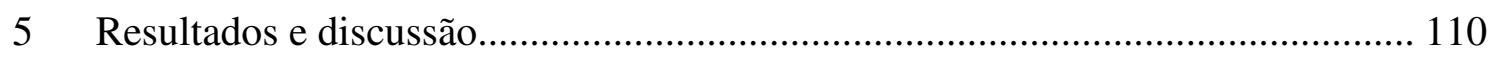

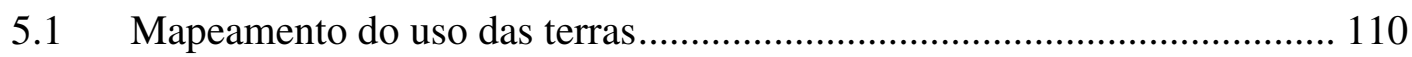

5.2 Seleção de caracteres e descritores ............................................................ 111

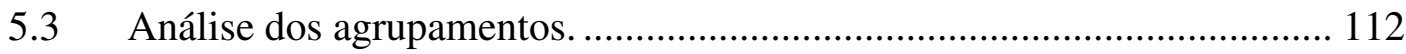

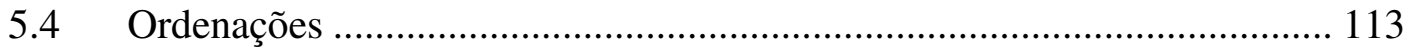

5.4.1 Quadro 115 ..................................................................... 113

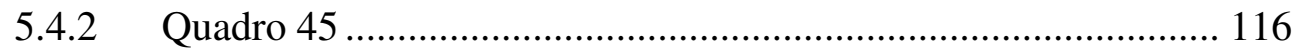

5.5 Composição e estrutura da comunidade ………………………………..... 117

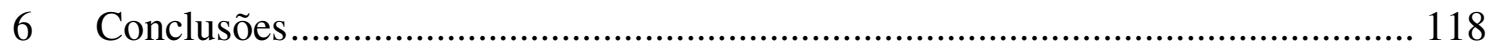

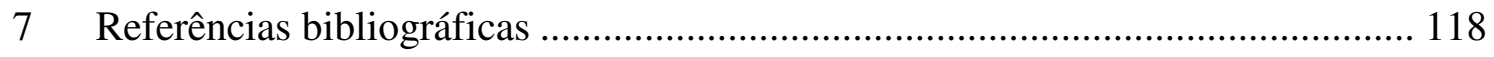

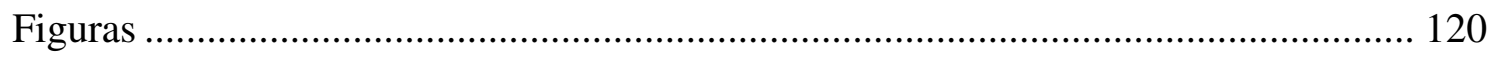

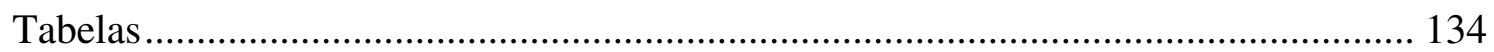

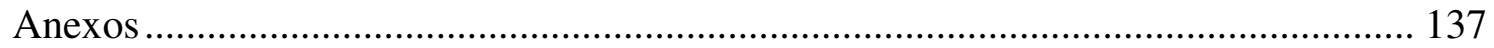

$\begin{array}{ll}\text { Conclusões gerais } & 152\end{array}$ 


\section{Introdução geral}

A estimativa disponível sobre o estado atual de conservação dos campos na região sul do Brasil indica uma conversão de cerca de $25 \%$ de fisionomias campestres em áreas agrícolas apenas no estado do Rio Grande do Sul (RS) entre 1970 e 1996 (Brasil 1996), representado uma diminuição de 14 para 10.5 milhões de hectares. Extrapolando-se a mesma taxa de conversão para o período entre 1996 e 2005, o valor total de área de campo perdida no RS atingiria 4.7 milhões de ha ${ }^{1}$ (Pillar 2006).

A política científica e de conservação não tem conferido a atenção adequada aos campos subtropicais úmidos (Brasil 2000 e Pillar 2006). Um dos indicativos dessa situação é a sua baixa representatividade no sistema de unidades de conservação brasileiro, bem como a ausência de áreas protegidas de grandes dimensões. Uma análise de lacunas de conservação (Grooves 2003) considerando apenas as unidades de conservação de proteção integral e de uso sustentável federais indica que o domínio campo sulino, agora oficialmente denominado bioma pampa (Brasil 2004a), tinha apenas $1.6 \%$ de sua área protegida em 2003 (Brasil 2004b). No caso específico do Rio Grande do Sul, área principal de ocorrência do domínio no Brasil, as unidades de conservação corresponderiam a apenas $0.36 \%$ dos campos (Pillar 2006).

Uma análise de lacunas para os campos da região sul do Brasil em um nível de análise mais detalhado foi executada para aferir a representatividade da proteção à biodiversidade dos campos. Considerando-se um único objeto de conservação (12 classes fitoecológicas do mapa de vegetação do Brasil, escala 1:5.000.000 - Brasil 1993) e uma meta de conservação padronizada de $25 \%$ da área original de cobertura, a análise (Tabela 1) indica um baixíssimo nível de proteção desses tipos de campos no sistema de unidades de conservação federal e estadual da região sul. Nenhum dos doze objetos de conservação atinge a meta de conservação sendo que 3 são lacunas parciais e 9 estão completamente desprotegidos (zero ou menor que $1 \%$ ). A situação ainda é mais crítica do ponto de vista das categorias das unidades de conservação onde nenhum tipo de campo tem ao menos $1 \%$ de sua área protegida. Também destaca-se a contribuição praticamente nula dos sistemas

\footnotetext{
${ }^{1}$ Essas estimativas em breve serão validadas com a divulgação do mapeamento dos remanescentes dos domínios brasileiros em 2002, coordenado pelo Projeto de Conservação e Utilização Sustentável da Diversidade Biológica Brasileira (PROBIO-MMA). Entretanto cabe a ressalva da dificuldade de distinção entre os campos e pastagens cultivadas na escala desse mapeamento.
} 
estaduais de unidades de conservação para a representação dos campos.

Tabela 1. Nível de proteção dos 12 objetos de conservação selecionados para a análise de lacunas do sistema de unidades de conservação da região sul do Brasil.

\begin{tabular}{|c|c|c|c|c|c|c|c|c|c|c|}
\hline \multirow[b]{3}{*}{ Classe vegetacional } & \multirow[b]{3}{*}{$\begin{array}{c}\text { Área } \\
\text { (ha) }\end{array}$} & \multicolumn{8}{|c|}{ Categoria } & \multirow{3}{*}{$\begin{array}{c}\text { Área } \\
\text { protegida } \\
\text { total }(\%)\end{array}$} \\
\hline & & \multicolumn{4}{|c|}{ Protecão Integral } & \multicolumn{4}{|c|}{ Uso Sustentável } & \\
\hline & & $\begin{array}{c}\text { Federal } \\
\text { (ha) }\end{array}$ & $\%$ & $\begin{array}{l}\text { Estadual } \\
\text { (ha) }\end{array}$ & $\%$ & $\begin{array}{c}\text { Federal } \\
\text { (ha) }\end{array}$ & $\%$ & $\begin{array}{l}\text { Estadual } \\
\text { (ha) }\end{array}$ & $\%$ & \\
\hline $\begin{array}{l}\text { Contato Estepe- } \\
\text { Floresta Estacional }\end{array}$ & 1.067 .262 & 237 & 0.0 & 5.051 & 0.5 & 0 & 0.0 & 0 & 0.0 & 0.5 \\
\hline $\begin{array}{l}\text { Contato Savana- } \\
\text { Floresta Estacional }\end{array}$ & 31.359 & 0 & 0.0 & 0 & 0.0 & 0 & 0.0 & 0 & 0.0 & 0.0 \\
\hline $\begin{array}{l}\text { Contatos Savana- } \\
\text { Floresta Ombrófila } \\
\text { Mista }\end{array}$ & 794.167 & 155 & 0.0 & 225 & 0.0 & 0 & 0.0 & 39 & 0.0 & 0.1 \\
\hline Estepe Arborizada & 585.120 & 108 & 0.0 & 0 & 0.0 & 0 & 0.0 & 0 & 0.0 & 0.0 \\
\hline $\begin{array}{l}\text { Estepe Atividades } \\
\text { Agrícolas }\end{array}$ & 3.270 .770 & 1.538 & 0.0 & 1.724 & 0.1 & 98 & 0.0 & 0 & 0.0 & 0.1 \\
\hline $\begin{array}{l}\text { Estepe Gramíneo- } \\
\text { lenhosa }\end{array}$ & 9.737 .593 & 47.001 & 0.5 & 11.334 & 0.1 & 124.705 & 1.3 & 33.088 & 0.3 & 2.2 \\
\hline Estepe Parque & 1.436 .185 & 220 & 0.0 & 0 & 0.0 & 0 & 0.0 & 0 & 0.0 & 0.0 \\
\hline $\begin{array}{l}\text { Savana Atividades } \\
\text { Agrícolas }\end{array}$ & 267.663 & 0 & 0.0 & 0 & 0.0 & 0 & 0.0 & 0 & 0.0 & 0.0 \\
\hline $\begin{array}{l}\text { Savana Estépica } \\
\text { Parque }\end{array}$ & 73.685 & 0 & 0.0 & 0 & 0.0 & 2.765 & 3.8 & 0 & 0.0 & 3.8 \\
\hline $\begin{array}{l}\text { Savana Estépica } \\
\text { Atividades Agrícolas }\end{array}$ & 168.350 & 0 & 0.0 & 0 & 0.0 & 0 & 0.0 & 0 & 0.0 & 0.0 \\
\hline $\begin{array}{l}\text { Savana Estépica } \\
\text { Gramíneo-lenhosa }\end{array}$ & 1.519 .728 & 110 & 0.0 & 0 & 0.0 & 189.628 & 12.5 & 0 & 0.0 & 12.5 \\
\hline $\begin{array}{l}\text { Savana Gramíneo- } \\
\text { lenhosa }\end{array}$ & 687.867 & 71 & 0.0 & 0 & 0.0 & 0 & 0.0 & 0 & 0.0 & 0.0 \\
\hline Total & 2608.211 & 949.539 & 0.5 & 243.109 & 0.7 & 415.098 & 17.6 & 72.088 & 0.3 & 19.2 \\
\hline
\end{tabular}

Parte deste cenário precário de conservação, os campos da parte sul do município de Itararé, SP, são remanescentes da porção norte dos campos do planalto que outrora recobriam o Arco de Ponta Grossa até a parte meridional do estado do Paraná. Estas formações tais como diversas outras áreas de campos da região sul do Brasil apresentam condições climáticas e edáficas favoráveis à expansão da floresta ombrófila mista (Pillar 2003). Entretanto este processo de regressão das áreas de campos tem sido estabilizado pela ação do fogo primeiro como possível uso em caçadas por indígenas e depois nos últimos séculos como prática sistemática para renovação de pastagens nativas (Pillar \& Quadros 1997). A implementação de florestamentos em diversas áreas de campo ao longo do Arco de Ponta Grossa e a consequiente eliminação dessa prática tem causado impactos nos campos como a invasão de pínus e mudanças em sua fisionomia. A questão do fogo como um distúrbio ecológico com influência sobre o padrão de distribuição atual dos campos é 
particularmente importante em termos da gestão das unidades de conservação.

Esta tese lida com um duplo problema. Em uma das faces examina os remanescentes de campos em Itararé, localizados em uma região muito interessante ecologicamente dada a sua elevada riqueza de espécies e a sua diversidade de fisionomias vegetais. Sua orientação é contribuir para elucidar as seguintes indagações: quais e como são os campos da região de Itararé? Quais as variáveis ecológicas responsáveis pela composição florística destas comunidades? Na outra face, procura fornecer elementos para subsidiar ações de conservação dos campos do planalto em São Paulo e no Paraná.

Esse documento está estruturado no formato de três artigos em versões expandidas em relação as que vão ser submetidas a publicação:

Cap. 1. Cartografia morfopedológica e de ocupação das terras como subsídio à avaliação ecológica: o caso dos campos do planalto em Itararé, SP.

Cap. 2. Análise florística e fitogeográfica dos campos de Itararé, SP.

Cap. 3. Estrutura dos campos e suas relações com o ambiente em Itararé, SP.

\section{Referências bibliográficas}

BRASIL. Censo Agropecuário de 1985 a 1996. Rio de Janeiro: IBGE, 1996.

BRASIL. Indicadores de desenvolvimento sustentável 2004. Rio de Janeiro: IBGE, 2004b.

BRASIL. Mapa de Biomas do Brasil. Primeira aproximação. Rio de Janeiro: IBGE, 2004a. Escala 1:5.000.000.

BRASIL. Mapa de vegetação do Brasil. Rio de Janeiro: IBGE, 1993. Escala 1:5.000.000.

Brasil. MMA. Avaliação e ações prioritárias para a conservação da biodiversidade da mata atlântica e campos sulinos. Brasília: SBF-MMA, 2000. Relatório técnico.

GROOVES, C.R. Drafting a conservation blueprint. Washington: Island Press, 2003.

PILLAR, V.P. Estado atual e desafios para a conservação dos campos. Porto Alegre: UFRGS, 2006. Relatório de seminário, 27/03/2006.

PILLAR, V.D. Dinâmica da expansão florestal em mosaicos de floresta e campos no sul do Brasil. In: CLAUDINO-SALES, V. (Ed.). Ecossistemas brasileiros: manejo e conservação. Fortaleza: Expressão, 2003. p. 209-216.

PILLAR, V.D.; QUADROS, F.L.F. Grassland-forest boundaries in southern Brazil. Coenoses, Gorizia, v. 12, p. 119-126, 1997. 


\title{
Capítulo 1. Cartografia morfopedológica e de ocupação das terras como subsídio à avaliação ecológica: o caso dos campos do planalto em Itararé, SP.
}

\begin{abstract}
RESUMO - (Cartografia morfopedológica e de ocupação das terras como subsídio à avaliação ecológica: o caso dos campos de planalto em Itararé, SP). Duas abordagens cartográficas pouco utilizadas no Brasil, morfopedológica e de ocupação das terras, foram aplicadas como parte de um projeto de análise florística, fitogeográfica, ecológica e de conservação dos remanescentes de campos de planalto, na porção sul do município de Itararé, São Paulo (escala 1:50.000). As duas abordagens traduzem em termos ecológicos a paisagem. A carta morfopedológica mapeia unidades cuja evolução, estrutura e problemática sejam correlacionadas, correspondendo a interações específicas entre o material, o modelado, a morfogênese e a pedogênese sob condições climáticas precisas; a carta de ocupação das terras mapeia uma combinação entre as formações vegetais e a influência humana em um território. Ambas as abordagens têm um potencial pouco explorado na gestão da paisagem e no ordenamento territorial no Brasil.
\end{abstract}

Palavras-chave: geoprocessamento, mapeamento, ecologia da paisagem, classificação ambiental, ordenamento territorial

\begin{abstract}
Morphopedologic and land occupation maps supporting ecological evaluation: the case of Itararé's grasslands, SP). Two cartographic approaches little used in Brazil, morphopedologic and land occupation, have been applied as part of a project to analyze the flora, phytogeography, ecology and conservation of grassland fragments of the southern portion of the Itararé county in São Paulo State. Both approaches translate the landscape in ecological terms. The morphopedologic theme maps units whose evolution, structure and problematic are correlated, corresponding to specific interactions between the material, the relief, morphogenesis and pedogenesis under precise climatic conditions. The land occupation theme maps the combination between the plant formations and the human influence in a territory. Both approaches have a potential little explored in landscape management and in land zoning in Brazil.
\end{abstract}

Key words: GIS, mapping, landscape ecology, environmental classification, land zoning

\section{Introdução}

O Zoneamento Ecológico-Econômico (ZEE) tem sido adotado como uma estratégia importante para o ordenamento territorial no Brasil (Brasil 2006a). O objetivo desse instrumento político e técnico de planejamento é promover políticas públicas para otimizar o uso do espaço territorial. Aplicado em diversos estados brasileiros, o ZEE tem sido muito difundido na região Amazônica (Prette \& Matteo 2006), com destaque para o Programa de ZEE da Amazônia Legal (PZEEAL) estabelecido pelo Governo Federal em 1991; e para sua participação no Sub-Programa dos Recursos Naturais SPRN do "Programa Piloto para a Conservação das Florestas Tropicais do Brasil" (PPG7), uma grande iniciativa de cooperação internacional para conservação da Amazônia (Brasil 2006b).

Apesar da existência de variações nos ZEE executados para cada estado, há uma forte influência do método padrão proposto inicialmente por Becker \& Egler (1996) e 
consolidado por Brasil (2001). Um dos componentes básicos do procedimento técnicooperacional é um diagnóstico do meio físico e biótico cujos resultados são usualmente consolidados em dois grupos de cartas temáticas sinópticas: classificação de ecossistemas (sistemas ambientais) e de vulnerabilidade ambiental (fragilidade potencial). Particularmente a avaliação de vulnerabilidade à erosão através da álgebra de mapas (Crepani et al, 2001) passou a ser muito difundida e utilizada como um dos critérios básicos para indicação de áreas potenciais prioritárias para recuperação, preservação e uso (Becker \& Egler 1996, Pereira \& Valério Filho 2001, Palmeira et al 2005).

O debate sobre a eficiência do ZEE tem sido muito focalizado em seus aspectos estruturais e sócio-políticos (Mahar \& Ducrot 1998, Mahar 2000, Nitsch 2002, Fearnside 2003). Um tema promissor para enriquecê-lo é a diversificação de técnicas e modelos empregados nos seus procedimentos operacionais (Spörl \& Ross 2004), no sentido de ampliar sua capacidade de suporte ao processo de tomada de decisão dos gestores ambientais e incorporar de forma mais consistente o planejamento da conservação da biodiversidade (Scaramuzza et al. 2006).

Dois métodos com potencial para contribuir para o aperfeiçoamento técnico dos ZEE no Brasil e da avaliação ecológica de um território de modo geral são a cartografia morfopedológica (Kilian 1972) e de ocupação das terras (Long 1974), apresentadas a seguir.

\subsection{Abordagem morfopedológica}

A abordagem morfopedológica (Tricart \& Kilian 1979, Tricart \& KiewietdeJonge 1992, Tricart 1994) é um método cartográfico temático capaz de sintetizar os aspectos fisiográficos e seu dinamismo, que tem sido utilizada esporadicamente no Brasil (Motti \& Motti 1975, Mantovani \& Riché 1982, Mantovani et al. 1983, Mantovani et al. 1991, Oliveira 1995).

A evolução do meio físico resulta de múltiplas interações entre suas variáveis (clima, solo, relevo, água e material) ocorrendo simultaneamente no tempo e no espaço (Tricart 1973, 1974, 1976 e 1977). Elucidar esse processo requer a adoção de uma abordagem sistêmica (Tricart 1979) capaz de evidenciar não só as diferenças na distribuição espacial dos componentes físicos, mas também a variação temporal do meio, em termos de sua estabilidade e instabilidade. Essa avaliação da estabilidade consiste em esclarecer as relações de causa e efeito entre a pedogênese e a morfogênese, processos indissociáveis (Kilian 1981). 
Uma unidade morfopedológica é definida como uma área de um território cuja evolução, estrutura e problemática sejam comuns. Estes espaços correspondem a interações específicas entre o material, o modelado, a morfogênese e a pedogênese, todas desenvolvidas ou desenvolvendo-se sob condições climáticas precisas (Kilian 1974).

Uma primeira característica da abordagem morfopedológica é percorrer uma trajetória, partindo de um nível de complexidade geral até enquadrar o particular. Em cada escala são reunidos e comparados componentes ambientais, naturais e interativos, sempre com a perspectiva de se inferir um diagnóstico da fisiografia de uma dada região (Kilian 1981).

Como segunda característica, a carta morfopedológica estabelece uma compreensão sobre o meio físico em seu aspecto descritivo e dinâmico através da análise e agregação dos seus fatores mais permanentes. Conseqüentemente, setores do território dotados de uma estrutura, evolução e problemas comuns são definidos pelas interações específicas entre relevo, material, ação hidrográfica, morfogênese e pedogênese, desenvolvidas ou desenvolvendo-se sob condições climáticas bem precisas. Essas unidades morfopedológicas expressam sistemas naturais relativamente homogêneos pela síntese dos múltiplos parâmetros envolvidos, de modo que é possível obter uma qualificação do espaço físico de uma região sintetizando as informações disponíveis. Esta síntese é apresentada sob a forma de uma legenda matricial e hierarquizada, cuja própria concepção permite relacionar as unidades mapeadas, dispostas nas linhas, com a sua descrição fisiográfica, sua situação atual e suas possibilidades de manejo, apresentadas sob a forma de colunas sucessivas (Tricart \& Kilian 1979).

A concepção dessa legenda matricial permite um uso múltiplo no ordenamento territorial subsidiando o planejamento não só de atividades rurais, como urbanização, infra-estruturas diversas, turismo e conservação de biodiversidade. Nesse caso as colunas mais detalhadas sobre o balanço pedogênese-morfogênese, tipos de pedogênese e classificações dos solos são substituídos por indicações sumárias, dando lugar a parâmetros mais adequados ao propósito do mapeamento como balanço e regime hídricos, mecânica dos solos e das rochas, etc.

Do ponto de vista geológico, os aspectos a serem considerados no mapeamento morfopedológico não são a estratigrafia ou a cronologia, e sim, a litologia e o arcabouço estrutural. A litologia aqui deve ser entendida não apenas como o substrato rochoso 
consolidado e litificado, mas também como qualquer rocha superficial servindo como material parental para o solo e meio de ação da morfogênese.

As propriedades físicas e químicas das rochas condicionam o tipo e a taxa do processo de intemperismo, o padrão morfogenético e pedogenético. Aspectos como textura, consistência, permeabilidade e fraturas são importantes na medida em que afetam a penetração das raízes, o regime e balanço hídrico, ou seja, o ambiente ecodinâmico. Podem ocorrer importantes diferenciações entre o intemperismo em profundidade, essencialmente de ordem química, e o próximo da superfície, onde as diferenciações que marcam a evolução pedogenética são bastante influenciadas por processos biológicos. Em termos cartográficos, essa possível disjunção espacial do intemperismo implica no princípio de que se a formação superficial está sob transformação, o mapeamento deve considerar a natureza e a tendência do processo de intemperismo (Tricart 1994).

Do ponto de vista da geomorfologia, o parâmetro importante é usar as informações sobre a geometria da terra para identificar as feições do relevo dominantes no território ou aquelas com uma participação efetiva nos processos ecodinâmicos. Desse modo evita-se simplesmente sobrepor o mapa geomorfológico sobre o pedológico, criando um cruzamento desprovido de informações adequadas para caracterizar as interações entre os elementos da paisagem. Basicamente, a morfogênese é considerada neste tipo de abordagem segundo dois componentes básicos: 1. o grau de topoestabilidade e sua influência sobre: a pedogênese, o equilíbrio morfogenético e pedogenético; 2. os processos do relevo com implicações na pedogênese tanto em termos da sua natureza quanto de sua intensidade (Tricart 1985).

Por fim, do ponto de vista pedológico, a perspectiva adotada no mapeamento morfopedológico não é a da classificação dos solos e sim a pedogenética. O principal objetivo é a identificação dos mecanismos pedogenéticos e a análise de seus efeitos sobre a dinâmica de uma porção do território. Desse modo o interesse recai sobre as transformações dos solos, sua cronologia e os efeitos das oscilações climáticas, levandose em conta a estrutura definida pela litologia e as interações com os processos genéticos do relevo (Tricart 1994).

Uma outra possível aplicação da abordagem morfopedológica é em estudos sinecológicos. Uma das formas para se compreender as relações entre variáveis ambientais e os padrões de distribuição espacial das espécies e das comunidades biológicas é delinear um plano de amostragem estratificado aleatório (Frontier 1983), 
capaz de orientar os levantamentos de campo de modo a captar a diversidade ambiental existente. Por sua característica sinóptica dos aspectos estruturais e dinâmicos do meio físico, o tema morfopedologia é um dos possíveis critérios de estratificação da paisagem (capítulo 3), orientando a formulação e a consecução de um plano de amostragem ao delimitar porções do território relativamente homogêneas, passíveis de serem avaliadas por um programa de coleta de dados ecológicos.

O sucesso quanto à aceitação dos produtos cartográficos originados pelo método morfopedológico, por diversos especialistas e técnicos voltados para temas ambientais, talvez encontre sua explicação nos seguintes fatos:

a) hierarquização dos sistemas partindo de compartimentos mais abrangentes, muitos deles facilmente reconhecíveis de forma genérica por não especialistas, até suas unidades subordinadas; cada unidade incluiria normalmente uma associação de solos representante da evolução pedoclimática, partindo de determinados tipos de material parental, em um determinado contexto morfológico e hídrico;

b) cada unidade representa um subsistema interligado aos condicionantes físicos primários da dinâmica ambiental, isto é, 1. um conjunto de exposições do terreno em face da entrada de energia solar, 2. um conjunto reflectância / emissividade da superfície, 3. o sistema de relevo que sob a ação do campo gravitacional terrestre controla a circulação de água e de materiais no solo e subsolo; e 4. o microclima local próprio de cada unidade que entre outros fatores modula as variações de umidade no solo e na atmosfera próxima à superfície;

c) um determinado padrão de terreno que associado aos adjacentes se traduz por condicionantes não só ao deslocamento de elementos biológicos relativos à fauna e flora, mas também de pessoas, veículos e cargas; facilitando ou não fluxos ao longo de corredores naturais ou artificiais.

\subsection{Ocupação das terras}

A segunda carta temática sintética apresentada por este trabalho é de ocupação das terras (Long 1974 e 1978). De natureza fisionômica, esse método cartográfico desenvolvido pelo "Centre d'Études Phytosociologiques et Ecologiques Louis Emberger" (Montpellier - França) retrata os seguintes elementos: a estrutura global da vegetação, as espécies dominantes e a ação antrópica sobre a vegetação e o meio físico (Miranda 1980).

Trata-se de um método não só orientado para inventariar os principais elementos da paisagem presentes em uma região, mas também compreender os padrões de 
ocupação de um território. De modo geral, pode-se dizer que o tema da ocupação das terras integra os temas da cobertura e do uso dos solos com uma análise das condições de uso dos recursos e do espaço pelo homem, permitindo que na maioria das vezes as classes de uso das terras possam ser generalizadas a partir das classes de ocupação das terras.

Desse modo, essa carta fitogeográfica aborda os aspectos dominantes do ambiente, englobando a vegetação espontânea e os usos antrópicos, incluindo infraestrutura urbana, rede viária e corpos d' água. Todos os constituintes da paisagem em um dado momento são representados através do conceito formas de vegetação, isto é unidades sintéticas de vegetação definidas essencialmente por sua estrutura (formações vegetais) e pela composição florística das espécies dominantes.

O impacto da ocupação humana sobre a estrutura da vegetação e a composição florística da unidade mapeada são classificados através do grau de artificialização, um indicador do peso relativo da pressão humana sobre os sistemas ecológicos em um dado território, sem avaliar a priori a qualidade do ambiente (Long 1978). Trata-se de uma apreciação qualitativa dos efeitos sobre a vegetação dos sistemas de cultivo e de produção agrossilvipastoris.

A repartição dos povoamentos vegetais naturais ou artificiais é expressa através da distribuição da: 1. vegetação atual (tipos de vegetais dominantes, estratos, recobrimento e espécies dominantes); 2. formas de vegetação antrópica (formação vegetal e grau de artificialização) e 3. uso das terras. Apesar de inicialmente concebida para uma representação cartográfica em escala grande (1:5.000 a 1:10.000), também pode ser aplicada em escalas médias e pequenas (Long 1974).

O mapeamento da ocupação das terras é mais complexo que o do uso das terras, pois além da interpretação dos padrões de distribuição nos dados remotos (fotos aéreas e imagens orbitais) requer um estudo de campo para uma identificação precisa das espécies dominantes e caracterização dos graus de artificialização.

O tema da ocupação das terras também pode ser utilizado na preparação de planos de amostragem estratificada aleatória para dados ecológicos. Sua aplicação pode dar-se como um critério de estratificação único ou de forma articulada com outros temas, nos casos em que for necessário discriminar áreas com um padrão de ocupação homogêneo dentro da cada unidade de mapeamento. Nessa situação uma das possibilidades é a interseção com o tema morfopedologia. 


\section{Objetivo}

Testar dois métodos cartográficos pouco utilizados no Brasil na região de Itararé, SP, como parte de um projeto para identificar e caracterizar os principais tipos de campos de planalto e suas relações com fatores ecológicos (Capítulo 2 e 3).

\section{Material}

\section{1 Área de estudo}

A flora e a ecologia dos campos de planalto na porção sul do município de Itararé, sudoeste do estado de São Paulo, Brasil (Figura 1), têm sido objeto de estudo por quase 20 anos (Miranda et al. 1988, capítulos 2 e 3). As suas áreas naturais, relativamente preservadas, apresentam um importante relicto de campos de planalto que outrora recobriam a região correspondente ao denominado Arco de Ponta Grossa, que marca as bordas da bacia sedimentar do Paraná em seu contato com os maciços cristalinos costeiros a leste. Esta paisagem dos campos de planalto se estende desde o extremo sul do estado de São Paulo até a parte meridional do estado do Paraná em um espectro diverso de situações fitoecológicas, climáticas e fisiográficas.

O limite da área de estudo (Figura 1) foi definido pela presença desses campos e seus gradientes para campos-cerrados e cerrados entre a sede da Fazenda Ibiti, ao sul da área urbana de Itararé, até a localidade de Ventania, vizinha da Estação Experimental do Instituto Agronômico (IAC), junto à divisa municipal sul, com Bom Sucesso de Itararé. A área mapeada (32.697 ha) é cortada pelo rio das Três Barras e outros afluentes menores do rio Itararé (limite interestadual confrontando com o município de Sengés, PR) e pelo rio Verde e seus tributários, todos pertencentes à bacia do Paranapanema.

\subsection{Geomorfologia}

Inserida no Planalto da Zona do Paranapanema, a região de Itararé caracteriza-se, do ponto de vista geomorfológico, como uma região plano-ondulada com colinas paralelas, morros alongados, encostas com baixa declividade, vales abertos, drenagem paralela, sentido preferencial NW e gradientes regionais acentuados da ordem de 20 a $25 \mathrm{~m} / \mathrm{km}$ (IPT 1981). O limite do Planalto corresponde ao contato entre as rochas sedimentares da Bacia Sedimentar do Paraná com as graníticas e metamórfitos do Planalto Cristalino Ocidental, freqüentemente sob a forma de feições ruiniformes. Essas 
escarpas $^{1}$ alcantiladas, formadas por rochas da Formação Furnas, apresentam um desnível de 200 m na região de Itararé. Sua gênese fortemente influenciada por efeitos tectônicos está associada ao sentido de sul para norte dos rios Jaguaricatu, Itararé e Pirituba partindo do Cristalino e penetrando o relevo sedimentar através de cânions e vales encaixados (IPT 1981).

\subsection{Geologia}

As rochas sedimentares predominam na região de Itararé e pertencem à Formação Furnas e à Formação Itararé, pertencentes respectivamente ao período Devoniano e ao Carbonífero Superior a Permiano Médio (vide coluna litoestratigráfica simplificada na Tabela 1).

Os arenitos, conglomerados basais e níveis de argilitos da Formação Furnas formam a base da seqüência sedimentar paleozóica na região, superpondo-se por discordância angular erosiva com o Planalto Cristalino, com o qual se limitam ao sul sob a forma de uma escarpa com desnível de $200 \mathrm{~m}$. O fraturamento e aparente dobramento local dessas rochas estão relacionados provavelmente com seu posicionamento sobre rochas calcárias do Grupo Açungui, susceptíveis às dissoluções. O conseqüente rebaixamento das camadas superpostas explicaria a presença de algumas dolinas, depressões semi-fechadas, restritas, aplainadas e parcialmente inundadas na porção sul da área de estudo (Brasil 1972; Francisconi 1980).

Com uma distribuição mais ampla, os arenitos, diacmititos, folhelhos e siltitos da Formação Itararé caracterizam-se em termos de sedimentação pela estratificação cruzada, tal qual a formação Furnas subjacente, porém, ao contrário desta, quase não afloram. A presença de um complexo de diversas litofácies sedimentares nessa formação, sucedendo-se rapidamente, tanto vertical quanto horizontalmente, relacionase provavelmente com a presença tanto de colinas com vertentes suavemente onduladas como dissecadas e ravinadas, entremeando-se com zonas quase planas no dorso dos interflúvios (Brasil 1972; Francisconi 1980).

Encaixados nos sedimentos da Formação Furnas e da Formação Itararé estão presentes intrusões de rochas básicas com origem no magmatismo fissural do Mesozóico. Esses diques e "sills" diabásicos (micrograbros) estão orientados para NW e

\footnotetext{
${ }^{1}$ Essa mesma feição geomorfológica é usualmente denominada Escarpa Devoniana no Paraná devido à idade da Formação Furnas, porém seu surgimento em termos geomorfológicos é muito mais recente (Quaternário, menos de 1,6 Ma, até o Neogeno Superior, até $10 \mathrm{Ma}$ ).
} 
são responsáveis por feições alongadas do relevo local (Brasil 1972; Francisconi 1980).

\subsection{Solos}

A fertilidade natural dos solos da região sul do município de Itararé é muito baixa e não há reservas minerais nas suas frações grosseiras, em razão do material de origem ser constituído por rochas sedimentares pobres em termos geoquímicos. A única exceção são faixas alongadas e estreitas de algumas dezenas de metros de solos formados sobre os diques de microgabro, um substrato muito mais rico (Rizzo \& Marinho 1986).

Em termos da paisagem, os solos argilosos e vermelhos ocorrem preferencialmente nas cristas, topos alongados e vertentes de declive suave. Trata-se predominantemente de Latossolo Vermelho Escuro - LVE - álico textura argilosa e horizonte A moderado ou proeminente, associados aos argilitos e siltitos da Formação Itararé. A heterogeneidade dessa unidade LVE com tonalidades mais acinzentadas e amareladas está relacionada com a influência da circulação de água nas áreas mais ravinadas ou onde as colinas passam a ser mais onduladas e densamente drenadas. Há também a presença de um caráter ligeiramente mais arenoso em determinados locais, possivelmente associado à influência subjacente do arenito Furnas (Rizzo \& Marinho 1986).

Os latossolos vermelho-amarelo (LVA) com A moderado ou proeminente e textura média estão associados às vertentes convexas ao logo dos vales dos riachos tributários dos rios principais como o Verde e o Itararé (Figura 1). A influência da Formação Furnas é nítida nessas feições, com a presença de horizontes B/C com material arenoso em processo de alteração. De um modo geral a transição entre LVE e LVA ocorre de forma difusa, sendo marcada pelos atributos de cor e granulometria (Rizzo \& Marinho 1986).

Ao longo de vertentes convexas, seguindo por riachos encaixados sobre o afloramento do arenito, as camadas de um arenito mais fino da Formação Furnas afloram, dando origem a um complexo de solos rasos com profundidade efetiva de 15 a $100 \mathrm{~cm}$ (Cambissolo + Neossolo álico, ambos com textura média e A moderado). Em algumas situações de meia encosta, quando as vertentes são côncavas, soma-se a esse complexo Gleissolos Háplicos Tb Distróficos e Melânicos Distróficos, com textura média devido à acumulação de água. A transição para os solos rasos não hidromórficos é gradual no sentido longitudinal da drenagem (Rizzo \& Marinho 1986).

As áreas de baixada nos fundos de vale em "U" aberto são cobertas por Gleissolos 
Melânicos Alumínicos, com textura média ou argilosa, em razão do escoamento lento e da conseqüente acumulação de água e matéria orgânica, explicada pela impermeabilidade do arenito e pelas vertentes suaves (Rizzo \& Marinho 1986).

Entre as cotas 1.100 e $1.150 \mathrm{~m}$, a cimeira do relevo suave-ondulado da Estação Experimental do Instituto Agronômico (IAC - vide Figura 1), situada na parte sul da área de estudo, é recoberta por Cambissolos com argila de atividade baixa, álicos, com A proeminente, argiloso a muito argiloso, em alguns casos húmico, e Latossolos com A úmbrico e espesso (Oliveira et al. 1976). O aumento dos teores de óxido de ferro e carbono em profundidade em todos os perfis desses solos sugere a ação de um processo de podzolização moderado, característico de áreas elevadas do sul do Brasil. Ainda associado aos topos e ao terço superior das vertentes, constatou-se a presença de Neossolos Distróficos com A úmico, proeminente sobre laterita, de nodular a lamelar em profundidade, intercalada com bolsões de areia. Os solos hidromórficos ocupam as porções inferiores das vertentes e fundos de vale, perfazendo $40 \%$ dos 495 ha da propriedade do IAC.

\subsection{Clima}

Conforme a classificação de Köeppen, a parte mais baixa da área de estudo próximo à área urbana corresponde a um clima subtropical $\mathrm{Cfa}$ - clima mesotérmico, sem estação seca, com verões quentes e com média do mês mais quente superior a 22 ${ }^{\mathrm{O}} \mathrm{C}$, e geadas freqüentes, conforme ilustrado pelo diagrama climático da Fazenda Ibiti (Figura 2). Segundo uma série de dados de 28 anos para essa estação meteorológica, não há estiagem; a média da precipitação anual é $1.313 \mathrm{~mm}$; a média anual de temperatura é $19,5{ }^{\circ} \mathrm{C}$; a temperatura média do mês mais quente $23,3{ }^{\circ} \mathrm{C}$ e a do mais frio $16{ }^{\circ} \mathrm{C}$; a média das máximas diárias do mês mais quente $29,7{ }^{\circ} \mathrm{C}$ e a média das mínimas diárias do mais frio $10,5^{\circ} \mathrm{C}$.

A região da Ventania, parte alta da área de estudo, é mais fria (média anual: 16,9 ${ }^{\mathrm{O}} \mathrm{C}$ ) e mais úmida (1.610 mm anuais), conforme ilustra o diagrama climático da Estação Experimental do IAC (Figura 2), elaborado a partir de uma série de dados de 20 anos. Seu clima corresponde ao tipo $\mathrm{Cfb}$ - clima mesotérmico, úmido e super-úmido, sem estação seca e com verões frescos, pois a temperatura média diária do mês mais quente $20,1{ }^{\mathrm{O}} \mathrm{C}$ está abaixo dos $22{ }^{\circ} \mathrm{C}$. No mês mais frio, a temperatura média diária é $13,6{ }^{\circ} \mathrm{C}$, enquanto que a média das máximas diárias do mês mais quente é $24,5{ }^{\circ} \mathrm{C}$ e a média das mínimas diárias do mês mais frio $8,5^{\circ} \mathrm{C}$

As geadas são severas e mais freqüentes na Ventania do que na parte mais baixa. 
Menos sujeito à influência marítima, o extremo sul de São Paulo, como um todo, apresenta média de ocorrência de geadas durante o ano variando de 5 a 10 dias (Nimer 1989). Evidentemente trata-se de geadas microclimáticas formadas por inversão térmica noturna que se desfazem nas primeiras horas do dia.

\section{$4 \quad$ Método}

Os temas da morfopedologia e da ocupação das terras foram interpretados em escala de semi-detalhe - 1:50.000, sobre 38 pares de fotos aéreas, tipo pancromático, escala 1:35.000, de 19/06/1980 e 26/07/1981 (Terrafoto 1981), utilizando-se um estereoscópio de espelho, com apoio de um mosaico semi-controlado da mesma cobertura aerofotogramétrica.

O conhecimento prévio do território necessário para subsidiar a fotointerpretação, com enfoque na caracterização fisiográfica e da paisagem, foi estabelecido através de etapa de reconhecimento no campo e análise do material cartográfico de apoio disponível. Esses elementos foram organizados em uma análise fisiográfica da porção sul de Itararé, SP.

A fotointerpretação de ambos os temas baseou-se na análise dos nove elementos fundamentais (Teng 1997), que podem ser agrupados em três conjuntos: A. tonalidade; B. geometria dos objetos - tamanho, forma, altura, sombra, arranjo espacial - textura e padrão; C. contexto dos objetos - associação, contexto e dinâmica temporal. A importância de cada elemento na delimitação dos polígonos foi diferenciada conforme o tema, com destaque para a tonalidade, geometria dos objetos na morfopedologia, arranjo espacial para a morfopedologia e a tonalidade, forma e padrão dos objetos para a ocupação das terras.

As unidades mapeadas foram verificadas em campanhas de campo, onde foram realizadas coletas de amostras de solo e documentação fotográfica. Após a incorporação dos aperfeiçoamentos identificados em campo, um esboço da carta morfopedológica e da de ocupação das terras foi gerado via restituição fotogramétrica. Nessa etapa a posição correta das imagens fotográficas sobre uma carta base foi estabelecida através do uso de epidiascópio e estereoplotador, corrigindo as distorções inerentes à cobertura aerofotogramética e gerando um mapa com a escala homogênea (Marchetti \& Garcia 1988).

\subsection{Morfopedologia}

O mapeamento da morfopedologia baseia-se no método desenvolvido por Kilian 
(1972) e adotado pelo "Institut de Recherches Agronomiques Tropicales" (IRAT 1981) cujo principal objetivo é caracterizar e explicar a dinâmica de um território do ponto de vista fisiográfico, delimitando e caracterizando unidades naturais reconhecíveis, considerando os fatores físicos relevantes de acordo com as especificidades e objetivos de cada mapeamento.

O primeiro passo do mapeamento morfopedológico foi estabelecer uma diagnose morfopedológica através da regionalização de unidades mapeáveis no espaço e no tempo (Tricart \& KiewietdeJonge 1992). Essa etapa é balizada por três fatores básicos: o propósito principal da execução do mapeamento, o tamanho dos objetos e os dados disponíveis.

No caso deste trabalho, o objetivo principal foi avaliar os condicionantes fisiográficos à distribuição da vegetação e utilizar o mapeamento resultante como parte de um plano de amostragem estratificado aleatório para o levantamento de dados em um estudo sinecológico dos campos de planalto em Itararé (capítulo 3). Deste modo, considerando-se o propósito, a escala das fotos aéreas disponíveis para a área de estudo e o tamanho das unidades mapeáveis, pode-se trabalhar com a escala usual dos mapas morfopedológicos: 1:25.000 a 1:50.000.

A identificação de padrões e o delineamento dos polígonos tiveram como uma de suas balizas detectar as diferenças entre as áreas situadas sob os arenitos da Formação Furnas e da Itararé, baseando-se principalmente em aspectos indicativos do controle litológico como descontinuidades e diferenças na densidade e nos padrões geométricos de drenagem ou da presença de áreas de deposição (Way \& Everett 1997). Além disso, foram interpretados os aspectos associados à cobertura de solos como os componentes e a textura da rede hidrográfica, formas de erosão, diferenças de tonalidades e da cobertura vegetal (Belcher 1997).

Outro critério adotado na fotointerpretação foi representar claramente o tipo e a intensidade das interações determinantes da dinâmica fisiográfica das unidades mapeáveis, mantendo um equilíbrio entre a legibilidade do mapa e a relevância da informação. Os dados de apoio utilizados no mapeamento foram os mapas topográficos, escala 1:50.000 (Brasil 1974, 1975 e 1985); mapas geológicos, escala 1:100.000 (Brasil 1981 e Francisconi 1980); mapas pedológicos, escala 1:40.000 (Oliveira et al. 1976 e Rizzo \& Marinho 1986); modelo numérico de terreno, resolução 90 m (SRTM 2003) e mosaicos semicontrolados de radar, escala 1:250.000 (Brasil 1976).

O mapeamento foi sobreposto sobre uma imagem sombreada gerada a partir do 
modelo numérico de terreno (STRM 2003) possibilitando uma visualização sintética da relação das subunidades com o relevo da região.

Depois de finalizada a fotointerpretação, durante a etapa de campo para validação do mapeamento, foi feita uma caracterização edáfica, avaliando a correspondência das unidades com os principais tipos de solo da região. Foram examinados sete perfis, totalizando dezenove estratos para os quais foram coletados amostras de solo. Além dessas, foram realizadas coletas a $25 \mathrm{~cm}$ nos 115 levantamentos fitoecológicos executados como parte de um projeto sobre a ecologia dos campos de Itararé (capítulo 3). Como a localização desses levantamentos obedeceu a um plano de amostragem estratificado aleatório baseado na carta morfopedológica, foi possível reunir amostras para todas as classes morfopedológicas mapeadas. Foram realizadas análises físicas (descrição de atributos e granulométrica) e químicas das amostras de solo recolhidas.

Utilizando-se pequenas caixas de cartolina foi montado um pedocomparador com essas 115 coletas para avaliação qualitativa (Prado 1993), sob a supervisão de um pedólogo experiente, dos seguintes atributos em amostras secas e úmidas: cor, textura, estrutura, consistência, porosidade, plasticidade e pegajosidade. Cada um dos atributos foi descrito segundo um formulário codificado para levantamento de dados (capítulo 3). Depois de um pré-tratamento dos dados coletados, as classes dos descritores para cada atributo foram reorganizadas para adaptar os seus limites ao espectro de variação identificado nas amostras de solo das unidades morfopedológicas.

A análise granulométrica das amostras de solo, através do método do densímetro (EMBRAPA 1999), foi realizada pelo Laboratório de Análise de Solos do Departamento de Ciência do Solo da ESALQ-USP. As seguintes classes de diâmetro (mm) foram avaliadas: I. areia, 5 frações: muito grossa, 2-1; grossa, 1-0,5; média, 0,50,25; fina, 0,25-0,10; muito fina, 0,10-0,05 e total, 2-0,05; II. silte, 0,05-0,002; e III. argila total com dispersante e argila em $\mathrm{H}_{2} 0$, ambas menores que 0,002. Os limites das classes de textura utilizados são: arenosa, até $14 \%$; média-arenosa, 15 a $24 \%$; médiaargilosa, 25 a $34 \%$; argilosa, 35 a $59 \%$; e muito argilosa, $60 \%$ ou superior.

As análises químicas das amostras de solo foram executadas pelo Laboratório de Análise de Solos do Departamento de Ciência do Solo da ESALQ-USP através do método IAC adaptado (Raij et al. 2001). Os seguintes atributos foram estimados: pH (acidez ativa) pelos métodos a. $\mathrm{H}_{2} \mathrm{O}$ deionizado, b. $\mathrm{KCl}(1 \mathrm{~N})$ e c. $\mathrm{CaCl}_{2}$ (0,01 M); matéria orgânica pelo método Walkey-Black (titulometria); fósforo, potássio, cálcio e magnésio pelo método de extração via resina trocadora de íons; alumínio trocável por 
titulometria $(\mathrm{KCl} 1 \mathrm{~N})$; e $\mathrm{H}^{+} \mathrm{Al}$ (acidez potencial) por titulometria (solução de acetato de cálcio $1 \mathrm{~N}$ a $\mathrm{pH} 7,0$ ). A partir desses foram determinados os valores da soma das bases, da capacidade de troca de cátions, saturação por bases e por alumínio (SB, T, V e m).

Utilizando-se o aplicativo Statistica (STATSOFT 2004), a significância das diferenças entre as médias dos atributos físicos qualitativos e dos parâmetros químicos quantitativos nas unidades morfopedológicas mapeadas foi testada através do método de análise de variância (ANOVA - Kutner et al. 2005). Nos casos em que a hipótese nula (igualdade entre as médias) foi rejeitada para um determinado parâmetro, os intervalos de confiança para as diferenças entre todos os pares de médias foram obtidos através do teste post hoc Tukey-Kramer, método adequado para comparações múltiplas entre pares de médias baseadas em amostras de tamanho desigual (Sokal \& Rohlf 1995).

Depois de concluídos o mapeamento e a verificação de campo, a legenda matricial da carta foi elaborada de modo que cada linha corresponda a uma unidade morfopedológica. As primeiras colunas à esquerda dessa tabela, indicam as unidades, sua denominação e seu arranjo taxonômico sob a forma de uma chave de classificação. Em seguida seguem colunas sucessivas dedicadas à descrição das classes sob diversas perspectivas: área, geologia e material de origem, geomorfologia, altimetria, declividade, hidrografia, densidade de drenagem, solos, uso e ocupação das terras.

As médias e os desvios padrões de altimetria e declividade por unidade morfopedológica foram obtidos através de uma estatística zonal (ESRI 2004) entre o plano de informação vetorial das unidades morfopedológicas e o modelo numérico de terreno (STRM 2003) e seu subproduto, o mapa de declividades. A densidade de drenagem foi calculada a partir da divisão da extensão da rede hidrográfica em cada unidade morfopedológica pela sua área. Foi feita uma tabulação cruzada entre mapas temáticos de ocupação das terras e morfopedologia de modo a incluir a ocupação das terras como um dos descritores das unidades morfopedológicas mapeadas.

\subsection{Ocupação das terras}

Os principais tipos de paisagem da área de estudo, na parte sul de Itararé, foram caracterizados segundo os seus tipos de ocupação das terras (Long 1974). Esquematicamente o processo de mapeamento seguiu o seguinte roteiro: 1. seleção do nível de percepção ecológica (setor) e definição da escala (1:50.000); 2. estabelecimento da unidade mínima mapeável; 3. seleção da base cartográfica; 4. definição de tipos de vegetação dominantes; 5. descrição da estrutura vertical (estratificação) e horizontal (elementos e mosaicos) da vegetação; 6. definição das formações vegetais mapeáveis; 7. 
designação de espécies dominantes, entendidas como aquelas que identificam a formação do ponto de vista fisionômico, estrutural e biológico; 8. avaliação do impacto do homem sobre a estrutura das unidades mapeadas através da classificação do grau de artificialização; e 9. definição das formas de vegetação a partir da combinação das formações vegetais mapeadas e o seu grau de artificialização.

A distribuição da vegetação nativa ou antropizada foi fotointerpretada segundo dois critérios básicos: as categorias de vegetais dominantes e a influência humana sobre a biosfera.

Em termos dos vegetais dominantes, as principais características consideradas na fotointerpretação das unidades de mapeamento foram: a estrutura da vegetação e a composição florística das espécies dominantes. A chave de classificação fisionômica das formações vegetais incorporou a estratificação vertical na definição dos três tipos básicos de vegetais dominantes: herbáceos, lenhosos baixos $(<2 \mathrm{~m})$ e altos $(>2 \mathrm{~m})$. Desse modo, estas 3 formações vegetais simples e as suas combinações entre si foram as unidades mapeáveis.

O principal documento de apoio utilizado na fotointerpretação foi o mapa de uso das terras do município de Itararé (escala 1:100.000 - Cavalli \& Miranda 1987) para dirimir as dúvidas sobre a natureza da cobertura vegetal em locais específicos.

Quanto ao segundo critério, Long (1974) propôs uma chave de classificação da intensidade da antropização de uma região com oito graus de artificialização crescentes: nulo, muito fraca, fraca, média, pouco forte, forte, muito forte e extremamente forte. A Tabela 2 descreve essas categorias associando-as com os tipos de uso das terras presentes na região sul de Itararé.

Esses dois critérios se articulam, combinando as formações vegetais com os graus de artificialização para gerar as formas de vegetação. A concepção de legenda da carta de ocupação das terras apresenta essas formas de vegetação definidas por dois eixos, um correspondendo às formações vegetais existentes e o outro, aos graus de artificialização da vegetação. A paleta de cores usualmente segue dois gradientes: um dos tons frios aos quentes, no sentido do aumento da antropização, e o outro dos tons claros para os escuros, conforme o aumento de biomassa das formações vegetais.

A verificação de campo não só indicou as modificações necessárias nos limites das áreas mapeadas, mas colheu subsídios para a conclusão da classificação de cada polígono quanto ao seu grau de artificialização. 


\section{$5 \quad$ Resultados e discussão}

\subsection{Fisiografia}

O município de Itararé situado na extremidade sudoeste do Estado de São Paulo apresenta um condicionamento geomorfológico melhor tipificado no compartimento tecno-estrutural do leste paranaense. Assim é possível distinguir uma situação, que no estado vizinho é denominada de $1^{\circ}$ Planalto Paranaense, a qual é formada por rochas cristalinas de baixo grau de metamorfismo pertencentes ao Grupo Açungui. Esta grande unidade geológica, em grande parte, encontra-se entalhada e dissecada pela rede hidrográfica da bacia do rio Ribeira de Iguape. Em seu conjunto de litologias predominam camadas sucessivas alongadas no sentido SW-NE formadas principalmente por filitos, mármores e quartzitos. Este conjunto litológico de idade neoproterozóica é cortado por alguns stocks e batólitos graníticos de idades situados entre o Neoproterozóico e o Cambro-Ordoviciano.

Vários diques de microgabro (diabásios) de idade entre 131 e 129 Ma, associados ao Arco de Ponta Grossa (Itararé se situa sobre o flanco norte deste arco tectônico Marques \& Ernesto 2004 e Milani 2004) cortam as rochas da região e são comuns no norte do Município como intrusivos nas rochas do Grupo Itararé. Na parte sul de Itararé, as observações de campo indicam que o número destas intrusões está subestimado nos mapeamentos consultados. Assim essas rochas básicas ricas em ferro, cálcio e magnésio têm idades indo do Hautereviano ao Barremiano no Eocretáceo. Sobre as rochas cristalinas se depositaram os estratos sedimentares paleozóicos da Bacia do Paraná. No setor estudado, a Formação Itararé apresenta uma predominância de arenitos com alguns níveis mais argilosos e poucos diamictitos associados. Desta forma ela contrasta pouco em termos litológicos com a Formação Furnas, constituída de camadas de arenitos com estratificação cruzada e poucos estratos argilosos.

A Formação Furnas cuja idade da sua parte basal é atribuída atualmente ao Pridoliano do Neosiluriano teve seu desenvolvimento restante durante o Eodevoniano (Gedinano, Segeniano e Ensiano). Ambas as formações Furnas e Itararé apresentam na região um evidente mergulho para norte que deve ser devido ao arqueamento do Arco de Ponta Grossa.

As implicações geomorfológicas destas estruturas levaram a formação de uma área de cabeceiras situada nos maciços cristalinos ao sul que servem de divisor de águas entre a Bacia do Paranapanema, representada pela bacia do rio Itararé ao norte, e a bacia 
do Ribeira de Iguape ao sul. A dissecação sobre o cristalino é bem maior do que sobre as rochas sedimentares, com as sub-bacias apresentando uma densidade de drenagem elevada, devido a menor permeabilidade média das rochas metamórficas presentes. Paralelamente os solos que delas derivam também têm uma permeabilidade média menor. Em conjunto as águas pluviais que incidem sobre o solo encontram maiores dificuldades para um escoamento subterrâneo favorecendo o escorrimento superficial, levando a maior dissecação por canais de drenagem.

O rio Itararé e seus afluentes, após desenvolverem uma ampla rede hidrográfica sobre os terrenos do planalto cristalino ao sul, conseguem transpor a assim denominada "Escarpa Devoniana" da Formação Furnas através de um entalhe com mais de $200 \mathrm{~m}$ de desnível (Figura 3) entre o topo das escarpas e o fundo talvegue ou entalhe fluvial desse rio. As escarpas situadas no setor de contato entre as rochas cristalinas e sedimentares consistem no limite entre a Bacia Sedimentar do Paraná e o Planalto Cristalino Ocidental em toda a região. A presença dessas escarpas causa um efeito cênico e orográfico na porção mais elevada da área de estudo, aumentando a pluviosidade e a nebulosidade (diagrama climático da Estação Experimental do Instituto Agronômico Figura 2).

Sobre as áreas sedimentares da área de estudo no sul do município, formadas sobretudo por arenitos, a dissecação pluvial é muito menos intensa do que na área do cristalino, apesar da menor resistência mecânica destas rochas, pois o escoamento através dos sistemas aqüíferos é muito mais intenso e eficaz, produzindo inclusive reduzida erosão química do substrato, tendo em vista a estabilidade química dos minerais presentes: quartzo, sesquióxidos de ferro e alumínio e argilas 1:1 da família da caolinita.

Vencido este obstáculo o rio Itararé passa a correr no planalto sedimentar ao norte. Nesse planalto, o setor sul de Itararé apresenta uma imensa rampa pouco acidentada, ou seja, aproximadamente plana e horizontal, e com uma suave e constante inclinação, doravante denominada de "clinoplano" da Ventania. Essa feição singular inicia-se próxima da escarpa em torno dos $1.150 \mathrm{~m}$ de altitude e prossegue no sentido norte até atingir a cota $650 \mathrm{~m}$ (Figura 3), próximo da sede municipal, sempre com um predomínio da exposição leste, oeste e noroeste (Figura 4). A superfície inclinada voltada para norte assume aspecto de verdadeira superfície estrutural, relacionando-se com o mergulho das camadas das formações Furnas e Itararé para NNW, sendo escalonada nos estratos sedimentares de ambas as formações. 
$\mathrm{Na}$ parte mais elevada da superfície inclinada, sobre a Formação Furnas, a drenagem hidrográfica tem maior densidade do que na parte mais baixa sobre a Formação Itararé (Figura 1) e as colinas apresentam-se com topos ligeiramente abaulados e vertentes curtas, não atingindo $100 \mathrm{~m}$, com declividades em sua grande maioria de 0 a 7,5 graus e raramente passando de 11,5 (Figura 5).

Descendo rapidamente no sentido norte, o relevo passa a ser mais movimentado, caracterizando-se por morros alongados com maior amplitude, com valores freqüentes de declividade entre 11,5 e 15,5 graus ou até mesmo maiores, especialmente na parte central da área de estudo (Figura 5). Os entalhes fluviais passam a ser mais encaixados e o padrão de drenagem torna-se menos denso do que na parte mais alta do clinoplano e mais organizado em coletores paralelos, especialmente na porção leste do município próximo da divisa com Itapeva, SP e na oeste próximo da divisa com Sengés, PR.

\subsection{Tema morfopedologia}

Como o balanço da morfogênese e da pedogênese na porção sul de Itararé é caracterizado principalmente por uma grande estabilidade e homogeneidade, o clinoplano da Ventania foi mapeado como uma única unidade morfopedológica, denominada Superfície Inclinada da Ventania, com nove subunidades (Tabela 3 e Figura 6). A posição dessas subunidades na legenda matricial segue sua posição principal no relevo: Espigões inclinados, interflúvios e Altas Vertentes, Vertentes Superiores e Topos, Vertentes Suaves e Fundos de Vale, Bordas da escarpa, Vertentes Ravinadas, Fundos de Vales Afogados, Entalhes Fluviais em V e Entalhes Fluviais Abertos. Essas denominações já indicam as feições de um relevo pouco movimentado, com predomínio de colinas suaves, onde foi impossível mapear tanto os limites entre áreas aplainadas dos topos e a parte superior das vertentes, como os dos fundos de vale com a porção inferior das vertentes.

Os Espigões Inclinados correspondem às situações onde foi possível delimitar claramente os topos das colinas (Figura 7). Essas áreas estão dispostas de forma alongada, com inclinação geral no sentido norte do clinoplano, cobertas por latossolos vermelho escuro e com a segunda menor declividade de todas as subunidades $\left(3,1^{\circ}\right)$.

Os Interflúvios e Altas Vertentes estão localizados na parte norte (Figura 6) e são as subunidades presentes com a maior área no clinoplano (38,9\%). Suas colinas têm uma conformação mais definida associada à morfogênese sobre as rochas mais argilosas da Formação Itararé (Figura 7). Seu posicionamento ao longo do eixo norte sul define um predomínio claro das exposições norte-noroeste e leste-nordeste (Figura 4). 
$\mathrm{Na}$ extremidade oeste do clinoplano e em áreas isoladas na parte leste (Figura 7) estão presentes as Vertentes Ravinadas (12,7\%) caracterizadas por suas colinas amplas e dissecadas com ravinas locais e por suas associações de cambissolos. Essa subunidade apresenta um grande número de capões de mata encaixados em rampas côncavas e uma maior densidade de drenagem $(15,4 \mathrm{~m} / \mathrm{ha})$.

A fisionomia se modifica com a passagem para as Vertentes Superiores e Topos $(12,7 \%$ da área) onde as feições se tornam muito mais suaves, com cambissolos desenvolvidos sobre a Formação Furnas. Essa subunidade junto com as Vertentes Suaves e Fundos de Vale define o relevo muito aplainado (Figura 5 e Figura 7) da parte sul-central do clinoplano. As Vertentes Suaves distinguem-se pela dissecação evidente em seus flancos e por uma das maiores densidades de drenagem $(43,0 \mathrm{~m} / \mathrm{ha})$. Sua drenagem espraiada (Figura 1) forma diversos banhados nos fundos das Estações Experimentais do Instituto Agronômico e do Instituto Florestal. Entre as subunidades Vertentes Superiores e Vertentes Suaves, estão situadas as depressões semi-fechadas dos Fundos de Vale Afogados, a classe mapeada com a menor área (142 ha) e a menor declividade $\left(3,0^{\circ}\right)$ no clinoplano.

Encaixadas nessas colinas com diferentes tipos de vertentes, os Entalhes Fluviais (Figura 7) se diferenciam em duas subunidades: 1. em V - localizados na parte oriental (5\% da área), caracterizados pela maior densidade de drenagem da área mapeada $(46,6$ $\mathrm{m} / \mathrm{ha})$ e por suas encostas curtas; 2. Abertos $(13,1 \%$ da área) dispostos preponderantemente em meio aos Interflúvios e Altas Vertentes na área central e ocidental do clinoplano com encostas côncavas onde se encontram as maiores florestas do clinoplano.

Uma das características interessantes da legenda matricial do mapeamento morfopedológico (Tabela 3) para o seu uso no planejamento territorial é a possibilidade de ser adaptada para outras aplicações através da agregação de outras colunas incluindo descritores, potencialidades, recomendações e restrições de manejo.

As análises dos atributos físicos e químicos das amostras de solos das diferentes subunidades corroboraram a percepção inicial, advinda da fotointerpretação e das etapas de campo, sobre a homogeneidade da cobertura pedológica no clinoplano, reflexo da semelhança litológica dos materiais de origem (arenitos com maior ou menor teor de argila).

Como a análise qualitativa dos atributos físicos tanto nas amostras secas como úmidas, apresentou um padrão semelhante para todos os parâmetros avaliados, 
selecionou-se a coloração para exemplificar o resultado obtido. Classificados segundo o sistema Munsell (1994), todos os matizes determinados dispõem-se em uma seqüência ininterrupta de seis tons, do laranja avermelhado (2,5YR) até o amarelo (5Y), sendo que $80 \%$ das amostras incide nas classes 10YR e 5 Y (Figura 8). A avaliação do valor da cor do solo, correlacionado com o teor de matéria orgânica, também apresentou um resultado semelhante com a predominância das classes tendendo ao preto $(90 \%$ das amostras menores que 5, em uma escala de 0 - preto até 10 - branco). Em termos de cor, o matiz é uma variável mais importante, para a distinção de solos de grupos e origens distintas, do que o valor e croma. A grande conformidade dos matizes e valores indica mais uma diferenciação supergênica a partir de migrações de ferro, processos de hidromorfia e enriquecimento de matéria orgânica.

Os resultados das análises granulométricas e químicas também apresentam pouca diferenciação entre as diferentes subunidades morfopedológicas (amostras dos perfís de solos na Tabela 4 e amostras de solos nas unidades morfopedológicas na Tabela 5), caracterizando-se em geral como ácidos, com caráter álico (saturação de bases baixa e saturação de alumínio elevada), valores de fósforo muito baixos e de matéria orgânica usuais (2 a $3 \%)$.

A análise de variância $(\alpha=0,05)$ indicou a rejeição da hipótese nula de igualdade entre as médias para os seguintes parâmetros $\left(\mathrm{pH}\right.$ em $\left.\mathrm{H}_{2} \mathrm{O}-p=0,022\right)$, acidez potencial $\left(\mathrm{H}^{+} \mathrm{Al}-p=0,013\right)$ e capacidade de troca catiônica $(\mathrm{T}-p=0,016)$. No caso desses três parâmetros, o teste Tukey-Kramer $(\alpha=0,05)$ indicou a presença de diferenças significativas entre o par de médias para $\mathrm{pH}$ em $\mathrm{H}_{2} \mathrm{O}$ entre Vertentes suaves, Fundos de Vale e Entalhes Fluviais Abertos e para os parâmetros acidez potencial e capacidade de troca catiônica entre Vertentes suaves, Fundos de Vale e Borda da Escarpa. De uma forma geral, a igualdade entre as médias para onze dos quatorze parâmetros indica que, do ponto de vista químico, as subunidades de mapeamento englobaram diferentes tipos de solos e associações de solos, sem apresentaram uma correspondência clara com determinados solos, com exceção das Vertentes suaves e Fundos de Vale. Nessa subunidade as médias para o potencial hidrogeniônico, alumínio, acidez potencial e capacidade de troca catiônica, foram as maiores, o que está de acordo com o predomínio da associação de Gleissolos Melânicos Alumínicos. A Borda da Escarpa e o Entalhe Fluvial em V apresentaram o maior potencial nutricional entre as subunidades conforme indicado pelo seu valor de saturação de bases.

A diferença mais significativa parece associada à granulometria dos solos (Tabela 
4), sendo que as classes mais argilosas são encontradas nos terços finais de vertentes próximas a eixos fluviais ou zonas mais deprimidas correspondendo às subunidades morfopedológicas Vertentes suaves e Fundos de Vale e Entalhes Fluviais Abertos.

A relevância da cartografia morfopedológica na avaliação da dinâmica do meio físico está principalmente relacionada com a valorização de um discernimento mais sutil e agudo, onde diferentes parâmetros podem ser integrados para indicar potencialidades e restrições de uso. Desse modo, sua aplicação no diagnóstico do território possibilita: uma integração melhor e de baixo custo entre os dados, recursos e meios disponíveis; uma reflexão mais objetiva sobre a dinâmica da paisagem orientada à solução de problemas de manejo e ordenamento territorial; e identificação de lacunas de

conhecimento para as quais são necessárias ações específicas de pesquisa e desenvolvimento.

\subsection{Tema ocupação das terras}

De um modo geral, associada aos solos profundamente intemperizados, com ausência de minerais instáveis, e ao clima chuvoso e frio, com ocorrência significativa de geadas, a cobertura vegetal pré-cabraliana do clinoplano era dominada pelos campos de planalto em um gradiente de fisionomias mais abertas até mais fechadas. Os campos limpo e sujo com a diminuição da altitude eram gradativamente substituídos por campo cerrado, cerrado stricto sensu e cerrado. Essas formações eram entremeadas por banhados (campos úmidos), capões de floresta subtropical com a presença de Araucaria angustifolia, localizada nas grotas ou em pontos específicos na calha dos riachos na porção mais elevada e por matas ripárias na parte mais baixa da superfície inclinada, onde predominavam os cerrados e matas mais secas.

Saint-Hilaire (1964 e 1976) relatou sua passagem em 1820 pelos campos de São Pedro, como era conhecida naquela época a região entre os rios Verde e Itararé e indicou que eram utilizadas como pastagens naturais. Esse uso persistiu até as últimas décadas do século passado quando porções significativas foram convertidas para florestas comerciais. Por serem áreas originalmente campestres, a implementação dessas plantações de eucalipto e pinheiro tratou-se de um verdadeiro florestamento e não um reflorestamento como usualmente denominado. Como na maior parte dos casos os talhões foram dispostos segundo a aptidão florestal, fragmentos dos campos de planalto foram conservados preferencialmente ao longo dos eixos de drenagem e de áreas com solos rasos.

Os remanescentes presentes nas estações experimentais do Instituto Agronômico 
(IAC) e do Instituto Florestal (IF), no entorno da sede da Fazenda Santa Maria do Espinho (Figura 1), bem como nas áreas das empresas de reflorestamento RIPASA Celulose e Papel (eucalipto) e Norske Skog PISA - Papel para Imprensa (pínus), constituem hábitat para mamíferos de médio porte (incluindo lobo guará e tamanduás) e aves.

No clinoplano da Ventania, a ocupação das terras em 1981 (Figura 9) foi mapeada segundo 14 diferentes formas de vegetação, resultantes da combinação de sete tipos de formações vegetais (1 nula, 2 simples e 4 complexas) com cinco graus de artificialização (Tabela 2). A composição das classes e a sua distribuição espacial caracterizavam um mosaico, dotado de várias formações vegetais nativas com influência humana baixa e diversos tipos de ocupação das terras. A classe preponderante era a forma de vegetação herbácea com grau de artificialização dois $(35,5 \%$ da área total - Tabela 6) que correspondia a pastagens nativas em grandes propriedades nas áreas de campos de planalto, seguida pela forma lenhosa alta com grau de artificialização três (florestamentos de pinheiros - 25,6 \%). Essas duas classes conferiam à paisagem, como um todo, um grau de artificialização baixo, conforme fica patente no predomínio das tonalidades frias no mapa (Figura 9). A área mais artificializada era a parte norte da área mapeada, correspondendo às formas de vegetação herbácea com grau cinco (agricultura intensiva) e rara ou nula (conurbação de Itararé).

Nesses 20 anos, houve uma significativa mudança do padrão de uso das terras na porção sul de Itararé, com substituição da pecuária extensiva pelo florestamento com eucalipto, conforme indicado pelo mapeamento do uso das terras apresentado no capítulo 2. Contudo, essa trajetória não implicou em mudança do parcelamento agrícola, ainda dominado por grandes propriedades, possibilitando que remanescentes da cobertura de campos de planalto e de sua transição para o cerrado ao longo do clinoplano da Ventania fossem preservados $(8.562$ ha $-27 \%$ da área de estudo em 1.990 e 5.766 ha - $18 \%$ em 2005 - capítulo 2), devido às dificuldades de implementação de florestas em solos rasos ou nos banhados.

O tema da ocupação das terras pode-se articular com o da morfopedologia contribuindo para a delimitação das unidades morfopedológicas e para a sua descrição como uma das colunas da legenda matricial da carta morfopedológica (Tabela 3).

O exame da carta de ocupação das terras (Figura 9) indica o seu caráter sinóptico de documento geral de base, de onde pode ser extraída uma série de outras informações, 
com usos específicos, como por exemplo: as espécies dominantes das formações vegetais, a estrutura e diversidade da paisagem, o uso do solo, a influência do homem e o risco de incêndios em função dos tipos de ocupação. Essa multiplicidade de usos potenciais da informação mapeada confere um caráter exaustivo ao tema da ocupação das terras e um grande valor como subsídio ao processo de gestão de um território, segundo a perspectiva da ecologia da paisagem. Nesse sentido esse tipo de mapeamento pode ser entendido como uma representação dos aspectos dominantes do ambiente (Long 1985).

Com a evolução intensa dos recursos do geoprocessamento nas últimas décadas tornou-se viável o estabelecimento de bases de dados georreferenciados sobre o cadastro das propriedades rurais. Uma possibilidade interessante, mas ainda não explorada é a geração de cartas de ocupação das terras no lugar do tema do uso das terras, constituindo um documento sinóptico mais adequado para apoiar iniciativas de ordenamento territorial, como por exemplo, os planos de manejo de unidades de conservação de uso sustentável, especialmente as Áreas de Proteção Ambiental.

\section{Conclusões}

O mapeamento dos temas da ocupação das terras e da morfopedologia mostraram-se adequados para a caracterização fisiográfica e fitoecológica da região de Itararé. A aplicação desses dois métodos isoladamente ou de forma articulada pode constituir-se em instrumentos muito úteis ao planejador, ao urbanista e aos responsáveis por planos de manejo rurais ou peri-urbano, ao fornecer uma visão sintética de baixo custo sobre o meio físico, a cobertura vegetal e a natureza da presença humana em um dado território e subsidiar o processo de tomada de decisão na gestão da paisagem, mesmo sob diferentes prismas (agrícola, expansão urbana ou de infra-estrutura, conservação de biodiversidade, atividades turísticas, etc).

Essas abordagens cartográficas representam apenas duas entre muitas outras ferramentas, técnicas e métodos disponíveis, pouco explorados no Brasil, que podem contribuir para os ZEE superar seus impasses e tornar-se um instrumento de planejamento mais efetivo no ordenamento territorial.

\section{Agradecimentos}

À F.F. Paternost, E. Fritzsons, M. Deur, M.S.F. Carneiro, L.C. Marino. M.T. Shimabukuro, M.A.M. Amparo e S. de M. Scaramuzza pelo apoio em diversas fases desse trabalho. À CAPES e CNPq pelas bolsas de pós-graduação ao primeiro autor. 
ALMEIDA, F.F.M de; MELO, M.S.A. Bacia do Paraná e o vulcanismo Mesozóico. In: ALMEIDA, F.F.M.; HASUI, Y.; PONÇANO, W.L.; DANTAS, A.S.L.; CARNEIRO, C.D.R.; MELO, M.S.; Bistrichi, C.A. (Ed.). Mapa Geológico do Estado de São Paulo. Nota explicativa. São Paulo: Instituto de Pesquisas Tecnológicas do Estado de São Paulo, 1981. v. 1, p. 46-81. Escala 1:500.000.

BECKER, B.K.; EGLER, C.A.G. Detalhamento da Metodologia para Execução do Zoneamento Ecológico-Econômico pelos Estados da Amazônia Legal. Brasília: MMA/SAE, 1996. 40 p.

BELCHER, D.J. Soils. In: PHILIPSON, W.R. Manual of photographic interpretation. 2 ed. Bethesda: American Society for Photogrammetry and Remote Sensing, 1997. p. 167-223.

BRASIL. Carta do Brasil. Rio de Janeiro: IBGE/IGC-SP, 1974. Folhas SF-22-Z-D-IV3 e SF-22-Z-D-IV-4, color. Escala 1:50.000.

BRASIL. Carta do Brasil. Rio de Janeiro: IBGE/IGC-SP, 1975. Folhas SG-22-X-B-I2, -3 e -4, color. Escala 1:50.000.

BRASIL. Carta do Brasil. Rio de Janeiro: IBGE/IGC-SP, 1985. Folhas: SG-22-X-B-I1, MI 2809-1, color.

BRASIL. Diretrizes metodológicas para o zoneamento Ecológico-Econômico do Brasil. Brasília: MMA/SDS, 2001. 106 p.

BRASIL. Mosaico semicontrolado de radar: Projeto RadamBrasil. Brasília: MME/DNPM, 1976. Folha SG22-X-B. Escala 1:250.000.

BRASIL. Programa Piloto para Proteção das Florestas Tropicais do Brasil - PPG-7. In: MINISTÉRIO DO MEIO AMBIENTE. Secretaria de Biodiversidade e Florestas. 2006b. Disponível em $<$ http://www.mma.gov.br/index.php?ido=conteudo.monta\&id $\quad$ Estrutura $=63>$. Acesso em: 13 jun. 2006.

BRASIL. Projeto integração e detalhe geológico no Vale do Ribeira, mapa geológico. São Paulo: CPRM/SUREG-SP/DNPM, 1981. Escala 1:100.000.

BRASIL. Projeto Sudeste do Estado de São Paulo: Relatório Geológico preliminar. Brasília: MME/DNPM, 1972. v. I e II. Folha de Itararé, SG22-X-B. Escala $1: 250.000$.

BRASIL. Zoneamento Ecológico-Econômico. In: MINISTÉRIO DO MEIO 
AMBIENTE. Secretaria de Desenvolvimento Sustentável. 2006a. Disponível em $<$ http://www.mma.gov.br/index.php?ido $=$ conteudo.monta\&idEstrutura $=28>$. Acesso em: 13 jun. 2006.

CAVALLI, A.C.; MIRANDA, E.E. Levantamento do uso das terras do Estado de São Paulo, município de Itararé. São Paulo: Terrafoto/CNPDA-EMBRAPA, 1987. Escala 1: 100.000 .

CREPANI, E.; MEDEIROS, J.S. de; HERNANDEZ, P.; FLORENZANO, T.G.; DUARTE, V.; BARBOSA, C.C.F. Sensoriamento Remoto e Geoprocessamento Aplicados ao Zoneamento Ecológico-Econômico e ao Ordenamento territorial. São José dos Campos: SAE/INPE, 2001. 124 p. INPE-8454-RPQ/722. EMBRAPA - Empresa Brasileira de Pesquisa Agropecuária. Manual de análises químicas de solos, plantas e fertilizantes. Brasília: Embrapa Solos/Embrapa Informática Agropecuária/Embrapa Comunicação para Transferência de Tecnologia, 1999. p. 370.

ESRI. Arcview 9.0. Redlands: ESRI, 2004.

FEARNSIDE, P.M. Conservation policy in Brazilian Amazonia: understanding the dilemmas. World Development, Washington, v. 31, n. 5, p. 757-779, 2003.

FRANCISCONI, O. Projeto integração e detalhe geológico no Vale do Ribeira: Relatório final. São Paulo: CPRM/SUREG/SP, 1980. v. 2, anexo 1. Mapa Geológico, Folha Itararé. Escala 1:100.000.

FRONTIER, S. Stratégies d échantillonnage em écologie. Paris: Masson, 1983. Colletion d'Ecologie, n. 17.

IPT. Mapa geomorfológico do Estado de São Paulo. São Paulo: IPT, 1981. Série Monografias, n. 6.

IRAT. Terres et Cartes. Montpellier: GERDAT/Institut de Recherches Agronomiques Tropicales et des Cultures vivrieres, 1981.

KILIAN, J. Assessment of environmental stability and instability in morphopedological cartography with a view to agricultural development. Switzerland: Institute of Geography/University of Bern, 1981. Trabalho apresentado: Workshop on the stability and instability of mountainous ecosystems, Berna, Switzerland, sep. 1981.

KILIAN, J. Étude du milieu physique en vue de son aménagement. Conceptions de travail. Méthodes cartographiques. Agronomie tropicale, Paris, v. 29, n. 2-3, p. 141-153, 1974. 
KILIAN, J. Les inventaires morphopédologiques. Conceptions, application au dévelopment agricole. Agronomie tropicale, Paris, v. 27, n. 9, p. 930-938, 1972. KUTNER, M.H.; NACHTSHEIM, C.J.; NETER, J.; LI, W. Applied linear statiscal models. New York: McGraw-Hill/Irwin, 2005.

LONG, G. Diagnostic phyto-écologique et aménagement du territoire, principes genéraux et méthodes. Paris: Masson, 1974. v.1. Colletion d'Ecologie, n. 4.

LONG, G. Phyto-écologie et aménagement rural. In: LAMOTTE, M. (Ed). Fondements rationnels de l'aménagement d'un territoire. Paris: Masson, 1985. p. 57-97.

LONG, G. Éssai sur les conditions de la détermination des ressources naturelles de l'espace rural. Bull. Ecol., New Brunswick, v. 9, n. 4, p. 323-332, 1978.

MAHAR, D.J. Agro-ecological zoning in Rondônia, Brazil: What are the lessons? In: HALL, A. (Ed.) Amazonia at the crossroads: the challenge of sustainable development. London: University of London, 2000. p. 115-128.

MAHAR, D.J.; DUCROT, C.E.H. Land-use zoning on tropical frontiers. Emerging lessons from the Brazilian Amazon. Washington: World Bank, 1998. p. 25.

MANTOVANI, L.E.; FRITZSONS, E.; BATISTELLA, M. Solos do Arquipélago de Fernando de Noronha. In: CONGRESSO BRASILEIRO DE CIÊNCIA DO SOLO, 23, 1991, Porto Alegre. Resumos... Campinas: Sociedade Brasileira de Ciência do Solo, 1991.MANTOVANI, L.E.; RICHÉ, G.; CARRILHO, P.F. Caracterização do quadro natural da área do exercício piloto - PDRI Nordeste. Salvador: EMATER-BA/CPATSA/ORSTOM, 1983. v. 2.

MANTOVANI, L.E.; RICHÉ, G.R. Unidades morfopedológicas do Sertão do Araripe: Uma contribuição ao estudo das paisagens rurais do Trópico Semi-Árido. In: SIMPÓSIO BRASILEIRO DO TRÓPICO SEMI-ÁRIDO, 1, 1982, Olinda. Anais... Petrolina: EMBRAPA/CPATSA, 1982.

MARCHETTI, D.A.B; GARCIA, G.J. Princípios de fotogrametria e fotointerpretação. São Paulo: Nobel, 1988. p. 257.

MARQUES, L.S.; ERNESTO, M. O magmatismo toleítico da Bacia do Paraná. In: MANTESSO-NETO, V.; BARTORELLI, A.; CARNEIRO, C.D.R.; NEVES, B.B.B. (Org.). Geologia do continente sul-americano: evolução da obra de Fernando Flávio Marques de Almeida. São Paulo: Beca, 2004. p. 245-263.

MILANI, E.J. Comentários sobre a origem e a evolução tectônica da Bacia do Paraná. In: MANTESSO-NETO, V.; BARTORELLI, A.; CARNEIRO, C.D.R.; NEVES, 
B.B.B. (Org.). Geologia do continente sul-americano: evolução da obra de Fernando Flávio Marques de Almeida. São Paulo: Beca, 2004. p. 265-279.

MIRANDA, E.E. Essai sur les desequilibres ecologiques et agricoles en zone tropicale-semi-aride, les cas de la region de Maradi au Niger. Montpellier: Université des Sciences et Techniques du Languedoc, 1980. Tese - Doutorado em Ecologia.

MIRANDA, E.E.; MIRANDA, J.R.; SCARAMUZZA, C.A. de M. Ecologia da vegetação na região de Itararé, SP. In: SIMPÓSIO BRASILEIRO DE SENSORIAMENTO REMOTO, 5., 1988, Natal. Anais... São José dos Campos: INPE/SELPER, 1988. p. 655-661, v. 3.

MOTTI, C.P.; MOTTI, P. Comentário do mapa morfopedológico do setor de Santa Quitéria (BA). Notícias Geomorfológicas, Campinas, v. 15, n. 30, p. 65-74, 1975.

MUNSELL Color Company. Munsell soil color charts. Baltimore: Munsell Color, 1994.

NIMER, E. Climatologia do Brasil. 2 ed. Rio de Janeiro: IBGE, 1989.

NITSCH, M. O futuro da Amazônia: questões críticas, cenários críticos. Estudos Avançados, São Paulo, v. 16, n. 46, p. 141-156, 2002.

OLIVEIRA, H.H. de. Proposta de criação e caracterização da Área de Proteção Ambiental de Descalvado, SP. São Paulo: IB-USP, 1995. Dissertação de Mestrado em Ecologia.

OLIVEIRA, H. H.; MANTOVANI, L. E.; BATISTELlA, M. Cartografia morfopedológica como subsídio ao planejamento ambiental da APA de Descalvado, SP. In: CONGRESSO DE ECOLOGIA DO BRASIL, 2., 1994, Londrina. Resumos... Londrina: UEL-DBAV-SEB, 1994. v. 2: p. 554.

OLIVEIRA, J.B.; VALADARES, J.M.A.S.; ROTTA, C.L. Levantamento pedológico detalhado da Estação Experimental de Itararé, SP. Bragantia, Campinas, v. 35, n. 26, p. 295-335, 1976.

PALMEIRA, A.F.; CREPANI, E.; MEDEIROS, J.S. Uso de técnicas de sensoriamento remoto e geoprocessamento na proposta de um mapa de ordenamento territorial do Município de Paragominas (Estado do Pará). In: SIMPÓSIO BRASILEIRO DE SENSORIAMENTO REMOTO, 12, 2005, Goiânia. Anais... São José dos Campos: INPE, 2005. p. 3207-3214.

PEREIRA, E.Q.; VALERIO FILHO, M. Técnicas de sensoriamento remoto e geoprocessamento aplicadas na elaboração de cartas síntese de ordenamento 
territorial. In: SIMPÓSIO BRASILEIRO DE SENSORIAMENTO REMOTO, 10, 2001, Foz do Iguaçu. Anais... São José dos Campos: INPE, 2001. p. 959-961.

PRADO, H. Manual de Classificação de solos do Brasil. Jaboticabal: FUNEP, 1993.

PRETTE, M.E.; MATTEO, K.C. Origens e Possibilidades do Zoneamento EcológicoEconômico no Brasil. In: CADERNO de referência: subsídios ao debate. Brasília: MMA/SDS, 2006. p. 8-34.

RAIJ, B. Van.; ANDRADE, J.C.; CANTAREllA, H.; QUAGGIO, J.A. Análise química para avaliação da fertilidade de solos tropicais. Campinas: Instituto Agronômico, 2001. p. 285.

RIZZO, L.T.; MARINHO, M.A. Caracterização do meio físico e classificação da capacidade de uso dos solos da Fazenda Ibiti, Município de Itararé, São Paulo. São Paulo: Rizzo Projetos Agropecuários S/C LTDA, 1986. Relatório Técnico.

SAINT-HILAIRE, A. Viagem à comarca de Curitiba. São Paulo: Companhia Editora Nacional, 1964.

SAINT-HILAIRE, A. Viagem à província de São Paulo. São Paulo: EDUSP, 1976.

SCARAMUZZA, C.A. de M.; MACHADO, R.B.; RODRIGUES, S.T.; RAMOS NETO, M.B.; PINAGÉ, E.R. \& DINIZ FILHO, J.A.F. Áreas prioritárias para conservação da biodiversidade em Goiás. In: FERREIRA, L.G. (Ed.) Conservação da biodiversidade e sustentabilidade ambiental em Goiás: Prioridades, estratégias e perspectivas. Goiânia: AGMA, 2006. p. 52. No prelo.

SOKAL, R.R.; ROHLF, F.J. Biometry. New York: W.H. Freeman, 1995.

SPÖRL, C.; ROSS, J.L.S. Análise comparativa da fragilidade ambiental com aplicação de três modelos. GEOUSP - Espaço e Tempo, São Paulo, n. 15, p. 39-49, 2004.

SRTM. SHUTTLE Radar Topography Mission. In: UNITED STATES GEOLOGICAL SURVEY. Fact Sheet 071-03. 2003. Disponível em $<$ http://mac.usgs.gov/isb/pubs/factsheets/fs07103.html\#data $>$. Acesso em: 18 jun. 2006.

STATSOFT. STATISTICA data analysis software system, version 7. 2004.

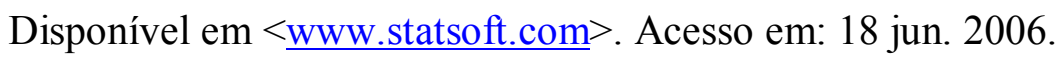

TENG, W.L. Fundamentals of photographic interpretation. In: PHILIPSON, W.R. Manual of photographic interpretation. 2 ed. Bethesda: American Society for Photogrammetry and Remote Sensing, 1997. p. 49-116.

TERRA FOTO S.A. Projeto Litoral Sul - CESP: fotos aéreas. São Paulo, 1981. 38 
fotos aéreas. Escala 1:35.000. Obra 407.

TRICART, J. De la géomorphologie à l'étude écographique intégrée. Agronomie Tropicale, Paris, v. 29, n. 2/3, p. 122-132, 1974.

TRICART, J. Ecodinâmica. Rio de Janeiro: IBGE, 1977. Série: Recursos Naturais e Meio Ambiente, v. 1.

TRICART, J. Écodynamique et aménagement. Revue de Geomorphologie Dynamique, Paris, n. 25, p. 19-32, 1976.

TRICART, J. Écogéographie des espaces ruraux. Paris: Nathan, 1994. 183 p.

TRICART, J. La géomorphologie dans les études intégrées d'aménagement du milieu naturel. Annales de Geographie, Paris, v. 82, n. 452, p. 421-453, 1973.

TRICART, J. L'analyse de système et l'étude intégrée du milieu naturel. Annales de Géographie, Paris, v. 88, n. 490, p. 705-714, 1979.

TRICART, J. L'apport de la géomorphologie à l'aménagement d'un territoire. In: LAMOTTE, M. (Ed). Fondements rationnels de l'aménagement d'un territoire. Paris: Masson, 1985. p. 98-113.

TRICART, J.; KIEWIETDEJONGE, C. Ecogeography and rural management: a contribution to the IGBP. Harlow: Longman, 1992.

TRICART, J.; KILIAN, J. L'éco-géographie et l'aménagement du milieu naturel. Paris: François Maspero, 1979.

WALTER, H.; LIETH, H. Klimadiagram-Weltatlas. Jena: Gustav Fischer, 1967.

WAY, D.S.; EVERETT, J.R. Landforms and geology. In: PHILIPSON, W.R. Manual of photographic interpretation. 2 ed. Bethesda: American Society for Photogrammetry and Remote Sensing, 1997.p. 117-166. 


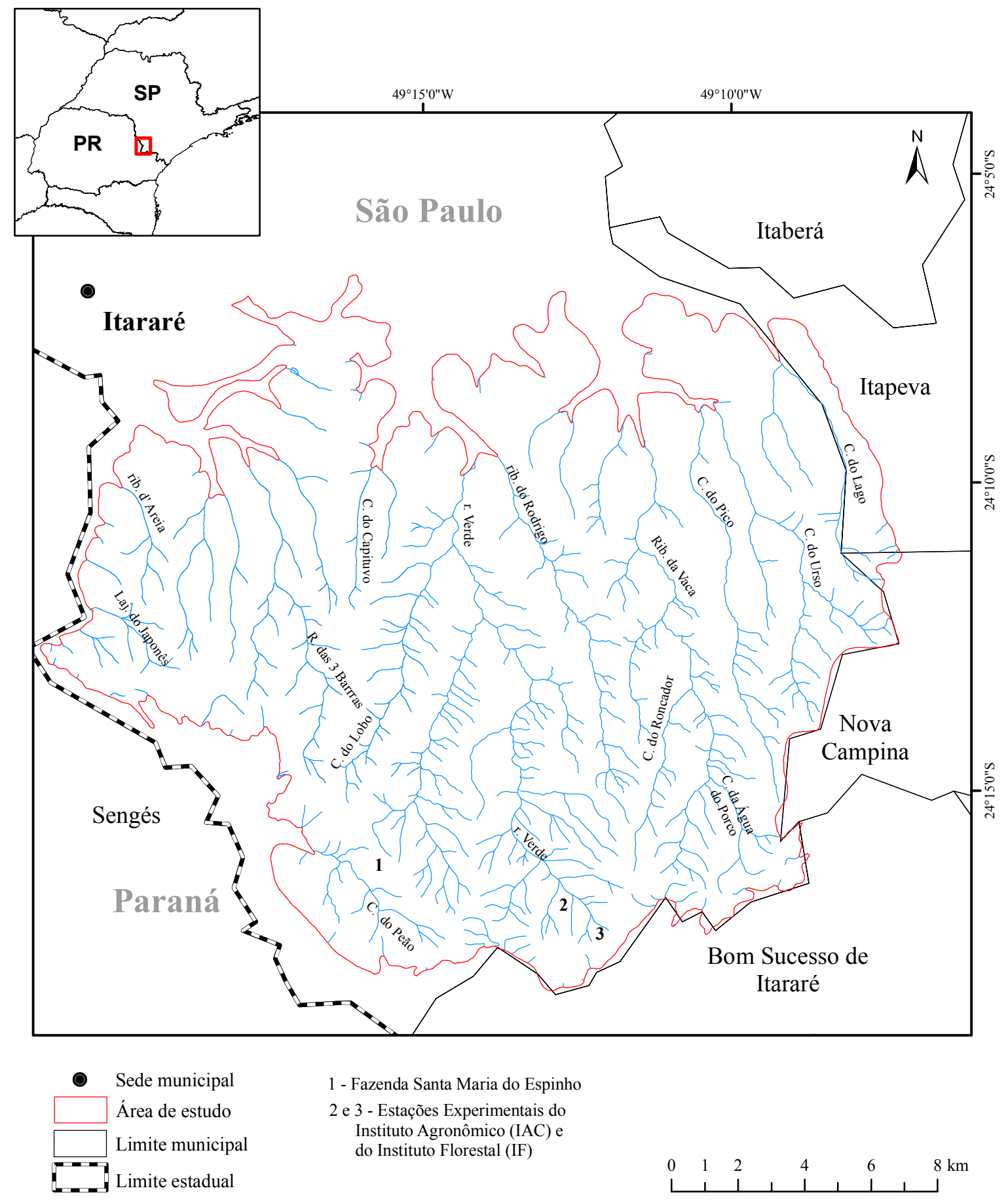

Figura 1. Localização da área de estudo e sua rede de drenagem na porção sul do município de Itararé, SP. 


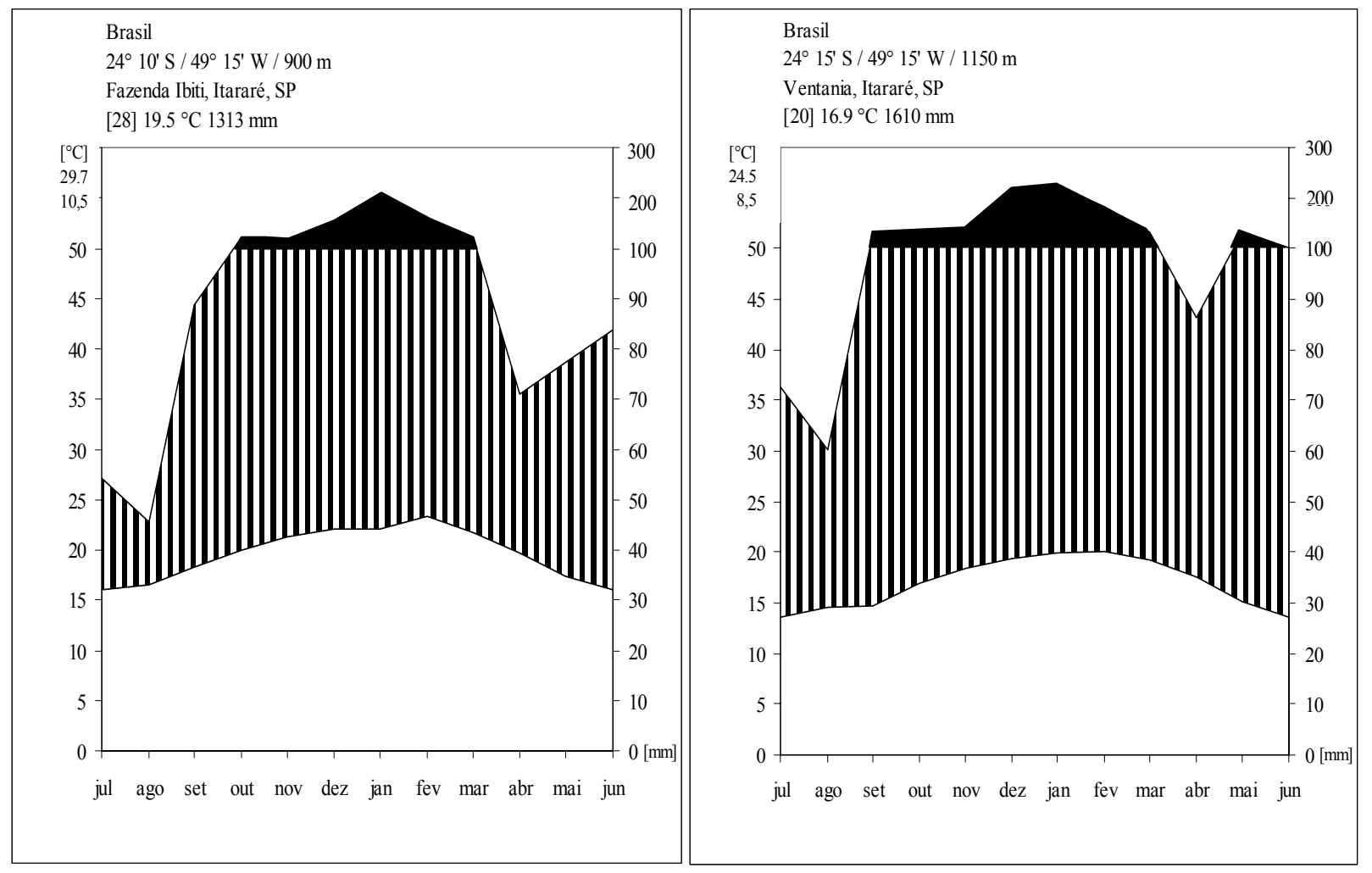

Figura 2. Diagramas climáticos conforme Walter \& Lieth (1967) para a estação meteorológica da Fazenda Ibiti e da Estação Experimental do Instituto Agronômico, município de Itararé, SP (Fonte: DAEE e IAC). 


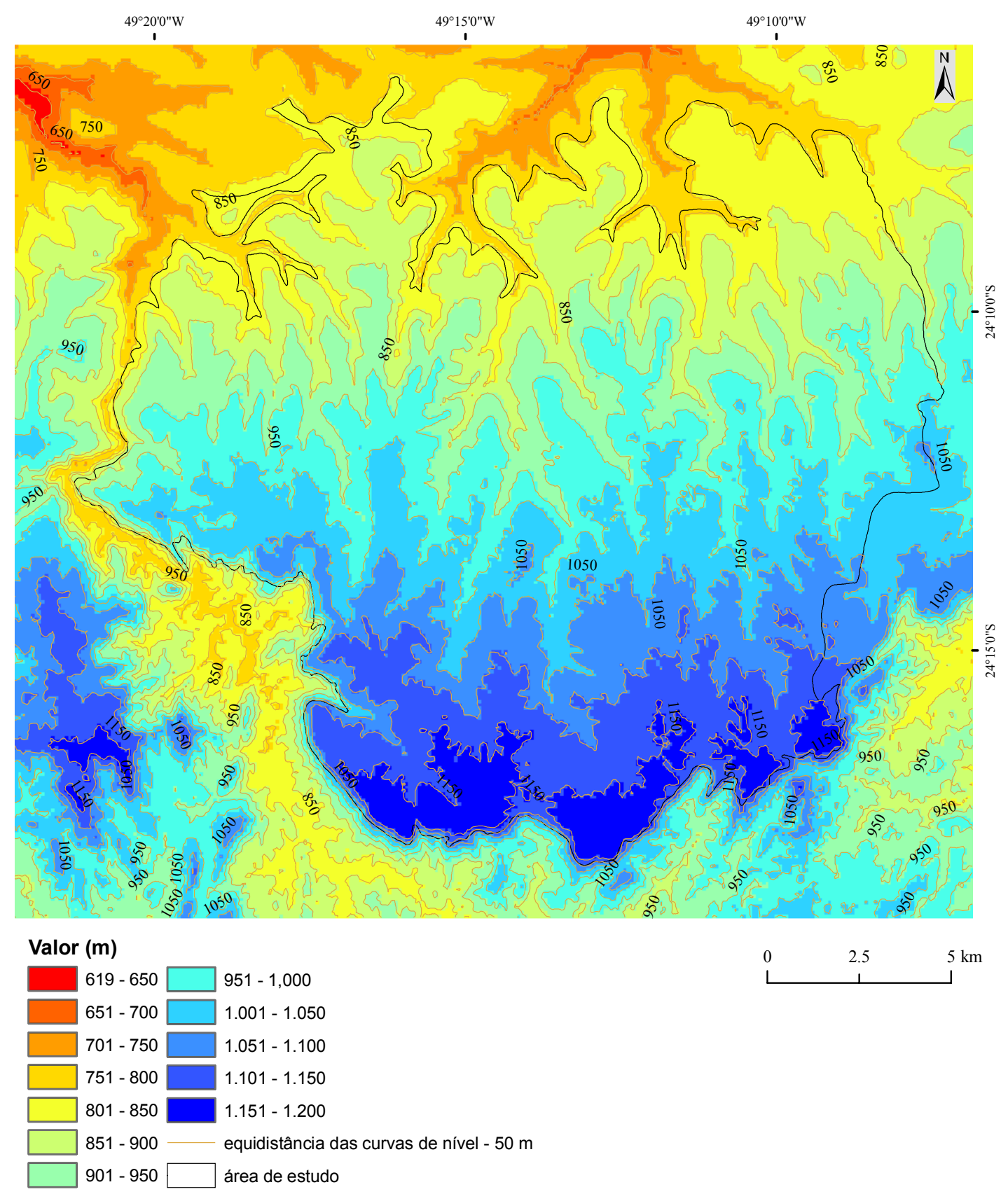

Figura 3. Hipsometria da região sul de Itararé. 


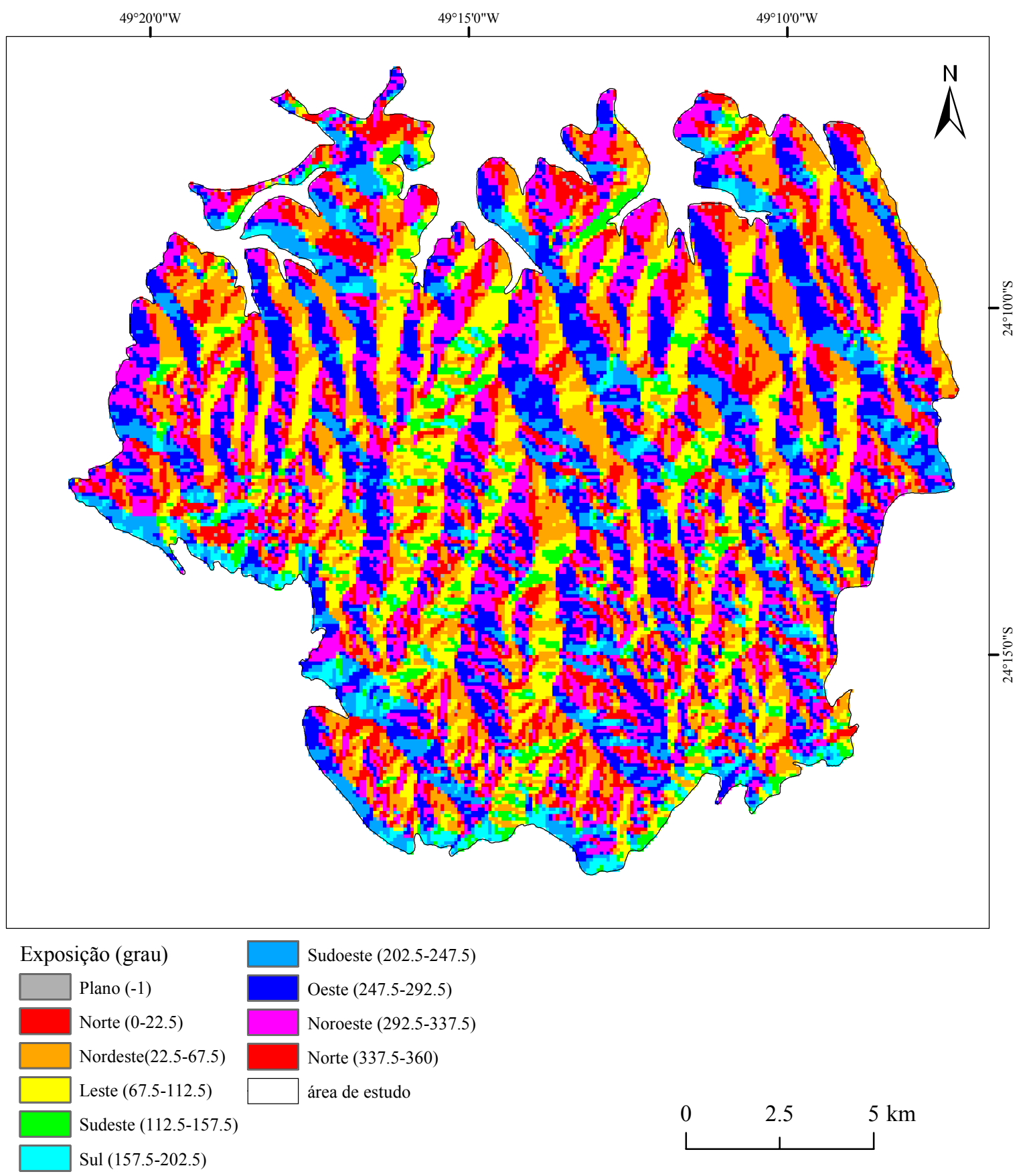

Figura 4. Superfície de exposição para a área de estudo na região sul de Itararé, SP. 


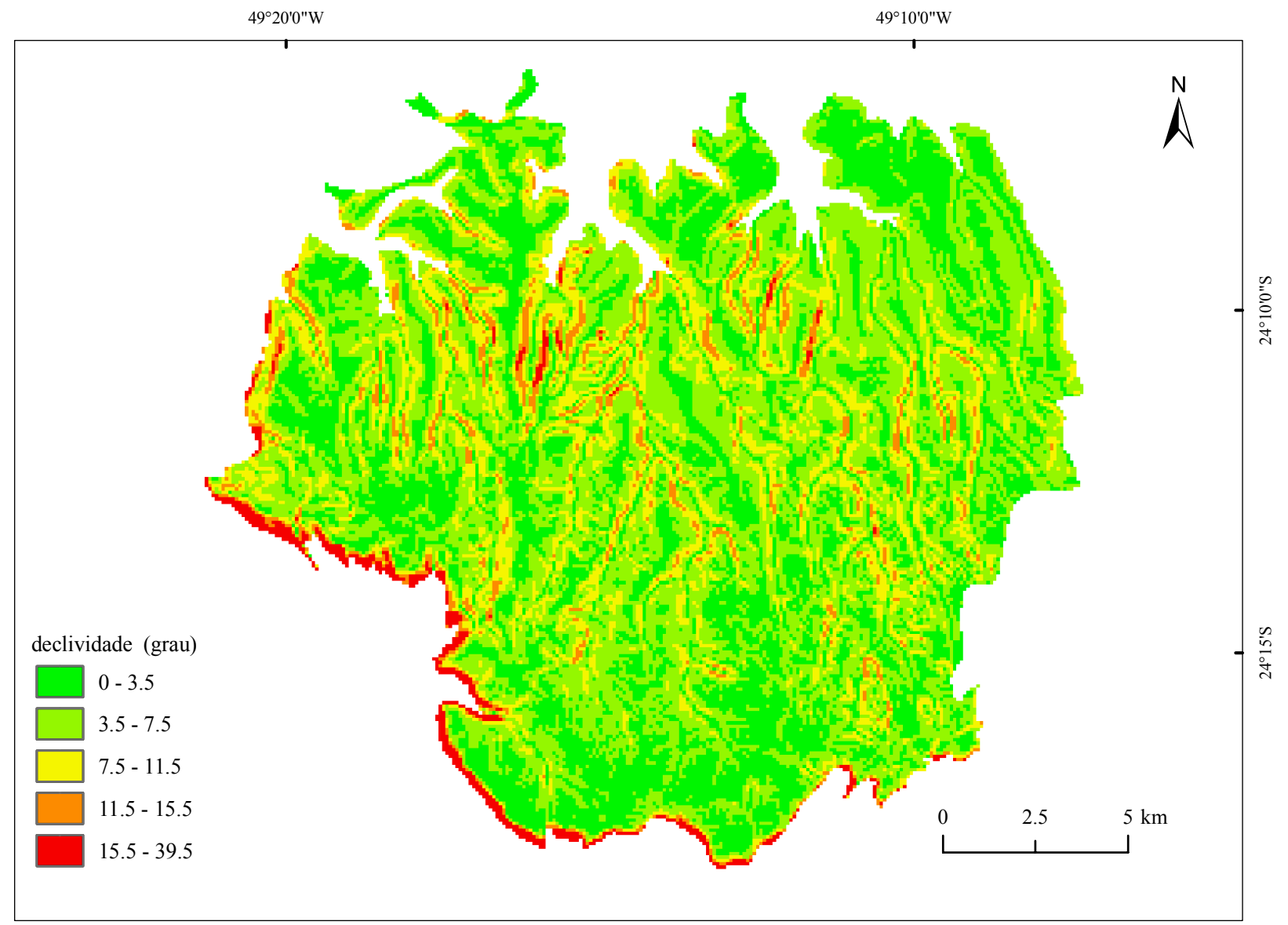

Figura 5. Superfície de declividade para a área de estudo na região sul de Itararé, SP. 

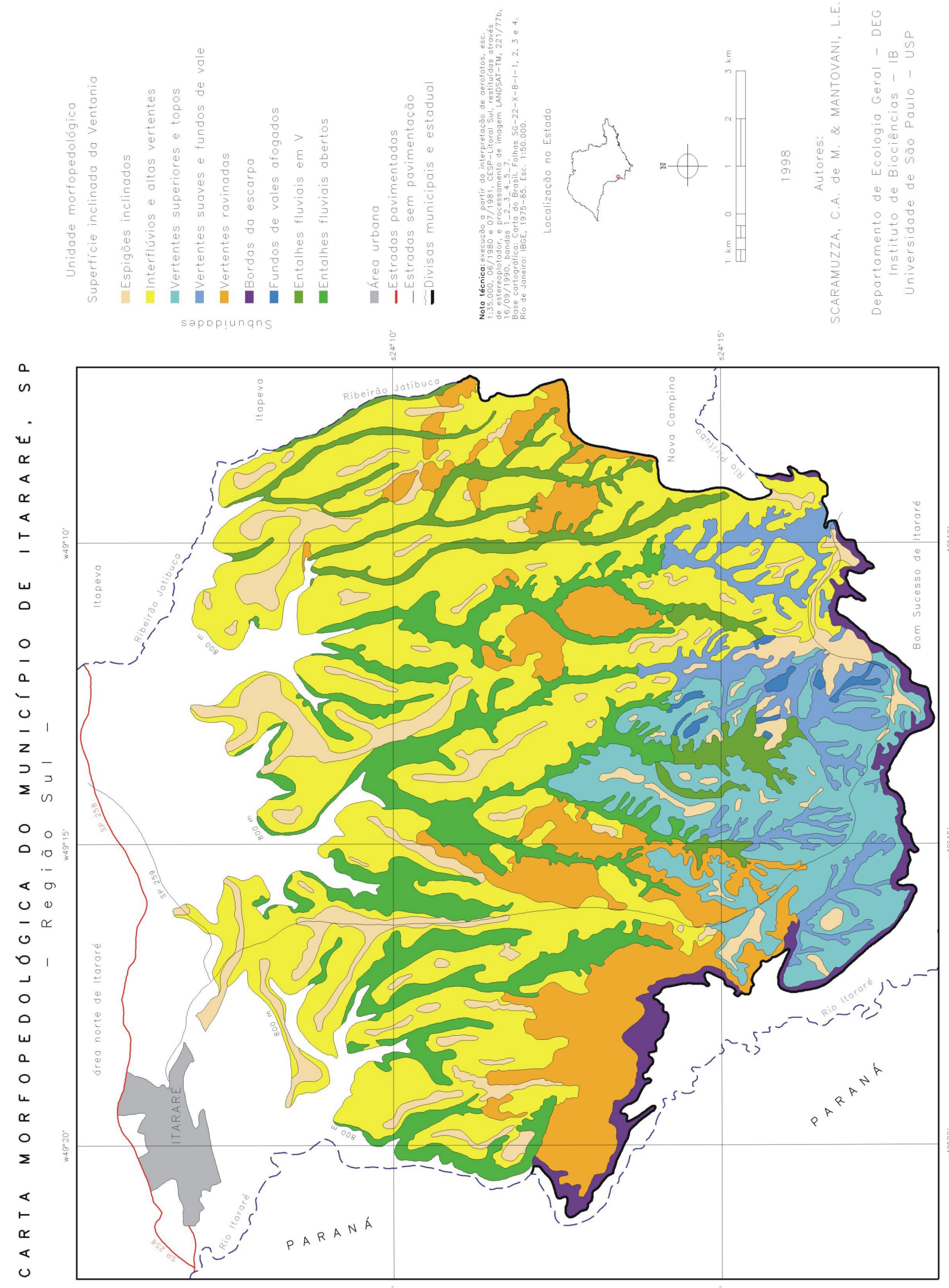


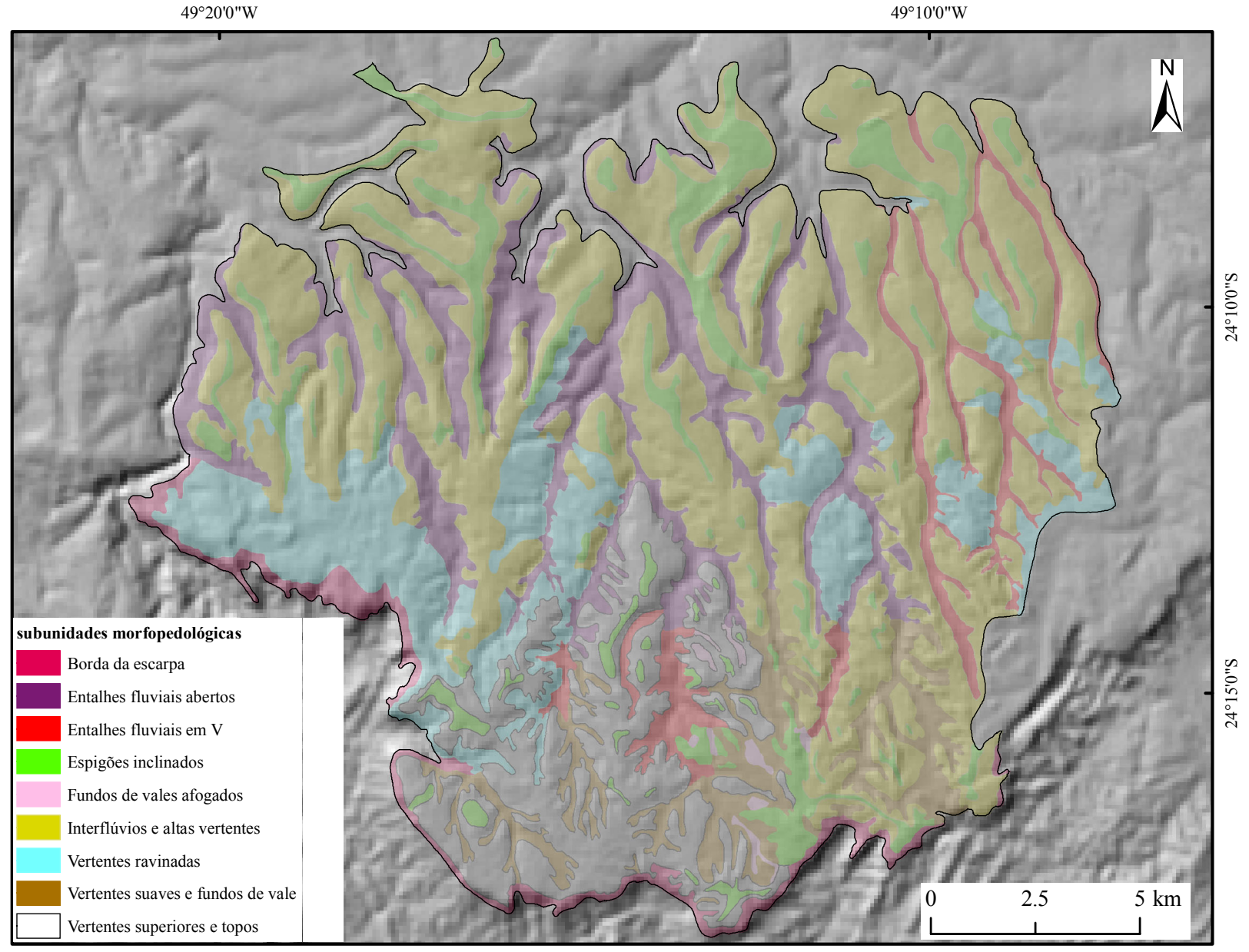

Figura 7. Mapeamento morfopedológico do clinoplano da Ventania, na região sul de Itararé, sobre um realce de relevo a partir de um modelo numérico de terreno (SRTM 2003) 

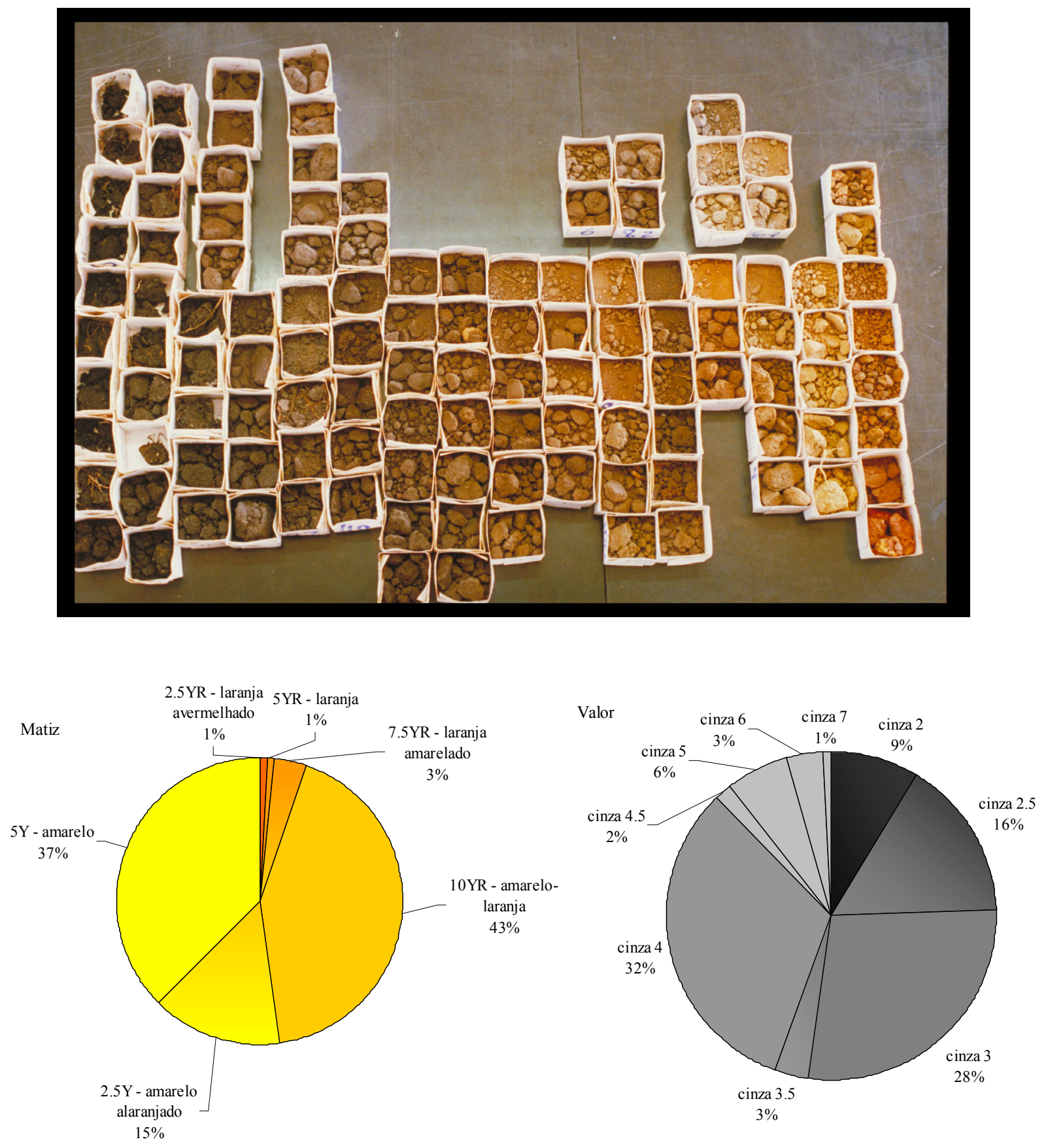

Figura 8. Pedocomparador e freqüência de ocorrência de matizes e valores de cores de solo, segundo o sistema de Munsell (1994), para as 115 amostras secas dos levantamentos fitoecológicos nos campos de Itararé, SP. 

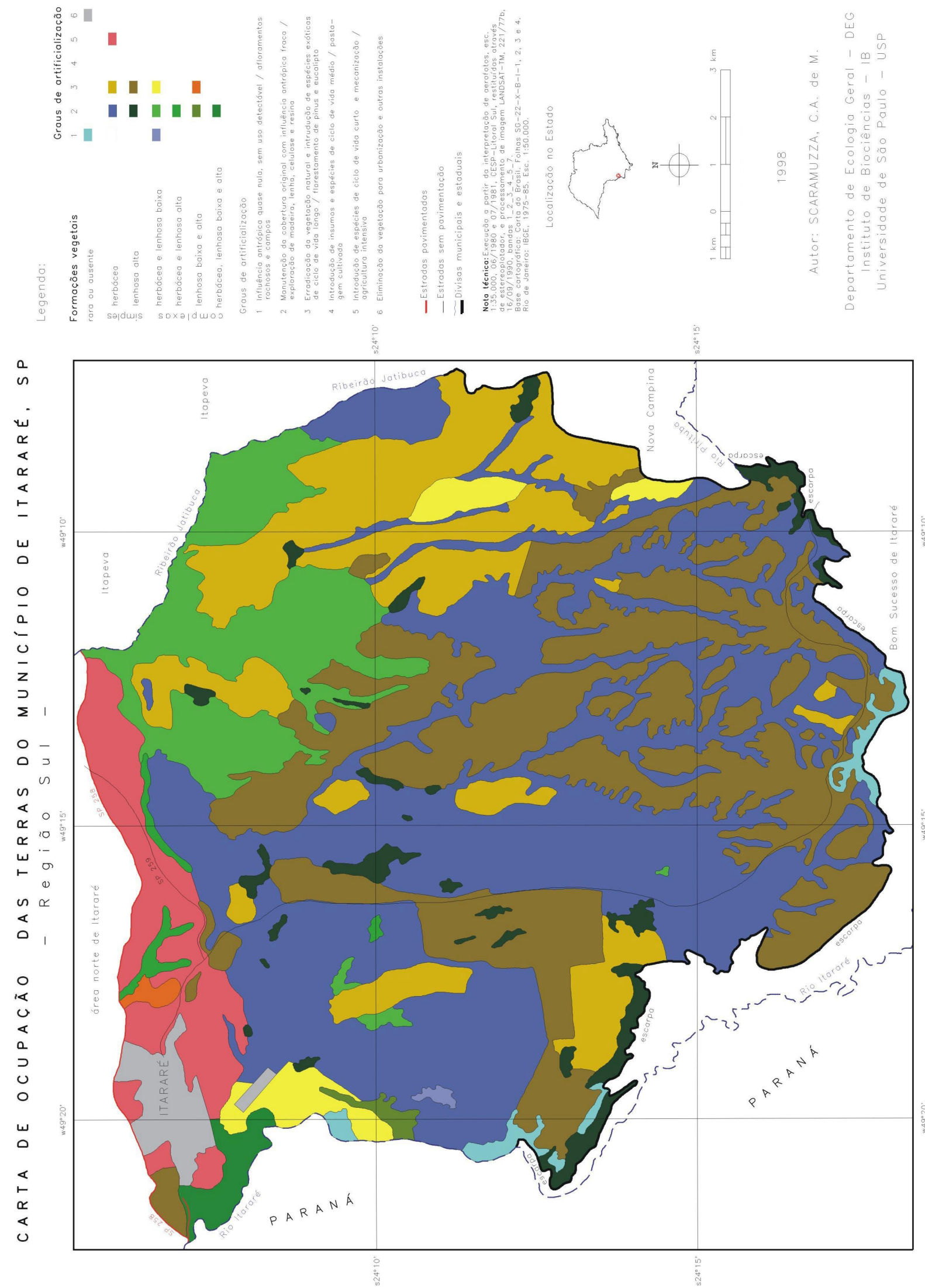

טิ 
Tabela 1. Coluna litoestratigráfica simplificada da região dos campos de Itararé, São Paulo (modificado a partir de Almeida \& Melo, 1981).

\begin{tabular}{|c|c|c|c|c|}
\hline \multicolumn{2}{|r|}{ Período geológico } & Grupo & Formação & Rochas \\
\hline \multirow{2}{*}{ 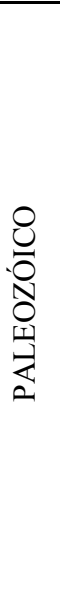 } & $\begin{array}{l}\text { Carbonífero } \\
\text { superior } \\
\text { Permiano } \\
\text { Médio }\end{array}$ & Tubarão & Itararé $(\mathrm{CPi})$ & $\begin{array}{l}\text { Depósitos glaciais continentais, glácio- } \\
\text { marinhos, fluviais, deltaícos, lacustres e } \\
\text { marinhos, compreendendo } \\
\text { principalmente arenitos de granulação } \\
\text { variada, imaturos, passando a arcósios; } \\
\text { conglomerados, diamictitos, tilitos, } \\
\text { siltitos, folhelhos, ritmitos; raras } \\
\text { camadas de carvão. }\end{array}$ \\
\hline & $\begin{array}{l}\text { Neo-Siluriano a } \\
\text { Eo-Devoniano }\end{array}$ & Paraná & Furnas (Df) & $\begin{array}{l}\text { Depósitos marinhos, predominando } \\
\text { arenitos de granulação grossa, } \\
\text { feldspáticos, de estratificação cruzada de } \\
\text { pequeno a médio porte e plano-paralela, } \\
\text { incluindo subordinadamente arenitos } \\
\text { finos, arenitos conglomeráticos } \\
\text { oligomíticos basais. }\end{array}$ \\
\hline
\end{tabular}

Tabela 2. Classificação dos graus de artificialização da cobertura vegetal segundo Long (1974) com exemplos de tipos de uso das terras presentes na região sul de Itararé, SP.

\begin{tabular}{|c|c|c|}
\hline Grau & Descrição & Uso das terras em Itararé \\
\hline Nulo & $\begin{array}{l}\text { influência antrópica quase nula sem uso } \\
\text { detectável, caracterizando normalmente a } \\
\text { vegetação climáxica }\end{array}$ & $\begin{array}{l}\text { afloramentos rochosos, } \\
\text { campos, cerrados, florestas }\end{array}$ \\
\hline Muito fraca & $\begin{array}{l}\text { manutenção da cobertura vegetal original com } \\
\text { influência antrópica fraca ou seja um } \\
\text { extrativismo sustentável de produtos naturais }\end{array}$ & $\begin{array}{l}\text { pastagem nativa, corte } \\
\text { seletivo de lenha }\end{array}$ \\
\hline Fraca & $\begin{array}{l}\text { ação humana importante ou prolongada no } \\
\text { passado, alterando profundamente a cobertura } \\
\text { vegetal original apesar de ser fraca atualmente }\end{array}$ & $\begin{array}{l}\text { florestamento } \\
\text { araucárias, pousios antigos, } \\
\text { florestas secundárias }\end{array}$ \\
\hline Média & $\begin{array}{l}\text { erradicação da vegetação original e introdução } \\
\text { de espécies exóticas de ciclo de vida longa } \\
\text { definindo as formações vegetais atuais, } \\
\text { explorando o meio de uma maneira fracamente } \\
\text { extensiva }\end{array}$ & $\begin{array}{l}\text { florestamento com pínus e } \\
\text { eucaliptos }\end{array}$ \\
\hline Pouco forte & $\begin{array}{l}\text { introdução de insumos (corretivos, } \\
\text { fertilizantes, defensivos) e espécies de ciclo de } \\
\text { vida média }\end{array}$ & pastagem cultivada \\
\hline Forte & $\begin{array}{l}\text { introdução de espécies de ciclo de vida curto e } \\
\text { mecanização }\end{array}$ & agricultura intensiva - grãos \\
\hline Muito forte & $\begin{array}{l}\text { introdução de uma cobertura vegetal para fins } \\
\text { estéticos ou recreativos, normalmente imerso } \\
\text { em áreas urbanas }\end{array}$ & $\begin{array}{l}\text { parques, praças, jardins em } \\
\text { áreas residenciais, } \\
\text { comerciais e industriais }\end{array}$ \\
\hline Extremamente forte & $\begin{array}{l}\text { eliminação da vegetação para urbanização e } \\
\text { outras instalações humanas }\end{array}$ & $\begin{array}{l}\text { edificações urbanas e } \\
\text { suburbanas de Itararé }\end{array}$ \\
\hline
\end{tabular}




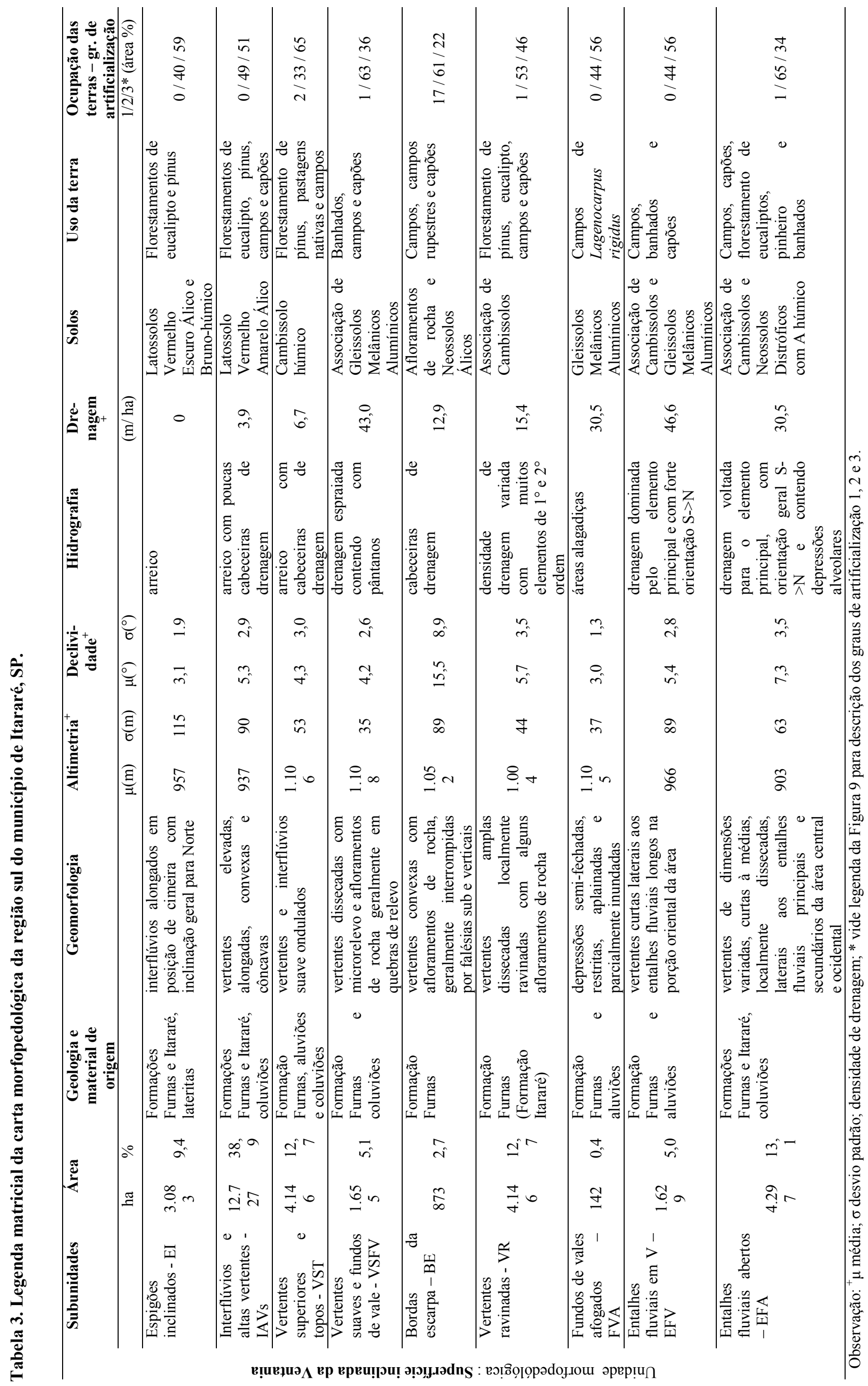




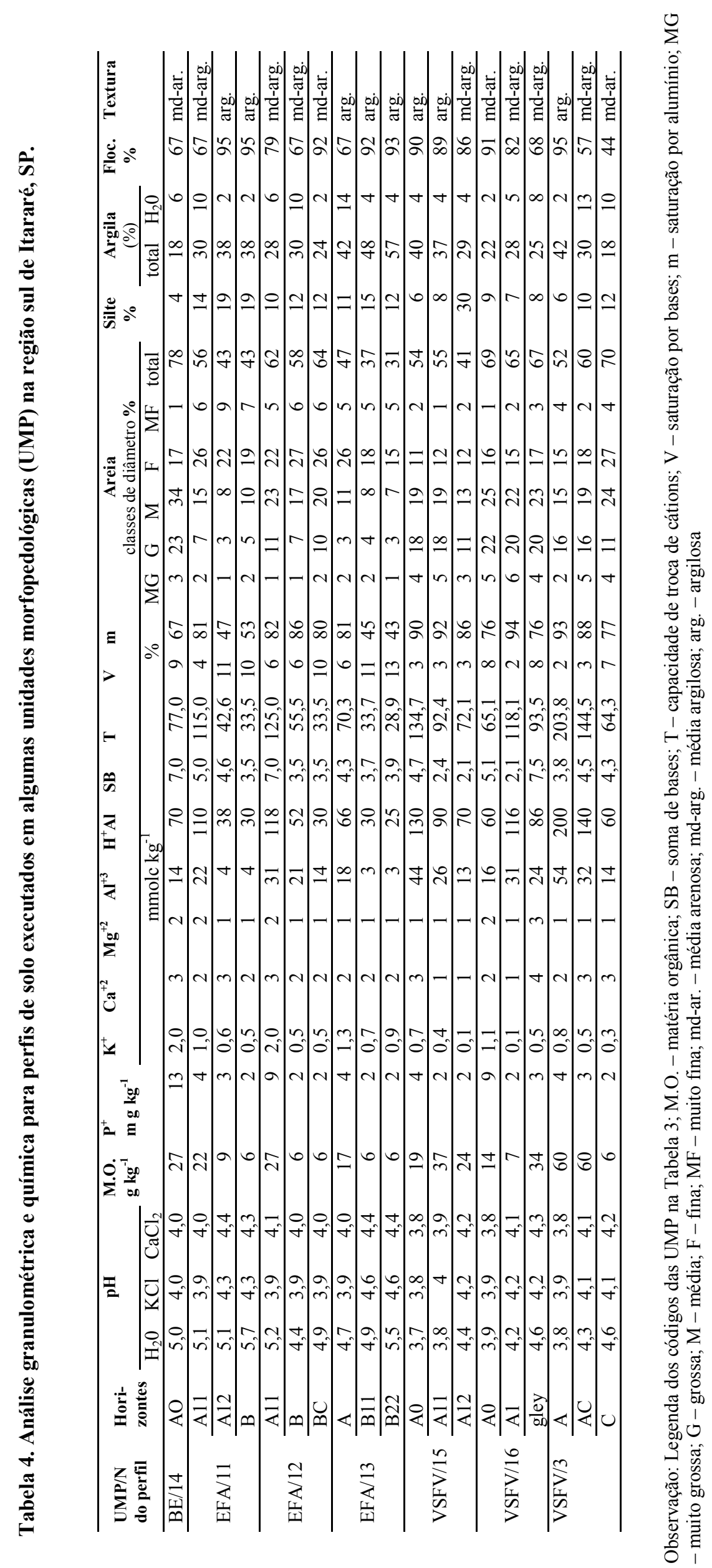


Tabela 5. Análises químicas de amostras de solo das unidades morfopedológicas (UMP) na região sul de Itararé, SP.

\begin{tabular}{|c|c|c|c|c|c|c|c|c|c|c|c|c|c|c|c|c|}
\hline \multirow[b]{2}{*}{ UMP } & \multirow[b]{2}{*}{ N. } & & \multicolumn{3}{|c|}{ pH } & \multirow{2}{*}{$\begin{array}{l}\text { M.O. } \\
\mathrm{g} \mathrm{kg}^{-1}\end{array}$} & \multirow{2}{*}{$\frac{\mathbf{P}^{+}}{\mathrm{mg} \mathrm{kg}_{1}^{-}}$} & \multirow[t]{2}{*}{$\mathbf{K}^{+}$} & \multirow[t]{2}{*}{$\mathrm{Ca}^{+2}$} & \multirow[t]{2}{*}{$\mathbf{M g}^{+2}$} & \multirow{2}{*}{\multicolumn{2}{|c|}{$\begin{array}{l}\mathbf{A l}^{+3} \quad \mathbf{H}^{+} \mathbf{A} \mathbf{l}^{*} \\
\mathrm{mmolc} \mathrm{kg}^{-1}\end{array}$}} & \multirow[t]{2}{*}{ SB } & \multirow[t]{2}{*}{$T^{*}$} & \multirow[t]{2}{*}{$\mathbf{V}$} & \multirow[t]{2}{*}{$\mathbf{m}$} \\
\hline & & & $\mathbf{H}_{2} \mathbf{0}^{*}$ & KCl & $\mathrm{CaCl}_{2}$ & & & & & & & & & & & \\
\hline \multirow{2}{*}{ EI } & \multirow[t]{2}{*}{5} & $\bar{X}$ & 4,3 & 3,8 & 3,9 & 30,0 & 4,8 & 0,8 & 1,4 & 1,2 & 13,6 & 77,6 & 3,4 & 81,0 & 4,0 & 79,6 \\
\hline & & $S^{2}$ & 0,0 & 0,0 & 0,0 & 68,5 & 1,2 & 0,0 & 0,8 & 0,2 & 27,3 & 130,8 & 2,2 & 139,1 & 3,0 & 16,3 \\
\hline \multirow{2}{*}{ IAV } & \multirow[t]{2}{*}{9} & $\bar{X}$ & 4,3 & 3,8 & 3,9 & 31,0 & 5,0 & 0,8 & 2,0 & 1,5 & 20,5 & 74,0 & 4,3 & 78,3 & 6,0 & 83,5 \\
\hline & & $S^{2}$ & 0,1 & 0,0 & 0,0 & 195,9 & 4,9 & 0,1 & 1,0 & 0,2 & 31,3 & 435,0 & 1,8 & 437,4 & 4,9 & 51,4 \\
\hline \multirow{2}{*}{ VST } & \multirow[t]{2}{*}{8} & $\bar{X}$ & 4,2 & 3,9 & 3,9 & 31,6 & 5,0 & 1,1 & 1,8 & 1,4 & 18,9 & 100,9 & 4,2 & 105,1 & 4,5 & 80,4 \\
\hline & & $S^{2}$ & 0,1 & 0,0 & 0,0 & 413,1 & 2,3 & 0,1 & 2,2 & 0,6 & 108,1 & 626,1 & 5,4 & 599,4 & 12,6 & 7,3 \\
\hline \multirow[t]{2}{*}{ VSFV } & \multirow[t]{2}{*}{5} & $\bar{X}$ & $3,9 * *$ & 3,9 & 3,9 & 27,2 & 4,6 & 0,7 & 1,4 & 1,2 & 26,4 & $113,2 * *$ & 3,3 & $116,5^{* *}$ & 3,8 & 86,6 \\
\hline & & $S^{2}$ & 0,0 & 0,0 & 0,0 & 447,7 & 7,3 & 0,1 & 0,3 & 0,2 & 277,3 & 3989,2 & 1,4 & 3986,2 & 6,2 & 53,8 \\
\hline \multirow[t]{2}{*}{$\mathrm{BE}$} & \multirow[t]{2}{*}{7} & $\bar{X}$ & 4,4 & 3,9 & 3,9 & 20,1 & 5,1 & 1,0 & 2,3 & 1,3 & 11,9 & $56,7 * *$ & 4,6 & $61,3 * *$ & 7,6 & 72,4 \\
\hline & & $S^{2}$ & 0,2 & 0,0 & 0,0 & 31,8 & 14,5 & 0,2 & 1,6 & 0,2 & 14,5 & 354,2 & 3,4 & 398,5 & 5,3 & 21,0 \\
\hline \multirow[t]{2}{*}{ VR } & \multirow[t]{2}{*}{8} & $\bar{X}$ & 4,5 & 3,8 & 3,9 & 25,8 & 5,4 & 1,1 & 1,9 & 1,1 & 11,6 & 62,3 & 4,1 & 66,3 & 6,4 & 71,5 \\
\hline & & $S^{2}$ & 0,1 & 0,0 & 0,0 & 36,5 & 2,6 & 0,1 & 2,7 & 0,1 & 28,3 & 174,2 & 3,7 & 156,1 & 11,7 & 265,7 \\
\hline \multirow[t]{2}{*}{ EFV } & \multirow[t]{2}{*}{2} & $\bar{X}$ & 4,3 & 3,8 & 3,9 & 19,5 & 5,0 & 1,2 & 3,0 & 1,5 & 12,5 & 65,0 & 5,7 & 70,7 & 8,5 & 69,0 \\
\hline & & $S^{2}$ & 0,0 & 0,0 & 0,0 & 144,5 & 18,0 & 0,2 & 2,0 & 0,5 & 0,5 & 450,0 & 2,6 & 383,6 & 24,5 & 50,0 \\
\hline \multirow{2}{*}{ EFA } & \multirow[t]{2}{*}{5} & $\bar{X}$ & $4,7 * *$ & 3,9 & 4,0 & 20,0 & 5,0 & 1,0 & 2,2 & 1,4 & 16,4 & 74,0 & 4,6 & 78,6 & 5,4 & 57,2 \\
\hline & & $S^{2}$ & 0,2 & 0,0 & 0,0 & 38,0 & 5,5 & 0,4 & 0,7 & 0,3 & 121,3 & 1474,0 & 2,5 & 1577,4 & 6,8 & 120,3 \\
\hline
\end{tabular}

Observação: Legenda dos códigos das UMP na Tabela $3 ; \bar{X}$ - médias e $S^{2}$ - variância; M.O. - matéria orgânica; SB - soma de bases; $\mathrm{T}$ - capacidade de troca de cátions; $\mathrm{V}$ - saturação por bases; $\mathrm{m}$ - saturação por alumínio; *hipótese nula de igualdade entre as médias rejeitadas (análise de variância, $\alpha=0,05, p=0,022 / \mathrm{pH}-\mathrm{H}^{2} 0, p=0,013 / \mathrm{H}^{+} \mathrm{Al}, p$ $=0,016 / \mathrm{T}$ ); $* *$ par de médias com diferença significativa (teste de Tukey-Kramer, $\alpha=0,05, p=0,011 / \mathrm{pH}-\mathrm{H}^{2} 0 ; p$

$\left.=0,029 / \mathrm{H}^{+} \mathrm{Al} ; p=0,036 / \mathrm{T}\right)$

Tabela 6. Principais formações vegetais, seu grau de artificialização e área (ha) na região sul de Itararé, SP.

\begin{tabular}{|c|c|c|c|c|c|c|c|}
\hline \multirow{2}{*}{\multicolumn{2}{|c|}{ Formações vegetais }} & \multicolumn{6}{|c|}{ Graus de artificialização $^{1}$} \\
\hline & & 1 & 2 & 3 & 5 & 6 & Total \\
\hline & rara ou ausente & 439 & & & & 707 & 1.146 \\
\hline \multirow[t]{2}{*}{ simples } & herbácea & & 14.253 & 5.709 & 2.236 & & 22.198 \\
\hline & lenhosa alta & & 1.135 & 10.246 & & & 11.381 \\
\hline \multirow[t]{4}{*}{ complexas } & herbácea e lenhosa baixa & 44 & 3.624 & 860 & & & 4.528 \\
\hline & herbácea e lenhosa alta & & 222 & & & & 222 \\
\hline & lenhosa baixa e alta & & 126 & 93 & & & 219 \\
\hline & herbácea, lenhosa baixa e alta & & 399 & & & & 399 \\
\hline Total & & 483 & 19.759 & 16.908 & 2.236 & 707 & 40.093 \\
\hline
\end{tabular}

\footnotetext{
${ }^{1}$ vide legenda da Figura 9 para descrição dos graus de artificialização
} 


\title{
Capítulo 2. Análise florística e fitogeográfica dos campos de Itararé, SP.
}

\begin{abstract}
RESUMO - (Análise florística e fitogeográfica dos campos de Itararé, São Paulo). A região de Itararé, no sudoeste do estado de São Paulo, junto à divisa do estado do Paraná, possui uma considerável diversidade climática, geológica, pedológica, florística e paisagística, onde ainda podem ser encontrados remanescentes significativos e bem preservados de campos de planalto, uma formação singular e pouco conhecida no estado de São Paulo. Como um primeiro passo para estudar a ecologia dos campos de planalto de Itararé e subsidiar um plano para sua conservação, a flora dos campos foi analisada. Um intensivo levantamento possibilitou a preparação de uma lista florística com 1.000 espécies em 120 famílias, dentre as quais 23 espécies são novas ocorrências para o estado de São Paulo, 71 são consideradas espécies vulneráveis e 22 em perigo, segundo a lista de plantas ameaçadas do estado de São Paulo. As oito famílias que mais contribuem para a riqueza de espécies são: Asteraceae $(17,8 \%)$; Poaceae (9,7 \%); Fabaceae (7,0 \%); Myrtaceae (4,1\%); Cyperaceae (3,9\%); Melastomataceae (3,9\%); Rubiaceae $(3,2 \%)$ e Apocynaceae $(2,9 \%)$. Uma análise de agrupamento foi efetuda para avaliar o posicionamento fitogeográfico dos campos de planalto de Itararé entre 47 listas florísticas disponíveis para localidades das regiões Sul e Sudeste e dos estados da Bahia, Goiás e Distrito Federal. Uma análise de correspondência canônica indicou as variáveis isotermalidade, sazonalidade térmica e precipitação do mês mais úmido como as mais correlacionadas com a distribuição das espécies dos campos.
\end{abstract}

Palavras-chave: campo, espécies ameaçadas, variáveis climáticas, análise multivariada, distribuição de espécies

\begin{abstract}
Floristic and phytogeography of the grasslands of Itararé, São Paulo). The region of Itararé, in southwestern of São Paulo state, at the border with the state of the Paraná, has a considerable climatic, geologic, pedologic, floristic and landscape diversity, where it's possible to find significative and well preserved grassland fragments, a singular and little known vegetation type in state of São Paulo. As a first step to study the ecology of the Itararé grasslands and to underpin a conservation plan, the flora of the fields was analyzed. An intensive survey made possible to prepare a floristic list with 1.000 species in 120 families, amongst them 23 new records for the State of São Paulo, 71 vulnerable and 22 endangered species according the Red List of São Paulo State. The eight families with major contributions to the species richness are: Asteraceae (17,8\%); Poaceae (9,7 \%); Fabaceae (7,0 \%); Myrtaceae (4,1\%); Cyperaceae (3,9 \%); Melastomataceae (3,9\%); Rubiaceae (3,2 \%) and Apocynaceae (2,9\%). A cluster analysis was performed to evaluate the phytogeographic position of the Itararé grasslands among 47 floristic lists available for South and Southeastern Brazil, as well for the states of Bahia, Goiás and Federal District. A canonical correspondence analysis indicated the climatic variables isothermality, temperature seasonality and precipitation of wettest month as the most correlated with species distribution of grasslands.
\end{abstract}

Key words: grasslands, endangered species, climatic variables, multivariate analysis, species distribution

\section{Introdução}

Associadas ao clima árido e frio do final da última glaciação e seco e quente da fase pós-glacial no início do período Holosceno, as formações campestres predominavam na região sul do Brasil, mantendo as florestas ombrófilas mistas nas áreas mais úmidas nos entalhes fluviais. Em aproximadamente $3.000 \mathrm{AP}$, a partir das florestas ciliares inicia-se uma progressão das florestas ombrófilas mistas dominadas por Araucária sobre os campos de planalto, indicando uma mudança em direção a um 
padrão climático mais úmido. Em torno de 1500 anos atrás, essa substituição dos campos pelas florestas nos planaltos torna-se mais forte no Paraná até atingir Santa Catarina 1000 anos atrás. Esse é o período onde o clima torna-se úmido sem a presença de uma estação seca, ao contrário dos 3 meses de estiagem característicos do início até a metade do Holosceno (Rambo 1956a, Klein 1975, Behling 1997 e Behling et al. 2004).

Apesar desse clima e dos solos bem desenvolvidos favoráveis às florestas (Pillar 2003), as formações campestres ainda estão bem representadas e são as características do bioma campo sulino (bioma pampa - Brasil 2004). Possivelmente o fator fogo, registrado desde o começo do Holosceno (aproximadamente 7.400 AP. Behling et al. 2004), tenha contribuído para manter a cobertura campestre estável até o presente. Com a chegada dos portugueses, a criação de muares e depois de gado, tornou-se a principal atividade econômica e o principal tipo de uso das terras. Tradicionalmente, o sistema de manejo dessas pastagens nativas incluía o uso regular do fogo como técnica de renovação (Pillar \& Quadros 1997).

Esse tipo de atividade primária, por não implicar em uma conversão das formações nativas, possibilitou historicamente a conservação dos campos, especialmente nos estados de Santa Catarina e Rio Grande do Sul. Entretanto, recentemente, mesmo nessas regiões tem surgido uma série de ameaças crescentes a estas pastagens nativas, como espécies invasoras (principalmente o capim anonni Eragrostis plana Nees) e a conversão de campos para: pastagens com gramíneas exóticas; áreas agrícolas e florestamentos (Nabinger et al. 2000, Pillar 2003 e Pillar 2006).

Em termos de caracterizações florísticas de áreas de campos, o Rio Grande do Sul é o estado com o maior número de estudos em suas diferentes regiões: Depressão Central - Boldrini \& Eggers 1996, Boldrini \& Miotto 1987 e Garcia et al. 2002; Serra do Sudeste - Boldrini et al. 1998 e Overbeck et al. 2006; Campanha - Girardi-Deiro et al. 2003 e Girardi-Deiro et al. 1992; Areais - Trindade 2003; e Campos de Cima da Serra Rambo 1956b. Entretanto são poucos e antigos, os trabalhos sobre florística desenvolvidos nas áreas de campos de Santa Catarina (Klein 1979), Paraná (Hatschbach \& Moreira Filho 1972 e Hatschbach et al. 2005) e São Paulo (Usteri 1911, Joly 1950 e Garcia \& Pirani 2005).

Os padrões de diferenciação florística têm sido explorados em diversas formações vegetais (Mata Atlântica - Oliveira-Filho \& Fontes 2000, incluindo uma avaliação da 
influência do clima; Scudeller et al. 2001; Florestas semidecíduas, decíduas e ripárias do Brasil central - Oliveira-Filho \& Ratter 1995; Cerrado - Ratter et al. 1996 e 2003). Entretanto esse tipo de abordagem fitogeográfica somente foi aplicado para formações campestres no Brasil por Garcia (2003), onde foram utilizados dados de presença e ausência, para gêneros e famílias de 13 áreas em 6 estados brasileiros e para espécies de Poaceae de 20 áreas em 8 estados.

O pequeno número de análises florísticas para áreas de campo, especialmente em São Paulo e Paraná, está em parte relacionado com a intensa conversão dessas áreas de campo em cultivos agrícolas ou nas grandes conurbações de São Paulo e Curitba.

Em São Paulo, umas das poucas áreas onde ainda podem ser encontrados remanescentes dos campos de planalto é a região de Itararé, divisa com o Paraná (Figura 1), em uma área de ecotono entre os domínios florísticos dos campos de planalto e dos cerrados do Brasil Central. A ocupação dessa região, primeiro por grandes fazendas de gado que exploravam as pastagens nativas, depois por estações experimentais do Instituto Agronômico e do Instituto Florestal (IAC e IF) e, mais recentemente, por grandes companhias de reflorestamento, que por limitações agronômicas não ocuparam toda a extensão de suas propriedades, permitiu a preservação de fragmentos significativos da cobertura vegetal original. Além disso, a região apresenta uma diversidade de formações vegetais, passando da fisionomia florestal pela savânica até a campestre, em um território relativamente restrito, onde ainda podem ser encontradas populações de pequenos mamíferos (Gheler-Costa \& Verdade 2005), tamanduás, lobos guarás, além de uma comunidade de aves com 176 espécies identificadas nas Fazendas Ibiti e Santa Isabel da RIPASA, sendo que sete delas estão presentes na lista de espécies ameaçadas no estado de São Paulo e uma, o papa-mosca do campo (Culicivora caudacuta), considerada vulnerável pela lista vermelha do IBAMA (Costa et al. 2006 e comunicação pessoal).

Em Itararé, a presença destes remanescentes de campos, cerrados e florestas têm viabilizado, ao longo das duas últimas décadas, diversas ações de ensino (Curso de Taxonomia de Campo da Escola Superior de Agricultura Luis de Queiroz - ESALQUSP) e pesquisa a respeito tanto da flora e da vegetação de Itararé (capítulos 1 e 3). Todos esses capítulos, bem como o presente estudo, possuem dois propósitos gerais: evidenciar a composição florística dos campos de planalto e avaliar sua organização em comunidades vegetais e suas relações com variáveis ecológicas. 


\section{Objetivo}

Os objetivos desse trabalho foram: 1. analisar a composição florística dos campos de planalto de Itararé, SP; 2. identificar grupos florísticos para diferentes tipos de campos da região centro sul e leste do Brasil e analisar suas relações com condicionantes climáticos.

\section{Material}

\section{1 Área de estudo}

Esse trabalho foi desenvolvido nos campos de planalto da porção sul de Itararé, município localizado na parte sudoeste do estado de São Paulo (Figura 1) abrangendo uma área de aproximadamente 40.093 ha. Seus principais atributos geológicos, geomorfológicos e climáticos estão descritos em detalhe no capítulo 1, onde são apresentados dois mapeamentos temáticos, um morfopedológico e outro de ocupação das terras, que descrevem e sintetizam a fisiografia e a paisagem da área de estudo.

A diversidade de formações vegetais nativas, presente em Itararé está relacionada ao fato da região ser uma zona de transição e contato, definida por uma diversidade climática, geológica, pedológica, florística e de usos das terras. Do ponto de vista fisiográfico, é o limite entre o Planalto Cristalino Ocidental e a Bacia Sedimentar do Paraná, com uma gradação litológica e morfopedológica suave ao longo do clinoplano da Ventania (capítulo 1) onde em $23 \mathrm{~km}$ há uma variação altitudinal de $503 \mathrm{~m}$, indo das cotas 600 até $1.100 \mathrm{~m}$. Do ponto de vista biótico, além de uma transição biogeográfica entre as floras dos campos de planalto e do cerrado, há um gradiente local definido pelo clinoplano, passando desde áreas altas, frias e úmidas, com capões de florestas de araucárias nas grotas e campos naturais nas colinas (cotas 1.000-1.100 m), até partes mais quentes e baixas cobertas por cerrados e matas nas vertentes mais íngremes e ao longo da drenagem (cotas 600-800 m). Os campos de planalto estão situados de forma recortada em meio de florestamentos de pínus e eucaliptos e ao longo dos rios e em três áreas mais extensas cobrindo tanto as áreas marginais aos eixos de drenagem como os interflúvios, em uma propriedade particular e nas estações experimentais do IAC e IF. 


\section{Método.}

\subsection{Análise florística}

Os levantamentos florísticos foram realizados ao longo de duas décadas (principalmente entre 1989 e 1994), de forma a cobrir todas as estações. Um esforço de coleta similar para todos os hábitats foi mantido visitando-se constantemente os mesmos remanescentes em cada campanha de campo. Além disso, em 1993, foram realizadas coletas florísticas em campos situados em diferentes feições de relevo, seguindo o plano de amostragem dos levantamentos fitoecológicos do estudo de ecologia dos campos de planalto (capítulo 3).

A identificação dos táxons foi realizada prioritariamente através da colaboração de especialistas na sistemática dos diferentes grupos (vide listagem em Agradecimentos), incluindo visitas a centros de excelência em agrostologia, como o Departamento de Botânica da Universidade Federal do Rio Grande do Sul e EMBRAPA Recursos Genéticos e Biotecnologia (CENARGEN), e a outros taxonomistas na Universidade Federal de Juiz de Fora, Jardim Botânico do Rio de Janeiro, Departamento de Botânica da Universidade Estadual de Campinas (herbário UEC - UNICAMP), Departamento de Botânica do Instituto de Biociências da USP (herbário SPF - IB-USP) e Instituto de Botânica de São Paulo (herbário SP - IBot). Nos casos em que não foi possível consultar especialistas, recorreu-se à literatura existente e a identificações por comparação com materiais de referência depositados nos principais herbários de São Paulo (ESA, SP, SPF e UEC). As espécies de pteridófitas e gimnospermas seguem a classificação proposta por Judd et al. (2002) e as de angiospermas a do Grupo de Filogenia de Angiospermas II (APGII - 2003), conforme Souza \& Lorenzi (2005).

As coletas, incluindo unicatas, foram depositadas principalmente no herbário ESA da ESALQ-USP, sendo que as duplicatas foram distribuídas para os especialistas colaboradores e/ou doadas a outros herbários de São Paulo, principalmente ao SPF.

A partir das anotações das fichas de coleta, foram classificados os hábitats (banhado, campo, cerrado e ecotono mata ciliar-cerrado) de todas as espécies da lista florística para caracterizar o seu espectro de ocorrência.

Utilizando-se os dados dos levantamentos fitoecológicos dos campos de Itararé (capítulo 3), o hábito e o estrato vertical dominante foi determinado para um subconjunto de 112 espécies mais freqüentes, ou seja, com ocorrência maior que 5 
levantamentos. As categorias adotadas foram delimitadas a partir de uma divisão em estratos verticais para os hábitos principais (ervas, graminóides, arbustos e pteridófitas). A atribuição para as classes de estruturas foi definida a partir do valor médio de todas as ocorrências registradas em campo para cada espécie.

\subsection{Análise fitogeográfica}

O padrão de distribuição geográfica para todas as espécies coletadas em Itararé foi determinado utilizando-se bibliografia especializada e a mesma classificação proposta por Garcia \& Pirani (2005). Para facilitar a análise, as categorias adotadas foram agrupadas da seguinte forma: 1. ampla - Afro-América, América, América do Sul, Brasil, cosmopolita, neotropical, pantropical, subespontânea; 2. regional - Argentina, Bolívia, Paraguai, Uruguai, DF, GO, Sul e Sudeste do Brasil e 3. endêmica - SP.

O posicionamento biogeográfico da flora dos campos de planalto de Itararé no espectro de formações campestres do centro-sul e leste do Brasil foi avaliado através de uma análise de similaridade entre diferentes listas florísticas.

Os critérios para a seleção das áreas a serem comparadas foram: evitar áreas claramente rupícolas e cobrir todos os tipos de fisionomias abertas, indo de campo limpo, passando por campo sujo até campo cerrado, incluindo os campos úmidos, em Goiás, Distrito Federal, Bahia, regiões Sul e Sudeste (Tabela 1). Desse modo, os trabalhos que não indicavam claramente os hábitats de coleta ou possuíam um número de espécies menor que cinqüenta não foram considerados.

Entre as listas selecionadas, eliminaram-se todas as identificações parciais ou com um indicativo de dúvida (cf. ou aff.). A primeira versão da matriz de ocorrência (dados binários) foi consolidada com 5.212 espécies, presentes em quarenta e sete localidades de formações campestres (Figura 2). Em seguida, procedeu-se uma verificação de sinonímias, a partir de consulta à bibliografia e aos especialistas, reduzindo-se o número de espécies para 4.630. Dentre essas, foram eliminadas todas as ocorrências únicas, definindo-se uma matriz final com 2.304 espécies em 47 listas florísticas.

O método de tratamento numérico global adotado foi a análise de agrupamentos, disponível no aplicativo PC-Ord (McCune \& Mefford 1999). Optou-se pelo índice de similaridade de Kulczynsky (Sorensen relativo) que além de valorizar as espécies com ocorrência comum, minimiza a interferência das diferenças no tamanho das amostras, no cálculo da semelhança entre a composição florística das quarenta e sete áreas. $\mathrm{O}$ método de aglomeração escolhido para a formação dos agrupamentos foi o $\beta$ flexível 
(Legendre \& Legendre 1998, valor =-0,25), por sua compatibilidade com uma medida de distância semi-métrica como a de Kulczynsky (McCune \& Grace 2002).

A definição dos grupos foi feita através da aplicação da análise de espécies indicadoras (Dufrêne \& Legendre 1997), que permitiu indicar simultaneamente quais espécies eram indicadoras para cada grupo. A significância estatística dos valores de correlação das espécies com cada um dos grupos foi calculada por meio de um teste de permutação de Monte Carlo (Manly 1991) com 1.000 repetições aleatórias. Foram consideradas espécies indicadoras aquelas com $P \leq 0,05$. O critério objetivo para o corte do dendrograma foi determinar o número de grupos com o menor valor de $P$ médio para todas as espécies. Secundariamente usou-se a informação mantida pelo arranjo dos grupos após o corte aplicado, medida pela função objetivo de Wishart (McCune \& Grace 2002), para avaliar o balanço entre um número de grupos coerente e ter uma boa homogeneidade interna dos dados.

Definido o número de grupos, as espécies com $P \leq 0,05$ são as indicadoras para aquele agrupamento com o qual o seu valor de correlação foi maior.

Com a finalidade de aprofundar a compreensão sobre os padrões de distribuição geográfica dos campos foi utilizada uma análise de correspondência canônica (CCA ter Braak 1987) para avaliar a correlação entre a distribuição das espécies campestres e um conjunto de variáveis climáticas.

Esses dados sobre o clima das quarenta e sete localidades foram obtidos a partir de superfícies climáticas globais interpoladas com resolução espacial de $1 \mathrm{~km}$ (WorldClim - Hijman et al 2005). Considerando-se uma relação de 1 variável para 10 amostras sugerida como adequada para a aplicação de CCA (para um conjunto de 47 amostras, o número de variáveis indicado seria 5) e utilizando-se o critério de maior impacto sobre a distribuição das comunidades de campo conforme discutido por Behling (1997) e Behling et al. (2004), foram selecionadas sete dentre dezenove variáveis bioclimáticas (Bioclim) disponíveis: isotermalidade (ISOT, - amplitude térmica diária média / amplitude térmica anual); sazonalidade térmica (SAZ_T - desvio padrão da média anual das médias de temperaturas semanais); temperatura máxima do mês mais quente (TMMQ); temperatura mínima do mês mais frio (TMMF); precipitação do mês mais úmido (PMU); precipitação do mês mais seco (PMS); e sazonalidade pluviométrica (SAZ_P - desvio padrão da média anual das médias de temperaturas semanais). Em função das imprecisões da referência geográfica adotada para alguma das localidades 
(Tabela 1), as variáveis climáticas utilizadas no CCA correspondem às médias dos valores contidos em buffers de três $\mathrm{km}$ criados ao redor da coordenada geográfica de modo a possibilitar uma amostragem da heterogeneidade climática local.

Desse modo, as duas matrizes necessárias para a execução do CCA são: 1. dados binários descrevendo a distribuição das 2.304 espécies com mais de uma ocorrência nas quarenta e sete localidades e 2. sete variáveis ambientais. Aplicou-se o teste de permutação de Monte Carlo para verificar a significância das correlações entre a matriz biológica e a ambiental.

\section{$5 \quad$ Resultados e discussão}

\subsection{Análise florística}

Foram feitas aproximadamente 12.000 coletas botânicas entre matérias férteis e vegetativos, nas diversas campanhas florísticas e fitoecológicas.

Os hábitats dominantes das espécies dos campos de planalto de Itararé são apresentados na Figura 3. O padrão mais expressivo são as espécies exclusivas dos campos (514 esp. - $51 \%$ ), seguido pelas ocorrências somente no cerrado (134 esp. - 13 $\%$ ) e banhado (128 esp. - $13 \%$ ). Depois em ordem de magnitude surgem espécies presentes em dois hábitats como, por exemplo: 'banhado e campo' (9\%) e 'campo e cerrado' (7 \%); seguidas por outras combinações (7 \%).

A preocupação constante desde o início do projeto no registro acurado dos hábitats nas fichas de coleta permitiu uma caracterização segura do espectro de ocorrência de todas as espécies nos campos de planalto de Itararé.

Estão presentes na lista florística dos campos de planalto de Itararé 120 famílias, com 975 espécies de fanerógamas e 25 pteridófitas, totalizando 1.000 espécies (Anexo 1). Desse total, trinta e sete possuem uma única espécie (Tabela 2).

As famílias com maior número de táxons: Asteraceae, Poaceae, Fabaceae (Figura 4) seguem o padrão de muitas formações campestres (campos: RS - Boldrini \& Miotto 1987, Boldrini \& Eggers 1996, Boldrini et al. 1998, Girardi-Deiro et al. 1992, Overback et al. no prelo e SP - Joly 1950; cerrado: SP - Batalha \& Mantovani 2001, Sasaki 2006 e DF - Felfili et al. 2004, Pereira \& Mecenas 2003; campo rupestre: MG - Giulietti et al. 1987 e BA - Harley \& Simmons 1986), onde essas famílias alternam-se como as três mais importantes. Considerando-se esse mesmo parâmetro, número de espécies por famílias, pelos principais tipos de hábitat, nota-se na mesma figura, o aumento da 
importância relativa de famílias como Cyperaceae e Eriocaulaceae nos banhados, em detrimento de Myrtaceae e Fabaceae.

A lista florística consistiu no principal material de apoio para a identificação das coletas botânicas, na sua maioria estéreis, dos levantamentos fitoecológicos executados para a avaliação da ecologia dos campos de planalto de Itararé (capítulo 3).

Segundo as informações fornecidas pelos especialistas consultados ou pela bibliografia disponível, vinte e três espécies de nove famílias (Acanthaceae; Asteraceae; Boraginaceae; Ericaceae; Fabaceae; Malvaceae, Poaceae; Solanaceae; Xyridaceae) são ocorrências inéditas para o estado de São Paulo (Anexo 1).

Também merecem destaques as seguintes espécies: Butia microspadix Burret por confirmar a ocorrência no estado de São Paulo, ampliando a distribuição conhecida (Paraná e Rio Grande do Sul); Evolvulus barbatus Meisn. e Lafoensia nummularifolia A. St.-Hil. - pelo fato da localidade típica ser, respectivamente, Itararé e a Fazenda Perituva, Itararé; Trimezia juncifolia (Klatt) Benth. \& Hook - por ser uma ocorrência rara para o estado de São Paulo; Pavonia reticulata Garcke, Microlicia myrtoidea Cham., Acicarpha tribuloides Juss e Declieuxia dusenii Standl. - por serem a $2^{\text {a }}$ coleta para o estado de São Paulo.

A identificação do material botânico (exsicatas férteis e estéreis) coletado nos levantamentos florísticos e fitoecológicos dos campos de planalto de Itararé foi uma etapa crítica devido: 1 . ao pequeno número de coletas em áreas de campo e inexistência de levantamentos sistemáticos; 2. ausência de bibliografia específica e atualizada sobre flora campestre; 3. carência de taxonomistas; 4. grande número de espécies presentes em área de ecótono entre os cerrados e os campos de planalto. Por exemplo, a falta de especialistas em muitos gêneros da família Asteraceae dificultou a determinação de 80 $\%$ dos materiais (62 gêneros e 177 espécies). Outras evidências significativas da complexidade da elaboração dessa lista florística foram: 1. descoberta de uma nova espécie na área estudada (Galianthe souzae E.L. Cabral \& Bacigalupo) descrita a partir de coletas realizadas no âmbito desse projeto; 2 . vinte e três novas ocorrências para o estado de São Paulo e 3. sete táxons raros ou com alterações significativas na sua área de distribuição.

Em termos de estrutura vertical das formações campestres em Itararé, analisando a distribuição das cento e doze espécies mais freqüentes (Figura 5) nota-se que apesar da importância do estrato de 10 a 45 cm, tanto para graminóides (19 \%) como para ervas 
(29 \%), há uma complexidade da organização vertical com a presença significativa de vários outros estratos como os graminóides de 40 a $80 \mathrm{~cm}$ (15\%), seguido por pteridófitas de 10 a $40 \mathrm{~cm}$ e ervas de 40 a $80 \mathrm{~cm}$, ambas com $7 \%$. Destaca-se também a presença reduzida dos arbustos (menor que $120 \mathrm{~cm}-3 \%$ ).

\subsection{Análise fitogeográfica}

O padrão dominante de distribuição geográfica entre as espécies da lista florística de Itararé (vide relação completa na Anexo 1) com ocorrência exclusiva nos três hábitats considerados (70, 69 e $58 \%$ respectivamente nos cerrados, banhados e campos) é o amplo (Figura 6). Já o regional é mais conspícuo no hábitat campestre (33, 25 e $21 \%$ para campos, cerrados e banhados). Esses padrões diferem um pouco dos obtidos por Garcia \& Pirani (2005) para os campos do Curucutu, onde a categoria regional é em torno de $50 \%$ para os dois tipos de campos considerados.

Além disso, sessenta e oito espécies nos campos de Itararé apresentam padrões de distribuição de característica austral, ou seja, iniciando-se na Argentina, Uruguai ou região sul do Brasil e extendendo-se até o seu limite norte em São Paulo, o que sugere uma maior influência dos elementos napeádicos em relação aos oreádicos.

Dentre as quinze espécies com um padrão de distribuição endêmica $(1,5 \%)$, seis espécies estão presentes até o momento somente na região de Itararé: Croton serpyllifolius Baill.; Eugenia jaguariaivensis Mattos; Galianthe souzae E.L. Cabral \& Bacigalupo; Hexachlamys itararensis Mattos; Heterocondylus jaraguensis (B.L. Rob.) R.M. King \& H. Rob; Myrceugenia franciscensis (O.Berg.) Landrum. Estas espécies endêmicas locais correspondem a $1 \%$ do número de espécies exclusivas dos banhados, campos e cerrados, valor bem menor que os obtidos para áreas de campo alto-montano na Serra do Mar entre o Rio de Janeiro e São Paulo (Safford 1999). Como não há nenhuma unidade de conservação protegendo suas áreas de ocorrência, a conservação dessas seis espécies endêmicas requer atenção imediata no sentido de avaliar seus efetivos populacionais.

Além disso, vinte e duas outras espécies (Alliaceae, Apiaceae, Asteraceae - 2, Cactaceae, Cunoniaceae, Gesneriaceae, Lentibulariaceae - 3, Malpighiaceae, Melastomataceae - 2, Orchidaceae, Orobanchaceae, Poaceae - 3, Polygalaceae, Rubiaceae, Xyridaceae - 2) estão em perigo de extinção e setenta e uma estão vulneráveis (Anexo 2) segundo a lista de espécies ameaçadas para o estado de São Paulo (São Paulo 2004). Por sua vez, na lista da flora brasileira ameaçada de extinção 
(Fundação Biodiversitas 2005), estão listadas nove espécies: vulneráveis - Alophia coerulea (Vell.) Chukr, Butia microspadix Burret, Ocotea porosa (Nees) Barroso, Quesnelia humilis Mez, Xyris augusto-coburgii Szyszyl, Zephyranthes candida (Lindl.) Herb.; em perigo - Dicksonia sellowiana (Presley) Hook. e criticamente em perigo Galianthe souzae E.L. Cabral \& Bacigalupo, Stevia leptophylla Sch. Bip. ex Baker. Dentre essas, quatro são comuns com a lista de São Paulo: Dicksonia sellowian (Presley) Hook, Galianthe souzae E.L. Cabral \& Bacigalupo, Stevia leptophylla Sch. Bip. ex Baker e Zephyranthes cândida (Lindl.) Herb.

Em relação à análise de similaridade entre listas florísticas de campos, a falta de uma descrição padronizada dos hábitats foi a principal dificuldade na seleção de áreas de campos para a análise do enquadramento fitogeográfico.

Foram exploradas diversas medidas de distância e métodos de aglomeração na análise de agrupamento, como por exemplo: Sorensen; Kulczynksy, ligação simples (vizinho mais próximo); ligação completa (vizinho mais distante); aglomeração por pesos proporcionais. Todos os agrupamentos formados por essas diferentes alternativas são muito semelhantes indicando a consistência das árvores obtidas.

Os grupos de listas florísticas, gerados por meio da análise de agrupamento (Figura 7), apresentam uma grande coerência com as relações de proximidade geográfica entre as 47 áreas, ou seja, em sua maioria reuniram localidades próximas entre si.

O número de grupos (Figura 7) que apresentou o menor valor de $P$ médio é 7, o que corresponde manter na análise $30 \%$ da informação sobre os padrões de ocorrência das espécies. Esse valor de corte elevado é coerente com a grande indeterminação na matriz dos dados florísticos, causada pelas espécies com um número de ocorrências muito baixo (menores que cinco).

Apesar do critério adotado na preparação da matriz dos dados de distribuição das espécies ter sido conservador, eliminando-se apenas as espécies com ocorrência única, verificou-se uma estrutura consistente na formação dos grupos, mesmo utilizando-se diferentes métodos de distância e aglomeração.

Os sete grupos florísticos (Figura 7) são: G1 campos da Chapada Diamantina (BA); G2 campos úmidos (SP, GO, DF e RS); G3 campos alto-montanos (SP e RJ); G4 campos de planalto (SP, PR, SC e RS); G5 campos cerrados do Brasil Central (DF); G6 campos cerrados do Brasil Centro-Sul (GO, SP e MG); e G7 campos sulinos (RS). 
De forma simplificada, cabem os seguintes comentários: G1 - campos da Chapada Diamantina onde os elementos da fisionomia dominante dos campos rupestres particularizam até mesmo as formações abertas e sem afloramentos rochosos, conhecidas localmente como gerais; G2 - campos úmidos com seu caráter azonal definido pela inundação periódica onde estão reunidas áreas dispersas do centro-oeste ao sul do Brasil; G3 - formado pelos campos alto-montanos (Serra dos Órgãos, Itatiaia e Campos do Jordão); G4 - composto por campos de planalto com 3 listas de São Paulo (Itararé, Butantã e São Paulo), 3 do Paraná, 1 de Santa Catarina (Itajaí) e outra do Rio Grande do Sul (campos do alto da serra em Aparados da Serra), fato que deve ser analisado à luz do baixo número de caracterizações florísticas para Santa Catarina e das dificuldades de interpretação dos hábitats e da atualização taxonômica de publicações antigas como as listas de São Paulo (1911), Itajaí (1979) e Aparados (1956); G5 e G6 agrupou listas de localidades do bioma cerrado do interior de São Paulo até o planalto central; e G7 - aglomerou as listas florísticas dos campos do Rio Grande do Sul com áreas da Serra do Sudeste, Depressão Central, Campanha e Areais;

Os campos de Itararé posicionam-se nos campos de planalto (G4) juntamente com todas as outras áreas paranaenses localizadas sobre os arenitos mais antigos da bacia sedimentar do Paraná (Formações Furnas e Itararé no arco de Ponta Grossa).

De um modo geral, esse tipo de análise ainda se beneficiaria muito com a inclusão de novas listas para cobrir especialmente as lacunas geográficas: 1. no norte de Minas Gerais, esclarecendo melhor o posicionamento das localidades da Bahia e a influência dos campos rupestres na composição florística dos campos desta parte do Brasil; e 2. em Santa Catarina e nos campos do alto da serra no Rio Grande do Sul para esclarecer melhor a posição dos campos da Serra Geral e a própria constituição heterogênea do grupo 4.

Esses padrões de distribuição identificados estão mais nítidos e interpretáveis do que os indicados pelas análises de agrupamento geradas a partir de dados de famílias e gêneros por Garcia (2003). A proximidade entre os grupos 3 e 4 está de acordo com relação sugerida pelo mesmo trabalho entre os campos do Curucutu e os campos altomontanos de Itatiaia e Campos do Jordão, porém os campos do Curucutu se agrupam primeiro com as turfeiras dos Aparados da Serra no Rio Grande do Sul dentro do G2 (áreas úmidas). Esse resultado e a maior proximidade do G2 com o G3 (campos altomontanos) ao invés do G4, onde estão os campos de planalto paulistanos (Butantã e São 
Paulo), corroboram as observações feitas por Garcia \& Pirani (2005). Já os padrões dos dendrogramas obtidos com as espécies de gramíneas (Garcia 2003) se aproximam mais aos obtidos nessa análise, com o agrupamento de áreas da Chapada Diamantina, dos campos alto-montanos e das áreas sulinas.

De um total de 2.304 espécies, 549 foram consideradas indicadoras dos 7 grupos florísticos (Tabela 3$)$, por serem estatisticamente significativas $(P<0,05)$ segundo o texto de permutação de Monte Carlo. As áreas com maior número de espécies indicadoras foram duas das mais distintas entre as consideradas nesse estudo: grupos 1 (Chapada Diamantina) e 5 (campo-cerrado do Brasil central), com respectivamente 223 e 254 espécies. Por sua vez, os grupos com o menor número de espécies significativas foram os campos-cerrado do Brasil Centro Sul, campos sulinos e campos úmidos, com 0, 2 e 5, respectivamente. No caso dos campos sulinos, esse pequeno número de espécies indicadoras pode estar relacionado com o fato da maior parte dessas listas terem um número reduzido de espécies. São listas geradas por levantamentos fitoecológicos usualmente menos exaustivos que os florísticos e onde predominam as espécies com distribuição geográfica mais ampla e com menor potencial de serem indicadoras. Dentre essas espécies indicadoras, para efeito de análise, selecionou-se um subconjunto com os dez menores valores de $P$ (Tabela 4). Também foram incluídas as espécies com valores iguais ao décimo menor (grupos 1, 4 e 5). Os noventa e seis táxons selecionados são diversificados em termos de famílias e gêneros, sem que se possa notar um predomínio de algum grupo taxonômico em particular, nem mesmo de Asteraceae ou Poaceae (Tabela 4).

Os dois primeiros eixos da CCA (Figura 8) explicaram em conjunto 11,6 \% (eixo $1-6,5 \%$ e $2-5,1 \%$ ) da variância global dos dados, indicando que grande proporção desse coeficiente de variação permanece sem explicação. Esses baixos valores percentuais da variância explicados pelos componentes, são comuns em dados de vegetação e não prejudicam a significância das relações espécie-ambiente (Leps \& Smilauer 2003). Segundo o teste de permutação de Monte Carlo pode-se rejeitar a hipotese $\mathrm{H}_{\mathrm{o}}$ : não existe relação entre a matriz de ocorrência de espécies e a ambiental $(P$ $<0,001$ ), ou seja, a distribuição das espécies é significativamente correlacionada com as variáveis climáticas selecionadas.

As variáveis climáticas com maiores correlações (Tabela 5) com o primeiro eixo de ordenação foram isotermalidade $(-0,962)$, sazonalidade térmica $(0,925)$, precipitação 
do mês mais seco $(0,873)$ e sazonalidade pluviométrica $(-0,871)$. Com o segundo eixo, apenas a precipitação do mês mais úmido apresentou um valor maior que $0,5(0,809)$.

As correlações ponderadas (Tabela 5) entre as variáveis climáticas apontam para inter-relações robustas (valores maiores que \pm 0.75 e em ordem crescente) da isotermalidade com sazonalidade térmica (negativa), precipitação do mês mais seco (neg.) e sazonalidade pluviométrica (positiva); da precipitação do mês mais seco com sazonalidade pluviométrica (neg.); da sazonalidade térmica com sazonalidade pluviométrica (neg.) e precipitação do mês mais seco (pos.); e da precipitação do mês mais úmido com sazonalidade pluviométrica (pos.).

No diagrama de ordenação (Figura 8), 6 dos 7 grupos obtidos na análise de agrupamentos foram bem discriminados em setores distintos, reunindo as listas segundo sua proximidade geográfica e reforçando a consistência dos grupos florísticos propostos para as áreas de campo analisadas. Apenas as listas florísticas dos grupos 2 (campos úmidos) apresentaram-se dispersas no diagrama. No caso dos campos úmidos, esse padrão deve estar relacionado com a sua azonalidade, ou seja, mesmo sob condições climáticas diversas o fator água explica sua semelhança florística.

A porção direita do eixo 1 discrimina os campos mais suceptíveis à sazonalidade térmica e à disponibilidade hídrica no período da seca, ou seja, as áreas no Rio Grande do sul e os campos de planalto em Paraná e extremo sudoeste de São Paulo. Desse modo, nesses quadrantes dispõe-se do modo contínuo os campos de planalto (G4) e os sulinos (G7) presentes nos biomas Mata Atlântica e Campos sulinos (Pampa).

$\mathrm{Na}$ outra extremidade desse mesmo eixo estão as listas referentes às fisionomias abertas do bioma cerrado, influenciadas por fatores como a temperatura do mês mais frio, com sua conseqüente associação com a ocorrência de geadas, sazonalidade das chuvas e isotermalidade. Em Garcia (2003), uma aplicação de análise de correspondência para os dados binários de distribuição de espécies da familia Poaceae e parâmetros climáticos, já tinha indicado a importância da temperatura na explicação da variância observada entre as 20 áreas avaliadas. Já o eixo 2 discrimina em sua parte superior claramente os campos em áreas mais úmidas (G3 - campos alto-montanos, AFRI - Fazenda Água Fria em Alto Paraíso de Goiás e CURU - campos de Curucutu em São Paulo). 


\section{Conclusões}

Esta avaliação da flora dos campos de planalto de Itararé indica uma riqueza de espécies elevada em um território reduzido, contendo muitos táxons inéditos e ameaçados de extinção para o estado de São Paulo ou cuja distribuição ainda é muito esparsamente documentada, corroborando a necessidade premente de conservar os campos de planalto e cerrados da região de Itararé.

A consecução deste projeto gerou uma base de conhecimento sobre a composição da flora dos campos de planalto da região sul de Itararé e sua distribuição espacial. Estas informações podem subsidiar técnico-cientificamente o esforço de conservação destes últimos remanescentes na região de Itapeva e Itararé, em São Paulo, e de Sengés e Jaguariaíva, no Paraná.

Uma outra contribuição foi, em uma escala mais ampla, explorar a inserção destes campos de Itararé no contexto fitogeográfico dos campos da região centro sul e leste do Brasil. Foi identificado um arranjo com sete grupos florísticos e avaliado o papel dos condicionantes climáticos na definição desses grupos. As variáveis mais importantes na explicação dos padrões de distribuição das espécies foram: isotermalidade, sazonalidade térmica, precipitação do mês mais seco, sazonalidade pluviométrica e precipitação do mês mais úmido.

\section{Agradecimentos}

Ao apoio inestimável dos taxonomistas A. Bidá (Symplocaceae); A. Sciamarelli (Fabaceae); A. Salino (Pteridófitas); A.M. Giulietti (Eriocaulaceae); A.B. Martins (Melastomataceae); C.M. Sakuragui (Araceae); C. Kameyama (Acanthaceae); D.C. Zappi (Cactaceae, Rubiaceae); E. Martins (Melastomataceae); F.A. Vitta (Cyperaceae, Juncaceae, Passifloraceae); F. Barros (Orchidaceae); F.F. Mazine (Myrtaceae); F.R. Salimena-Pires (Verbenaceae); G.V. Somner (Sapindaceae); G.L. Esteves (Malvaceae, Turneraceae); G.P. Lewis (Fabaceae); H.F. Leitão Filho (Asteraceae); H.M.LonghiWagner (Poaceae); I.I. Boldrini (Poaceae); I. Cordeiro (Euphorbiaceae, Gentianaceae); I. Koch (Apocynaceae); J. Prado (Pteridófitas); J.L.A. Moreira (Fabaceae); J.R. Stehmann (Solanaceae); J. Semir (Asteraceae, Melastomataceae); J.F.M. Valls (Poaceae); J.P. Souza (Plantaginaceae, Violaceae); J. Dutilh (Alliaceae, Amaryllidaceae); K. Yamamoto (Ochnaceae); L.P.di Lazzari (Eriocaulaceae); L. Landrum (Myrtaceae); L. Capellari Jr. (Aristolochiaceae); L. Rossi (Thymelaeaceae); L.S. Kinoshita (Apocynaceae, 
Ericaceae); L.G. Clark (Poaceae); M.A. Correia (Lentibulariaceae); M.C.H. Mamede (Malpighiaceae); M.G.L. Wanderley (Bromeliaceae, Mayacaceae, Menyanthaceae, Xyridaceae); M.C.E. Amaral (Commelinaceae, Pontederiaceae); M.C. Marques (Polygalaceae); M.L. Kawasaki (Myrtaceae, Vochysiaceae); M. Sugiyama (Loranthaceae); N.S. Chukr (Iridaceae); P.H. Miyagi (Bignoniaceae); P.T. Sano (Eriocaulaceae); P.L.R. Moraes (Lauraceae); R.M. Harley (Lamiaceae); R.C. de Oliveira (Poaceae); R. Goldenberg (Melastomataceae); R. Mello-Silva (Annonaceae); R. SimãoBianchini (Asteraceae, Convolvulaceae); S.L. Jung-Mendaçolli (Myrsinaceae, Rubiaceae); S.C. Boechat (Poaceae); T.B. Cavalcanti (Lythraceae); T.R. Silva (Droseraceae); T.S. Filgueiras (Poaceae); V. Bittrich (Clusiaceae) e a A.H. Scaramuzza, S. de M. Scaramuzza, E.R. Pinagé e Alessandra Fidelis pelo apoio na geração dos dados.

\section{Referências bibliográficas}

BATALHA, M.A.; MANTOVANI, W. Floristic composition of the Cerrado in the Péde-Gigante Reserve (Santa Rita do Passa Quatro, Southeastern, Brazil). Acta Botânica Brasílica, Porto Alegre, v. 15, n. 3, p. 289-304, 2001.

BATALHA, M.A.; MARTINS, R.F. The vascular flora of the cerrado in Emas National Park (Goiás, Central Brazil). Sida, Dallas, v. 20, n. 1, p. 295-311, 2002.

BEHLING, H. Late Quaternary vegetation, climate and fire history in the Araucaria forest and Campos region from Serra Campos Gerais (Paraná), S. Brazil. Review of palaeobotany and palynology, Amsterdam, v. 97, p. 109-121, 1997.

BEHLING, H.; PILLAR, V.; ORLOCI, L.; BAUERMANN, S.G. Late Quaternary Araucaria forest, grassland (Campos), fire and climate dynamics, studied by high resolution pollen, charcoal and multivariate analysis of the Cambará do Sul core in southern Brazil. Palaeogeogr. Palaeoclimatol. Palaeoecol, Amesterdan, v. 203, p. 277-297, 2004.

BOLDRINI, I.I.; EGGERS, L. Vegetação campestre do sul do Brasil: dinâmica de espécies à exclusão do gado. Acta Botânica Brasílica, Porto Alegre, v. 10, n. 1, p. 37-50, 1996.

BOLDRINI, I.I.; MIOTTO, S.T.S. Levantamento fitossociológico de um campo limpo da Estação Experimental Agronômica, UFRGS, Guaíba, RS. 1'. Etapa. Acta Botânica Brasílica, Porto Alegre, v. 1, n. 1, p. 49-56, 1987. 
BOLDRINI, I.I.; MIOTTO, S.T.S.; LONGHI-WAGNER, H.M.; PILLAR, V.D.P.; MARZALL, K. Aspectos florísticos e ecológicos da vegetação do Morro da Polícia, Porto Alegre, RS, Brasil. Acta Botânica Brasílica, Porto Alegre, v. 12, n. 1, p. 89-100, 1998.

BRADE, A.C. A flora do PN do Itatiaia. Boletim do PN Itatiaia, Itatiaia, v. 5, p. 1-99, 1956.

BRANDÃO, M.; GAVILANES, M.L. Cobertura vegetal do município de Pedro Leopoldo, MG: formações vegetais e composição florística. Daphne, Belo Horizonte, v. 7, n. 2, p. 32-50, 1997.

BRANDÃO, M.; GAVILANES, M.L.; ARAÚJO, M.G. Cobertura vegetal do município de Prudente de Morais, MG. Daphne, Belo Horizonte, v. 6, n. 2, p. 40-58, 1996.

BRASIL. Mapa de Biomas do Brasil. Primeira aproximação. Rio de Janeiro: IBGE, 2004. Escala 1:5.000.000.

CONCEIÇÃO, A.A. Ecologia da vegetação em afloramentos rochosos na Chapada Diamantina, Bahia, Brasil. São Paulo: IB/USP, 2003. Tese - Doutorado em Botânica.

CONCEIÇÃO, A.A.; GIULIETTI, A.M. Composição florística e aspectos estruturais de campo rupestre em dois platôs do Morro do Pai Inácio, Chapada Diamantina, Bahia, Brasil. São Paulo. Hoehnea, São Paulo, v. 29, n. 1, p. 37-48, 2002.

COSTA, J.C.; BETINI, G.S.; VERDADE, L.M. Distribuição de aves em áreas de silvicultura de eucalipto do estado de São Paulo. In: CONGRESSO BRASILEIRO DE ORNITOLOGIA, 14, 2006, Ouro Preto. Resumos... Ouro Preto: UFOP/SBO, 2006.

DUFRENE, M.; LEGENDRE, P. Species assemblages and indicator species: the need for a flexible asymmetrical approach. Ecological Monographs, Durham, v. 67, n. 3, p. 34-366, 1997.

FELFILI, J.M.; SANTOS, A.A.B.; SAMPAIO, J.C. Flora e diretrizes ao plano de manejo da APA Gama e Cabeça de Veado. Brasília: UNB, 2004.

FUNDAÇÃO BIODIVERSITAS. Centro de Dados para a Conservação da Biodiversidade. Lista da flora brasileira ameaçada de extinção. Belo Horizonte: Fundação Biodiversitas, 2005.

GARCIA, E.N.; BOLDRINI, I.I.; JACQUES, A.V.A. Dinâmica de formas vitais de uma vegetação campestre sob diferentes práticas de manejo e exclusão. Iheringia, 
Porto Alegre, v. 57, p. 215-241, 2002.

GARCIA, R.J.F. Estudo florístico dos campos alto-montanos e matas nebulares do Parque Estadual da Serra do Mar - Núcleo Curucutu, São Paulo, SP, Brasil. São Paulo: IB-USP, 2003. Tese - Doutorado em Botânica.

GARCIA, R.J.F.; PIRANI, J.R. Análise florística, ecológica e fitogeográfica do Núcleo Curucutu, Parque Estadual da Serra do Mar (São Paulo, SP), com ênfase nos campos junto à crista da Serra do Mar. Hoehnea, São Paulo, v. 32, n. 1, p. 1-48, 2005.

GHELER-COSTA, C.; VERDADE, L.M. Distribuição e abundância de pequenos mamíferos em áreas de interação entre florestas semidecíduas, cerrado e florestas implantadas de eucalipto. In: CONGRESSO BRASILEIRO DE MASTOZOOLOGIA, 3, 2005, Aracruz. Resumos... Vitória: UFES/SBMz, 2005.

GIRARDI-DEIRO, A.M.; GOMES, K.E.; SILVEIRA, V.C.P.; RODRIGUES, C.A.G.; DEBLE, L.P. Composição florística outonal e relação com a qualidade da forragem em campos naturais na APA do Ibirapuitã, RS. Bagé: EMBRAPA/CPPSul, 2003. Documentos 05.

GIRARDI-DEIRO, A.M.; GONÇALVES, J.O.N.; GONZAGA, S.S. Campos naturais ocorrentes nos diferentes tipos de solo no município de Bagé, RS. 2: fisionomia e composição florística. Iheringia: Série Botânica, Porto Alegre, v. 42, p. 55-79, 1992.

GIULIETTI, A.M.; MENEZES, N.L.; PIRANI, J.R.; MEGURO, M.; WANDERLEY, M.G.L.. Flora da Serra do Cipó, Minas Gerais: caracterização e lista das espécies. Boletim de Botânica da Universidade de São Paulo, São Paulo, v. 9, p. 1-151, 1987.

HARLEY, R.M.; SIMMONS, N.A. Florula of Mucugê. Kew: RBG, 1986.

HATSCHBACH, G.; LINSINGEN, L.; UHKMANN, A.; CERVI, A.C.; SONEHRA, J.S.; RIBAS, O.S. Levantamento florístico do cerrado (savana) paranaense e vegetação associada. Boletim do Museu Botânico Municipal, Curitiba, v. 66, p. $1-40,2005$.

HATSCHBACH, G.; MOREIRA FILHO, H.. Catálogo florístico do PE de Vila Velha. Boletim da UFPR: Botânica, Curitiba, v. 28, p. 1-54, 1972.

HIJMANS, R.J.; CAMERON, S.E.; PARRA, J.L.; JONES P.G.; JARVIS, A.. Very high resolution interpolated climate surfaces for global land areas. International 
Journal of Climatology, Chichester West, v. 25, p. 1965-1978, 2005.

JOLY, A.B. Estudo fitogeográfico dos campos de Butantã (São Paulo). Bol. Fac. Ciênc. Letras Univ. São Paulo: Botânica, São Paulo, v. 8, p. 5-67, 1950.

JUDD, W. S.; CAMPBELL, C.S.; KELlOG, E.A.; STEVENS, P.F.; DONOGHUE, M.J. Plant systematics: a phylogenetic approach. Sunderland: Sinauer, 2002.

KLEIN, R.M. Southern Brazilian phytogeographic features and the probable influence of upper quaternary climatic changes in the floristic distribution. Bol. Paran. Geociências, Curitiba, v. 33, p. 67-88, 1975.

KLEIN, R.M.. Ecologia da flora e vegetação do Vale do Itajaí. Sellowia, Florianópolis, v. 31, p. 1-164, 1979.

LEGENDRE, P.; LEGENDRE, L. Numerical ecology. Amsterdam: Elsevier, 1998.

LEPS, J.; SMILAUER, P. Multivariate analysis of ecological data using Canoco. Cambridge: Cambridge University Press, 2003.

LONGHI-WAGNER, H.M. Poaceae. In: WANDERLEY, M.G.L.; SHEPHERD, G.J.; GIUliETTI, A.M. (Ed). Flora Fanerogâmica do Estado de São Paulo. São Paulo: FAPESP/HUCITEC, 2001. v. 1.

MANLY, B.F.J. Randomization and Monte Carlo methods in biology. London: Chapman \& Hall, 1991. p 281.

McCUNE, B.; GRACE, J. B. Analysis of ecological communities. Gleneden Beach: MjM Softwares Design, 2002.

McCUNE, B.; MEFFORD, M.J. PC-ORD: Multivariate analyis of ecological data, version 4. Gleneden Beach: MjM Softwares Design, 1999.

MUNHOZ, C.B.R. Padrões de distribuição sazonal e espacial das espécies do estrato herbáceo-subarbustivo em comunidades de campo limpo úmido e de campo sujo. Brasília: UNB, 2003. Tese - Doutorado em Botânica.

MUNHOZ, C.B.R.; FELFILI, J.M. Fenologia do estrato herbáceo-subarbustivo de uma comunidade de campo sujo na Fazenda água Limpa no Distrito Federal, Brasil. Acta Botânica Brasílica, Porto Alegre, v. 19, n. 4, p. 979-988, 2005.

NABINGER, C.A.; MORAES, A. de; MARASCHIN, G.E. Campos in southern Brazil. In: LEMAIRE, G.; HODGSON, J.G.; MORAES, A. de; MARASCHIN, G.E. (Ed.). Grassland ecophysiology and grazing ecology. Wallingford: CABI Publishing, 2000. p 355-376.

OLIVEIRA FILHO, A.T.; RATTER, J.A. A study of the origin of central Brazilian 
forests by the analysis of plant species distribution patterns. Edinburgh Journal of Botany, Edinburgh, v. 52, p. 141-194, 1995.

OLIVEIRA-FILHO, A.T.; FONTES, M.A.L. Patterns of Floristic Differentiation among Atlantic Forests in Southeastern Brazil and the Influence of Climate. Biotropica, Washington, v. 32, n. 4b, p.793-810, 2000.

OVERBECK, G.E.; MÜLLER, S.C.; PILLAR, V.D.; PFADENHAUER, J. Floristic composition, environmental variation and species distribution patterns in burned grassland in southern Brazil. Brazilian Journal of Biology, São Carlos, v. 67, n. 2, 2006. No prelo.

PEREIRA, B.A.S.; MECENAS, V.V. Lista das espécies nativas de fanerógamas registradas na APA de Cafuringa, com suas respectivas formas de vida e fitofisionomias de ocorrência. In: SEMARH, 2003?. Disponível em $<$ http://www.semarh.df.gov.br/semarh/site/cafuringa/FrameSets/Frameset_sec4.ht m>. Acesso em: 18 jun. 2006.

PILLAR, V.D. Dinâmica da expansão florestal em mosaicos de floresta e campos no sul do Brasil. In: CLAUDINO-SALES, V. (Ed.). Ecossistemas brasileiros: manejo e conservação. Fortaleza: Expressão, 2003. p. 209-216.

PILLAR, V.P. Estado atual e desafios para a conservação dos campos. Porto Alegre: UFRGS, 2006. Relatório de seminário, 27/03/2006.

PILLAR, V.D.; QUADROS, F.L.F. Grassland-forest boundaries in southern Brazil. Coenoses, Gorizia, v. 12, p. 119-126, 1997.

RAMBO, B. A fisionomia do Rio Grande do Sul. Porto Alegre: Selbach, 1956a. p. 472.

RAMBO, B. A flora fanerogâmica dos Aparados Riograndenses. Sellowia, Florianópolis, v. 7, p. 235-298, 1956 b.

RATTER, J.A.; BRIDGEWATER S.; ATKINSON, R.; FELIPE J.F. Analysis of the floristic composition of the Brazilian cerrado vegetation III: comparison of the woody vegetation of 376 acres. Edinburgh Journal of Botany, Edinburgh, v. 60, p. 57-109, 2003.

RATTER, J.A.; BRIDGEWATER S.; ATKINSON, R.; Felipe J.F. Analysis of the floristic composition of the Brazilian cerrado vegetation II: Comparison of the woody vegetation of 98 areas. Edinburgh Journal of Botany, Edinburgh, v. 53, n. 2, p. 153-180, 1996. 
RIZZINI, C.T. Flora organensis. Arquivos do Jardim Botânico do Rio de Janeiro, Rio de Janeiro, v. 13, p. 11-243, 1954.

ROBIM, M.J.; PASTORE, J.A.; AGUIAR, O.T.; BAITELLO, J.B. Flora arbóreo arbustiva e herbácea do Parque Estadual de Campos do Jordão (SP). Rev. Inst. Florestal, São Paulo, v. 2, n. 1, p. 31-53, 1990.

SAFFORD, H.D. Brazilian páramos I: An introduction to the physical environment and vegetation of the campos de altitude. Journal of Biogeography, Oxford, v. 26, p. 693-712, 1999.

SÃO PAULO (Estado). Resolução SMA n. 48, de 2004. Lista oficial das espécies da flora do Estado de São Paulo ameaçadas de extinção. Diário Oficial do Estado de São Paulo, Poder Executivo, São Paulo, SP, 22 set. 2004. Seção Meio Ambiente.

SASAKI, D. Levantamento florístico no cerrado de Pedregulho, São Paulo, Brasil. São Paulo: IB/USP, 2006. Dissertação - Mestrado em Botânica.

SCUDELLLER, V.V.; MARTINS, F.R.; SHEPHERD, G.J. Distribution and abundance of arborealspecies in the Atlantic ombrophilous dense forest in Southeastern Brazil. Plant Ecology, Dordrecht , v. 152, p. 185-99, 2001.

SILVA, J.B.; FERREIRA, M.B.; AVELAR, B.C. Contribuição ao conhecimento da vegetação de campo-cerrado de Sete Lagoas - MG. Oreades, Belo Horizonte, v. 5, n. 7/9, p. 92-117, 1976.

SOUZA, V.C.; LORENZI, H. Botânica sistemática. Nova Odessa: Instituto Plantarum, 2005.

STANNARD, B.L. (Ed.). Flora of the Pico das Almas, Chapada Diamantina, Brazil. Kew: Royal Botanic Gardens, 1995.

TANNUS, J.L.S.; ASSIS, M.A. Composição de espécies vasculares de campo sujo e campo úmido em área de cerrado, Itirapina - SP, Brasil. Revista Brasileira de Botânica, São Paulo, v. 27, n. 3, p. 489-506, 2004.

TER BRAAK, C.J.F. The analysis of vegetation-environment relationships by canonical correspondence analysis. Vegetatio, Dordrecht, v. 69, n. 1, p. 69-77, 1987.

TRICART, J.; KIEWIETDEJONGE, C. Ecogeography and rural management: a contribution to the IGBP. Harlow: Longman, 1992.

TRINDADE, J.P.P. Processos de degradação e regeneração da vegetação campestre do entorno de areais do sudoeste do Rio Grande do Sul. Porto Alegre: UFRGS, 2003. Tese - Doutorado em Zootecnia. 
UNESCO. Vegetação no Distrito Federal: tempo e espaço. Brasília: UNESCO, 2000.

USTERI, A. Flora der Umgebung von Stadt São Paulo in Brasilien. Jena: Gustav Ficher, 1911.

VINCENT, R.C.; MIYAZAKI, S.L.; GOMES, E.P.C.; MANTOVANI, W. Estrutura e composição florística do cerrado de Emas, Pirassununga, SP. In: CONGRESSO DA SOCIEDADE DE BOTÂNICA DE SÃO PAULO, 8., 1992, Campinas. Anais.... São Paulo: SBSP, 1992. p. 139-151.

ZAPPI, D.C.; LUCAS, E.; STANNARD, B.L.; LUGHADHA, E.N.; PIRANI, J.R.; QUEIROZ, L.P.; ATKINS, S.; HIND, D.J.N.; GIULIETTI, A.M.; HARLEY, R.M.; CARVALHO, A.M. Lista das plantas vasculares de Catolés, Chapada Diamantina, Bahia, Brasil. Bol. Bot. Univ. São Paulo, São Paulo, v. 21, n. 2, p. 345-398, 2003. 


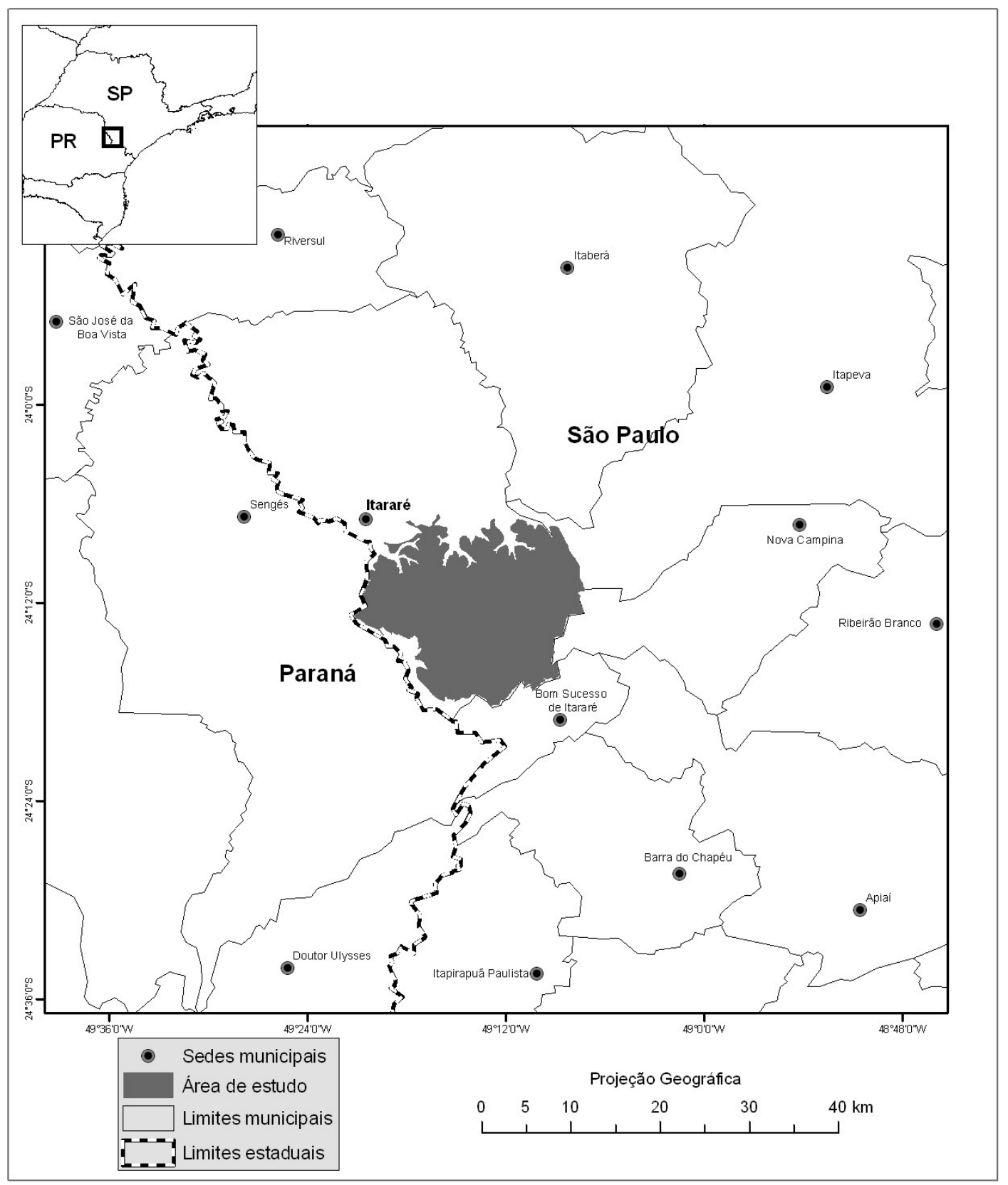

Figura 1. Localização da área de estudo na porção sul do município de Itararé, SP. 


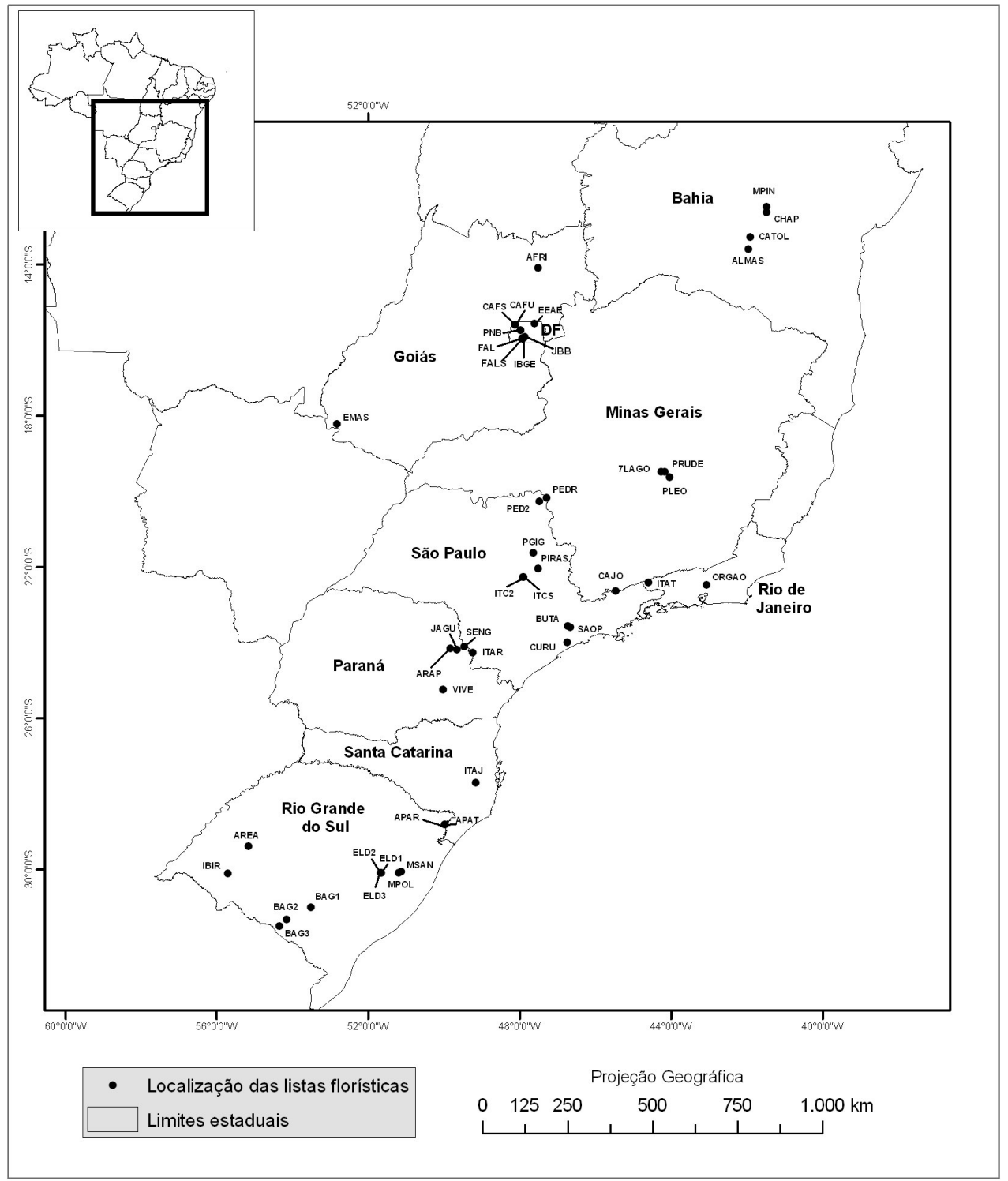

Figura 2. Localização das 47 listas florísticas de formações campestres utilizadas na análise fitogeográfica.

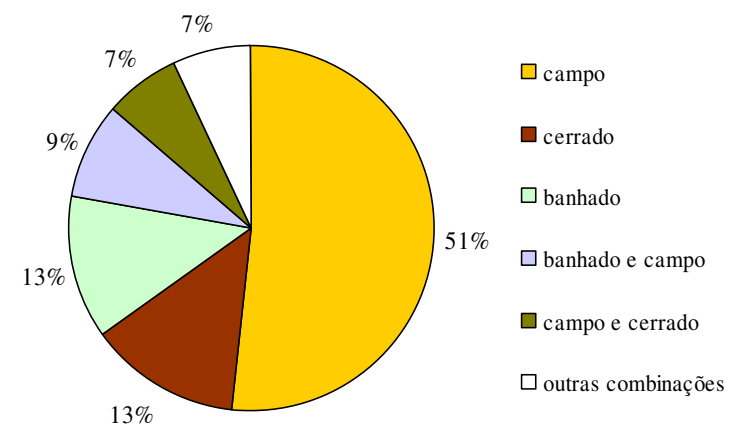

Figura 3. Distribuição das espécies segundo os principais hábitats na porção sul de Itararé, SP. 


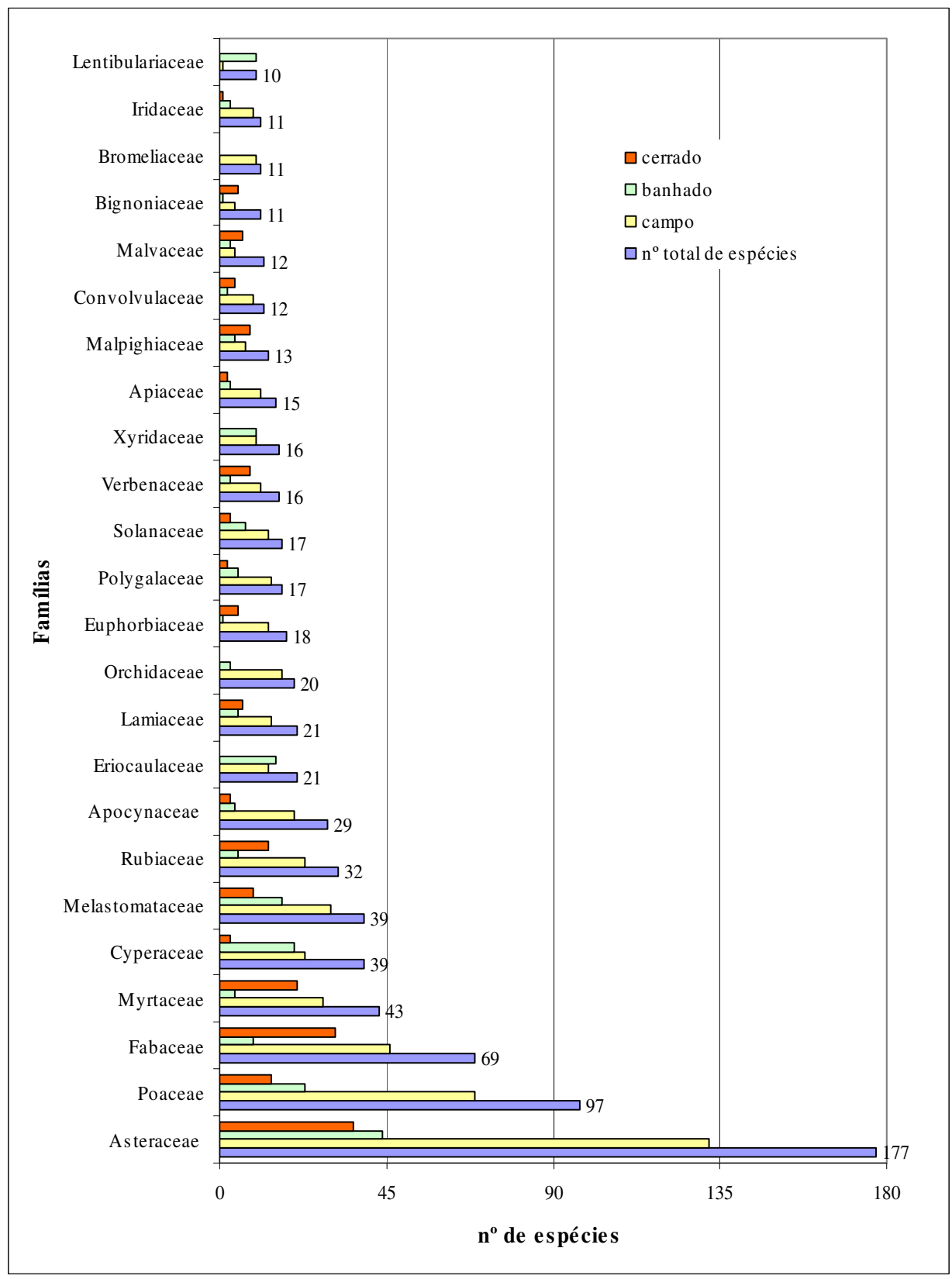

Figura 4. Famílias com mais de dez espécies distribuídas segundo os diferentes hábitats dos campos de planalto de Itararé, SP. 


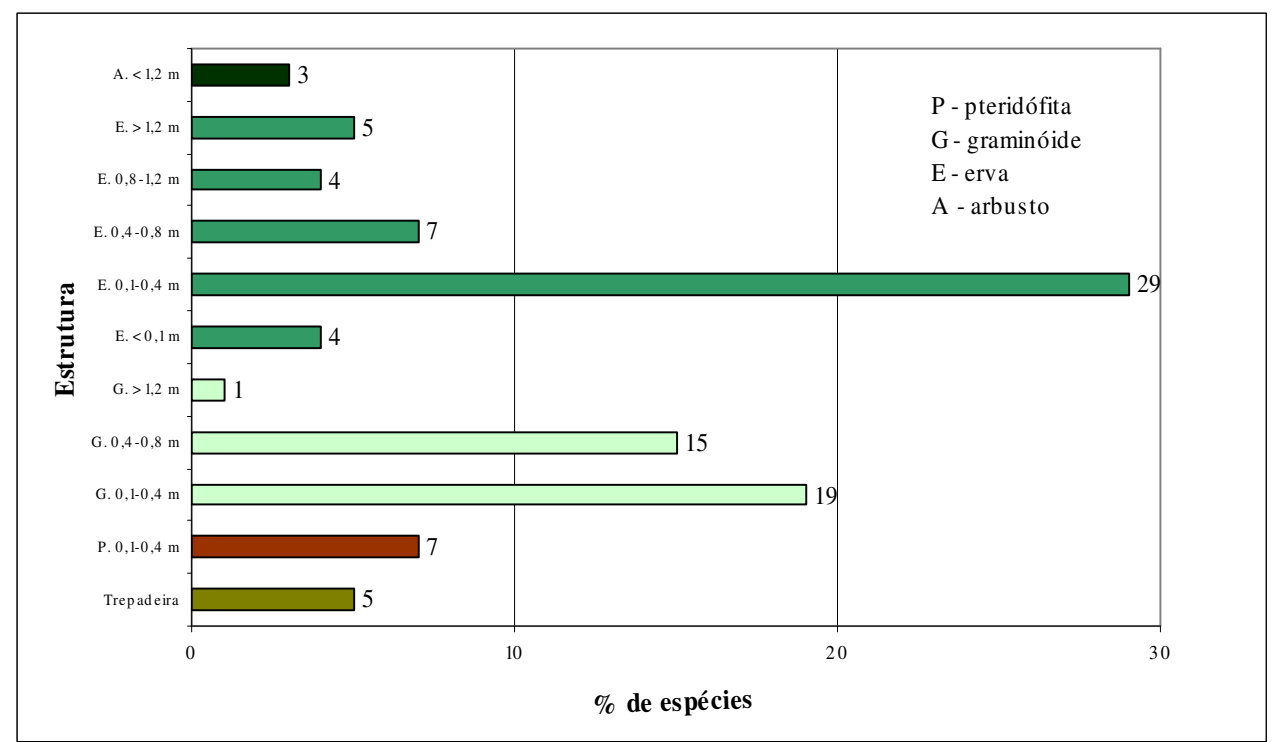

Figura 5. Distribuição de espécies comuns em função da estrutura: trepadeiras, pteridófitas, graminóides, ervas e arbustos, nos campos de planalto da porção sul de Itararé, SP.

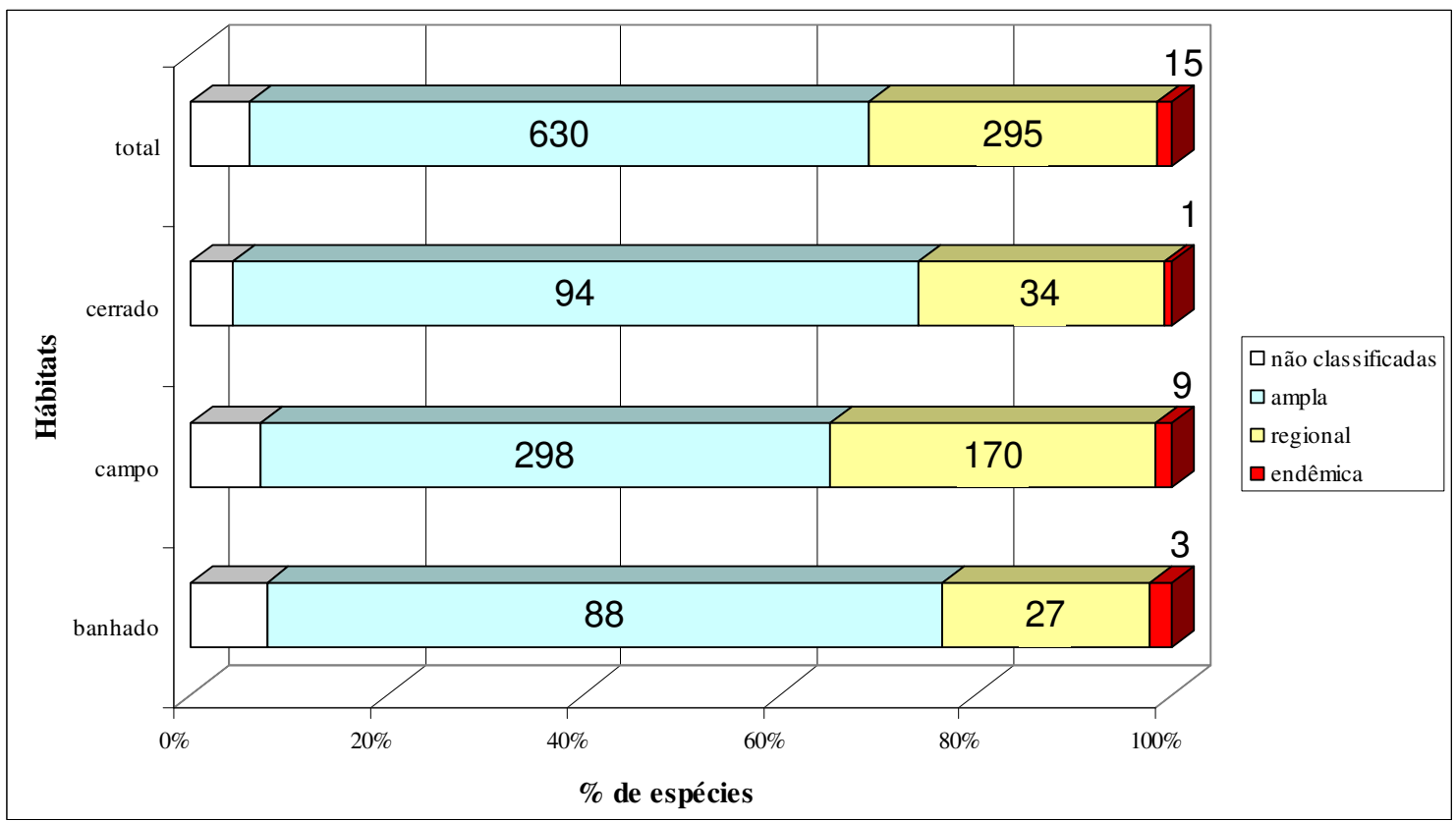

Figura 6. Padrões de distribuição geográfica das espécies (\% e $\mathrm{n}^{0}$ total) segundo os principais hábitats dos campos de planalto da porção sul de Itararé, SP (ampla - Afro-América, América, América do Sul, Brasil, cosmopolita, neotropical, pantropical, subespontânea; regional - Argentina, Bolívia, Paraguai, Uruguai, DF, GO, regiões S e SE do Brasil; endêmica - SP) 


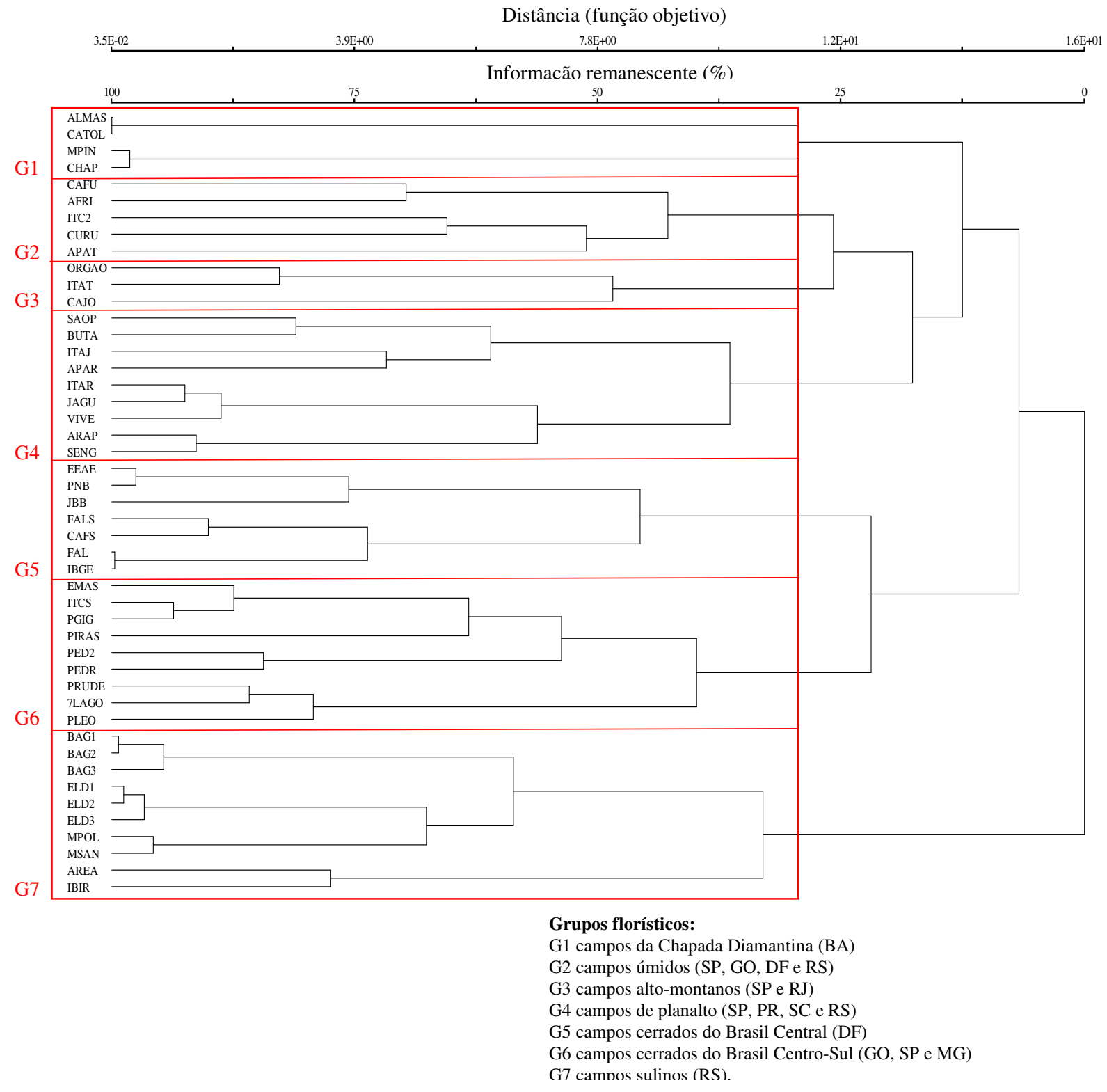

Figura 7. Dendrograma das 47 listas florísticas de formações campestres obtido pela análise de agrupamento (índice de similaridade de Kulczynsky e método de aglomeração $\beta$ flexível; códigos das listas conforme aTabela 1), com indicação do corte adotado acompanhado dos respectivos grupos florísticos. 


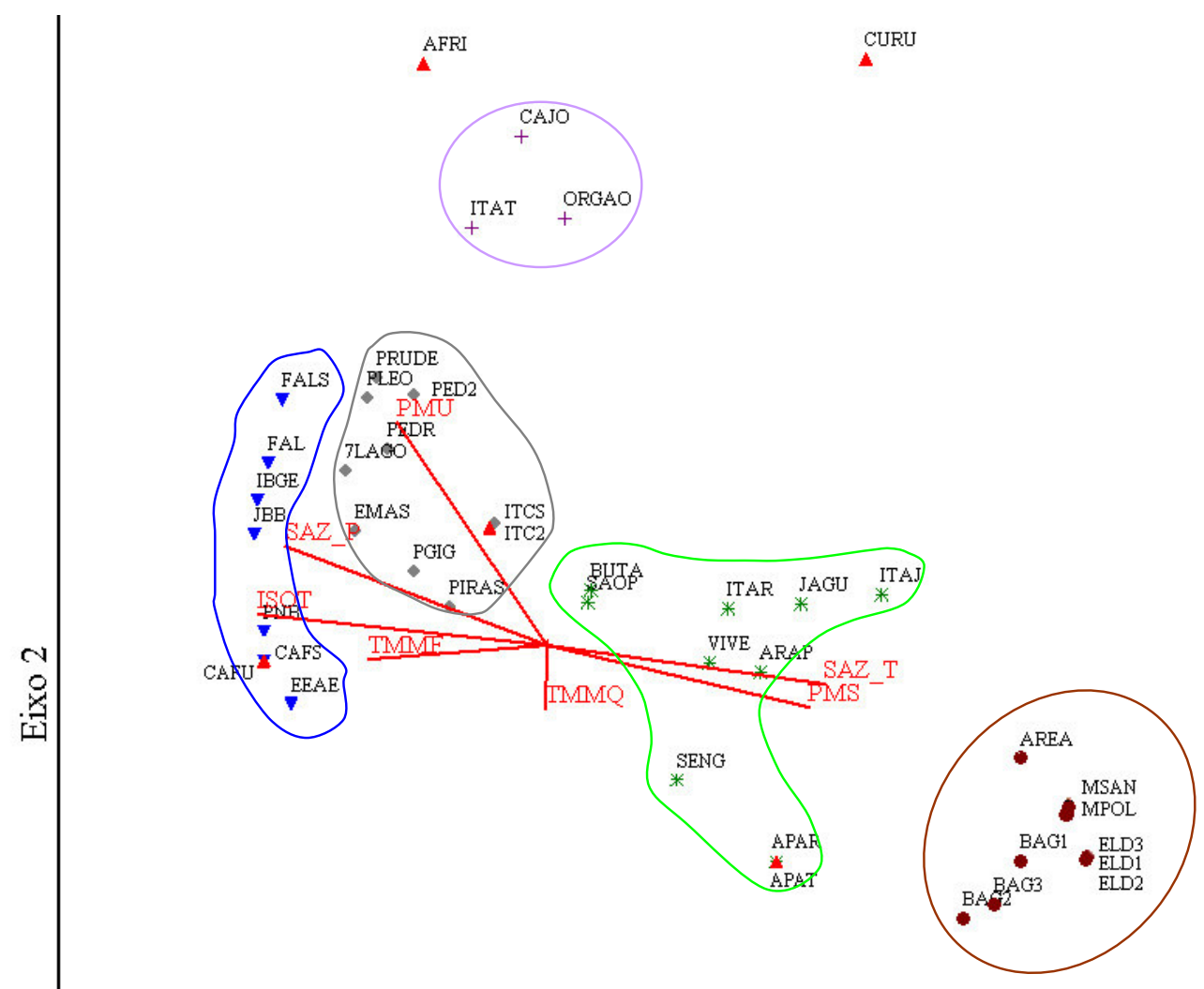

Grupos florísticos:

- G1campos da Chapada Diamantina (BA)

^ G2 campos úmidos (SP, GO, DF e RS)

+ G3 campos alto-montanos ( $\mathrm{SP}$ e RJ)

* G4 campos de planalto (SP, PR, SC e RS)

v G5 campos cerrados do Brasil Central (DF)

- G6 campos cerrados do Brasil Centro-Sul (GO, SP e MG)

- G7 campos sulinos (RS).

\section{Eixo 1}

Figura 8. Diagrama de ordenação das listas florísticas (legenda dos códigos das localidades na Tabela 1) baseado na distribuição da ocorrência das espécies e sua correlação com 7 variáveis ambientais (ISOT - isotermalidade; SAZ_T - sazonalidade térmica; TMMQ temperatura máxima do mês mais quente; TMMF - temperatura mínima do mês mais frio; PMU - precipitação do mês mais úmido; PMS - precipitação do mês mais seco; e SAZ_P - sazonalidade pluviométrica). 


\section{Tabela 1. Relação das listas florísticas utilizadas na análise de padrões biogeográficos para as formações campestres brasileiras.}

\begin{tabular}{|c|c|c|c|c|c|c|c|c|c|c|}
\hline Código & Referência & Fisionomia & $\begin{array}{l}\begin{array}{l}\text { Riqueza } \\
\text { de } \\
\text { espécies }\end{array} \\
\end{array}$ & $\begin{array}{l}\text { Método } \\
\text { de } \\
\text { coleta }\end{array}$ & Referência geográfica & Município & UF & Altitude (m) & $\begin{array}{l}\text { Latitude } \\
\text { (S) }\end{array}$ & $\begin{array}{l}\text { Longitude } \\
\text { (W) }\end{array}$ \\
\hline 7LAGO & Silva et al. 1976 & campo cerrado & 117 & EC & Alto das Seriemas & Sete Lagoas & MG & 750 a 800 & $19^{\circ} 28^{\prime}$ & $44^{\circ} 15^{\prime}$ \\
\hline AFRI & Munhoz 2003 & campo úmido & 123 & $\mathrm{EC}$ & Fazenda Água Fria & Alto Paraíso de Goiás & GO & 1.340 & $14^{\circ} 04^{\prime}$ & $47^{\circ} 30^{\prime}$ \\
\hline ALMAS & Stannard 1995 & campo & 339 & $\mathrm{EC}$ & Pico das Almas & $\begin{array}{l}\text { Rio de Contas, Livramento } \\
\text { do Brumado, Água Quente }\end{array}$ & $\mathrm{BA}$ & 1.958 & $13^{\circ} 34^{\prime}$ & $41^{\circ} 57^{\prime}$ \\
\hline APAR & Rambo 1956b & campo & 207 & $\mathrm{EC}$ & $\begin{array}{l}\text { Itaimbezinho, Cambará, Serra da Rocinha, PN } \\
\text { Aparados da Serra }\end{array}$ & $\begin{array}{l}\text { Cambará do Sul, São José } \\
\text { dos Ausentes }\end{array}$ & RS & 1.220 & $28^{\circ} 48^{\prime}$ & $49^{\circ} 58^{\prime}$ \\
\hline APAT & Rambo 1956b & turfeira & 98 & $\mathrm{EC}$ & $\begin{array}{l}\text { Itaimbezinho, Cambará, Serra da Rocinha, PN } \\
\text { Aparados da Serra }\end{array}$ & $\begin{array}{l}\text { Cambará do Sul, São José } \\
\text { dos Ausentes }\end{array}$ & RS & 1.220 & $28^{\circ} 48^{\prime}$ & $49^{\circ} 58^{\prime}$ \\
\hline ARAP & Hatschbach et al. 2005 & campo & 232 & $\mathrm{EC}$ & $\begin{array}{l}\text { Sede municipal, cabeceiras do rio das Cinzas e } \\
\text { bacia do rio Jaguariaíva }\end{array}$ & Arapoti & PR & 730 a 1.300 & $24^{\circ} 09^{\prime}$ & $49^{\circ} 49^{\prime}$ \\
\hline AREA & Trindade 2003 & campo & 38 & QD & Areais & $\begin{array}{l}\text { São Francisco de Assis, } \\
\text { Manoel Viana e Alegrete }\end{array}$ & RS & 200 & $29^{\circ} 23^{\prime}$ & $55^{\circ} 09^{\prime}$ \\
\hline BAG1 & Girardi-Deiro et al. 1992 & campo limpo & 161 & TR & $\begin{array}{l}\text { Unidade mapeamento de solo associação } \\
\text { Guaritas com afloramentos de rocha }\end{array}$ & Bagé & RS & 200 a 500 & $31^{\circ} 00^{\prime}$ & $53^{\circ} 30^{\prime}$ \\
\hline BAG2 & Girardi-Deiro et al. 1992 & $\begin{array}{l}\text { campo limpo e } \\
\text { sujo }\end{array}$ & 163 & TR & Unidade mapeamento de solo Bexigoso & Bagé & RS & 180 a 200 & $31^{\circ} 19^{\prime}$ & $54^{\circ} 09^{\prime}$ \\
\hline BAG3 & Girardi-Deiro et al. 1992 & campo limpo & 113 & TR & Unidade mapeamento de solo Bagé & Bagé & RS & 60 a 180 & $31^{\circ} 30^{\prime}$ & $54^{\circ} 20^{\prime}$ \\
\hline BUTA & Joly 1950 & campo & 343 & $\mathrm{EC}$ & Campus do Butantã, USP & São Paulo & SP & 800 & $23^{\circ} 33^{\prime}$ & $46^{\circ} 43^{\prime}$ \\
\hline$\overline{\text { CAFS }}$ & Pereira \& Mecenas 2003 & campo & 246 & $\overline{\mathrm{EC}}$ & APA do Cafuringa & Brasília & $\mathrm{DF}$ & 1.330 & $15^{\circ} 35^{\prime}$ & $48^{\circ} 06^{\prime}$ \\
\hline CAFU & Pereira \& Mecenas 2003 & campo úmido & 86 & $\mathrm{EC}$ & APA do Cafuringa & Brasília & $\mathrm{DF}$ & 1.330 & $15^{\circ} 35^{\prime}$ & $48^{\circ} 06^{\prime}$ \\
\hline CAJO & $\begin{array}{l}\text { Robim et al. 1990; Longhi- } \\
\text { Wagner } 2001\end{array}$ & campo & 118 & $\mathrm{EC}$ & PE de Campos do Jordão & Campos do Jordão & SP & 1.030 a 2.007 & $22^{\circ} 37^{\prime} 19^{\prime \prime}$ & $45^{\circ} 26^{\prime} 43^{\prime \prime}$ \\
\hline CATOL & Zappi et al. 2003 & campo geral & 320 & $\mathrm{EC}$ & Campos de Ouro Fino, Catolés & Abaira, Piatã & BA & 1.700 a 1.800 & $13^{\circ} 15^{\prime}$ & $41^{\circ} 54^{\prime}$ \\
\hline CHAP & Conceição 2003 & campo geral & 82 & QD & Chapada Diamantina & Palmeiras, Mucugê & $\mathrm{BA}$ & 1.100 a 1.430 & $12^{\circ} 36^{\prime}$ & $41^{\circ} 28^{\prime}$ \\
\hline CURU & Garcia \& Pirani 2005 & campo & 122 & EC & $\begin{array}{l}\text { Trilha do campo, PE da Serra do Mar, Núcleo } \\
\text { Curucutu }\end{array}$ & São Paulo & SP & 750 a 800 & $23^{\circ} 59^{\prime} 24^{\prime \prime}$ & $46^{\circ} 43^{\prime} 48^{\prime \prime}$ \\
\hline EEAE & UNESCO 2000 & $\begin{array}{l}\text { campo úmido, } \\
\text { limpo, sujo e } \\
\text { campo cerrado }\end{array}$ & 139 & $\mathrm{EC}$ & EE de Águas Emendadas & Brasília & $\mathrm{DF}$ & 1.050 & $15^{\circ} 33^{\prime}$ & $47^{\circ} 36^{\prime}$ \\
\hline ELD1 & Boldrini \& Miotto 1987 & campo & 111 & QD, TR & Estação Experimental Agronômica, UFRGS & Eldorado do Sul & RS & 46 & $30^{\circ} 05^{\prime}$ & $51^{\circ} 39^{\prime}$ \\
\hline ELD2 & Boldrini \& Eggers 1996 & campo & 128 & $\mathrm{EC}, \mathrm{QD}$ & EEA, UFRGS & Eldorado do Sul & RS & 46 & $30^{\circ} 05^{\prime}$ & $51^{\circ} 39^{\prime}$ \\
\hline ELD3 & Garcia et al 2002 & campo & 115 & QD & EEA, UFRGS & Eldorado do Sul & RS & 46 & $30^{\circ} 05^{\prime} 27^{\prime \prime}$ & $51^{\circ} 40^{\prime} 18^{\prime \prime}$ \\
\hline EMAS & Batalha \& Martins 2002 & $\begin{array}{l}\text { campo limpo e } \\
\text { campo cerrado }\end{array}$ & 396 & EC & PN das Emas & $\begin{array}{l}\text { Mineiros, Chapadão do } \\
\text { Céu, Costa Rica }\end{array}$ & $\begin{array}{l}\text { GO, } \\
\text { MS }\end{array}$ & 720 a 888 & $18^{\circ} 12^{\prime} 33^{\prime \prime}$ & $52^{\circ} 49^{\prime} 09^{\prime \prime}$ \\
\hline FAL & Felfili et al. 2004 & $\begin{array}{l}\text { campo úmido, } \\
\text { limpo, sujo e } \\
\text { campo cerrado }\end{array}$ & 474 & $\mathrm{EC}$ & Fazenda Água Limpa, UNB & Brasília & $\mathrm{DF}$ & 1.050 & $15^{\circ} 57^{\prime}$ & $47^{\circ} 55^{\prime}$ \\
\hline FALS & Munhoz \& Felfili 2005 & campo sujo & 229 & TR & Córrego Taquara, Fazenda Água Limpa, UNB & Brasília & DF & 1.050 & $15^{\circ} 55^{\prime} 45^{\prime \prime}$ & $47^{\circ} 54^{\prime} 21^{\prime \prime}$ \\
\hline
\end{tabular}




\begin{tabular}{|c|c|c|c|c|c|c|c|c|c|c|}
\hline Código & Referência & Fisionomia & $\begin{array}{l}\text { Riqueza } \\
\text { de } \\
\text { espécies }\end{array}$ & $\begin{array}{l}\text { Método } \\
\text { de } \\
\text { coleta }\end{array}$ & Referência geográfica & Município & UF & Altitude (m) & $\begin{array}{l}\text { Latitude } \\
\text { (S) }\end{array}$ & $\begin{array}{l}\text { Longitude } \\
\text { (W) }\end{array}$ \\
\hline IBGE & Felfili et al. 2004 & $\begin{array}{l}\text { campo úmido, } \\
\text { limpo, sujo e } \\
\text { campo cerrado }\end{array}$ & 550 & EC & Reserva Ecológica do IBGE & Brasília & $\mathrm{DF}$ & 1.100 & $15^{\circ} 56^{\prime}$ & $47^{\circ} 53^{\prime}$ \\
\hline IBIR & Girardi-Deiro et al. 2003 & campo & 56 & $\mathrm{EC}$ & Estância do Vinte e Oito, APA do Ibirapuitã & Alegrete & RS & 120 & $30^{\circ} 05^{\prime} 73^{\prime \prime}$ & $55^{\circ} 41^{\prime} 27^{\prime \prime}$ \\
\hline ITAJ & Klein 1979 & campo & 235 & $\mathrm{EC}$ & $\begin{array}{l}\text { Chapada Serra da Boa Vista, nascentes do rio } \\
\text { Paletas e Pombinhas, bacia do Itajaí }\end{array}$ & $\begin{array}{l}\text { Rancho Queimado, Pouso } \\
\text { Redondo e Ponte Alta }\end{array}$ & $\mathrm{SC}$ & 1.174 & $27^{\circ} 41^{\prime} 46^{\prime \prime}$ & $49^{\circ} 08^{\prime} 54^{\prime \prime}$ \\
\hline ITAR & Capítulo 2 & campo & 637 & $\mathrm{EC}, \mathrm{QD}$ & Ventania & Itararé & SP & 800 a 1.000 & $24^{\circ} 16^{\prime}$ & $49^{\circ} 14^{\prime}$ \\
\hline ITAT & Brade 1956 & campo & 150 & $\mathrm{EC}$ & PN Itatiaia & $\begin{array}{l}\text { Itatiaia, Resende, Itamonte, } \\
\text { Alagoa e Bocaina de Minas }\end{array}$ & $\begin{array}{l}\text { RJ, } \\
\text { MG }\end{array}$ & 2.000 a 2.200 & $22^{\circ} 24^{\prime}$ & $44^{\circ} 35^{\prime}$ \\
\hline ITC2 & Tannus \& Assis 2004 & campo úmido & 95 & $\mathrm{EC}$ & Fazenda da Máquina & Itirapina & SP & 700 & $22^{\circ} 15^{\prime} 48^{\prime \prime}$ & $47^{\circ} 54^{\prime}$ \\
\hline ITCS & Tannus \& Assis 2004 & campo sujo & 214 & $\mathrm{EC}$ & Fazenda da Máquina & Itirapina & SP & 700 & $22^{\circ} 15^{\prime} 45^{\prime \prime}$ & $47^{\circ} 53^{\prime}$ \\
\hline JAGU & Hatschbach et al. 2005 & campo & 475 & EC & Parque Estadual do Cerrado & Jaguariaíva & PR & 730 a 1.300 & $24^{\circ} 10^{\prime}$ & $49^{\circ} 39^{\prime}$ \\
\hline JBB & Felfili et al. 2004 & $\begin{array}{l}\text { campo úmido, } \\
\text { limpo, sujo e } \\
\text { campo cerrado }\end{array}$ & 164 & $\mathrm{EC}$ & Jardim Botânico & Brasília & $\mathrm{DF}$ & 1.160 & $15^{\circ} 54^{\prime}$ & $47^{\circ} 51^{\prime}$ \\
\hline MPIN & Conceição \& Giulietti 2002 & campo geral & 75 & QD & Morro do Pai Inácio & Palmeiras & BA & 1.100 a 1.170 & $12^{\circ} 27^{\prime}$ & $41^{\circ} 28^{\prime}$ \\
\hline MPOL & Boldrini et al. 1998 & campo & 215 & PN, TR & Morro da Polícia & Porto Alegre & RS & 160 a 280 & $30^{\circ} 05^{\prime}$ & $51^{\circ} 11^{\prime}$ \\
\hline MSAN & Overbeck et al. 2006 & campo & 174 & QD, TR & $\begin{array}{l}\text { Morro de Santana, Campus da Agronomia, } \\
\text { UFRGS }\end{array}$ & Porto Alegre & RS & 311 & $30^{\circ} 03^{\prime}$ & $51^{\circ} 07^{\prime}$ \\
\hline ORGAO & Rizzini 1954 & campo & 70 & EC & $\begin{array}{l}\text { Campo das Antas, Castelo, Isabeloca, Pedra do } \\
\text { Açu, PN Serra dos Órgãos }\end{array}$ & $\begin{array}{l}\text { Teresópolis, Petrópolis, } \\
\text { Magé, Guapimirim }\end{array}$ & RJ & 2.000 a 2.262 & $22^{\circ} 28^{\prime}$ & $43^{\circ} 03^{\prime}$ \\
\hline PED2 & Sasaki 2006 & campo sujo & 189 & QD & PE Furnas do Bom Jesus & Pedregulho & SP & 977 a 1.000 & $20^{\circ} 14^{\prime} 52^{\prime \prime}$ & $47^{\circ} 27^{\prime} 37^{\prime \prime}$ \\
\hline PEDR & Sasaki 2006 & campo cerrado & 133 & QD & Distrito de Estreito & Pedregulho & SP & 710 a 730 & $20^{\circ} 09^{\prime} 52^{\prime \prime}$ & $47^{\circ} 16^{\prime} 23^{\prime \prime}$ \\
\hline PGIG & Batalha \& Mantovani 2001 & campo cerrado & 232 & $\mathrm{EC}$ & ARIE Pé do Gigante & Santa Rita do Passa Quatro & SP & 590 a 740 & $21^{\circ} 37^{\prime}$ & $47^{\circ} 38^{\prime}$ \\
\hline PIRAS & Vincent et al. 1992 & campo cerrado & 110 & PN, QD & $\begin{array}{l}\text { Centro Regional Latino-Americano de } \\
\text { Aqüicultura, Cerrado de Emas }\end{array}$ & Pirassununga & SP & 575 & $22^{\circ} 02^{\prime}$ & $47^{\circ} 30^{\prime}$ \\
\hline PLEO & Brandão \& Gavilanes 1997 & $\begin{array}{l}\text { campo cerrado } \\
\text { e campo úmido }\end{array}$ & 112 & $\mathrm{EC}$ & Sede municipal & Pedro Leopoldo & MG & 810 & $19^{\circ} 37^{\prime}$ & $44^{\circ} 02^{\prime}$ \\
\hline PNB & UNESCO 2000 & $\begin{array}{l}\text { campo úmido, } \\
\text { limpo, sujo e } \\
\text { campo cerrado }\end{array}$ & 146 & EC & PN de Brasília & Brasília & $\mathrm{DF}$ & 1.110 & $15^{\circ} 43^{\prime}$ & $47^{\circ} 58^{\prime}$ \\
\hline PRUDE & Brandão et al. 1996 & $\begin{array}{l}\text { campo cerrado } \\
\text { e campo úmido }\end{array}$ & 182 & EC & Sede municipal & Prudente de Morais & MG & 740 & $19^{\circ} 28^{\prime}$ & $44^{\circ} 09^{\prime}$ \\
\hline SAOP & Usteri 1911 & campo & 187 & EC & Vila Mariana & São Paulo & SP & 835 & $23^{\circ} 35^{\prime} 30^{\prime \prime}$ & $46^{\circ} 38^{\prime} 47^{\prime \prime}$ \\
\hline SENG & Hatschbach et al. 2005 & campo & 196 & EC & $\begin{array}{l}\text { Sede municipal, cabeceiras do rio das Cinzas e } \\
\text { bacia do rio Jaguariaíva }\end{array}$ & Sengés & PR & 730 a 1.300 & $24^{\circ} 06^{\prime}$ & $49^{\circ} 27^{\prime}$ \\
\hline VIVE & $\begin{array}{l}\text { Hatschbach \& Moreira Filho } \\
1972\end{array}$ & campo & 433 & $\mathrm{EC}$ & Vila Velha & Ponta Grossa & PR & 794 a 916 & $25^{\circ} 14^{\prime} 14^{\prime \prime}$ & $50^{\circ} 00^{\prime} 20^{\prime \prime}$ \\
\hline
\end{tabular}


Tabela 2. Distribuição das espécies por famílias nos campos de planalto da porção sul de Itararé, SP.

\begin{tabular}{|c|c|c|c|c|c|c|c|c|}
\hline Famílias & $n^{0}$ de $s p$. & $\%$ & Famílias & $n^{0}$ de $s p$. & $\%$ & Famílias & $n^{0}$ de sp. & $\%$ \\
\hline LYCOPHYTA & & & Lythraceae & 9 & 0,9 & Smilacaceae & 2 & 0,2 \\
\hline Lycopodiaceae & 4 & 0,4 & Lauraceae & 8 & 0,8 & Styracaceae & 2 & 0,2 \\
\hline Selaginellaceae & 2 & 0,2 & Amaranthaceae & 7 & 0,7 & Turneraceae & 2 & 0,2 \\
\hline PTEROPHYTA & & & Annonaceae & 6 & 0,6 & Vitaceae & 2 & 0,2 \\
\hline Pteridaceae & 4 & 0,4 & Erythroxylaceae & 6 & 0,6 & Alliaceae & 1 & 0,1 \\
\hline Blechnaceae & 3 & 0,3 & Gentianaceae & 6 & 0,6 & Alstromeriaceae & 1 & 0,1 \\
\hline Cyatheaceae & 2 & 0,2 & Orobanchaceae & 6 & 0,6 & Aristolochiaceae & 1 & 0,1 \\
\hline Gleicheniaceae & 2 & 0,2 & Aquifoliaceae & 5 & 0,5 & Begoniaceae & 1 & 0,1 \\
\hline Polypodiaceae & 2 & 0,2 & Campanulaceae & 5 & 0,5 & Brassicaceae & 1 & 0,1 \\
\hline Dennstaedtiaceae & 1 & 0,1 & Ericaceae & 5 & 0,5 & Burseraceae & 1 & 0,1 \\
\hline Dicksoniaceae & 1 & 0,1 & Myrsinaceae & 5 & 0,5 & Cactaceae & 1 & 0,1 \\
\hline Dryopteridaceae & 1 & 0,1 & Ochnaceae & 5 & 0,5 & Calyceraceae & 1 & 0,1 \\
\hline Hymenophyllaceae & 1 & 0,1 & Plantaginaceae & 5 & 0,5 & Caryocaraceae & 1 & 0,1 \\
\hline Schizaeaceae & 1 & 0,1 & Acanthaceae & 4 & 0,4 & Clethraceae & 1 & 0,1 \\
\hline Thelypteridaceae & 1 & 0,1 & Anacardiaceae & 4 & 0,4 & Dilleniaceae & 1 & 0,1 \\
\hline PINOPHYTA & & & Caryophyllaceae & 4 & 0,4 & Ebenaceae & 1 & 0,1 \\
\hline Podocarpaceae & 1 & 0,1 & Cunoniaceae & 4 & 0,4 & Escalloniaceae & 1 & 0,1 \\
\hline MAGNOLIOPHYTA & & & Gesneriaceae & 4 & 0,4 & Haloragaceae & 1 & 0,1 \\
\hline Asteraceae & 177 & 17,7 & Oxalidaceae & 4 & 0,4 & Linaceae & 1 & 0,1 \\
\hline Poaceae & 97 & 9,7 & Sapindaceae & 4 & 0,4 & Loganiaceae & 1 & 0,1 \\
\hline Fabaceae & 69 & 6,9 & Symplocaceae & 4 & 0,4 & Loranthaceae & 1 & 0,1 \\
\hline Myrtaceae & 43 & 4,3 & Vochysiaceae & 4 & 0,4 & Magnoliaceae & 1 & 0,1 \\
\hline Cyperaceae & 39 & 3,9 & Boraginaceae & 3 & 0,3 & Marcgraviaceae & 1 & 0,1 \\
\hline Melastomataceae & 39 & 3,9 & Burmanniaceae & 3 & 0,3 & Mayacaceae & 1 & 0,1 \\
\hline Rubiaceae & 32 & 3,2 & Celastraceae & 3 & 0,3 & Menispermaceae & 1 & 0,1 \\
\hline Apocynaceae & 29 & 2,9 & Clusiaceae & 3 & 0,3 & Menyanthaceae & 1 & 0,1 \\
\hline Eriocaulaceae & 21 & 2,1 & Droseraceae & 3 & 0,3 & Moraceae & 1 & 0,1 \\
\hline Lamiaceae & 21 & 2,1 & Hypericaceae & 3 & 0,3 & Phyllanthaceae & 1 & 0,1 \\
\hline Orchidaceae & 20 & 2,0 & Onagraceae & 3 & 0,3 & Phytolaccaceae & 1 & 0,1 \\
\hline Euphorbiaceae & 18 & 1,8 & Passifloraceae & 3 & 0,3 & Piperaceae & 1 & 0,1 \\
\hline Polygalaceae & 17 & 1,7 & Scrophulariaceae & 3 & 0,3 & Polygonaceae & 1 & 0,1 \\
\hline Solanaceae & 17 & 1,7 & Amaryllidaceae & 2 & 0,2 & Pontederiaceae & 1 & 0,1 \\
\hline Verbenaceae & 16 & 1,6 & Araceae & 2 & 0,2 & Ranunculaceae & 1 & 0,1 \\
\hline Xyridaceae & 16 & 1,6 & Araliaceae & 2 & 0,2 & Rhamnaceae & 1 & 0,1 \\
\hline Apiaceae & 15 & 1,5 & Arecaceae & 2 & 0,2 & Salicaceae & 1 & 0,1 \\
\hline Malpighiaceae & 13 & 1,3 & Commelinaceae & 2 & 0,2 & Santalaceae & 1 & 0,1 \\
\hline Convolvulaceae & 12 & 1,2 & Cucurbitaceae & 2 & 0,2 & Theaceae & 1 & 0,1 \\
\hline Malvaceae & 12 & 1,2 & Juncaceae & 2 & 0,2 & Thymelaeaceae & 1 & 0,1 \\
\hline Bignoniaceae & 11 & 1,1 & Magnoliopsida & 2 & 0,2 & Urticaceae & 1 & 0,1 \\
\hline Bromeliaceae & 11 & 1,1 & Proteaceae & 2 & 0,2 & Violaceae & 1 & 0,1 \\
\hline Iridaceae & 11 & 1,1 & Rosaceae & 2 & 0,2 & Winteraceae & 1 & 0,1 \\
\hline Lentibulariaceae & 10 & 1,0 & Sapotaceae & 2 & 0,2 & Total & 1.000 & 100 \\
\hline
\end{tabular}


Tabela 3. Número de espécies indicadoras $(P<0,05)$ dos grupos florísticos de áreas de campo da região centro sul e leste do Brasil.

\begin{tabular}{llrr}
\hline & & espécies indicadoras & \\
\hline código & Grupo floristico & total & selecionadas \\
\hline 1 & campos da chapada diamantina & 223 & 40 \\
\hline 2 & campos umidos & 5 & 5 \\
\hline 3 & campos alto-montanos & 48 & 9 \\
\hline 4 & campos de planalto & 17 & 14 \\
\hline 5 & campos-cerrado do Brasil central & 254 & 21 \\
\hline 6 & campos-cerrado do Brasil centro-sul & 0 & 0 \\
\hline 7 & campos sulinos & 2 & 2 \\
\hline total & & 549 & 91 \\
\hline
\end{tabular}


Tabela 4. Espécies indicadoras dos grupos florísticos de áreas de campo da região centro sul e leste do Brasil (valores de $P<0,05$ e vide Tabela 3 para legenda dos grupos).

\begin{tabular}{|c|c|c|c|c|c|}
\hline Espécie indicadora & grupo & $\boldsymbol{P}$ & Espécie indicadora & grupo & $\boldsymbol{P}$ \\
\hline $\begin{array}{l}\text { Bahianthus viscosus (Spreng.) R.M.King \& } \\
\text { H.Rob. }\end{array}$ & 1 & 0,001 & Brosimum gaudichaudii Trécul & 3 & 0,005 \\
\hline Begonia grisea DC. & 1 & 0,001 & Weinmannia discolor Gard. & 3 & 0,005 \\
\hline Cambessedesia tenuis Markgr. & 1 & 0,001 & $\begin{array}{l}\text { Austroeupatorium laetevirens (Hook. \& Arn.) } \\
\text { R.M.King \& H.Rob. }\end{array}$ & 3 & 0,006 \\
\hline Croton betulaster Müll.Arg. & 1 & 0,001 & Coccocypselum condalia Pers & 3 & 0,006 \\
\hline Cuphea ericoides Cham. \& Schlecht. & 1 & 0,001 & Eryngium paniculatum Cav. \& Dombey ex F.Delaroche & 3 & 0,006 \\
\hline Cynanchum myrtifolium Decne. & 1 & 0,001 & Xyris augusto-coburgii Szyszyl. & 3 & 0,006 \\
\hline Cyrtopodium edmundoi Pabst & 1 & 0,001 & Baccharis calvescens DC. & 3 & 0,008 \\
\hline Declieuxia aspalathoides Müll.Arg. & 1 & 0,001 & Prescottia micrantha Lindl. & 4 & 0,020 \\
\hline Diospyros hispida DC. & 1 & 0,001 & Gochnatia velutina Cabrera & 4 & 0,034 \\
\hline Epidendrum secundum Jacq. & 1 & 0,001 & Arrabidaea pulchella Bureau & 4 & 0,035 \\
\hline Epistephium lucidum Cogn. & 1 & 0,001 & Aspicarpa pulchella (Griseb.) O`Donell \& Lourteig & 4 & 0,035 \\
\hline Eryngium paraguariense Urb. & 1 & 0,001 & Bauhinia holophylla (Bong.) Steud. & 4 & 0,035 \\
\hline Evolvulus jacobinus Moric. & 1 & 0,001 & Callisthene major Mart. & 4 & 0,035 \\
\hline Gochnatia discoidea (Less.) Cabrera & 1 & 0,001 & Cuphea acinifolia A.St.-Hil. & 4 & 0,035 \\
\hline Gomphrena mollis Mart. & 1 & 0,001 & Declieuxia mucronulata Mart. & 4 & 0,035 \\
\hline Ilex amara (Vell.) Loes. & 1 & 0,001 & Ichthyothere rufa Gard. & 4 & 0,035 \\
\hline Lantana caatingensis Moldenke & 1 & 0,001 & Lippia obscura Briq. & 4 & 0,035 \\
\hline Leiothrix angustifolia (Koern.) Ruhl. & 1 & 0,001 & Panicum pseudisachne $\mathrm{Mez}$ & 4 & 0,035 \\
\hline Lippia alnifolia Schauer & 1 & 0,001 & Peixotoa parviflora A.Juss. & 4 & 0,035 \\
\hline Lippia rigida Schauer & 1 & 0,001 & Tabebuia aurea (Silva Manso) S.Moore. & 4 & 0,035 \\
\hline Lychnophora triflora (Mattf.) H.Rob. & 1 & 0,001 & Vernonanthura oligactoides (Less.) H.Rob. & 4 & 0,035 \\
\hline Mandevilla tenuifolia (Mikan) Woodson & 1 & 0,001 & Aeschynomene paucifolia Vogel & 5 & 0,001 \\
\hline Oncidium warmingii Rchb.f. & 1 & 0,001 & Byrsonima basiloba A.Juss. & 5 & 0,001 \\
\hline Panicum cumbucana Renvoize & 1 & 0,001 & Cambessedesia espora DC. & 5 & 0,001 \\
\hline Panicum trinii Kunth & 1 & 0,001 & Cuphea spermacoce A.St.-Hil. & 5 & 0,001 \\
\hline Paralychnophora bicolor (DC.) MacLeish & 1 & 0,001 & Dalechampia caperonioides Baill. & 5 & 0,001 \\
\hline Paspalum rupium Renvoize & 1 & 0,001 & Davilla elliptica A.St-Hil. & 5 & 0,001 \\
\hline Phyllanthus klotzschianus Müll.Arg. & 1 & 0,001 & Eremanthus goyazensis (Gard.) Sch.Bip. & 5 & 0,001 \\
\hline Polypogon elongatus Kunth & 1 & 0,001 & Eriosema defoliatum Benth. & 5 & 0,001 \\
\hline Sauvagesia semicylindrifolia Sastre & 1 & 0,001 & Galactia grewiifolia (Benth.) Taub. & 5 & 0,001 \\
\hline Schultesia pachyphylla Griseb. & 1 & 0,001 & Hybanthus lanatus (A.St.-Hil.) Baill. & 5 & 0,001 \\
\hline Siphocampylus imbricatus (Cham.) G.Don & 1 & 0,001 & Hypenia brachystachys (Pohl ex Benth.) Harley & 5 & 0,001 \\
\hline Skeptrostachys congestiflora (Cogn.) Garay & 1 & 0,001 & Ichthyothere latifolia Baker & 5 & 0,001 \\
\hline Spigelia pulchella Mart. & 1 & 0,001 & Lippia rotundifolia Cham. \& Schltdl. & 5 & 0,001 \\
\hline Stillingia saxatilis Müll.Arg. & 1 & 0,001 & Mimosa lanuginosa (Glaz.) Burkart & 5 & 0,001 \\
\hline Tibouchina oreophila Wurdack & 1 & 0,001 & Ouratea floribunda Engl. & 5 & 0,001 \\
\hline Tibouchina pereirae Brade \& Markgr. & 1 & 0,001 & Paspalum gardnerianum Nees & 5 & 0,001 \\
\hline Trachypogon macroglossus Trin. & 1 & 0,001 & Passiflora clathrata Mast. & 5 & 0,001 \\
\hline Vellozia sincorana L.B.Sm. \& Ayensu & 1 & 0,001 & Protium ovatum Engl. & 5 & 0,001 \\
\hline Waltheria cinerescens A.St.-Hil. & 1 & 0,001 & Sabicea brasiliensis Wernham & 5 & 0,001 \\
\hline Buchnera integrifolia Larrañaga & 2 & 0,016 & Staelia capitata K.Schum. & 5 & 0,001 \\
\hline Ocotea corymbosa (Meiss.) Mez & 2 & 0,016 & Streptostachys macrantha (Trin.) Zuloaga \& Soderstr. & 5 & 0,001 \\
\hline Eragrostis maypurensis (Kunth) Steud. & 2 & 0,028 & Rhynchospora corymbosa (L.) Britt. & 7 & 0,030 \\
\hline $\begin{array}{l}\text { Chromolaena squarrulosa (Hook. \& Arn.) R.M. } \\
\text { King \& H. Rob. }\end{array}$ & 2 & 0,036 & Axonopus suffultus (Mikan ex Trin.) Parodi & 7 & 0,045 \\
\hline Lippia turnerifolia Cham. & 2 & 0,050 & & & \\
\hline Utricularia subulata $\mathrm{L}$. & 3 & 0,001 & & & \\
\hline Bulbostylis sphaerocephala (Boeck.) C.B. Clarke & 3 & 0,004 & & & \\
\hline
\end{tabular}


Tabela 5. Análise de correspondência canônica (CCA) de 47 listas floristicas de áreas de campo da região centro sul e leste do Brasil. Os valores são correlações internas ("intraset") nos dois primeiros eixos de ordenação e de correlações ponderadas entre as variáveis climáticas utilizadas na análise.

\begin{tabular}{|c|c|c|c|c|c|c|c|c|c|}
\hline \multirow{2}{*}{$\begin{array}{l}\text { Variáveis } \\
\text { climáticas }\end{array}$} & \multicolumn{9}{|c|}{ Correlações ponderadas } \\
\hline & Eixo 1 & Eixo 2 & ISOT & SAZ_T & TMMQ & TMMF & PMU & PMS & SAZ_P \\
\hline ISOT & $-0,962$ & 0,114 & 1 & - & - & - & - & - & - \\
\hline SAZ_T & 0,925 & $-0,143$ & $-0,959$ & 1 & - & - & - & - & - \\
\hline TMMQ & $-0,006$ & $-0,230$ & 0,079 & 0,009 & 1 & - & - & - & - \\
\hline TMMF & $-0,595$ & $-0,049$ & 0,664 & $-0,723$ & 0,579 & 1 & - & - & - \\
\hline $\mathrm{PMU}$ & $-0,501$ & $\mathbf{0 , 8 0 9}$ & 0,606 & $-0,619$ & $-0,201$ & 0,284 & 1 & - & - \\
\hline PMS & $\mathbf{0 , 8 7 3}$ & $-0,224$ & $-0,914$ & 0,849 & $-0,161$ & $-0,615$ & $-0,625$ & 1 & - \\
\hline SAZ_P & $-0,871$ & 0,359 & 0,907 & $-0,872$ & 0,03 & 0,572 & 0,766 & $-0,956$ & 1 \\
\hline
\end{tabular}

Valores absolutos $>0.75$ estão em negrito.

Variáveis climáticas:

ISOT - isotermalidade;

SAZ_T - sazonalidade térmica;

TMMQ - temperatura máxima do mês mais quente;

TMMF - temperatura mínima do mês mais frio;

PMU - precipitação do mês mais úmido;

PMS - precipitação do mês mais seco;

SAZ_P - sazonalidade pluviométrica 
Anexo 1. Relação das espécies vasculares dos campos de planalto da porção sul de Itararé, SP. Coletores: CAMS: C.A.de M. Scaramuzza, CMS: C M. Sakuragui, VCS: V. C. Souza. Plantas depositadas no herbário ESA, exceto quando indicado. Estrutura para as 112 espécies com freqüência maior que 5 nos levantamentos fitoecológicos (capítulo 3): A1: Arbusto < 1,2 m; E1: Erva < 0,1 m; E2: Erva 0,1-0,4 m; E3: Erva 0,4-0,8 m; E4: Erva 0,8-1,2 m; E5: Erva > 1,2 m; G2: Graminóide 0,1-0,4 m; G3: Graminóide 0,4-0,8 m; G5: Graminóide > 1,2 m; P2: Pteridófita 0,1-0,4 m; T: Trepadeira. Habitáts: c: campo; b: banhado; m: mata-ciliar; r: cerrado. Distribuição geográfica: Af: Afro-americana; Am: América; AmS: América do Sul; Arg: Argentina; BA: Bahia; Bol: Bolívia; Br: Brasil; Cosmo: cosmopolita; DF: Distrito Federal; GO: Goiás; i: espécie inédita em São Paulo; LN: limite norte em São Paulo; LS: limite sul em São Paulo; MG: Minas Gerais; Neo: Neotropical; Pan: Pantropical; Par: Paraguai; PR: Paraná; S: sul do Brasil; SE: sudeste do Brasil; SP: São Paulo; Sub: subespontânea; Uru: Uruguai. * Espécies vulneráveis e ** em perigo pela lista da flora paulista ameaçada de extinção (São Paulo 2004). \# Espécies vulneráveis, \# \# em perigo e \# \# \# criticamente em perigo pela lista da flora brasileira ameaçada de extinção (Fundação Biodiversitas 2005).

\begin{tabular}{|c|c|c|c|c|}
\hline DIVISÃO/Família/Espécie & Coletor & Estrutura & Hábitat & $\begin{array}{l}\text { Distribuiçã } \\
\text { o geográfica }\end{array}$ \\
\hline \multicolumn{5}{|l|}{ LYCOPHYTA } \\
\hline \multicolumn{5}{|l|}{ LYCOPODIACEAE } \\
\hline Huperzia reflexa (Lam.) Trevis. & CAMS 931e & & $\mathrm{c}$ & Neo \\
\hline Lycopodiella alopecuroides (L.) Cranfill & VCS 2452 & & $\mathrm{~b}, \mathrm{c}$ & $\mathrm{Am}$ \\
\hline Lycopodiella cernua (L.) Pic. Serm. & VCS 3643 & & $\mathrm{c}$ & Pan \\
\hline Lycopodium clavatum $\mathrm{L}$. & CAMS 1155 & P2 & $\mathrm{b}$ & $\mathrm{Am}$ \\
\hline \multicolumn{5}{|l|}{ SELAGINELLACEAE } \\
\hline Selaginella muscosa Spreng. & VCS 3957 & & $\mathrm{c}$ & AmS \\
\hline Selaginella sp. 1 & VCS 6170 & & $\mathrm{c}$ & - \\
\hline \multicolumn{5}{|l|}{ PTEROPHYTA } \\
\hline \multicolumn{5}{|l|}{ BLECHNACEAE } \\
\hline Blechnum brasiliense Desv. & CAMS 767 & & $\mathrm{c}$ & Neo \\
\hline Blechnum regnellianum (Kuntze) C. Chr. & CAMS 750 & & $\mathrm{c}$ & $\mathrm{S}, \mathrm{SE}$ \\
\hline Blechnum schomburgkii (Klotzsch) C. Chr. & CAMS 782 & $\mathrm{P} 2$ & $\mathrm{~b}$ & $\mathrm{AmS}$ \\
\hline \multicolumn{5}{|l|}{ CYATHEACEAE } \\
\hline Trichipteris corcovadensis (Raddi) Copel. & CAMS 929e & & $\mathrm{c}$ & S, SE \\
\hline Trichipteris villosa (Willd.) Tryon & VCS 3668 & $\mathrm{P} 2$ & $\mathrm{c}$ & Neo \\
\hline \multicolumn{5}{|l|}{ DENNSTAEDTIACEAE } \\
\hline Pteridium aquilinum (L.) Kuhn ex Decker & VCS 3626 & & $\mathrm{c}$ & Neo \\
\hline \multicolumn{5}{|l|}{ DICKSONIACEAE } \\
\hline Dicksonia sellowiana (Presley) Hook. * \#\# & CAMS 701 & & $\mathrm{c}$ & AmS \\
\hline \multicolumn{5}{|l|}{ DRYOPTERIDACEAE } \\
\hline Rumorha adiantiformis Ching & VCS 3500 & & $\mathrm{c}$ & Pan \\
\hline \multicolumn{5}{|l|}{ GLEICHENIACEAE } \\
\hline Dicranopteris flexuosa (L.) Underw. & VCS 2442 & & $\mathrm{c}$ & Neo \\
\hline Gleichenia pennigera (Mart.) Moore & CAMS 702 & & $\mathrm{c}$ & Neo \\
\hline \multicolumn{5}{|l|}{ HYMENOPHYLLACEAE } \\
\hline Trichomanes pilosum Raddi & CMS 383 & & $\mathrm{c}$ & $\mathrm{Br}$ \\
\hline \multicolumn{5}{|l|}{ POLYPODIACEAE } \\
\hline Polypodium hirsutissimum Raddi & CMS 343 & & $\mathrm{c}$ & $\mathrm{Br}$ \\
\hline Polypodium latipes Langsd. \& Fisch. & CAMS 704 & $\mathrm{P} 2$ & $\mathrm{c}$ & Neo \\
\hline \multicolumn{5}{|l|}{ PTERIDACEAE } \\
\hline Adiantopsis chlorophylla (Sw.) Fée & CAMS 885 & $\mathrm{P} 2$ & $\mathrm{c}$ & Neo \\
\hline Doryopteris crenulans (Fée) C. Chr. & VCS 3713 & & $\mathrm{c}$ & $\mathrm{AmS}$ \\
\hline Doryopteris lomariacea Klotzsch & VCS 3894 & $\mathrm{P} 2$ & $\mathrm{c}$ & $\mathrm{AmS}$ \\
\hline Eriosorus myriophyllus (L.) Copel. & CAMS 276 & $\mathrm{P} 2$ & $\mathrm{r}$ & Neo \\
\hline \multicolumn{5}{|l|}{ SCHIZAEACEAE } \\
\hline Anemia raddiana Link & VCS 3801 & & $\mathrm{c}$ & AmS \\
\hline \multicolumn{5}{|l|}{ THELYPTERIDACEAE } \\
\hline Thelypteris rivularioides (Fée) Abbiatti & VCS 3573 & $\mathrm{P} 2$ & $\mathrm{c}$ & S, SE, Par \\
\hline \multicolumn{5}{|l|}{ PINOPHYTA } \\
\hline \multicolumn{5}{|l|}{ PODOCARPACEAE } \\
\hline Podocarpus sellowii Klotzsch ex Endl. & VCS 4377 & & $\mathrm{c}$ & $\mathrm{Br}$ \\
\hline MAGNOLIOPHYTA & & & & \\
\hline
\end{tabular}




\begin{tabular}{|c|c|c|c|c|}
\hline DIVISÃO/Família/Espécie & Coletor & Estrutura & Hábitat & $\begin{array}{l}\text { Distribuiçã } \\
\text { o geográfica }\end{array}$ \\
\hline \multicolumn{5}{|l|}{ ACANTHACEAE } \\
\hline Dyschoriste hygrophiloides (Nees) Kuntze & VCS 4298 & & $\mathrm{c}$ & S, SE, Arg \\
\hline Ruellia geminiflora Humb., Bonpl. \& Kunth & VCS 4176 & & $\mathrm{c}$ & Neo \\
\hline Ruellia morongii Britton & CAMS $586 \&$ VCS & & $\mathrm{c}$ & $\begin{array}{l}\text { S, SE, Arg, } \\
\text { Par, Uru, } \\
\text { LN, i }\end{array}$ \\
\hline Ruellia multifolia (Nees) Lindau & VCS 7308 & & $\mathrm{c}$ & $\mathrm{Br}, \mathrm{Arg}, \mathrm{Par}$ \\
\hline \multicolumn{5}{|l|}{ ALLIACEAE } \\
\hline Nothoscordum aff. bonariense (Pers.) Beauv. ** & VCS 4386 & & $\mathrm{c}$ & S, SE, Arg \\
\hline \multicolumn{5}{|l|}{ ALSTROEMERIACEAE } \\
\hline Alstroemeria apertiflora Baker & VCS 7364 & & $\mathrm{~b}$ & $\mathrm{Br}, \mathrm{Arg}$ \\
\hline \multicolumn{5}{|l|}{ AMARANTHACEAE } \\
\hline Amaranthus hybridus L. & M Kuhlmann 61 & & $\mathrm{r}$ & Cosmo \\
\hline Amaranthus spinosus L. & M Kuhlmann 1407 & & $\mathrm{r}$ & Pan \\
\hline Gomphrena macrocephala A. St.-Hil. & CAMS 1079 & & $\mathrm{c}$ & $\mathrm{Br}$, Par \\
\hline Gomphrena virgata Mart. & VCS 8751 & & $\mathrm{~b}$ & $\mathrm{Br}$ \\
\hline Pfaffia gnaphalioides (L. f.) Mart.* & CAMS $590 \&$ VCS & & $\mathrm{c}, \mathrm{r}$ & $\mathrm{AmS}$ \\
\hline Pfaffia jubata Moq. * & $\begin{array}{l}\text { CAMS } 380 \& \text { M } \\
\text { Godron }\end{array}$ & & $\mathrm{c}$ & $\mathrm{Br}$ \\
\hline Pfaffia tuberosa (Spreng.) Hicken & VCS 2401 & & $\mathrm{c}$ & $\mathrm{AmS}$ \\
\hline \multicolumn{5}{|l|}{ AMARYLLIDACEAE } \\
\hline Hippeastrum glaucescens (Mart.) Herb. & CAMS $475 \&$ VCS & & $\mathrm{c}$ & $\mathrm{Br}, \mathrm{Arg}$ \\
\hline Zephyranthes candida (Lindl.) Herb. ${ }^{*}{ }^{\#}$ & VCS 2249 & & $\mathrm{c}$ & S, SE, LN \\
\hline \multicolumn{5}{|l|}{ ANACARDIACEAE } \\
\hline Anacardium humile A. St.-Hil. & CAMS $531 \&$ VCS & & $\mathrm{c}$ & $\mathrm{AmS}$ \\
\hline Astronium graveolens Jacq. & CAMS 378 & & $\mathrm{r}$ & Neo \\
\hline Lithraea molleoides (Vell.) Engl. & CMS 488 & & $\mathrm{r}$ & $\mathrm{Neo}$ \\
\hline Schinus terebinthifolius Raddi & CAMS 598 \& VCS & & $\mathrm{c}$ & $\mathrm{AmS}$ \\
\hline \multicolumn{5}{|l|}{ ANNONACEAE } \\
\hline Annona cornifolia A. St.-Hil. * & VCS 4632 & & $\mathrm{~b}$ & $\mathrm{AmS}$ \\
\hline Annona crassiflora Mart. & VCS 3652 & & $\mathrm{c}$ & $\mathrm{Br}, \mathrm{Par}$ \\
\hline Annona dioica A. St.-Hil. & VCS 4631 & & $\mathrm{~b}$ & $\mathrm{AmS}$ \\
\hline Duguetia furfuracea (A. St.-Hil) Benth. \& Hook. f. & VCS 3294 & & $\mathrm{c}$ & $\mathrm{Br}, \mathrm{Par}$ \\
\hline Duguetia lanceolata A. St.-Hil. & $\begin{array}{l}\text { CAMS } 321 \& \text { M } \\
\text { Godron }\end{array}$ & & $\mathrm{r}$ & $\mathrm{S}, \mathrm{SE}$ \\
\hline Guatteria australis A. St.-Hil. & $\begin{array}{l}\text { CAMS } 379 \& \text { M } \\
\text { Godron }\end{array}$ & & $\mathrm{r}$ & S, SE \\
\hline \multicolumn{5}{|l|}{ APIACEAE } \\
\hline Apium leptophyllum (Pers.) F. Müll. & VCS 3867 & & $\mathrm{c}$ & Neo \\
\hline Centella asiatica $(\mathrm{L}$.$) Urb.$ & CAMS $540 \&$ VCS & & $\mathrm{c}$ & Sub \\
\hline Eryngium canaliculatum Cham. \& Schltdl. & CAMS 73 \& VCS & E2 & $\mathrm{c}$ & $\mathrm{S}, \mathrm{SE}$ \\
\hline Eryngium cf. ekmanii $\mathrm{H}$. Wolff & CAMS 886 & & $\mathrm{c}$ & - \\
\hline Eryngium ebracteatum Lam. & VCS 4578 & & $\mathrm{~b}$ & $\mathrm{Neo}$ \\
\hline Eryngium elegans Cham. \& Schltdl. & VCS 4417 & & $\mathrm{~b}$ & $\mathrm{AmS}$ \\
\hline Eryngium eriophorum Cham. \& Schltdl. ** & VCS 3995 & & $\mathrm{c}$ & $\mathrm{AmS}$ \\
\hline Eryngium floribundum Cham. \& Schltdl. & VCS 7306 & & $\mathrm{c}$ & $\mathrm{AmS}$ \\
\hline Eryngium horridum Malme & VCS 4351 & & $\mathrm{r}$ & $\begin{array}{l}\text { S, SE, Arg, } \\
\text { Uru }\end{array}$ \\
\hline Eryngium junceum Cham. \& Schltdl. & CAMS 1088 & E2 & $\mathrm{c}$ & AmS \\
\hline Eryngium juncifolium (Urb.) Mathias \& Constance & VCS 7164 & & $\mathrm{r}$ & $\mathrm{AmS}$ \\
\hline Eryngium marginatum Pohl ex Urb. * & P Gibbs 1735 & & $\mathrm{c}$ & $\mathrm{Br}$ \\
\hline Eryngium pandanifolium Cham. \& Schltdl. & VCS 3632 & & $\mathrm{c}$ & $\begin{array}{l}\text { S, SE, Arg, } \\
\text { Uru }\end{array}$ \\
\hline Eryngium pohlianum Urb. & VCS 3547 & & $\mathrm{c}$ & S, SE \\
\hline Eryngium subinerme (H.Wolff) Mathias \& Constance * & VCS 4585 & & $\mathrm{~b}, \mathrm{c}$ & $\mathrm{S}, \mathrm{SE}$ \\
\hline \multicolumn{5}{|l|}{ APOCYNACEAE } \\
\hline Asclepias aequicornu E. Fourn. & VCS 7166 & & $\mathrm{c}$ & $\mathrm{Br}$ \\
\hline Aspidosperma subincanum Mart. & CMS 487 & & $\mathrm{r}$ & $\mathrm{Br}$ \\
\hline Aspidosperma tomentosum Mart. * & CAMS $567 \&$ VCS & & $\mathrm{c}$ & Br, Par \\
\hline Barjonia erecta (Vell.) K. Schum. & VCS 3642 & & $\mathrm{c}$ & $\mathrm{Br}$ \\
\hline Blepharodon lineare (Decne.) Decne. & VCS 4572 & & $\mathrm{~b}$ & $\mathrm{Br}, \mathrm{Arg}, \mathrm{Par}$ \\
\hline Blepharodon nitidum (Vell.) J.F. Macbr. & $\begin{array}{l}\text { MA Farinaccio } 560 \\
\text { (SPF) }\end{array}$ & & $\mathrm{b}$ & $\mathrm{AmS}$ \\
\hline Condylocarpon isthmicum (Vell.) A. DC. & VCS 7132 & & $\mathrm{~m}$ & $\mathrm{Br}$ \\
\hline Ditassa acerosa Mart. * & VCS 6173 & & $\mathrm{c}$ & $\mathrm{Br}, \mathrm{Arg}$ \\
\hline
\end{tabular}




\begin{tabular}{|c|c|c|c|c|}
\hline DIVISÃO/Família/Espécie & Coletor & Estrutura & Hábitat & $\begin{array}{l}\text { Distribuiçã } \\
\text { o geográfica }\end{array}$ \\
\hline Forsteronia velloziana (A. DC.) Woodson * & J Mattos 14961 & & $\mathrm{c}$ & $\mathrm{S}, \mathrm{SE}$ \\
\hline Hemipogon setaceus Decne. * & PH Miyagi 369 & & $\mathrm{c}$ & $\mathrm{Br}, \mathrm{Par}$ \\
\hline Jobinia lindbergii E. Fourn. & VCS 7133 & & $\mathrm{c}$ & $\mathrm{Br}, \mathrm{Arg}$ \\
\hline Macrosiphonia longiflora (Desf.) Müll. Arg. & CMS 444 & & $\mathrm{c}$ & $\mathrm{AmS}$ \\
\hline Macrosiphonia virescens (A. St.-Hil.) Müll. Arg. * & $\begin{array}{l}\text { CAMS } 377 \& \text { M } \\
\text { Godron }\end{array}$ & & $\mathrm{c}$ & Br, Arg, Par \\
\hline Mandevilla atroviolacea (Stadelm.) Woodson & KD Barreto 3258 & & $\mathrm{~m}$ & S, SE \\
\hline Mandevilla coccinea (Hook. \& Arn.) Woodson * & VCS 4667 & & $\mathrm{c}$ & AmS \\
\hline Mandevilla pohliana (Mart. ex Stadelm.) A.H. Gentry * & VCS 4574 & & $\mathrm{r}$ & $\mathrm{AmS}$ \\
\hline Mandevilla tenuifolia (J.C. Mikan) Woodson * & CAMS 663 \& VCS & & $\mathrm{c}$ & $\mathrm{AmS}$ \\
\hline Oxypetalum aequaliflorum E. Fourn. * & VCS 4403 & & $\mathrm{~b}$ & S, SE \\
\hline Oxypetalum appendiculatum Mart. & CAMS $460 \&$ VCS & & $\mathrm{c}$ & $\mathrm{Br}, \mathrm{Arg}, \mathrm{Par}$ \\
\hline Oxypetalum capitatum Mart. & VCS 4639 & & $\mathrm{~b}$ & $\mathrm{Br}, \mathrm{Arg}, \mathrm{Par}$ \\
\hline Oxypetalum cf. pachygynum Decne. ex A. DC. & CAMS 884 & & $\mathrm{c}$ & - \\
\hline Oxypetalum cf. pannosum Decne. & CAMS 788 & & $\mathrm{c}$ & - \\
\hline Oxypetalum erectum Mart. & CAMS 883 & & $\mathrm{c}$ & $\mathrm{S}, \mathrm{SE}$ \\
\hline Oxypetalum insigne (Decne.) Malme & VCS 3862 & & $\mathrm{c}$ & S, SE \\
\hline Oxypetalum molle Hook. \& Arn. & M Kuhlmann 1401 & & $\mathrm{c}$ & $\mathrm{Br}$ \\
\hline Oxypetalum sublanatum Malme & CAMS 748 & & $\mathrm{c}$ & $\mathrm{S}, \mathrm{SE}, \mathrm{Arg}$ \\
\hline Oxypetalum wightianum Hook. \& Arn. & VCS 10635 & & $\mathrm{c}$ & S, SE, Par \\
\hline Prestonia riedelii (Müll. Arg.) Markgr. & CAMS $626 \&$ VCS & & $\mathrm{r}$ & $\mathrm{AmS}$ \\
\hline Tassadia subulata (Vell.) Fontella \& E.A. Schwarz & VCS 3686 & & $\mathrm{c}$ & $\mathrm{AmS}$ \\
\hline \multicolumn{5}{|l|}{ AQUIFOLIACEAE } \\
\hline Ilex brasiliensis (Spreng.) Loes. & VCS 7409 & & $\mathrm{c}, \mathrm{m}, \mathrm{r}$ & Br, Par \\
\hline Ilex theezans Mart. & CMS 426 & & $\mathrm{c}$ & $\mathrm{Br}, \mathrm{Arg}, \mathrm{Par}$ \\
\hline Ilex chamaedryfolia Reissek & VCS 3754 & & $\mathrm{c}$ & $\mathrm{S}, \mathrm{SE}$ \\
\hline Ilex dumosa Reissek ex Mart. & VCS 4357 & & $\mathrm{c}$ & $\mathrm{S}, \mathrm{SE}$ \\
\hline Ilex paraguariensis A. St.-Hil. & F Chung 79 & & $\mathrm{r}$ & $\begin{array}{l}\text { Br, Arg, Par, } \\
\text { Uru }\end{array}$ \\
\hline \multicolumn{5}{|l|}{ ARACEAE } \\
\hline Anthurium langsdorffii Schott & CAMS 659 \& VCS & & $\mathrm{c}$ & $\mathrm{Br}$ \\
\hline Anthurium sp. 1 & CAMS $484 \&$ VCS & & $\mathrm{c}$ & - \\
\hline \multicolumn{5}{|l|}{ ARALIACEAE } \\
\hline Hydrocotyle quinqueloba Ruiz \& Pav. & CMS 340 & & $\mathrm{c}$ & AmS \\
\hline Schefflera vinosa (Cham. \& Schltdl.) Frodin & CAMS $41 \&$ VCS & & $\mathrm{r}$ & $\mathrm{Br}$ \\
\hline \multicolumn{5}{|l|}{ ARECACEAE } \\
\hline Attalea geraensis Barb. Rodr. & CAMS $243 \&$ VCS & & $\mathrm{c}$ & $\mathrm{Br}, \mathrm{Par}$ \\
\hline 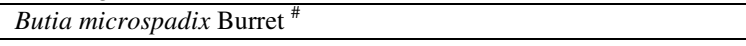 & VCS 3281 & & $\mathrm{c}$ & S, SE, LN \\
\hline \multicolumn{5}{|l|}{ ARISTOLOCHIACEAE } \\
\hline Aristolochia melastoma J. Silva-Manso & CMS 393 & & $\mathrm{~b}$ & S, SE \\
\hline \multicolumn{5}{|l|}{ ASTERACEAE } \\
\hline Acanthospermum australe (Loefl.) Kuntze & VCS 2398 & & $\mathrm{c}$ & $\mathrm{Am}$ \\
\hline Achyrocline alata (Humb., Bonpl. \& Kunth) DC. & CAMS 1104 & E3 & $\mathrm{c}$ & $\mathrm{AmS}$ \\
\hline Achyrocline satureioides (Lam.) DC. & $\begin{array}{l}\text { CAMS } 375 \& \mathrm{M} \\
\text { Godron }\end{array}$ & E2 & $\mathrm{c}$ & $\mathrm{AmS}$ \\
\hline Acmella bellidioides (Sm. ex Rees) R.K. Jansen & VCS 3787 & & $\mathrm{c}$ & S, SE, Arg \\
\hline Ageratum conyzoides $\mathrm{L}$. & CAMS 217 \& VCS & & $\mathrm{b}, \mathrm{m}$ & $\mathrm{Br}$ \\
\hline Ageratum fastigiatum (Gardn.) R.M. King \& H. Rob. & VCS 8947 & & $\mathrm{c}$ & $\mathrm{Br}$ \\
\hline Aspilia foliacea (Spreng.) Baker & CAMS $536 \&$ VCS & E2 & $\mathrm{c}$ & $\mathrm{Br}$, Par \\
\hline Aspilia montevidensis (Spreng.) Kuntze & CAMS 713 & E2 & $\mathrm{c}$ & Br, Uru \\
\hline Aspilia reflexa (Sch. Bip. ex Baker) Baker & CAMS 367 & & $\mathrm{c}$ & S, SE \\
\hline Austroeupatorium inulaefolium (H.B.K.) R.M. King \& H. Rob. & CAMS $13 \&$ VCS & & $\mathrm{r}$ & AmS \\
\hline Austroeupatorium laetevirens (Hook. \& Arn.) R.M. King \& H. Rob. & VCS 3503 & E2 & $\mathrm{b}, \mathrm{c}$ & $\mathrm{Br}$, Arg, Par \\
\hline Baccharidastrum triplinerve (Less.) Cabrera & VCS 2347 & & $\mathrm{~b}$ & S, SE \\
\hline Baccharis articulata (Lam.) Pers. & CAMS $488 \&$ VCS & & $\mathrm{c}$ & $\begin{array}{l}\text { S, SE, Uru, } \\
\text { LN }\end{array}$ \\
\hline Baccharis brachylaenoides DC. & CAMS 453 \& VCS & & $\mathrm{c}$ & $\begin{array}{l}\text { S, SE, } \\
\text { Guiana } \\
\end{array}$ \\
\hline Baccharis brevifolia DC. & CAMS $188 \&$ VCS & E3 & $\mathrm{b}, \mathrm{c}$ & $\mathrm{S}, \mathrm{SE}$ \\
\hline Baccharis calvescens DC. & CAMS 816 & & $\mathrm{c}$ & $\mathrm{Br}, \mathrm{i}$ \\
\hline Baccharis camporum DC. & $\begin{array}{l}\text { CAMS } 370 \& \mathrm{M} \\
\text { Godron }\end{array}$ & & $\mathrm{c}$ & $\mathrm{S}, \mathrm{SE}, \mathrm{LN}$ \\
\hline Baccharis caprariaefolia DC. & VCS 3739 & E3 & $\mathrm{b}, \mathrm{c}$ & $\begin{array}{l}\text { S, SE, Arg, } \\
\text { Par }\end{array}$ \\
\hline
\end{tabular}




\begin{tabular}{|c|c|c|c|c|}
\hline DIVISÃO/Família/Espécie & Coletor & Estrutura & Hábitat & $\begin{array}{l}\text { Distribuiçã } \\
\text { o geográfica }\end{array}$ \\
\hline Baccharis coridifolia DC. & CAMS 771 & & $\mathrm{c}$ & S, SE, LN \\
\hline Baccharis dracunculifolia $\mathrm{DC}$. & $\begin{array}{l}\text { CAMS } 619 \& \text { M } \\
\text { Deur }\end{array}$ & $\mathrm{A} 1$ & $\mathrm{~b}, \mathrm{c}, \mathrm{r}$ & $\mathrm{Br}$ \\
\hline Baccharis elaeagnoides Steud. & CAMS 747 & & $\mathrm{c}$ & S, SE, Par \\
\hline Baccharis erigeroides DC. & VCS 4262 & & $\mathrm{c}$ & S, SE, LN \\
\hline Baccharis erioclada DC. & CAMS $126 \&$ VCS & & $\mathrm{c}$ & S, SE \\
\hline Baccharis gaudichaudiana DC. & CAMS $187 \&$ VCS & & $\mathrm{b}$ & S, SE, LN \\
\hline Baccharis gracilis $\mathrm{DC}$ & VCS 4255 & & $\mathrm{c}$ & $\mathrm{S}, \mathrm{SE}$ \\
\hline Baccharis helichrysoides DC. & CAMS 779 & & $\mathrm{c}$ & $\mathrm{Br}, \mathrm{Arg}, \mathrm{Par}$ \\
\hline Baccharis illinita DC. & CAMS 1009 & & $\mathrm{~b}$ & $\mathrm{Br}$ \\
\hline Baccharis myricaefolia DC. & VCS 2340 & & $\mathrm{~b}, \mathrm{r}$ & S, SE, LN \\
\hline Baccharis pauciflosculosa DC. & VCS 2172 & & $\mathrm{~b}$ & S, SE, LN \\
\hline Baccharis schultzii Baker & CAMS 523 \& VCS & & $\mathrm{c}$ & $\mathrm{S}, \mathrm{SE}$ \\
\hline Baccharis semiserrata DC. & VCS 3775 & & $\mathrm{c}$ & S, SE \\
\hline Baccharis tarchonanthoides DC. & CAMS $479 \&$ VCS & & $\mathrm{c}$ & S, SE \\
\hline Baccharis tridentata Vahl var. deltoidea (Baker) Heering & VCS 4348 & & $\mathrm{r}$ & $\mathrm{S}, \mathrm{SE}, \mathrm{LN}$ \\
\hline Baccharis tridentata Vahl var. subopposita (DC.) Cabrera & VCS 4100 & & $\mathrm{c}$ & $\begin{array}{l}\text { S, SE, Arg, } \\
\text { Par, Uru }\end{array}$ \\
\hline Baccharis trimera DC. & VCS 4023 & E5 & $\mathrm{b}$ & $\mathrm{AmS}$ \\
\hline Baccharis trinervis (Lam.) Pers. & VCS 6039 & & $\mathrm{c}$ & Neo \\
\hline Baccharis vismioides DC. & CAMS 744 & & $\mathrm{c}$ & S, SE, LN \\
\hline Barrosoa betonicaeformis (DC.) R.M. King \& H. Rob. & VCS 3545 & & $\mathrm{c}$ & Br, Uru \\
\hline Barrosoa cf. candolleana (Hook. \& Arn.) R.M. King \& H. Rob. & CAMS $193 \&$ VCS & & $\mathrm{b}$ & $\begin{array}{l}\text { S, SE, Arg, } \\
\text { Par, Uru, LN }\end{array}$ \\
\hline Calea cuneifolia DC. & VCS 4666 & & $\mathrm{c}$ & $\mathrm{Br}$ \\
\hline Calea cymosa Less. & VCS 7118 & & $\mathrm{r}$ & $\begin{array}{l}\text { S, SE, Arg, } \\
\text { Par }\end{array}$ \\
\hline Calea marginata S.F. Blake & CAMS 669 \& VCS & E3 & $\mathrm{b}, \mathrm{c}$ & S, SE \\
\hline Calea parvifolia (DC.) Baker & CAMS 872 & & $\mathrm{~b}, \mathrm{c}$ & $\mathrm{S}, \mathrm{SE}$ \\
\hline Calea pinnatifida (R.Br.) Less. & CMS 489 & & $\mathrm{r}$ & $\begin{array}{l}\text { S, SE, Arg, } \\
\text { Par }\end{array}$ \\
\hline Calea verticillata (Klatt) Pruski & $\begin{array}{l}\text { CAMS } 366 \& \text { M } \\
\text { Godron }\end{array}$ & & $\mathrm{b}, \mathrm{c}, \mathrm{r}$ & $\mathrm{Br}, \mathrm{Par}$ \\
\hline Campovassouria cruciata (Vell.) R.M. King \& H. Rob. & CAMS $597 \&$ VCS & & $\mathrm{c}$ & AmS \\
\hline $\begin{array}{l}\text { Campuloclinium purpurascens (Sch. Bip. ex Baker) R.M. King \& } \\
\text { H. Rob. }\end{array}$ & VCS 2475 & & $\mathrm{c}$ & $\begin{array}{l}\text { S, SE, Arg, } \\
\text { Par }\end{array}$ \\
\hline Chaptalia graminifolia (Dusén ex Malme) Cabrera & VCS 4071 & & $\mathrm{c}$ & $\mathrm{S}, \mathrm{SE}, \mathrm{LN}$ \\
\hline Chaptalia integerrima (Vell.) Burkart & CAMS 594 \& VCS & & $\mathrm{c}, \mathrm{r}$ & $\mathrm{AmS}$ \\
\hline Chaptalia nutans (L.) Polák & CAMS 364 & & $\mathrm{c}$ & Neo \\
\hline Chionolaena arbuscula DC. & CAMS 1181e & E2 & $\mathrm{c}$ & S, SE \\
\hline Chresta sphaerocephala DC. & CAMS $428 \&$ VCS & & $\mathrm{c}, \mathrm{r}$ & $\mathrm{Br}$ \\
\hline Chromolaena aff. kleinii (Cabrera) R.M. King \& H. Rob. & VCS 2321 & & $\mathrm{~b}$ & - \\
\hline Chromolaena arrayana (Gardn.) R.M. King \& H. Rob. ** & PH Miyagi 612 & & $\mathrm{c}$ & $\mathrm{SP}, \mathrm{GO}$ \\
\hline Chromolaena congesta (Hook. \& Arn.) R.M. King \& H. Rob. & VCS 2318 & E2 & $\mathrm{b}, \mathrm{c}$ & $\begin{array}{l}\text { S, SE, Arg, } \\
\text { Par, Uru }\end{array}$ \\
\hline Chromolaena laevigata (Lam.) R.M. King \& H. Rob. & $\begin{array}{l}\text { CAMS } 620 \& \mathrm{M} \\
\text { Deur }\end{array}$ & & $\mathrm{b}$ & Neo \\
\hline Chromolaena maximilianii (Schrad. ex DC.) R.M. King \& H. Rob. & CAMS 30 \& VCS & & $\mathrm{r}$ & $\mathrm{AmS}$ \\
\hline Chromolaena squalida (DC.) R.M. King \& H. Rob. & CAMS $248 \&$ VCS & & $\mathrm{c}, \mathrm{r}$ & AmS \\
\hline Chromolaena stachyophylla (Spreng.) R.M. King \& H. Rob. & J Mattos 12877 & & $\mathrm{r}$ & $\mathrm{Br}$ \\
\hline Chromolaena subvelutina (DC.) R.L. Esteves comb. ined. & $\begin{array}{l}\text { CAMS \& M Godron } \\
355\end{array}$ & & $\mathrm{r}$ & $\mathrm{AmS}$ \\
\hline Chromolaena xylorhiza (Sch. Bip. ex Baker) R.M. King \& H. Rob. & $\begin{array}{l}\text { CAMS } 357 \& \text { M } \\
\text { Godron }\end{array}$ & & $\mathrm{c}$ & S, SE, i \\
\hline Clibadium armani (Balb.) Sch. Bip. & VCS 3543 & & $\mathrm{c}$ & AmS \\
\hline Conyza bonariensis (L.) Cronquist & CAMS $253 \&$ VCS & E2 & $\mathrm{b}, \mathrm{c}, \mathrm{r}$ & Neo \\
\hline Dasyphyllum brasiliense (Spreng.) Cabrera & CAMS 478 \& VCS & & c & $\begin{array}{l}\text { S, SE, Arg, } \\
\text { Par }\end{array}$ \\
\hline Disynaphia ericoides (DC.) R.M. King \& H. Rob. ** & CAMS 76 \& VCS & & $\mathrm{c}$ & S, SE, LN, i \\
\hline Elephantopus mollis Humb., Bonpl. \& Kunth & VCS 3764 & & $\mathrm{c}$ & Neo \\
\hline Emilia fosbergii Nicolson & CAMS $10 \&$ VCS & & $\mathrm{r}$ & $\mathrm{Neo}$ \\
\hline Erechtites hieracifolia (L.) Raf. ex DC. & CAMS 741 & & $\mathrm{c}$ & $\mathrm{Neo}$ \\
\hline Erechtites valerianaefolia (Wolff.) DC. & CAMS 795 & & $\mathrm{c}$ & $\mathrm{AmS}$ \\
\hline Erigeron maximus (Less.) Link \& Otto & VCS 2329 & & $\mathrm{~b}, \mathrm{c}$ & $\mathrm{Br}$ \\
\hline Facelis retusa $($ Lam.) Sch. Bip. & VCS 4302 & & $\mathrm{~b}$ & $\begin{array}{l}\text { S, SE, Arg, } \\
\text { Par, Uru }\end{array}$ \\
\hline
\end{tabular}




\begin{tabular}{|c|c|c|c|c|}
\hline DIVISÃO/Família/Espécie & Coletor & Estrutura & Hábitat & $\begin{array}{l}\text { Distribuiçã } \\
\text { o geográfica }\end{array}$ \\
\hline Gamochaeta americana (Mill.) Wedd. & CAMS 352 & & $\mathrm{c}$ & $\mathrm{Am}$ \\
\hline Gamochaeta hiemalis (Rizzini) Cabrera & CAMS 874 & & $\mathrm{c}$ & S, SE \\
\hline Gamochaeta stachydifolia (Lam.) Cabrera & CAMS $469 \&$ VCS & & $\mathrm{c}$ & AmS \\
\hline Gnaphalium cheiranthifolium (Pers.) Lam. & CAMS 1060 & & $\mathrm{~b}$ & $\mathrm{AmS}$ \\
\hline Gochnatia paniculata (Less.) Cabrera & CAMS 583 \& VCS & & $\mathrm{c}$ & S, SE \\
\hline Gochnatia polymorpha (Less.) Cabrera & $\begin{array}{l}\text { CAMS } 350 \& \text { M } \\
\text { Godron }\end{array}$ & & $\mathrm{r}$ & $\begin{array}{l}\text { S, SE, Arg, } \\
\text { Par }\end{array}$ \\
\hline Grazielia intermedia (DC.) R.M. King \& H. Rob. & $\begin{array}{l}\text { CAMS } 602 \& \text { M } \\
\text { Deur }\end{array}$ & E5 & $\mathrm{b}, \mathrm{c}$ & $\begin{array}{l}\text { S, SE, GO, } \\
\text { Uru }\end{array}$ \\
\hline Grazielia multifida (DC.) R.M. King \& H. Rob. & CAMS 94 \& VCS & E1 & $\mathrm{b}, \mathrm{c}$ & S, SE, LN \\
\hline Gyptis lanigera (Hook. \& Arn.) R.M. King \& H. Rob. & CAMS $192 \&$ VCS & & $\mathrm{b}, \mathrm{c}$ & $\begin{array}{l}\text { S, SE, Arg, } \\
\text { Par, Uru }\end{array}$ \\
\hline Gyptis pinnatifida Cass. * & CAMS $466 \&$ VCS & & $\mathrm{c}$ & S, SE, LN \\
\hline Heterocondylus alatus (Vell.) R.M. King \& H. Rob. & $\begin{array}{l}\text { CAMS } 611 \& \mathrm{M} \\
\text { Deur }\end{array}$ & E2 & $\mathrm{c}$ & $\mathrm{S}, \mathrm{SE}$ \\
\hline Heterocondylus jaraguensis (B.L. Rob.) R.M. King \& H. Rob. & VCS 3274 & & $\mathrm{c}$ & $\begin{array}{l}\text { Endêmica } \\
\text { Itararé }\end{array}$ \\
\hline Hieracium cf. warmingii (Sch. Bip.) Baker & VCS 3833 & & $\mathrm{c}$ & - \\
\hline Hieracium commersonii Monnier & VCS 7405 & & $\mathrm{c}$ & $\begin{array}{l}\text { S, SE, Arg, } \\
\text { Uru }\end{array}$ \\
\hline Holocheilus illustris (Vell.) Cabrera & VCS 4275 & & $\mathrm{~b}$ & $\begin{array}{l}\text { S, SE, Arg, } \\
\text { Par, Uru, } \\
\text { LN, i }\end{array}$ \\
\hline Hypochaeris lutea (Vell.) Britton & VCS 4713 & & $\mathrm{c}$ & S, SE, Par \\
\hline Hypochaeris radicata $\mathrm{L}$. & VCS 2178 & & $\mathrm{~b}, \mathrm{c}$ & Pan \\
\hline Hypochaeris rosengurttii Cabrera & CMS 417 & & $\mathrm{c}$ & S, SE, Arg \\
\hline Icthyothere agrestis Baker & CAMS $544 \&$ VCS & E2 & $\mathrm{c}$ & $\mathrm{S}, \mathrm{SE}$ \\
\hline Icthyothere latifolia Baker & VCS 4597 & & $\mathrm{r}$ & $\mathrm{Br}$ \\
\hline Inulopsis scaposa (Baker) O. Hoffm. ex Engl. \& Prantl & CAMS 58 \& VCS & & $\mathrm{c}$ & S, SE, Par \\
\hline Isostigma cf. peucedanifolium (Spreng.) Less. & CAMS 887e & & $\mathrm{c}$ & - \\
\hline Lucilia acutifolia (Poir.) Cassini & CAMS 693 & & $\mathrm{c}$ & AmS \\
\hline Lucilia nitens Less. & $\begin{array}{l}\text { CAMS } 335 \& \text { M } \\
\text { Godron }\end{array}$ & E2 & $\mathrm{r}$ & $\begin{array}{l}\text { S, SE, Arg, } \\
\text { Uru, LN }\end{array}$ \\
\hline Mikania decumbens Malme & CAMS 1022 & & $\mathrm{~b}$ & SE, i \\
\hline Mikania hemisphaerica Sch. Bip. ex Baker & VCS 3477 & & $\mathrm{c}$ & $\mathrm{Br}, \mathrm{LS}$ \\
\hline Mikania hirsutissima DC. & CAMS 812 & & $\mathrm{c}$ & $\mathrm{Br}, \mathrm{Arg}, \mathrm{Par}$ \\
\hline Mikania hoffmanniana Dusén ex Malme & CAMS 524 \& VCS & & $\mathrm{c}$ & S, SE \\
\hline Mikania officinalis Mart. & VCS 2458 & & $\mathrm{c}$ & $\mathrm{Br}$ \\
\hline Mikania sessilifolia DC. & CAMS 227 \& VCS & & $\mathrm{c}, \mathrm{r}$ & $\mathrm{Br}$ \\
\hline Mikania trachypleura B.L. Rob. & CAMS 219 \& VCS & & $\mathrm{c}, \mathrm{m}$ & $\mathrm{Br}, \mathrm{Arg}, \mathrm{Par}$ \\
\hline Mikania triphylla (L.) Spreng. & CAMS 703 & & $\mathrm{c}$ & SP, MG \\
\hline Noticastrum gnaphalioides (Baker) Cuatrec. & $\begin{array}{l}\text { CAMS } 388 \& \text { M } \\
\text { Godron }\end{array}$ & & $\mathrm{c}$ & S, SE, Arg \\
\hline Oligandra lycopodioides Less. & $\begin{array}{l}\text { CAMS } 312 \& \text { M } \\
\text { Godron }\end{array}$ & E2 & $\mathrm{c}, \mathrm{r}$ & S, SE \\
\hline Orthopappus angustifolius (Sw.) Gleason & $\begin{array}{l}\text { CAMS } 363 \& \text { M } \\
\text { Godron }\end{array}$ & & $\mathrm{c}$ & Neo \\
\hline Piptocarpha axillaris (Less.) Baker & CAMS $526 \&$ VCS & & $\mathrm{c}$ & S, SE \\
\hline Piptocarpha rotundifolia (Less.) Baker & PH Miyagi 328 & & $\mathrm{r}$ & $\mathrm{Br}$ \\
\hline Pluchea oblongifolia DC. & CAMS 694 & & $\mathrm{c}$ & S, SE \\
\hline Porophyllum ruderale (Jacq.) Cass. & CAMS $12 \&$ VCS & & $\mathrm{r}$ & $\mathrm{AmS}$ \\
\hline Praxelis cappilaris (DC.) Sch. Bip. & P Gibbs 1727 & & $\mathrm{c}$ & $\mathrm{Br}$ \\
\hline Praxelis sanctopaulensis (B.L. Rob.) R.M. King \& H. Rob. & CAMS $22 \&$ VCS & & $\mathrm{c}, \mathrm{r}$ & S, SE, Arg \\
\hline Pterocaulon alopecuroides (Lam.) DC. & CAMS 225 \& VCS & & $\mathrm{r}$ & $\mathrm{Neo}$ \\
\hline Pterocaulon angustifolium DC. & $\begin{array}{l}\text { CAMS } 348 \& \text { M } \\
\text { Godron }\end{array}$ & & $\mathrm{c}$ & $\mathrm{AmS}$ \\
\hline Raulinoreitzia cf. tremula (Hook. \& Arn.) R.M. King \& H. Rob. & CAMS 892e & & $\mathrm{c}$ & - \\
\hline Raulinoreitzia crenulata (Spreng.) R.M. King \& H. Rob. & CAMS 85 \& VCS & & $\mathrm{c}$ & $\mathrm{AmS}$ \\
\hline Richterago radiata (Vell.) Roque & VCS 2342 & E1 & $\mathrm{b}$ & $\mathrm{Br}$ \\
\hline Schlechtendalia luzulaefolia Less. & CAMS 913e & & $\mathrm{c}$ & $\begin{array}{l}\text { S, SE, Arg, } \\
\text { Uru }\end{array}$ \\
\hline Senecio adamantinus Bong. & VCS 7377 & & $\mathrm{c}$ & S, SE \\
\hline Senecio brachycodon Baker & VCS 3261 & & $\mathrm{~b}, \mathrm{c}$ & S, SE, i \\
\hline Senecio brasiliensis (Spreng.) Less. & $\begin{array}{l}\text { CAMS } 337 \& \text { M } \\
\text { Godron }\end{array}$ & E4 & $\begin{array}{ll}\mathrm{r} \\
\mathrm{n}\end{array}$ & $\begin{array}{l}\text { S, SE, Arg, } \\
\text { Par, Uru }\end{array}$ \\
\hline Senecio hoehnei Cabrera & CAMS 113 & & $\mathrm{c}$ & $\mathrm{S}, \mathrm{SE}, \mathrm{LN}, \mathrm{i}$ \\
\hline
\end{tabular}




\begin{tabular}{|c|c|c|c|c|}
\hline DIVISÃO/Família/Espécie & Coletor & Estrutura & Hábitat & $\begin{array}{l}\text { Distribuiçã } \\
\text { o geográfica }\end{array}$ \\
\hline Senecio leptoschizus Bong. & CAMS $62 \&$ VCS & & $\mathrm{c}$ & $\mathrm{S}, \mathrm{SE}$ \\
\hline Senecio oleosus Vell. & CAMS $454 \&$ VCS & E3 & $\mathrm{b}, \mathrm{c}$ & S, SE \\
\hline Senecio pulcher Hook. \& Arn. & VCS 4271 & & $\mathrm{c}$ & $\begin{array}{l}\text { S, SE, Arg, } \\
\text { Uru, LN, i }\end{array}$ \\
\hline Senecio vernonioides Sch. Bip. & CAMS 566 \& VCS & & $\mathrm{c}$ & $\mathrm{S}, \mathrm{SE}$ \\
\hline Solidago chilensis Meyen & $\begin{array}{l}\text { CAMS 622 \& M } \\
\text { Deur }\end{array}$ & & $\mathrm{b}, \mathrm{c}$ & $\mathrm{AmS}$ \\
\hline Stevia commixta B.L. Rob. & VCS 3625 & & $\mathrm{c}$ & S, SE \\
\hline Stevia leptophylla Sch. Bip. ex Baker*\#\#\# & CAMS 66 \& VCS & & $\mathrm{c}$ & S, SE \\
\hline Stevia lundiana $\mathrm{DC}$. & CAMS 83 \& VCS & E2 & $\mathrm{c}$ & $\begin{array}{l}\text { S, SE, Arg, } \\
\text { Par }\end{array}$ \\
\hline Stevia myriadenia Sch. Bip. ex Baker & CAMS 96 \& VCS. & & $\mathrm{c}$ & S, SE, LN \\
\hline Stevia ophryophylla B.L. Rob. & CAMS 345 \& VCS & & $\mathrm{c}$ & $\mathrm{S}, \mathrm{SE}, \mathrm{LN}$ \\
\hline Symphyopappus cuneatus (DC.) Sch. Bip. ex Baker & CAMS 1112 & & $\mathrm{c}$ & $\mathrm{S}, \mathrm{SE}$ \\
\hline Symphyopappus lyman-smithii B.L. Rob. & VCS 2290 & & $\mathrm{c}$ & S, SE, LN \\
\hline Symphyopappus polystachyus Baker & CAMS $150 \&$ VCS & E5 & $\mathrm{b}$ & $\mathrm{Br}$ \\
\hline Symphyopappus reticulatus Baker & CAMS 711 & & $\mathrm{~b}$ & S, SE \\
\hline Synedrella nodiflora $(\mathrm{L}$.$) Gaertn.$ & VCS 3868 & & $\mathrm{c}$ & Neo \\
\hline Trichocline speciosa Less. & CAMS $173 \&$ VCS & & $\mathrm{b}$ & $\begin{array}{l}\text { S, SE, Arg, } \\
\text { Par }\end{array}$ \\
\hline Trichogoniopsis adenantha (DC.) R.M. King \& H. Rob. & CAMS 627 \& VCS & & $\mathrm{c}, \mathrm{r}$ & $\mathrm{Br}, \mathrm{LS}$ \\
\hline Trixis lessingii $\mathrm{DC}$ & VCS 7288 & & $\mathrm{r}$ & $\begin{array}{l}\text { S, SE, Arg, } \\
\text { Par, Uru }\end{array}$ \\
\hline Trixis nobilis (Vell.) Katinas & VCS 2504 & & $\mathrm{~b}, \mathrm{c}$ & S, SE, Arg \\
\hline Verbesina cf. heterosperma Griseb. & CAMS 692 & & $\mathrm{c}$ & - \\
\hline Verbesina cf. viguieroides Baker & CAMS $368 \&$ VCS & & $\mathrm{b}, \mathrm{r}$ & - \\
\hline Vernonia aff. grandiflora Less. & VCS 3762 & & $\mathrm{c}$ & $\mathrm{Br}, \mathrm{Par}$ \\
\hline Vernonia aff. oligactoides Less. & CAMS $183 \&$ VCS & & $\mathrm{b}$ & S, SE, LN \\
\hline Vernonia arachniolepis Ekman \& Dusén & VCS 2438 & & $\mathrm{c}$ & $\mathrm{Br}, \mathrm{i}$ \\
\hline Vernonia argentea Less. & CAMS 870 & & $\mathrm{c}$ & $\mathrm{Br}, \mathrm{Par}$ \\
\hline Vernonia bardanoides Less. & CAMS 55 \& VCS & & $\mathrm{r}$ & $\mathrm{Br}, \mathrm{LS}$ \\
\hline Vernonia brevifolia Less. & CAMS $538 \&$ VCS & & $\mathrm{c}$ & S, SE \\
\hline Vernonia chamaedrys Less. & CAMS 576 \& VCS & & $\mathrm{c}$ & $\begin{array}{l}\text { S, SE, Arg, } \\
\text { Par, Uru, LN }\end{array}$ \\
\hline Vernonia crassa (Vell.) E. Ekman ex Malme & CAMS $465 \&$ VCS & & $\mathrm{c}$ & S, SE, LN \\
\hline Vernonia discolor Less. & VCS 2891 & & $\mathrm{c}$ & S, SE \\
\hline Vernonia elegans Gardn. & CAMS 198 \& VCS & & $\mathrm{c}$ & $\mathrm{Br}, \mathrm{LS}$ \\
\hline Vernonia flexuosa Sims & $\begin{array}{l}\text { CAMS } 342 \& \text { M } \\
\text { Godron }\end{array}$ & & $\mathrm{c}$ & $\begin{array}{l}\text { S, SE, Arg, } \\
\text { Par, Uru }\end{array}$ \\
\hline Vernonia glabrata Less. & VCS 2323 & & $\mathrm{~b}$ & $\begin{array}{l}\text { S, SE, Arg, } \\
\text { Uru, LN }\end{array}$ \\
\hline Vernonia graminifolia Gardn. & VCS 3610 & & $\mathrm{c}$ & $\mathrm{Br}$ \\
\hline Vernonia grandiflora Less. & CAMS 725 & & $\mathrm{c}$ & $\mathrm{Br}$ \\
\hline Vernonia herbacea (Vell.) Rusby & CAMS $178 \&$ VCS & & $\mathrm{b}$ & $\mathrm{Br}, \mathrm{LS}$ \\
\hline Vernonia hypochlora Malme & VCS 4389. & & $\mathrm{c}$ & S, SE, LN, i \\
\hline Vernonia megapotamica Spreng. var. hexantha (Sch.Bip.) Cabrera & $\begin{array}{l}\text { CAMS } 344 \& \text { M } \\
\text { Godron }\end{array}$ & & $\mathrm{c}$ & $\begin{array}{l}\text { S, SE, Arg, } \\
\text { Par }\end{array}$ \\
\hline Vernonia molissima D. Don ex Hook. \& Arn. & VCS 4257 & & $\mathrm{c}$ & $\mathrm{Br}, \mathrm{Arg}, \mathrm{Par}$ \\
\hline Vernonia mucronulata Less. & CAMS $431 \&$ VCS & & $\mathrm{c}, \mathrm{r}$ & $\mathrm{Br}$ \\
\hline Vernonia oligolepis Sch. Bip. ex Baker & $\begin{array}{l}\text { CAMS } 252 \& \text { M } \\
\text { Godron }\end{array}$ & & $\mathrm{c}, \mathrm{r}$ & S, SE, Par \\
\hline Vernonia oxylepis Sch. Bip. ex Baker & CAMS 720 & & $\mathrm{~b}$ & SP \\
\hline Vernonia platensis (Spreng.) Less. & CAMS $251 \&$ VCS & E2 & $\mathrm{b}, \mathrm{c}, \mathrm{r}$ & $\begin{array}{l}\text { S, SE, Arg, } \\
\text { Uru }\end{array}$ \\
\hline Vernonia polianthes Less. & VCS 3613 & & $\mathrm{c}$ & - \\
\hline Vernonia polyphylla Sch. Bip. ex Baker & CAMS 844 & & $\mathrm{c}$ & $\begin{array}{l}\text { S, SE, Arg, } \\
\text { Par }\end{array}$ \\
\hline Vernonia propinqua Hieron. & $\begin{array}{l}\text { CAMS } 341 \& \text { M } \\
\text { Godron }\end{array}$ & & $\mathrm{c}$ & $\begin{array}{l}\text { S, SE, Arg, } \\
\text { Uru }\end{array}$ \\
\hline Vernonia psammophila Dusén & CAMS $117 \&$ VCS & & $\mathrm{b}, \mathrm{c}$ & S, SE, i \\
\hline Vernonia quinqueflora Less. & CAMS 482 \& VCS & & $\mathrm{c}$ & S, SE \\
\hline Vernonia sellowii Less. & CMS 420B & & $\mathrm{c}$ & $\begin{array}{l}\text { S, SE, Arg, } \\
\text { Par, Uru }\end{array}$ \\
\hline Vernonia simplex Less. & CAMS $537 \&$ VCS & & $\mathrm{c}$ & $\mathrm{Br}$ \\
\hline Vernonia westiniana Less. & CAMS 633 \& VCS & & $\mathrm{b}, \mathrm{r}$ & S, SE \\
\hline Viguiera aff. subdentata S.F. Blake & CAMS 20 \& VCS & & $\mathrm{r}$ & S, SE \\
\hline
\end{tabular}




\begin{tabular}{|c|c|c|c|c|}
\hline DIVISÃO/Família/Espécie & Coletor & Estrutura & Hábitat & $\begin{array}{l}\text { Distribuiçã } \\
\text { o geográfica }\end{array}$ \\
\hline Viguiera robusta Gardn. & CAMS $32 \&$ VCS & & $\mathrm{r}$ & $\mathrm{Br}$ \\
\hline Vittetia orbiculata (DC.) R.M. King \& H. Rob. & CAMS $37 \&$ VCS & & $\mathrm{r}$ & S, SE, LN \\
\hline Asteraceae sp. 11 & VCS 7042b & & & - \\
\hline \multicolumn{5}{|l|}{ BEGONIACEAE } \\
\hline Begonia cucullata Willd. & CAMS 1107 & & $\mathrm{~b}$ & $\mathrm{Am}$ \\
\hline \multicolumn{5}{|l|}{ BIGNONIACEAE } \\
\hline Anemopaema prostratum DC. & KD Barreto 3274 & & $\mathrm{c}$ & $\mathrm{Br}, \mathrm{Bol}$ \\
\hline Arrabidaea pulchella (Cham.) Bureau & VCS 4468 & & $\mathrm{r}$ & S, SE, Par \\
\hline Arrabidaea triplinervea (DC.) Baill. ex Bureau & CAMS 334 & & $\mathrm{~m}$ & $\mathrm{Br}, \mathrm{Par}$ \\
\hline Fredericia speciosa Mart. & KD Barreto 3261 & & $\mathrm{c}$ & SE, PR, BA \\
\hline Jacaranda caroba (Vell.) A. DC. & CMS 325 & & $\mathrm{r}$ & $\mathrm{Br}$ \\
\hline Jacaranda decurrens Cham. & VCS 6256 & & $\mathrm{r}$ & $\mathrm{Br}$ \\
\hline Pithecoctenium cf. crucigerum (L. f.) A.H. Gentry & CAMS 919e & & $\mathrm{c}$ & - \\
\hline Pyrostegia venusta (Ker Gawl.) Miers & CAMS $226 \&$ VCS & & $\mathrm{r}$ & $\mathrm{AmS}$ \\
\hline Tabebuia aurea (Silva Manso) Benth. \& Hook. f. ex S.Moore & CAMS $552 \&$ VCS & & $\mathrm{b}, \mathrm{r}$ & $\mathrm{Br}$ \\
\hline Tabebuia chrysotricha (Mart. ex DC.) Standl. & CAMS 223 \& VCS & & $\mathrm{m}$ & $\mathrm{Br}$ \\
\hline Zeyheria montana Mart. & VCS 3206 & & $\mathrm{c}$ & $\mathrm{Br}$ \\
\hline \multicolumn{5}{|l|}{ BORAGINACEAE } \\
\hline Cordia monosperma (Jacq.) Roem. et Schult. & CAMS $15 \&$ VCS & & $\mathrm{b}$ & $\mathrm{AmS}$ \\
\hline Cynoglossum amabile Stapf \& J.R. Drumm. & CMS 338 & & $\mathrm{c}$ & S, SE, Arg \\
\hline Moritzia dusenii I.M. Johnston & VCS 4339 & & $\mathrm{r}$ & S, SE, LN, i \\
\hline \multicolumn{5}{|l|}{ BRASSICACEAE } \\
\hline Raphanus raphanistrum $\mathrm{L}$. & VCS 2332 & & $\mathrm{~b}$ & Sub \\
\hline \multicolumn{5}{|l|}{ BROMELIACEAE } \\
\hline Aechmea distichantha Lem. & CAMS $497 \&$ VCS & & $\mathrm{c}$ & $\mathrm{AmS}$ \\
\hline Aechmea wittmackiana (Regel) Mez & CAMS 943 & & $\mathrm{c}$ & SP \\
\hline Dyckia remotiflora Otto \& Dietr. & VCS 7173 & & $\mathrm{c}$ & $\begin{array}{l}\text { S, SE, Arg, } \\
\text { Uru }\end{array}$ \\
\hline Dyckia tuberosa (Vell.) Beer & CAMS $496 \&$ VCS & & $\mathrm{c}$ & S, SE \\
\hline Pitcairnia flammea Lindl. & VCS 4751 & & $\mathrm{c}$ & SE, LS \\
\hline Quesnelia humilis $\mathrm{Mez}^{\#}$ & KD Barreto 2952 & & $\mathrm{c}$ & SP \\
\hline Tillandsia mallemontii Glaz. ex Mez * & CAMS 456 \& VCS & & $\mathrm{c}$ & $\mathrm{Br}$ \\
\hline Tillandsia stricta Sol. & VCS 4154 & & $\mathrm{c}$ & $\mathrm{AmS}$ \\
\hline Tillandsia tenuifolia $\mathrm{L}$. & CAMS 495 \& VCS & & $\mathrm{c}$ & $\mathrm{AmS}$ \\
\hline Tillandsia usneoides (L.) L. & CAMS $216 \&$ VCS & & $\mathrm{m}$ & Neo \\
\hline Vriesea platynema Gaudich. & CAMS 843 & & $\mathrm{c}$ & Neo \\
\hline \multicolumn{5}{|l|}{ BURMANNIACEAE } \\
\hline Apteria aphylla (Nutt.) Barnh. ex Small & VCS 7431 & & $\mathrm{c}$ & Neo \\
\hline Burmannia alba Mart. & VCS 6143 & & $\mathrm{c}$ & $\mathrm{Br}$, Par \\
\hline Burmannia capitata (Walter ex Gmelin) Martius & VCS 8650 & & $\mathrm{c}$ & Neo \\
\hline \multicolumn{5}{|l|}{ BURSERACEAE } \\
\hline Protium heptaphyllum (Aubl.) Merchant & $\begin{array}{l}\text { CAMS } 332 \& \text { M } \\
\text { Godron }\end{array}$ & & $\mathrm{r}$ & $\mathrm{AmS}$ \\
\hline \multicolumn{5}{|l|}{ CACTACEAE } \\
\hline Rhipsalis dissimilis (G. Lindb.) K. Schum. ex Mart. ** & CAMS $461 \&$ VCS & & $\mathrm{c}$ & $\mathrm{S}, \mathrm{SE}$ \\
\hline \multicolumn{5}{|l|}{ CALYCERACEAE } \\
\hline Acicarpha tribuloides Juss. & CAMS 949e, 951e & & $\mathrm{c}$ & $\mathrm{Am}$ \\
\hline \multicolumn{5}{|l|}{ CAMPANULACEAE } \\
\hline Lobelia camporum Pohl & CAMS $645 \&$ VCS & & $\mathrm{b}, \mathrm{c}, \mathrm{r}$ & $\mathrm{Br}, \mathrm{Arg}$ \\
\hline Lobelia hassleri Zahlbr. & $\begin{array}{l}\text { CAMS } 331 \& \mathrm{M} \\
\text { Godron }\end{array}$ & & $\mathrm{r}$ & $\begin{array}{l}\text { Br, Arg, Par, } \\
\text { LN }\end{array}$ \\
\hline Siphocampylus lycioides (Cham.) G. Don * & CAMS $500 \&$ VCS & & $\mathrm{c}$ & $\mathrm{Br}$ \\
\hline Siphocampylus sulfureus E. Wimm. & VCS 3839 & & $\mathrm{~b}, \mathrm{c}$ & S, SE \\
\hline Wahlenbergia linarioides (Lam.) A. DC. & VCS 4496 & & $\mathrm{r}$ & $\mathrm{AmS}$ \\
\hline \multicolumn{5}{|l|}{ CARYOCARACEAE } \\
\hline Caryocar brasiliense A. St.-Hil. & CAMS $1 \&$ VCS & & $\mathrm{r}$ & $\mathrm{AmS}$ \\
\hline \multicolumn{5}{|l|}{ CARYOPHYLLACEAE } \\
\hline Paronychia communis Cambess. & VCS 7188 & & $\mathrm{c}$ & $\mathrm{AmS}$ \\
\hline Silene antirrhina $\mathrm{L}$. & J Mattos 12899 & & $\mathrm{r}$ & Sub \\
\hline Silene armeria $\mathrm{L}$. & JP Souza 2013 & & $\mathrm{c}$ & Sub \\
\hline Silene gallica $\mathrm{L}$. & JP Souza 2012 & & $\mathrm{c}$ & Sub \\
\hline \multicolumn{5}{|l|}{ CELASTRACEAE } \\
\hline Peritassa campestris (Cambess.) A.C. Sm. & CAMS $551 \&$ VCS & E2 & $\mathrm{c}, \mathrm{r}$ & $\mathrm{Br}, \mathrm{Par}$ \\
\hline Plenckia populnea Reissek & CAMS $244 \&$ VCS & & $\mathrm{r}$ & AmS \\
\hline
\end{tabular}




\begin{tabular}{|c|c|c|c|c|}
\hline DIVISÃO/Família/Espécie & Coletor & Estrutura & Hábitat & $\begin{array}{l}\text { Distribuiçã } \\
\text { o geográfica }\end{array}$ \\
\hline Tontelea micrantha (Mart. ex Schult.) A.C. Sm. & VCS 2390 & & $\mathrm{c}$ & $\mathrm{Br}$, Par \\
\hline \multicolumn{5}{|l|}{ CLETHRACEAE } \\
\hline Clethra scabra Pers. & CAMS $214 \&$ VCS & & $\mathrm{m}$ & $\mathrm{S}, \mathrm{SE}$ \\
\hline \multicolumn{5}{|l|}{ CLUSIACEAE } \\
\hline Clusia criuva Cambess. ssp. parviflora Vesque & CAMS $662 \&$ VCS & & $\mathrm{c}$ & $\mathrm{S}, \mathrm{SE}$ \\
\hline Kielmeyera coriacea Mart. \& Zucc. ${ }^{*}$ & VCS 4596 & & $\mathrm{~b}$ & $\mathrm{Br}, \mathrm{Par}$ \\
\hline $\begin{array}{l}\text { Kielmeyera variabilis Mart. \& Zucc. ssp. paranaensis (Saddi) } \\
\text { Bittrich* }\end{array}$ & VCS 3979 & & $\mathrm{c}$ & $\mathrm{S}, \mathrm{SE}$ \\
\hline \multicolumn{5}{|l|}{ COMMELINACEAE } \\
\hline Commelina erecta $\mathrm{L}$. & $\begin{array}{l}\text { CAMS } 329 \& \text { M } \\
\text { Godron }\end{array}$ & & $\mathrm{r}$ & Am \\
\hline Commelina obliqua Vahl & VCS 7314 & & $\begin{array}{l}\mathrm{b}, \mathrm{c}, \mathrm{m}, \\
\mathrm{r}\end{array}$ & $\mathrm{Neo}$ \\
\hline \multicolumn{5}{|l|}{ CONVOLVULACEAE } \\
\hline Cuscuta racemosa Mart. & $\begin{array}{l}\text { CAMS } 601 \& \text { M } \\
\text { Deur }\end{array}$ & $\mathrm{T}$ & $\mathrm{c}$ & Neo \\
\hline Dichondra sericea $\mathrm{Sw}$. & VCS 3976 & & $\mathrm{c}$ & $\mathrm{Neo}$ \\
\hline Evolvulus barbatus Meisn. & VCS 4169 & & $\mathrm{c}$ & S, SE \\
\hline Evolvulus glomeratus Nees \& Mart. & VCS 7417 & & $\mathrm{c}$ & $\mathrm{AmS}$ \\
\hline Evolvulus riedelii Meisn. & $\begin{array}{l}\text { CAMS } 313 \& \text { M } \\
\text { Godron }\end{array}$ & & $\mathrm{c}$ & SP \\
\hline Evolvulus sericeus $\mathrm{Sw}$. & VCS 4411 & $\mathrm{~T}$ & $\mathrm{~b}, \mathrm{r}$ & Neo \\
\hline Evolvulus serpylloides Meisn. ${ }^{*}$ & CAMS $61 \&$ VCS & & $\mathrm{c}$ & S, SE \\
\hline Ipomoea delphinioides Choisy & VCS 2354 & & $\mathrm{c}, \mathrm{r}$ & $\mathrm{S}, \mathrm{SE}, \mathrm{GO}$ \\
\hline Ipomoea indica (Burm. f.) Merr. & VCS 2502 & & $\mathrm{c}$ & $\mathrm{Neo}$ \\
\hline Ipomoea purpurea (L.) Roth ex Meisn. & CAMS $258 \&$ VCS & & $\mathrm{m}$ & $\mathrm{Neo}$ \\
\hline Jacquemontia ferruginea Choisy & VCS 7434 & & $\mathrm{r}$ & $\mathrm{Br}$ \\
\hline Merremia digitata (Spreng.) Hallier f. & CAMS $435 \&$ VCS & $\mathrm{T}$ & $\mathrm{b}, \mathrm{c}, \mathrm{r}$ & $\mathrm{Br}$ \\
\hline \multicolumn{5}{|l|}{ CUCURBITACEAE } \\
\hline Cayaponia espelina (Silva Manso) Cogn. & CAMS $158 \&$ VCS & & $\mathrm{r}$ & $\mathrm{Br}$ \\
\hline Cayaponia martiana (Cogn.) Cogn. & CAMS 815 & & $\mathrm{~b}, \mathrm{c}$ & $\begin{array}{l}\text { S, SE, Arg, } \\
\text { Uru }\end{array}$ \\
\hline \multicolumn{5}{|l|}{ CUNONIACEAE } \\
\hline Lamanonia cuneata (Cambess.) Kuntze ** & VCS 4768 et al & & $\mathrm{c}, \mathrm{r}$ & $\mathrm{S}, \mathrm{SE}$ \\
\hline Lamanonia ternata Vell. & CAMS $212 \&$ VCS & & $\mathrm{m}$ & $\mathrm{Br}$ \\
\hline Weinmannia cf. pinnata L. & CAMS 97 \& VCS & & $\mathrm{c}$ & - \\
\hline Weinmannia discolor Gardn. & VCS 3528 & & $\mathrm{c}$ & S, SE \\
\hline \multicolumn{5}{|l|}{ CYPERACEAE } \\
\hline Ascolepis brasiliensis (Kunth) Benth. ex C.B. Clarke & VCS 4623 & & $\mathrm{~b}$ & $\mathrm{Neo}$ \\
\hline Bulbostylis cf. paradoxa (Boeck.) C.B. Clarke & CAMS 942e & & $\mathrm{c}$ & - \\
\hline Bulbostylis consanguinea (Kunth) C.B. Clarke & $\begin{array}{l}\text { CAMS } 314 \& \text { M } \\
\text { Godron }\end{array}$ & & $\mathrm{c}$ & $\mathrm{AmS}$ \\
\hline Bulbostylis hirtella (Schrad.) Urban & VCS 2472 & & $\mathrm{~b}$ & $\mathrm{AmS}$ \\
\hline Bulbostylis sellowiana (Kunth) Palla & VCS 4180 & & $\mathrm{c}$ & $\mathrm{Br}$ \\
\hline Bulbostylis sp. 2 & VCS 3623 & & $\mathrm{c}$ & - \\
\hline Bulbostylis sphaerocephala (Boeck.) C.B. Clarke & VCS 3495 & & $\mathrm{c}$ & $\mathrm{AmS}$ \\
\hline Carex brasiliensis A. St.-Hil. & KD Barreto 3180 & & $\mathrm{~b}$ & $\begin{array}{l}\text { S, SE, Arg, } \\
\text { Par, Uru }\end{array}$ \\
\hline Cyperus aggregatus (Willd.) Endl. & VCS 2474 & & $\mathrm{~b}, \mathrm{c}$ & Neo \\
\hline Cyperus haspan $\mathrm{L}$. & VCS 4625 & & $\mathrm{~b}, \mathrm{c}$ & Pan \\
\hline Cyperus intricatus Schrad. ex Schult. & CMS 456 & & $\mathrm{c}$ & $\mathrm{Neo}$ \\
\hline Cyperus sp. 2 & KD Barreto 2904 & & $\mathrm{~b}$ & - \\
\hline Eleocharis elata Boeck. & VCS 4447 & & $\mathrm{~b}$ & $\mathrm{AmS}$ \\
\hline Eleocharis glauco-virens Boeck. & VCS 4599 & & $\mathrm{~b}, \mathrm{c}$ & $\mathrm{AmS}$ \\
\hline Eleocharis minima Kunth & VCS 4650 & & $\mathrm{~b}$ & Neo \\
\hline Eleocharis nudipes (Kunth) Palla & VCS 4187 & & $\mathrm{c}$ & $\mathrm{Br}, \mathrm{Arg}, \mathrm{Par}$ \\
\hline Fimbristylis complanata (Retz) Link & VCS 2233 & & $\mathrm{c}$ & Pan \\
\hline Fuirena incompleta Nees & VCS 4622 & & $\mathrm{~b}$ & $\mathrm{Neo}$ \\
\hline Kyllinga odorata $\mathrm{Vahl}$ & VCS 2338 & & $\mathrm{~b}$ & Neo \\
\hline Lagenocarpus rigidus (Kunth) Nees & CAMS 177 \& VCS & G5 & $\mathrm{b}$ & $\mathrm{AmS}, \mathrm{LS}$ \\
\hline Machaerina ensifolia (Boeck.) Koyama & VCS 4709 & & $\mathrm{c}$ & $\mathrm{S}, \mathrm{SE}$ \\
\hline Rhynchospora albiceps Kunth & CAMS 419 \& VCS & & $\mathrm{b}, \mathrm{c}, \mathrm{r}$ & Br, Par \\
\hline Rhynchospora cf. trispicata (Nees) Schrad. & VCS 4602 & & $\mathrm{~b}$ & - \\
\hline Rhynchospora consanguinea (Kunth) Boeck. & KD Barreto 2907 & & $\mathrm{c}$ & $\mathrm{Neo}$ \\
\hline Rhynchospora emaciata (Nees) Boeck. & CAMS 717 & & $\mathrm{~b}$ & $\mathrm{Neo}$ \\
\hline
\end{tabular}




\begin{tabular}{|c|c|c|c|c|}
\hline DIVISÃO/Família/Espécie & Coletor & Estrutura & Hábitat & $\begin{array}{l}\text { Distribuiçã } \\
\text { o geográfica }\end{array}$ \\
\hline Rhynchospora exaltata Kunth & CAMS 157 \& VCS & & $\mathrm{r}$ & Neo \\
\hline Rhynchospora flexuosa C.B. Clarke & VCS 3956 & & $\mathrm{c}$ & S, SE \\
\hline Rhynchospora globosa (Kunth) Roem. \& Schult. & CAMS 723 & G3 & $\mathrm{b}$ & $\mathrm{Neo}$ \\
\hline Rhynchospora loefgrenii Boeck. & VCS 3569 & & $\mathrm{c}$ & $\mathrm{AmS}$ \\
\hline Rhynchospora nervosa (Vahl) Boeck. & PH Miyagi 322 & & $\mathrm{c}, \mathrm{r}$ & $\mathrm{Neo}$ \\
\hline Rhynchospora polyantha Steud. & CAMS 762 & & $\mathrm{~b}, \mathrm{c}$ & $\mathrm{AmS}$ \\
\hline Rhynchospora rigida (Kunth) Boeck. & CAMS 726 & & $\mathrm{c}$ & $\mathrm{Br}$ \\
\hline Rhynchospora robusta (Kunth) Boeck. & CAMS 879 & & $\mathrm{c}$ & Neo \\
\hline Rhynchospora rugosa (Vahl) Gale & CAMS 881 & & $\mathrm{~b}, \mathrm{c}$ & Neo \\
\hline Rhynchospora setigera (Kunth) Boeck. & CAMS 708 & G2 & $\mathrm{c}$ & $\begin{array}{l}\text { Br, Arg, Par, } \\
\text { Uru }\end{array}$ \\
\hline Rhynchospora speciosa Kunth & VCS 2907 & & $\mathrm{~b}$ & $\mathrm{Br}$ \\
\hline Rhynchospora tenuis Link & VCS 2346 & & $\mathrm{~b}$ & Neo \\
\hline Scleria distans Poir. & CAMS 716 & & $\mathrm{c}$ & Neo \\
\hline Cyperaceae sp. 1 & VCS 7399a & & & - \\
\hline \multicolumn{5}{|l|}{ DILLENIACEAE } \\
\hline Davilla rugosa Poir. & CAMS $570 \&$ VCS & & $\mathrm{c}$ & Neo \\
\hline \multicolumn{5}{|l|}{ DROSERACEAE } \\
\hline Drosera communis A. St.-Hil. & VCS 4827 & & $\mathrm{~b}$ & $\mathrm{AmS}$ \\
\hline Drosera montana A. St.-Hil. & CAMS 655 & & $\mathrm{c}$ & $\mathrm{Br}$ \\
\hline Drosera villosa A. St.-Hil. & VCS 3902 & & $\mathrm{~b}, \mathrm{c}$ & S, SE \\
\hline \multicolumn{5}{|l|}{ EBENACEAE } \\
\hline Diospyros hispida A. DC. & CAMS 43 \& VCS & & $\mathrm{c}$ & $\mathrm{AmS}$ \\
\hline \multicolumn{5}{|l|}{ ERICACEAE } \\
\hline Agarista chlorantha $($ Cham.) G. Don & VCS 4013 & & $\mathrm{~b}, \mathrm{c}$ & S, SE, DF \\
\hline Agarista niederleinii (Sleumer) Judd var. acutifolia Judd & VCS 2919 & & c & S, SE, LN, i \\
\hline Agarista pulchella Cham. ex G. Don * & VCS 4064 & & $\mathrm{~b}, \mathrm{c}$ & S, SE \\
\hline Gaylussacia brasiliensis Cham. \& Schltdl. & VCS 4057 & & $\mathrm{c}$ & $\mathrm{Br}$ \\
\hline Gaylussacia pseudogaultheria Cham. \& Schltdl. & CAMS 1124 & E3 & $\mathrm{c}$ & S, SE \\
\hline \multicolumn{5}{|l|}{ ERIOCAULACEAE } \\
\hline Eriocaulon helichrysoides Bong. & VCS 4293 & & $\mathrm{~b}, \mathrm{c}$ & SP, MG \\
\hline Eriocaulon ligulatum (Vell.) L.B. Sm. & CAMS $424 \&$ VCS & & $\mathrm{b}, \mathrm{c}$ & S, SE \\
\hline Eriocaulon modestum Kunth & VCS 3720 & & $\mathrm{~b}$ & $\mathrm{Br}$, Uru \\
\hline Eriocaulon sellowianum Kunth & VCS 4579 & & $\mathrm{~b}$ & $\mathrm{Br}, \mathrm{Arg}, \mathrm{Par}$ \\
\hline Leiothrix flavescens (Bong.) Ruhland & CAMS 534 \& VCS & G2 & $\mathrm{b}, \mathrm{c}$ & $\mathrm{AmS}$ \\
\hline Paepalanthus albo-vaginatus Silveira & CAMS $510 \&$ VCS & & $\mathrm{c}$ & S, SE \\
\hline Paepalanthus flaccidus (Bong.) Kunth & CAMS 65 \& VCS & & $\mathrm{b}, \mathrm{c}$ & S, SE \\
\hline Paepalanthus planifolius (Bong.) Körn. & CAMS $532 \&$ VCS & & $\mathrm{c}$ & $\mathrm{Br}$ \\
\hline Paepalanthus polyanthus (Bong.) Kunth & CAMS $98 \&$ VCS & & $\mathrm{c}$ & S, SE \\
\hline Paepalanthus sp. 1 & CAMS $498 \&$ VCS & & $\mathrm{c}$ & - \\
\hline Paepalanthus sp. 2 & VCS 4427 & & $\mathrm{~b}$ & - \\
\hline Paepalanthus sp. 3 & VCS 2280 & & $\mathrm{~b}$ & - \\
\hline Paepalanthus sp. 4 & VCS 7373 & & $\mathrm{~b}$ & - \\
\hline Paepalanthus speciosus (Bong.) Körn. & VCS 4192 & & $\mathrm{c}$ & AmS \\
\hline Syngonanthus caulescens (Körn.) Ruhland & CAMS $638 \&$ VCS & & $\mathrm{b}, \mathrm{c}$ & $\mathrm{AmS}$ \\
\hline Syngonanthus fischerianus (Bong.) Ruhland & CAMS 728 & & $\mathrm{~b}$ & $\mathrm{AmS}$ \\
\hline Syngonanthus gracilis (Bong.) Ruhland & VCS 4209 & & $\mathrm{c}$ & $\mathrm{AmS}$ \\
\hline Syngonanthus helminthorrhizus (Mart.) Ruhland & CAMS 421 VCS & & $\mathrm{b}$ & $\mathrm{Br}$ \\
\hline Syngonanthus nitens (Bong.) Ruhland & VCS 2270 & & $\mathrm{~b}, \mathrm{c}$ & AmS \\
\hline Syngonanthus sp. 1 & VCS 7367 & & $\mathrm{~b}$ & - \\
\hline Syngonanthus xeranthemoides (Bong.) Ruhland & CAMS 69 \& VCS & & $\mathrm{b}, \mathrm{c}$ & AmS \\
\hline \multicolumn{5}{|l|}{ ERYTHROXYLACEAE } \\
\hline Erythroxylum campestre A. St.-Hil. & CAMS $579 \&$ VCS & & $\mathrm{c}, \mathrm{r}$ & $\mathrm{Br}$ \\
\hline Erythroxylum cuneifolium (Mart.) O.E. Schulz & VCS 7467 et al & & $\mathrm{r}$ & AmS \\
\hline Erythroxylum deciduum A. St.-Hil. & CAMS $578 \&$ VCS & & $\mathrm{c}$ & $\mathrm{AmS}$ \\
\hline Erythroxylum microphyllum A. St.-Hil. & CMS 322 & & $\mathrm{c}, \mathrm{r}$ & $\mathrm{AmS}$ \\
\hline Erythroxylum nanum A. St.-Hil. & CAMS $562 \&$ VCS & & $\mathrm{c}, \mathrm{r}$ & $\mathrm{Br}$ \\
\hline Erythroxylum suberosum A. St.-Hil. & CAMS 437 \& VCS & & $\mathrm{c}, \mathrm{r}$ & $\mathrm{AmS}$ \\
\hline \multicolumn{5}{|l|}{ ESCALLONIACEAE } \\
\hline Escallonia farinacea A. St.-Hil. & CAMS 1007 & & $\mathrm{~b}, \mathrm{c}$ & $\begin{array}{l}\text { S, SE, Arg, } \\
\text { Uru }\end{array}$ \\
\hline \multicolumn{5}{|l|}{ EUPHORBIACEAE } \\
\hline Alchornea glandulosa Poepp. & CAMS $1185 \mathrm{e}$ & & $\mathrm{c}$ & $\mathrm{AmS}$ \\
\hline Chamaesyce caecorum (Boiss.) Croizat & VCS 4270 & & $\mathrm{c}$ & $\mathrm{AmS}$ \\
\hline
\end{tabular}




\begin{tabular}{|c|c|c|c|c|}
\hline DIVISÃO/Família/Espécie & Coletor & Estrutura & Hábitat & $\begin{array}{l}\text { Distribuiçã } \\
\text { o geográfica }\end{array}$ \\
\hline Croton antisyphiliticus Mart. & CAMS $525 \&$ VCS & E2 & $\mathrm{c}$ & $\mathrm{Br}, \mathrm{Par}$ \\
\hline Croton floribundus Spreng. & CAMS $215 \&$ VCS & & $\mathrm{m}$ & $\mathrm{Br}, \mathrm{Par}$ \\
\hline Croton glandulosus $\mathrm{L}$. & CAMS $135 \&$ VCS & & $\mathrm{r}$ & $\begin{array}{l}\text { Neo, } \\
\text { Austrália }\end{array}$ \\
\hline Croton glechomaefolius Baill. & VCS 4175 & & $\mathrm{c}$ & S, SE, LN \\
\hline Croton grandivelus Baill. & KD Barreto 3170 & & $\mathrm{r}$ & $\mathrm{Br}, \mathrm{Bol}$ \\
\hline Croton heterodoxus Baill. & CAMS 1119 & & $\mathrm{c}$ & $\begin{array}{l}\text { S, SE, Uru, } \\
\text { LN }\end{array}$ \\
\hline Croton lanatus Lam. & VCS 2250 & & c & $\begin{array}{l}\text { S, SE, Arg, } \\
\text { Uru }\end{array}$ \\
\hline Croton pallidulus Baill. & VCS 4042 & & $\mathrm{~m}$ & S, SE \\
\hline Croton serpyllifolius Baill. & CAMS $172 \&$ VCS & & $\mathrm{r}$ & $\begin{array}{l}\text { Endêmica } \\
\text { Itapeva, } \\
\text { Itararé }\end{array}$ \\
\hline Croton serratifolius Baill. & VCS 4039 & & $\mathrm{c}$ & $\mathrm{Br}, \mathrm{Arg}, \mathrm{Par}$ \\
\hline Dalechampia humilis Müll. Arg. & VCS 2463 & & $\mathrm{~b}, \mathrm{c}$ & AmS \\
\hline Euphorbia peperomioides Boiss. & CAMS 783 & $\mathrm{~T}$ & $\mathrm{c}$ & S, SE, LN \\
\hline Julocroton fuscencens (Spreng.) Baill. & $\begin{array}{l}\text { H.F.Leitão Filho } \\
4732 \text { SP }\end{array}$ & & $\mathrm{c}$ & $\mathrm{SP}, \mathrm{MG}$ \\
\hline Julocroton humilis Didr. & CAMS $646 \&$ VCS & & $\mathrm{c}, \mathrm{r}$ & $\mathrm{Br}$ \\
\hline Pera glabrata (Schott) Baill. & $\begin{array}{l}\text { CAMS } 320 \& \text { M } \\
\text { Godron }\end{array}$ & & $\mathrm{c}, \mathrm{r}$ & $\mathrm{Br}$ \\
\hline Sebastiania myrtilloides (Mart.) Pax & VCS 7427 & & $\mathrm{c}$ & $\mathrm{Br}$ \\
\hline \multicolumn{5}{|l|}{ FABACEAE } \\
\hline Acosmium subelegans (Mohl.) Yakovlev & CAMS $240 \&$ VCS & & $\mathrm{c}, \mathrm{r}$ & $\mathrm{AmS}$ \\
\hline Aeschynomene histrix Poir. & VCS 4401 & E1 & $\mathrm{b}$ & Neo \\
\hline Anadenanthera falcata (Benth.) Speg. & VCS 6250 & & $\mathrm{r}$ & S, SE \\
\hline Andira laurifolia Benth. & CAMS $548 \&$ VCS & & $\mathrm{b}, \mathrm{c}$ & $\mathrm{Br}, \mathrm{Par}$ \\
\hline Bauhinia forficata Link & CAMS 381 & & $\mathrm{r}$ & Neo \\
\hline Bauhinia longifolia (Bong.) Steud. * & $\begin{array}{l}\text { CAMS } 390 \& \mathrm{M} \\
\text { Godron }\end{array}$ & & $\mathrm{r}$ & $\mathrm{AmS}$ \\
\hline Bauhinia rufa (Bong.) Steud. & CAMS $159 \&$ VCS & & $\mathrm{r}$ & AmS \\
\hline Calliandra dysantha Benth. & CAMS $549 \&$ VCS & E2 & $\mathrm{c}, \mathrm{r}$ & $\mathrm{Br}, \mathrm{LS}$ \\
\hline Camptosema rubicundum Hook. \& Arn. & CAMS $264 \&$ VCS & & $\mathrm{m}, \mathrm{r}$ & $\mathrm{AmS}$ \\
\hline Centrosema bracteosum Benth. * & CAMS 719 & & $\mathrm{c}$ & $\mathrm{Br}, \mathrm{Par}$ \\
\hline Centrosema venosum Mart. ex Benth. & SI Elias 244 & & $\mathrm{c}$ & $\mathrm{AmS}$ \\
\hline Chamaecrista cathartica (Mart.) H.S. Irwin \& Barneby & CAMS $651 \&$ VCS & E2 & $\mathrm{c}$ & $\mathrm{Br}$ \\
\hline Chamaecrista desvauxii (Collad.) Killip & CAMS $521 \&$ VCS & & $\mathrm{c}$ & Neo \\
\hline Chamaecrista nictitans (L.) Moench & CAMS $21 \&$ VCS & & $\mathrm{c}, \mathrm{r}$ & Neo \\
\hline Chamaecrista punctata (Vogel) H.S. Irwin \& Barneby * & VCS 2211 & & $\mathrm{c}$ & S, SE, LN \\
\hline Chamaecrista ramosa (Vogel) H.S. Irwin \& Barneby & CAMS 59 \& VCS & E2 & $\mathrm{c}$ & AmS \\
\hline Chamaecrista rotundifolia (Pers.) Greene & VCS 7027 & & $\mathrm{r}$ & Neo, Af \\
\hline Clitoria laurifolia Poir. * & CAMS 1186 & & $\mathrm{c}$ & Neo \\
\hline Collaea speciosa (Loisel.) DC. & VCS 4091 & & $\mathrm{c}, \mathrm{m}$ & $\mathrm{AmS}$ \\
\hline Copaifera langsdorfii (Desf.) Kuntze * & CAMS $660 \&$ VCS & & $\mathrm{c}$ & AmS \\
\hline Crotalaria breviflora DC. & VCS 6040 & & $\mathrm{c}$ & $\mathrm{Br}, \mathrm{LS}$ \\
\hline Crotalaria maypurensis Kunth & CAMS $17 \&$ VCS & & $\mathrm{b}, \mathrm{r}$ & $\mathrm{Neo}$ \\
\hline Crotalaria micans Link & VCS 2180 & & $\mathrm{r}$ & Pan \\
\hline Crotalaria stipularia Desv. & VCS 8747 & & $\mathrm{c}$ & Neo \\
\hline Dalbergia miscolobium Benth. * & CAMS $440 \&$ VCS & & $\mathrm{c}, \mathrm{r}$ & $\mathrm{Br}, \mathrm{Bol}$ \\
\hline Desmodium adscendens (Sw.) DC. & VCS 1788 & & $\mathrm{c}$ & Pan \\
\hline Desmodium barbatum (L.) Benth. & $\begin{array}{l}\text { CAMS } 382 \& \text { M } \\
\text { Godron }\end{array}$ & & $\mathrm{c}$ & Pan \\
\hline Desmodium discolor Vogel & CAMS $625 \&$ VCS & & $\mathrm{c}, \mathrm{r}$ & $\mathrm{Br}, \mathrm{Arg}$ \\
\hline Eriosema campestre Benth. & VCS 4511 & & $\mathrm{r}$ & $\begin{array}{l}\text { S, SE, Arg, } \\
\text { Par, LN }\end{array}$ \\
\hline Eriosema crinitum (Humb., Bonpl. \& Kunth) G. Don & CAMS 44 \& VCS & & $\mathrm{b}, \mathrm{r}$ & Neo \\
\hline Eriosema heterophyllum Benth. & CAMS 384 & $\mathrm{~T}$ & $\mathrm{c}, \mathrm{r}$ & S, SE \\
\hline Eriosema longifolium Benth. & VCS 4680 & & $\mathrm{c}$ & $\mathrm{Br}, \mathrm{Par}$ \\
\hline Galactia macrophylla (Benth.) Taub. & CAMS $507 \&$ VCS & & $\mathrm{c}$ & $\mathrm{Br}, \mathrm{Arg}, \mathrm{Par}$ \\
\hline Galactia neesii DC. & $\begin{array}{l}\text { CAMS } 391 \& \text { M } \\
\text { Godron }\end{array}$ & & $\mathrm{c}$ & $\begin{array}{l}\text { S, SE, Arg, } \\
\text { Par }\end{array}$ \\
\hline Indigofera asperifolia Bong. ex Benth. & VCS 4343 & & $\mathrm{r}$ & $\mathrm{AmS}$ \\
\hline Indigofera bongardiana (Kuntze) Burkart & CAMS $542 \&$ VCS & & $\mathrm{c}$ & $\mathrm{AmS}$ \\
\hline Lupinus sellowianus Harms & VCS 3291 & & $\mathrm{c}$ & S, SE \\
\hline
\end{tabular}




\begin{tabular}{|c|c|c|c|c|}
\hline DIVISÃO/Família/Espécie & Coletor & Estrutura & Hábitat & $\begin{array}{l}\text { Distribuiçã } \\
\text { o geográfica }\end{array}$ \\
\hline Mimosa aff. bocainae Barneby & VCS 6096 & & $\mathrm{c}$ & $\mathrm{SP}$ \\
\hline Mimosa cf. regnellii Benth. & VCS 3790 & & $\mathrm{c}$ & - \\
\hline Mimosa daleoides Benth. & CAMS $444 \&$ VCS & & $\mathrm{c}, \mathrm{r}$ & $\mathrm{AmS}$ \\
\hline Mimosa debilis Humb. \& Bonpl. ex Willd. & CAMS 666 & & $\mathrm{c}$ & $\mathrm{Neo}$ \\
\hline Mimosa dolens Vell. ssp. acerba var. acerba (Benth.) Barneby & $\begin{array}{l}\text { CAMS } 386 \& \text { M } \\
\text { Godron }\end{array}$ & E2 & $\mathrm{c}$ & $\mathrm{AmS}$ \\
\hline Mimosa dolens Vell. var. rudis (Benth.) Barneby. & CAMS 778 & E2 & $\mathrm{c}$ & S, SE, Par \\
\hline Mimosa dolens Vell. ssp. eriophylla (Benth.) Barneby & VCS 2176 & E2 & $\mathrm{b}$ & S, SE, LN \\
\hline Mimosa filipetiola Burkart & VCS 3264 & & $\mathrm{c}$ & S, SE, LN, i \\
\hline Mimosa furfuracea Benth. & CAMS $224 \&$ VCS & & $\mathrm{c}, \mathrm{r}$ & $\mathrm{Br}$ \\
\hline Mimosa hilariana Barneby & CAMS 423 \& VCS & & $\mathrm{b}$ & S, SE, LN \\
\hline Mimosa invisa Mart. ex Colla & VCS 2184 & & $\mathrm{r}$ & $\mathrm{AmS}$ \\
\hline Mimosa micropteris Benth. & CAMS $665 \&$ VCS & & $\mathrm{c}$ & S, SE, LN \\
\hline Mimosa orthacantha Benth. & VCS 4672 & & $\mathrm{c}$ & S, SE \\
\hline Mimosa paranapiacabae Barneby & CAMS $661 \&$ VCS & & $\mathrm{c}$ & $\mathrm{S}, \mathrm{SE}, \mathrm{LN}, \mathrm{i}$ \\
\hline Mimosa sp. 1 & VCS 7054 & & $\mathrm{r}$ & - \\
\hline Mimosa xanthocentra Mart. & CAMS $4 \&$ VCS & & $\mathrm{b}, \mathrm{c}, \mathrm{r}$ & $\mathrm{AmS}$ \\
\hline Periandra mediterranea (Vell.) Taub. & CAMS 64 & E4 & $\mathrm{c}, \mathrm{r}$ & $\mathrm{Br}$ \\
\hline Rhynchosia corylifolia Mart. ex Benth. * & CAMS $563 \&$ VCS & & $\mathrm{c}$ & $\mathrm{AmS}$ \\
\hline Rhynchosia melanocarpa Grear & CAMS 556 \& VCS & & $\mathrm{c}$ & $\mathrm{AmS}$ \\
\hline Senna pendula (Willd.) H.S. Irwin \& Barneby & CAMS $203 \&$ VCS & & $\mathrm{b}$ & $\mathrm{Neo}$ \\
\hline Senna rugosa (G. Don) H.S. Irwin \& Barneby & CAMS $18 \&$ VCS & & $\mathrm{r}$ & $\mathrm{AmS}$ \\
\hline Senna sp. 1 & CAMS 54 \& VCS & & $\mathrm{r}$ & - \\
\hline Stryphnodendron adstringens (Mart.) Coville & CAMS $149 \&$ VCS & & $\mathrm{c}, \mathrm{r}$ & $\mathrm{Br}$ \\
\hline Stylosanthes acuminata M.B. Ferr. \& Costa & VCS 4481 & & $\mathrm{r}$ & $\mathrm{AmS}$ \\
\hline Stylosanthes gracilis H.B.K. & CAMS 245 \& VCS & & $\mathrm{r}$ & Neo \\
\hline Stylosanthes guianensis (Aubl.) Sw. & VCS 4582 & & $\mathrm{r}$ & Pan \\
\hline Tephrosia rufescens Benth. * & CAMS 740 & & $\mathrm{c}$ & AmS \\
\hline Vigna venusta (Piper) Maréchal, Mascherpa \& Stainier & VCS 6165 & & $\mathrm{c}$ & $\mathrm{AmS}$ \\
\hline Zornia cryptantha Arechav. & CAMS $591 \&$ VCS & & $\mathrm{c}$ & $\mathrm{AmS}$ \\
\hline Zornia glabra Desv. & VCS 4485 & & $\mathrm{r}$ & $\mathrm{Br}$ \\
\hline Zornia ramboiana Mohlenbr. & CAMS 649 \& VCS & & $\mathrm{c}$ & S, SE, LN \\
\hline Zornia reticulata $\mathrm{Sm}$. & CAMS $592 \&$ VCS & & $\mathrm{b}, \mathrm{c}, \mathrm{r}$ & $\mathrm{Neo}$ \\
\hline \multicolumn{5}{|l|}{ GENTIANACEAE } \\
\hline Curtia conferta (Mart.) Knobl. & VCS 2380 & & $\mathrm{c}$ & S, SE \\
\hline Irlbachia alata (Aubl.) Maas & CAMS $128 \&$ VCS & & $\mathrm{c}$ & Neo \\
\hline Irlbachia oblongifolia (Mart.) Maas & VCS 2382 & & $\mathrm{c}$ & $\mathrm{Br}$ \\
\hline Irlbachia pedunculata (Cham. \& Schltdl.) Maas & CAMS $122 \&$ VCS & & $\mathrm{b}$ & $\mathrm{Br}$ \\
\hline Schultesia gracilis Mart. & PH Miyagi 339 & & $\mathrm{c}$ & $\mathrm{Br}, \mathrm{LS}$ \\
\hline Voyria aphylla (Jacq.) Pers. & CAMS $141 \&$ VCS & & $\mathrm{r}$ & Neo \\
\hline \multicolumn{5}{|l|}{ GESNERIACEAE } \\
\hline Sinningia aggregata (Ker Gawl.) Wiehler & J Mattos 12883 & & $\mathrm{c}$ & $\mathrm{Br}$, Par \\
\hline Sinningia allagophylla (Mart.) Wiehler & VCS 4402 & & $\mathrm{~b}$ & $\begin{array}{l}\text { Br, Arg, Par, } \\
\text { Uru }\end{array}$ \\
\hline Sinningia canescens (Mart.) Wiehler ** & VCS 4125 & & $\mathrm{c}$ & S, SE \\
\hline Sinningia elatior (Kunth) Chautems & $\begin{array}{l}\text { CAMS } 606 \& \text { M } \\
\text { Deur }\end{array}$ & & $\mathrm{b}, \mathrm{c}$ & $\mathrm{AmS}$ \\
\hline \multicolumn{5}{|l|}{ HALORAGACEAE } \\
\hline Laurembergia tetrandra (Schott) Kanitz & VCS 2455 & & $\mathrm{~b}$ & $\mathrm{Br}$ \\
\hline \multicolumn{5}{|l|}{ HYPERICACEAE } \\
\hline Hypericum brasiliense Choisy & CAMS $644 \&$ VCS & E1 & $\mathrm{b}, \mathrm{c}$ & AmS \\
\hline Hypericum connatum Lam. & VCS 3666 & & $\mathrm{~b}, \mathrm{c}$ & $\begin{array}{l}\text { S, SE, Arg, } \\
\text { Par, Uru }\end{array}$ \\
\hline Hypericum ternum A. St.-Hil. * & CMS 361 & & $\mathrm{c}$ & $\mathrm{S}, \mathrm{SE}$ \\
\hline \multicolumn{5}{|l|}{ IRIDACEAE } \\
\hline Alophia coerulea (Vell.) Chukr ${ }^{\#}$ & VCS 4706 & & $\mathrm{c}$ & $\mathrm{Br}$ \\
\hline Calydorea campestris (Klatt) Baker * & VCS 4562 & & $\mathrm{c}$ & $\begin{array}{l}\text { S, SE, Arg, } \\
\text { Par }\end{array}$ \\
\hline Crocosmia X crocosmiiflora (Lem. ex Morren) N.E.Br. & CAMS $634 \&$ VCS & & $\mathrm{b}$ & Sub \\
\hline Sisyrinchium commutatum Klatt & VCS 7370 & & $\mathrm{c}$ & Br, Par \\
\hline Sisyrinchium luzula Klotzsch ex Klatt & CAMS 547 \& VCS & & $\mathrm{c}$ & $\mathrm{Br}$ \\
\hline Sisyrinchium micranthum Cav. & VCS 4561 & & $\mathrm{~b}, \mathrm{c}$ & $\mathrm{Neo}$ \\
\hline Sisyrinchium palmifolium $\mathrm{L}$. & CAMS $535 \&$ VCS & & $\mathrm{c}$ & AmS \\
\hline Sisyrinchium restioides Spreng. ${ }^{*}$ & VCS 6103 & & $\mathrm{~b}, \mathrm{c}$ & S, SE, Uru \\
\hline
\end{tabular}




\begin{tabular}{|c|c|c|c|c|}
\hline DIVISÃO/Família/Espécie & Coletor & Estrutura & Hábitat & $\begin{array}{l}\text { Distribuiçã } \\
\text { o geográfica }\end{array}$ \\
\hline Sisyrinchium vaginatum Spreng. & CAMS $588 \&$ VCS & $\mathrm{G} 2$ & $\mathrm{c}$ & $\mathrm{AmS}$ \\
\hline Trimezia juncifolia (Klatt) Benth. \& Hook. & VCS 4685 & & $\mathrm{c}$ & $\mathrm{Br}$ \\
\hline Trimezia spathata (Klatt) Baker* & KD Barreto 3222 & & $\mathrm{r}$ & $\mathrm{Br}, \mathrm{Arg}, \mathrm{Par}$ \\
\hline \multicolumn{5}{|l|}{ JUNCACEAE } \\
\hline Juncus micranthus Schrad. ex E. Mey. & VCS 3696 & & $\mathrm{c}$ & $\mathrm{AmS}$ \\
\hline Juncus microcephalus H.B.K. & KD Barreto 2903 & & $\mathrm{~b}$ & Neo, LS \\
\hline \multicolumn{5}{|l|}{ LAMIACEAE } \\
\hline Aegiphila integrifolia (Jacq.) Moldenke & $\begin{array}{l}\text { CAMS } 615 \& \text { M } \\
\text { Deur }\end{array}$ & & $\mathrm{c}$ & Neo \\
\hline Aegiphila verticillata Vell. & CAMS 88 \& VCS & A1 & $\mathrm{c}$ & $\mathrm{AmS}$ \\
\hline Eriope crassipes Benth. & VCS 4256 & E2 & $\mathrm{c}, \mathrm{r}$ & $\mathrm{AmS}$ \\
\hline Eriope macrostachya Mart. ex Benth. & CAMS 463 \& VCS & & $\mathrm{c}$ & $\mathrm{AmS}$ \\
\hline Hoehnea sp. 1 & CAMS $106 \&$ VCS & & $\mathrm{c}$ & - \\
\hline Hypenia macrantha (A. St.-Hil. ex Benth.) Harley & KD Barreto 3174 & & $\mathrm{r}$ & AmS \\
\hline Hyptis brevipes Poit. & VCS 2203 & & $\mathrm{~b}$ & $\begin{array}{l}\text { Neo, Ásia } \\
\text { Tropical }\end{array}$ \\
\hline Hyptis caespitosa (Kuntze) A. St.-Hil. ex Benth. & CAMS 325 & & $\mathrm{c}$ & $\mathrm{Br}, \mathrm{Par}$ \\
\hline Hyptis cf. pulchella Briq. & VCS 7278 & & $\mathrm{c}$ & - \\
\hline Hyptis cf. tweedii Benth. & VCS 4643 & & $\mathrm{~b}$ & - \\
\hline Hyptis crinita Benth. & CAMS $571 \&$ VCS & & $\mathrm{b}, \mathrm{c}$ & $\mathrm{Br}, \mathrm{LS}$ \\
\hline Hyptis lantanifolia Poit. * & CAMS $26 \&$ VCS & & $\mathrm{r}$ & $\mathrm{Neo}$ \\
\hline Hyptis lappulacea Mart. ex Benth. & VCS 2319 & & $\mathrm{~b}$ & S, SE, Par \\
\hline Hyptis marrubioides Epling & CAMS $242 \&$ VCS & & $\mathrm{c}, \mathrm{r}$ & S, SE \\
\hline Hyptis plectranthoides Benth. & VCS 3489 & & c & $\mathrm{Br}$ \\
\hline Marsypianthes chamaedrys (Vahl) O. Kuntze & VCS 2512 & & $\mathrm{r}$ & $\mathrm{Neo}$ \\
\hline Peltodon rugosus Tolm. & VCS 3551 & & $\mathrm{c}$ & $\mathrm{S}, \mathrm{SE}, \mathrm{LN}$ \\
\hline Peltodon tomentosus Pohl & CAMS $256 \&$ VCS & & $\mathrm{r}$ & $\mathrm{Br}$ \\
\hline Rhabdocaulon lavanduloides (Benth.) Epling & CAMS $672 \&$ VCS & & $\mathrm{b}, \mathrm{c}$ & S, SE, LN \\
\hline Salvia nervosa Benth. & CMS 430 & & $\mathrm{c}$ & $\begin{array}{l}\text { S, SE, Arg, } \\
\text { Par, LN }\end{array}$ \\
\hline Vitex polygama Cham. & VCS 3909 & & $\mathrm{c}$ & $\mathrm{Br}$ \\
\hline \multicolumn{5}{|l|}{ LAURACEAE } \\
\hline Cinnamomum sellowianum (Nees \& Mart.) Kosterm. & VCS 4774 & & $\mathrm{c}$ & S, SE, LN \\
\hline Ocotea corymbosa (Meisn.) Mez & VCS 8686 & & $\mathrm{r}$ & SE, LS \\
\hline Ocotea lancifolia $($ Schott $) \mathrm{Mez}$ & VCS 3916 & & $\mathrm{c}$ & $\mathrm{Br}, \mathrm{Par}$ \\
\hline Ocotea porosa (Nees) Barroso ${ }^{\#}$ & KD Barreto 2969 & & c & S, SE, Par \\
\hline Ocotea pulchella (Nees) Mez & VCS 4823 & & $\mathrm{~b}, \mathrm{r}$ & $\begin{array}{l}\text { Br, Arg, Par, } \\
\text { Uru }\end{array}$ \\
\hline Ocotea tristis (Nees) Mez & VCS 6184 & & $\mathrm{c}, \mathrm{r}$ & S, SE \\
\hline Persea pyrifolia Nees & $\begin{array}{l}\text { CAMS 327e \& M } \\
\text { Godron }\end{array}$ & & $\mathrm{r}$ & $\mathrm{Br}$ \\
\hline Persea venosa Nees \& Mart. ex Nees & VCS 4376 & & $\mathrm{~b}, \mathrm{c}$ & $\mathrm{S}, \mathrm{SE}$ \\
\hline \multicolumn{5}{|l|}{ LENTIBULARIACEAE } \\
\hline Genlisea aurea A. St.-Hil. ** & VCS 8943 & & $\mathrm{~b}, \mathrm{c}$ & $\mathrm{Br}$ \\
\hline Genlisea repens Benj. ** & VCS 7211 & & $\mathrm{~b}$ & AmS \\
\hline Utricularia cucculata A. St.-Hil. \& Girard & VCS 8651 & & $\mathrm{~b}$ & AmS \\
\hline Utricularia gibba $\mathrm{L}$. & JP Souza 2041 & & $\mathrm{~b}$ & Pan \\
\hline Utricularia laxa A. St.-Hil. \& Girard & VCS 4030 & & $\mathrm{~b}$ & $\mathrm{AmS}$ \\
\hline Utricularia nervosa G. Weber ex Benj. & VCS 8774 & & $\mathrm{~b}$ & AmS \\
\hline Utricularia nigrescens Sylvén $* *$ & FR Lopes 414 & & $\mathrm{~b}$ & $\mathrm{Br}$ \\
\hline Utricularia praelonga A. St.-Hil. & VCS 7325 & & $\mathrm{~b}$ & $\mathrm{Br}, \mathrm{Arg}, \mathrm{Par}$ \\
\hline Utricularia subulata $\mathrm{L}$. & VCS 4202 & & $\mathrm{~b}$ & Pan \\
\hline Utricularia tricolor A. St.-Hil. & VCS 7209 & & $\mathrm{~b}$ & AmS \\
\hline \multicolumn{5}{|l|}{ LINACEAE } \\
\hline Linum brevifolium A. St.-Hil. \& Naudin & VCS 7333 & & $\mathrm{c}$ & S, SE \\
\hline \multicolumn{5}{|l|}{ LOGANIACEAE } \\
\hline Spigelia cf. martiana Cham. & VCS 7421 & & $\mathrm{c}$ & - \\
\hline \multicolumn{5}{|l|}{ LORANTHACEAE } \\
\hline Tripodanthus acutifolius (Ruiz \& Pav.) Thiegh. & VCS 4144 & & $\mathrm{c}$ & AmS \\
\hline \multicolumn{5}{|l|}{ LYTHRACEAE } \\
\hline Cuphea calophylla Cham. \& Schltdl. & CAMS 301 & & $\mathrm{~b}, \mathrm{c}$ & $\mathrm{AmS}$ \\
\hline Cuphea glutinosa Cham. \& Schltdl. & VCS 4415 & & $\mathrm{~b}, \mathrm{c}$ & $\mathrm{Br}$ \\
\hline Cuphea linarioides Cham. \& Schltdl. * & VCS 4373 & & $\mathrm{c}$ & $\mathrm{Br}$ \\
\hline Cuphea polymorpha A. St.-Hil. & CAMS $442 \&$ VCS & & $\mathrm{b}, \mathrm{c}$ & Br, Par \\
\hline
\end{tabular}




\begin{tabular}{|c|c|c|c|c|}
\hline DIVISÃO/Família/Espécie & Coletor & Estrutura & Hábitat & $\begin{array}{l}\text { Distribuiçã } \\
\text { o geográfica }\end{array}$ \\
\hline Cuphea racemosa (L. f.) Spreng. & VCS 7419 & & $\mathrm{c}$ & Neo \\
\hline Cuphea thymoides Cham. \& Schltdl. & CAMS $653 \&$ VCS & & $\mathrm{c}$ & S, SE, Arg \\
\hline Heimia myrtifolia Cham. \& Schltdl. & CAMS 300 & & $\mathrm{c}$ & $\begin{array}{l}\text { S, SE, Arg, } \\
\text { Uru }\end{array}$ \\
\hline Lafoensia nummularifolia A. St.-Hil. & CAMS 773 & & $\mathrm{c}$ & $\mathrm{SP}, \mathrm{PR}, \mathrm{LN}$ \\
\hline Lafoensia pacari A. St.-Hil. & CAMS $218 \&$ VCS & & $\mathrm{m}$ & $\mathrm{Br}$ \\
\hline \multicolumn{5}{|l|}{ MAGNOLIACEAE } \\
\hline Talauma ovata A. St.-Hil. & VCS 6211 & & $\mathrm{~m}$ & $\mathrm{AmS}$ \\
\hline \multicolumn{5}{|l|}{ MALPIGHIACEAE } \\
\hline Aspicarpa sericea (A. St.-Hil.) Nied. * & VCS 3550 & E2 & $\mathrm{b}, \mathrm{c}$ & $\mathrm{AmS}$ \\
\hline Banisteriopsis adenopoda (Juss.) B. Gates & CAMS $133 \&$ VCS & & $\mathrm{r}$ & $\mathrm{S}, \mathrm{SE}$ \\
\hline Banisteriopsis campestris (A. Juss.) Little & VCS 4586 & & $\mathrm{c}, \mathrm{r}$ & $\mathrm{Br}$ \\
\hline Banisteriopsis laevifolia (A. Juss.) B. Gates & CAMS $33 \&$ VCS & & $\mathrm{r}$ & $\mathrm{Br}, \mathrm{LS}$ \\
\hline Byrsonima brachybotrya Nied. ** & $\begin{array}{l}\text { CAMS } 600 \& \text { M } \\
\text { Deur }\end{array}$ & E5 & $\mathrm{c}$ & S, SE, LN \\
\hline Byrsonima cf. guilleminiana A. Juss. & CAMS 920e & & $\mathrm{c}$ & - \\
\hline Byrsonima coccolobifolia Humb., Bonpl. \& Kunth & CAMS 757 & & $\mathrm{~b}, \mathrm{r}$ & $\mathrm{AmS}$ \\
\hline Byrsonima intermedia Juss. & CAMS $401 \&$ VCS & E5 & $\mathrm{b}, \mathrm{c}, \mathrm{r}$ & $\mathrm{Br}, \mathrm{Par}$ \\
\hline Byrsonima salzmanniana Juss. & VCS 3620 & & $\mathrm{c}$ & $\mathrm{Br}$ \\
\hline Byrsonima verbascifolia (L.) Rich. ex A. Juss. & CAMS 630 \& VCS & & $\mathrm{c}, \mathrm{r}$ & $\mathrm{Neo}$ \\
\hline Heteropterys anceps Nied. & VCS 4588 & & $\mathrm{~b}$ & S, SE, Par \\
\hline Tetrapterys multiglandulosa A. Juss. & CAMS $629 \&$ VCS & & $\mathrm{r}$ & $\mathrm{AmS}$ \\
\hline Tetrapterys salicifolia (A. Juss.) Nied. & VCS 7108 et al & & $\mathrm{r}$ & $\mathrm{S}, \mathrm{SE}$ \\
\hline \multicolumn{5}{|l|}{ MALVACEAE } \\
\hline Byttneria hatschbachii Cristóbal & CMS 442 & & $\mathrm{c}$ & $\mathrm{S}, \mathrm{SE}, \mathrm{LN}, \mathrm{i}$ \\
\hline Corchorus sp. 1 & CAMS $263 \&$ VCS & & $\mathrm{r}$ & - \\
\hline Krapovickasia macrodon (DC.) Fryxell & $\begin{array}{l}\text { CAMS } 291 \& \text { M } \\
\text { Godron }\end{array}$ & $\mathrm{T}$ & $\mathrm{c}$ & $\mathrm{AmS}$ \\
\hline Pavonia communis A. St.-Hil. & VCS 3869 & & $\mathrm{c}$ & $\mathrm{AmS}$ \\
\hline Pavonia reticulata Garcke * & VCS 7033 & & $\mathrm{r}$ & $\begin{array}{l}\text { S, SE, Uru, } \\
\text { LN }\end{array}$ \\
\hline Peltaea polymorpha (A. St.-Hil.) Krapov. \& Cristóbal & VCS 4577 & & $\mathrm{~b}$ & $\mathrm{AmS}$ \\
\hline Peltaea speciosa (Humb., Bonpl. \& Kunth) Krapov. \& Cristóbal & CAMS $185 \&$ VCS & & $\mathrm{b}, \mathrm{r}$ & $\mathrm{AmS}$ \\
\hline Sida cordifolia $\mathrm{L}$. & CAMS 631 & & $\mathrm{r}$ & Pan \\
\hline Sida glaziovii K. Schum. & CAMS $11 \&$ VCS & & $\mathrm{r}$ & $\mathrm{AmS}$ \\
\hline Sida linifolia Cav. & VCS 4608 & & $\mathrm{~b}$ & $\mathrm{Neo}, \mathrm{Af}$ \\
\hline Waltheria cf. douradinha A. St.-Hil. & CAMS 405 & & $\mathrm{c}$ & - \\
\hline Waltheria communis A. St.-Hil. & VCS 4593 & & $\mathrm{r}$ & $\mathrm{AmS}$ \\
\hline \multicolumn{5}{|l|}{ MARCGRAVIACEAE } \\
\hline Marcgravia polyantha Delp. & KD Barreto 3254 & & $\mathrm{c}$ & $\mathrm{S}, \mathrm{SE}$ \\
\hline \multicolumn{5}{|l|}{ MAYACACEAE } \\
\hline Mayaca sellowiana Kunth & VCS 2397 & & $\mathrm{c}$ & $\mathrm{AmS}$ \\
\hline \multicolumn{5}{|l|}{ MELASTOMATACEAE } \\
\hline Acisanthera alsinaefolia Triana & CAMS 1066 & $\mathrm{E} 2$ & $\mathrm{~b}, \mathrm{c}$ & $\mathrm{AmS}$ \\
\hline Cambessedesia hilariana (A. St.-Hil. ex Bonpl.) DC. & CAMS 93 \& VCS & & $\mathrm{c}$ & $\mathrm{Br}$ \\
\hline Chaetostoma pungens Mart. \& Schrad. ex DC. & VCS 3847 & & $\mathrm{c}$ & $\mathrm{Br}$ \\
\hline Lavoisiera bergii Cogn. * & VCS 4026 & & $\mathrm{c}$ & $\mathrm{Br}$ \\
\hline Lavoisiera phyllocalycina Cogn. ${ }^{* *}$ & CAMS 1045 & & $\mathrm{c}$ & S, SE, LN \\
\hline Lavoisiera pulchella Cham. ** & VCS 2313 & E3 & $\mathrm{b}, \mathrm{c}$ & $\mathrm{S}, \mathrm{SE}, \mathrm{LN}$ \\
\hline Leandra aurea Cogn. & VCS 4090 & & $\mathrm{~b}, \mathrm{c}, \mathrm{r}$ & $\mathrm{Br}, \mathrm{Bol}$ \\
\hline Leandra balansae Cogn. & VCS 4833 & & $\mathrm{c}$ & $\begin{array}{l}\text { S, SE, Arg, } \\
\text { Par }\end{array}$ \\
\hline Leandra dispar (Gardn.) Cogn. & VCS 6192 & & $\mathrm{c}$ & $\mathrm{S}, \mathrm{SE}$ \\
\hline Leandra erostrata (DC.) Cogn. & VCS 2174 & E2 & $\mathrm{b}, \mathrm{c}, \mathrm{r}$ & $\mathrm{AmS}$ \\
\hline Leandra hirtella Cogn. & VCS 3529 & E2 & $\mathrm{b}, \mathrm{c}$ & $\mathrm{S}, \mathrm{SE}, \mathrm{LN}$ \\
\hline Leandra lacunosa Cogn. & VCS 4095 & & $\mathrm{~b}, \mathrm{c}$ & $\mathrm{AmS}$ \\
\hline Leandra paulina (Schrank \& Mart.) DC. & VCS 2350 & E2 & $\mathrm{b}$ & $\mathrm{S}, \mathrm{SE}$ \\
\hline Leandra polystachya (Naud.) Cogn. & VCS 6057 & & $\mathrm{~b}$ & $\mathrm{Br}$ \\
\hline Leandra salicina (DC.) Cogn. & JM Torezan 716 & & $\mathrm{c}$ & SE, PR, GO \\
\hline Leandra simplicicaulis (Naud.) Cogn. & CAMS $148 \&$ VCS & & $\mathrm{r}$ & $\mathrm{S}, \mathrm{SE}, \mathrm{LN}$ \\
\hline Leandra sp. 4 & VCS 4440 & & $\mathrm{c}$ & - \\
\hline Miconia albicans (Sw.) Triana & VCS 4581 & & $\mathrm{c}, \mathrm{r}$ & $\mathrm{Neo}$ \\
\hline Miconia cf. cinerascens Miq. & $\begin{array}{l}\text { CAMS } 293 \& \text { M } \\
\text { Godron }\end{array}$ & & $\mathrm{r}$ & - \\
\hline
\end{tabular}




\begin{tabular}{|c|c|c|c|c|}
\hline DIVISÃO/Família/Espécie & Coletor & Estrutura & Hábitat & $\begin{array}{l}\text { Distribuiçã } \\
\text { o geográfica }\end{array}$ \\
\hline Miconia chamissois Naudin & VCS 6199 & & $\mathrm{~b}, \mathrm{c}$ & $\mathrm{AmS}$ \\
\hline Miconia hyemalis A. St.-Hil. \& Naudin ex Naudin & CAMS $231 \&$ VCS & & $\mathrm{c}, \mathrm{r}$ & $\begin{array}{l}\text { S, SE, Uru, } \\
\text { LN }\end{array}$ \\
\hline Miconia latecrenata (DC.) Naudin & $\begin{array}{l}\text { CAMS } 294 \& \text { M } \\
\text { Godron }\end{array}$ & & $\mathrm{r}$ & $\mathrm{Br}$ \\
\hline Miconia ligustroides (DC.) Naudin & CAMS $246 \&$ VCS & & $\mathrm{r}$ & $\mathrm{Br}$ \\
\hline Miconia sellowiana (Cham.) Naudin & VCS 4628 & & $\mathrm{~b}, \mathrm{c}$ & $\mathrm{Br}$ \\
\hline Miconia stenostachya Schrank \& Mart. ex DC. & VCS 6200 & & $\mathrm{c}$ & Neo \\
\hline Miconia theaezans (Bonpl.) Cogn. & VCS 6210 & & $\mathrm{~b}, \mathrm{c}$ & Neo \\
\hline Microlepis oleifolia (Schrank \& Mart. ex DC.) Triana & CAMS 118 \& VCS & E4 & $\mathrm{b}$ & $\mathrm{Br}$ \\
\hline Microlicia humilis Naudin * & VCS 4576 & & $\mathrm{~b}$ & SP? \\
\hline Microlicia myrtoidea Cham. & VCS 4655 & & $\mathrm{~b}$ & S, SE \\
\hline Rhynchantera cordata DC. & VCS 3524 & & $\mathrm{~b}, \mathrm{c}$ & $\mathrm{AmS}$ \\
\hline Tibouchina cerastifolia (Naud.) Cogn. & CAMS 888 & & $\mathrm{c}$ & $\mathrm{AmS}$ \\
\hline Tibouchina chamissoana Cogn. & CMS 371 & & $\mathrm{c}$ & S, SE \\
\hline Tibouchina gracilis (Bonpl.) Cogn. & VCS 3221 & E2 & $\mathrm{c}, \mathrm{r}$ & $\mathrm{AmS}$ \\
\hline Tibouchina hatschbachii Wurdack & $\begin{array}{l}\text { CAMS } 617 \& \text { M } \\
\text { Deur }\end{array}$ & & $\mathrm{c}$ & S, SE, LN \\
\hline Tibouchina herbacea (DC.) Cogn. & CAMS $110 \&$ VCS & & $\mathrm{c}$ & $\mathrm{AmS}$ \\
\hline Tibouchina martialis (Cham.) Cogn. & VCS 3508 & & $\mathrm{c}$ & $\mathrm{Br}, \mathrm{Bol}$ \\
\hline Tibouchina ursina (Cham.) Cogn. * & CAMS 87 \& VCS & & $\mathrm{b}, \mathrm{c}$ & S, SE \\
\hline Trembleya parviflora Cogn. & CAMS 1057 & A1 & $\mathrm{b}, \mathrm{c}$ & $\mathrm{Br}$ \\
\hline Trembleya phlogiformis DC. * & CAMS $650 \&$ VCS & & $\mathrm{c}$ & $\mathrm{Br}$ \\
\hline \multicolumn{5}{|l|}{ MENISPERMACEAE } \\
\hline Cissampelos ovalifolia DC. & VCS 4911 & & $\mathrm{c}$ & AmS \\
\hline \multicolumn{5}{|l|}{ MENYANTHACEAE } \\
\hline Nymphoides indica (L.) Kuntze & VCS 3273 & & $\mathrm{~b}$ & Af \\
\hline \multicolumn{5}{|l|}{ MORACEAE } \\
\hline Brosimum gaudichaudii Trécul & VCS 4629 & & $\mathrm{~b}, \mathrm{r}$ & $\mathrm{Br}$ \\
\hline \multicolumn{5}{|l|}{ MYRSINACEAE } \\
\hline Anagallis filiformis Cham. \& Schltdl. & VCS 2261 & & $\mathrm{~b}, \mathrm{c}$ & AmS \\
\hline Myrsine coriacea (Sw.) R.Br. ex Roem. \& Schult. & CAMS $260 \&$ VCS & & $\mathrm{m}$ & AmS \\
\hline Myrsine gardneriana A. DC. & VCS 4274 & & $\mathrm{~b}, \mathrm{c}$ & $\mathrm{Br}$ \\
\hline Myrsine guianensis (Aubl.) Kuntze & VCS 3643 & & $\mathrm{c}, \mathrm{r}$ & Neo \\
\hline Myrsine umbellata Mart. & CMS 495 & & $\mathrm{r}$ & $\mathrm{Br}$ \\
\hline \multicolumn{5}{|l|}{ MYRTACEAE } \\
\hline Blepharocalyx salicifolius (Humb., Bonpl. \& Kunth) O. Berg. & VCS 4435 & & $\mathrm{c}$ & AmS \\
\hline Calypthranthes grandifolia O. Berg & $\begin{array}{l}\text { CAMS 396e \& M } \\
\text { Godron }\end{array}$ & & $\mathrm{r}$ & S, SE \\
\hline Campomanesia adamantium (Cambess.) O. Berg & VCS 7407 & & $\mathrm{~m}$ & Br, Par \\
\hline Campomanesia aurea $\mathrm{O}$. Berg & FF Mazine 1034 & & $\mathrm{r}$ & $\begin{array}{l}\text { S, SE, Arg, } \\
\text { Uru, LN }\end{array}$ \\
\hline Campomanesia guaviroba (DC.) Kiaersk. & FF Mazine 1048 & & $\mathrm{r}$ & $\begin{array}{l}\text { S, SE, Arg, } \\
\text { Par }\end{array}$ \\
\hline Campomanesia pubescens (DC.) O. Berg. & CAMS $580 \&$ VCS & E4 & $\mathrm{c}, \mathrm{r}$ & $\mathrm{Br}, \mathrm{Par}$ \\
\hline Campomanesia xanthocarpa O. Berg & VCS 4114 & & $\mathrm{c}$ & $\begin{array}{l}\text { S, SE, Arg, } \\
\text { Par }\end{array}$ \\
\hline Eugenia bimarginata $\mathrm{DC}$. & CAMS $452 \&$ VCS & & $\mathrm{c}, \mathrm{r}$ & Neo \\
\hline Eugenia calycina Cambess. & FF Mazine 1025 & & $\mathrm{r}$ & $\mathrm{Br}$ \\
\hline Eugenia dysenterica DC. * & VCS s.n. & & $\mathrm{r}$ & $\mathrm{AmS}$ \\
\hline Eugenia florida DC. & $\begin{array}{l}\text { CAMS } 398 \& \text { M } \\
\text { Godron }\end{array}$ & & $\mathrm{r}$ & Neo \\
\hline Eugenia involucrata DC. & CAMS $581 \&$ VCS & & $\mathrm{c}$ & $\begin{array}{l}\text { S, SE, Arg, } \\
\text { Par, Uru }\end{array}$ \\
\hline Eugenia jaguariaivensis Mattos & VCS 4422 & & $\mathrm{~b}, \mathrm{r}$ & $\begin{array}{l}\text { Endêmica } \\
\text { Itararé, } \\
\text { Jaguariaíva }\end{array}$ \\
\hline Eugenia pitanga $(\mathrm{O}$. Berg.) Kiaersk. & CAMS $546 \&$ VCS & & $\mathrm{c}, \mathrm{r}$ & $\begin{array}{l}\text { S, SE, Arg, } \\
\text { Uru }\end{array}$ \\
\hline Eugenia punicifolia (Humb., Bonpl. \& Kunth) DC. & CAMS 433 \& VCS & & $\mathrm{b}, \mathrm{c}, \mathrm{r}$ & Neo \\
\hline Eugenia pyriformis Cambess. & CAMS $1003 \mathrm{e}$ & & $\mathrm{c}$ & $\begin{array}{l}\text { S, SE, Arg, } \\
\text { Par }\end{array}$ \\
\hline Eugenia suberosa Cambess. & VCS 3224 & & $\mathrm{c}$ & $\mathrm{S}, \mathrm{SE}$ \\
\hline Eugenia uniflora $\mathrm{L}$. & CAMS $241 \&$ VCS & & $\mathrm{c}, \mathrm{r}$ & $\begin{array}{l}\text { S, SE, Arg, } \\
\text { Uru }\end{array}$ \\
\hline Hexachlamys hamiltonii Mattos & VCS 3548 & & $\mathrm{c}$ & $\mathrm{S}, \mathrm{SE}, \mathrm{LN}$ \\
\hline
\end{tabular}




\begin{tabular}{|c|c|c|c|c|}
\hline DIVISÃO/Família/Espécie & Coletor & Estrutura & Hábitat & $\begin{array}{l}\text { Distribuiçã } \\
\text { o geográfica }\end{array}$ \\
\hline Hexachlamys humilis O. Berg & VCS 2436 & & $\mathrm{c}$ & $\begin{array}{l}\text { S, SE, Uru, } \\
\text { LN }\end{array}$ \\
\hline Hexachlamys itararensis Mattos & VCS 3735 & & $\mathrm{c}$ & Endêmica? \\
\hline Marlierea laevigata $(\mathrm{DC}$.$) Kiaersk.$ & CMS 367 & & $\mathrm{c}$ & $\mathrm{S}, \mathrm{SE}$ \\
\hline Myrceugenia franciscensis (O.Berg.) Landrum & VCS 2373 & & $\mathrm{c}, \mathrm{m}$ & $\begin{array}{l}\text { Endêmica } \\
\text { Itararé, } \\
\text { Jaguariaíva }\end{array}$ \\
\hline Myrceugenia ovata (Burret) Landrum & J. Mattos $14900-$ SP & & $\mathrm{c}$ & S, SE \\
\hline Myrceugenia rufescens (DC.) D. Legrand et Kraus & J. Mattos 14106 - SP & & $\mathrm{c}$ & SP \\
\hline Myrcia breviramis (O. Berg) D. Legrand & VCS 4750 & & $\mathrm{c}, \mathrm{m}, \mathrm{r}$ & S, SE, LN \\
\hline Myrcia cf. calumbaensis Kiaersk. & CAMS $237 \&$ VCS & & $\mathrm{c}$ & - \\
\hline Myrcia guianensis (Aubl.) DC. & VCS 4429 & & $\mathrm{c}$ & $\mathrm{AmS}$ \\
\hline Myrcia multiflora (Lam.) DC. & VCS 4471 & & $\mathrm{r}$ & AmS \\
\hline Myrcia retorta Cambess. & F Chung 160 & & $\mathrm{c}$ & S, SE \\
\hline Myrcia richardiana $\mathrm{O}$. Berg & CAMS $632 \&$ VCS & & $\mathrm{r}$ & S, SE \\
\hline Myrcia rostrata DC. & VCS 4594 & & $\mathrm{~b}, \mathrm{r}$ & $\mathrm{AmS}$ \\
\hline Myrcia venulosa DC. & VCS 4445 & & $\mathrm{c}, \mathrm{r}$ & $\mathrm{Br}$ \\
\hline Myrciaria cuspidata O. Berg & VCS 2493 & & $\mathrm{c}$ & $\mathrm{AmS}$ \\
\hline Myrciaria delicatula $\mathrm{O}$. Berg & CMS 369 & & $\mathrm{c}$ & $\begin{array}{l}\text { S, SE, Arg, } \\
\text { Par }\end{array}$ \\
\hline Myrciaria floribunda (West. ex Willd.) O. Berg. & $\begin{array}{l}\text { CAMS } 395 \& \text { M } \\
\text { Godron }\end{array}$ & & $\mathrm{r}$ & Neo \\
\hline Psidium australe Cambess. & VCS 6023 & & $\mathrm{c}$ & $\begin{array}{l}\text { S, SE, Arg, } \\
\text { Par }\end{array}$ \\
\hline Psidium cf. cuneatum Cambess. & FF Mazine 1037 & & $\mathrm{r}$ & - \\
\hline Psidium cinereum Mart. ex DC. & $\begin{array}{l}\text { CAMS } 400 \& \mathrm{M} \\
\text { Godron }\end{array}$ & & $\mathrm{c}, \mathrm{r}$ & $\mathrm{AmS}$ \\
\hline Psidium luridum (Spreng.) Burret & VCS 3292 & & $\mathrm{c}$ & $\begin{array}{l}\text { S, SE, Arg, } \\
\text { Par }\end{array}$ \\
\hline Psidium pilosum Vell. & CAMS 1006 & & $\mathrm{c}$ & SE?, LS? \\
\hline Psidium suffruticosum $\mathrm{O}$. Berg & VCS 4615 & & $\mathrm{~b}$ & $\mathrm{~S}, \mathrm{SE}$ \\
\hline Psidium warmingianum Kiaersk. & VCS 7244 & & $\mathrm{r}$ & S, SE \\
\hline \multicolumn{5}{|l|}{ OCHNACEAE } \\
\hline Ouratea aff. salicifolia (A. St.-Hil \& Tul.) Engl. & CAMS $519 \&$ VCS & & $\mathrm{c}$ & $\mathrm{Br}, \mathrm{Bol}$ \\
\hline Ouratea cf. humilis (A. St.-Hil.) Engl. & CAMS $430 \&$ VCS & & $\mathrm{c}, \mathrm{r}$ & - \\
\hline Ouratea spectabilis (Mart.) Engl. & CAMS $564 \&$ VCS & & $\mathrm{c}$ & $\mathrm{Br}, \mathrm{Bol}$ \\
\hline Sauvagesia erecta $\mathrm{L}$. & VCS 32107 & & $\mathrm{~b}$ & Neo, Af \\
\hline Sauvagesia racemosa A. St.-Hil. & CAMS 57 \& VCS & & $\mathrm{c}, \mathrm{r}$ & AmS \\
\hline \multicolumn{5}{|l|}{ ONAGRACEAE } \\
\hline Fuchsia regia (Vand.) Munz & VCS 2359 & & $\mathrm{~m}$ & S, SE \\
\hline Ludwigia nervosa (Poir. ex Lam.) Hara & CAMS $24 \&$ VCS & & $\mathrm{b}, \mathrm{r}$ & Neo \\
\hline Ludwigia peruviana (L.) Hara & CAMS 636 \& VCS & & $\mathrm{b}$ & Neo, Ásia \\
\hline \multicolumn{5}{|l|}{ ORCHIDACEAE } \\
\hline Bifrenaria harrisoniae (Hook.) Rchb. f. & CMS 350 & & $\mathrm{c}$ & S, SE, LN \\
\hline Cleistes sp. 1 & CAMS 896e & & $\mathrm{c}$ & - \\
\hline Cyanaeorchis arundinae (Rchb. f.) Barb. Rodr. * & VCS 7230 & & $\mathrm{c}$ & $\mathrm{Br}, \mathrm{Par}$ \\
\hline Epidendrum aquaticum Lindl. & VCS 4656 & & $\mathrm{~b}$ & $\mathrm{Neo}$ \\
\hline Epidendrum elongatum Jacq. & CAMS $120 \&$ VCS & & $\mathrm{c}$ & Neo \\
\hline Epistephium cf. sclerophyllum Lindl. & CAMS $180 \&$ VCS & & $\mathrm{b}$ & - \\
\hline Epistephium sp. 1 & CAMS 897e & & $\mathrm{c}$ & - \\
\hline Eulophia alta (L.) Fawc. \& Rendle & PH Miyagi 622 & & $\mathrm{c}$ & $\mathrm{Am}$ \\
\hline Habenaria balansae Cogn. & VCS 7208 & & $\mathrm{c}$ & Br, Par \\
\hline Habenaria cf. sceptrum Schltr. & VCS 3651 & & $\mathrm{c}$ & - \\
\hline Habenaria edwallii Cogn. * & VCS 4708 & & $\mathrm{c}$ & $\mathrm{Br}$ \\
\hline Habenaria loefgrenii Cogn. & VCS 2451 & & $\mathrm{c}$ & SP \\
\hline Habenaria parviflora Lindl. & VCS 4659 & & $\mathrm{~b}$ & $\begin{array}{l}\text { S, SE, Arg, } \\
\text { Par, Uru }\end{array}$ \\
\hline Habenaria setacea Lindl. & PH Miyagi 303 & & $\mathrm{c}$ & $\mathrm{AmS}$ \\
\hline Oncidium blanchetii Rchb. f. & VCS 4777 & & $\mathrm{c}$ & AmS \\
\hline Pelexia sp. & VCS 4698 & & $\mathrm{c}$ & - \\
\hline Stenorrhynchos cf. paraguayensis (Rchb. f.) Cogn. & VCS 3689 & & $\mathrm{c}$ & - \\
\hline Stenorrhynchos lanceolatum (Aubl.) Rich. ex Spreng & VCS 4385 & & $\mathrm{c}$ & Neo \\
\hline Zygopetalum mackayi Hook. & VCS 4105 & & $\mathrm{c}$ & $\mathrm{Br}$ \\
\hline Zygopetalum sellowii Rchb. f. *** & VCS 4761 & & $\mathrm{c}$ & $\mathrm{Br}$ \\
\hline OROBANCHACEAE & & & & \\
\hline
\end{tabular}




\begin{tabular}{|c|c|c|c|c|}
\hline DIVISÃO/Família/Espécie & Coletor & Estrutura & Hábitat & $\begin{array}{l}\text { Distribuiçã } \\
\text { o geográfica }\end{array}$ \\
\hline Buchnera juncea Cham. \& Schltdl. * & CAMS $104 \&$ VCS & & $\mathrm{c}, \mathrm{r}$ & $\mathrm{Br}, \mathrm{Par}$ \\
\hline Buchnera lavandulacea Cham. \& Schltdl. & VCS 6059 & & $\mathrm{~b}$ & $\mathrm{Br}, \mathrm{Par}$ \\
\hline Buchnera longifolia Kunth ** & VCS 2456 & & $\mathrm{c}$ & Neo \\
\hline Buchnera ternifolia Kunth & VCS 4418 & & $\mathrm{~b}$ & AmS \\
\hline Esterhazya nervosa Benth. & CAMS $181 \&$ VCS & & $\mathrm{b}, \mathrm{c}$ & $\mathrm{Br}$ \\
\hline Esterhazya splendida Mikan & $\begin{array}{l}\text { CAMS } 613 \& \text { M } \\
\text { Deur }\end{array}$ & & $\mathrm{c}$ & Br, Par \\
\hline \multicolumn{5}{|l|}{ OXALIDACEAE } \\
\hline Oxalis conorrhiza (Feuillée) Jacq. & VCS 4483 & & $\mathrm{c}, \mathrm{r}$ & S, SE, LN \\
\hline Oxalis myriophylla A. St.-Hil. & CAMS $267 \&$ VCS & & $\mathrm{c}$ & S, SE, LN \\
\hline Oxalis rupestris A. St.-Hil. & VCS 4353 & & $\mathrm{c}$ & $\mathrm{AmS}$ \\
\hline Oxalis tenerrima $\mathrm{R}$. Knuth & VCS 7126 & & $\mathrm{r}$ & $\mathrm{AmS}$ \\
\hline \multicolumn{5}{|l|}{ PASSIFLORACEAE } \\
\hline Passiflora amethystina J.C. Mikan & VCS 6123 & & $\mathrm{c}$ & AmS \\
\hline Passiflora haematostigma Mart. ex Mast. & CMS 385 & & $\mathrm{c}$ & $\mathrm{Br}$ \\
\hline Passiflora lepidota Mast. & VCS 4677 & & $\mathrm{c}$ & S, SE, LN \\
\hline \multicolumn{5}{|l|}{ PHYLLANTHACEAE } \\
\hline Phyllanthus niruri $\mathrm{L}$. & VCS 7428 & & $\mathrm{c}$ & Pan \\
\hline \multicolumn{5}{|l|}{ PHYTOLACCACEAE } \\
\hline Phytolacca thyrsiflora Fenzl ex Schmidt & CAMS $228 \&$ VCS & & $\mathrm{r}$ & $\mathrm{Neo}$ \\
\hline \multicolumn{5}{|l|}{ PIPERACEAE } \\
\hline Peperomia sp. & CAMS $261 \&$ VCS & & $\mathrm{m}$ & - \\
\hline \multicolumn{5}{|l|}{ PLANTAGINACEAE } \\
\hline Mercadonia serpylloides (Cham. \& Schltdl.) Pennell & VCS 2229 & & $\mathrm{~b}$ & S, SE \\
\hline Plantago australis Lam. & VCS 7224 & & $\mathrm{r}$ & Neo \\
\hline Plantago guilleminiana Decne. $*$ & VCS 4157 & & $\mathrm{c}$ & S, SE \\
\hline Plantago lanceolata $\mathrm{L}$. & CAMS $1170 \mathrm{e}$ & & $\mathrm{c}$ & Sub \\
\hline Scoparia dulcis L. & CAMS 1094 & & $\mathrm{~b}, \mathrm{c}$ & Pan \\
\hline \multicolumn{5}{|l|}{ POACEAE } \\
\hline Agenium leptocladum (Hack.) Clayton ** & VCS 3809 & $\mathrm{G} 2$ & $\mathrm{c}$ & $\mathrm{Br}, \mathrm{Arg}, \mathrm{Par}$ \\
\hline Agenium villosum (Nees) Pilger & VCS 3883 & & $\mathrm{c}$ & Br, Arg, Par \\
\hline Agrostis longiberbis Hack. ex L.B. Sm. & VCS 2294 & & $\mathrm{~b}, \mathrm{c}$ & S, SE \\
\hline Agrostis montevidensis Spreng. ex Nees & CAMS 687 & & $\mathrm{c}$ & $\mathrm{AmS}$ \\
\hline Andropogon bicornis $\mathrm{L}$. & CAMS 53 \& VCS & & $\mathrm{c}, \mathrm{r}$ & Neo \\
\hline Andropogon laterallis Nees & CAMS 698 & G3 & $\mathrm{c}$ & $\mathrm{AmS}$ \\
\hline Andropogon leucostachyus Kunth & CAMS $130 \&$ VCS & G2 & $\mathrm{b}, \mathrm{c}$ & $\mathrm{Neo}$ \\
\hline Andropogon macrothrix Trin. & $\begin{array}{l}\text { HM Longhi-Wagner } \\
3188\end{array}$ & & $\mathrm{~b}$ & $\mathrm{AmS}$ \\
\hline Andropogon selloanus (Hack.) Hack. & CAMS 271 & & $\mathrm{~b}, \mathrm{c}$ & $\mathrm{Neo}$ \\
\hline Aristida filifolia (Arechav.) Herter ** & CAMS 1182e & & $\mathrm{c}$ & $\begin{array}{l}\text { S, SE, Uru, } \\
\text { LN }\end{array}$ \\
\hline Aristida jubata (Arechav.) Herter & CAMS 413 & G2 & $\mathrm{c}$ & AmS \\
\hline Aristida megapotamica Spreng. & CAMS 8 \& VCS & G3 & $\mathrm{r}$ & $\mathrm{AmS}$ \\
\hline Arundinella hispida (Willd.) Kuntze & CAMS 449 \& VCS & & $\mathrm{b}$ & Neo \\
\hline Axonopus brasiliensis (Spreng.) Kuhlm. & VCS 3748 & G2 & $\mathrm{c}$ & $\mathrm{Br}$, Par \\
\hline Axonopus marginatus (Trin.) Chase $*$ & CAMS 781 & G3 & $\mathrm{c}$ & $\mathrm{AmS}$ \\
\hline Axonopus pellitus (Nees ex Trin.) Hitchc. \& Chase * & CAMS 28 \& VCS & & $\mathrm{r}$ & S, SE, LN \\
\hline Axonopus pressus (Steud.) Parodi & CAMS 772 & G2 & $\mathrm{c}$ & $\mathrm{Br}, \mathrm{Par}$ \\
\hline Axonopus siccus (Nees) Kuhlm. * & $\begin{array}{l}\text { CAMS } 275 \& \mathrm{M} \\
\text { Godron }\end{array}$ & G3 & $\mathrm{b}$ & AmS \\
\hline Briza calotheca (Trin.) Hack. & VCS 4303 & & $\mathrm{~b}$ & AmS \\
\hline Briza uniolae (Nees) Nees ex Steud. & VCS 4530 & & $\mathrm{~b}$ & $\mathrm{Br}$, Arg, Par \\
\hline Bromus brachyanthera Döll & VCS 4545 & & $\mathrm{~m}$ & $\begin{array}{l}\text { S, SE, Arg, } \\
\text { Uru }\end{array}$ \\
\hline Calamagrostis viridiflavescens (Poir.) Steud. & CAMS 273 & G3 & $\mathrm{c}$ & AmS \\
\hline Ctenium polystachyum Balansa $*$ & CAMS $156 \&$ VCS & & $\mathrm{r}$ & S, SE, Par \\
\hline Cynodon dactylon (L.) Pers. & $\begin{array}{l}\text { M Kuhlmann } 1431 \text { - } \\
\text { SP }\end{array}$ & & $\mathrm{c}$ & Cosmo \\
\hline Digitaria insularis (L.) Fedde & CAMS 731 & & $\mathrm{c}$ & Neo \\
\hline Elionurus muticus (Spreng.) Kuntze & VCS 4297 & G3 & $\mathrm{c}$ & Af \\
\hline Eragrostis airoides Nees & $\begin{array}{l}\text { HM Longhi-Wagner } \\
3200\end{array}$ & & $\mathrm{c}$ & $\mathrm{Am}$ \\
\hline Eragrostis bahiensis Schult. & JR Mattos 12846 & & $\mathrm{~b}$ & $\mathrm{Am}$ \\
\hline Eragrostis leucosticta Nees ex Döll & CAMS $249 \&$ VCS & & $\mathrm{c}, \mathrm{r}$ & $\mathrm{Br}$ \\
\hline
\end{tabular}




\begin{tabular}{|c|c|c|c|c|}
\hline DIVISÃO/Família/Espécie & Coletor & Estrutura & Hábitat & $\begin{array}{l}\text { Distribuiçã } \\
\text { o geográfica }\end{array}$ \\
\hline Eragrostis lugens Nees & VCS 3630 & G2 & $\mathrm{c}$ & $\mathrm{Am}$ \\
\hline Eragrostis neesii Trin. ** & VCS 2896 & & $\mathrm{c}$ & $\mathrm{AmS}$ \\
\hline Eragrostis perennis Döll & VCS 4295 & & $\mathrm{c}$ & $\mathrm{AmS}$ \\
\hline Eragrostis plana Nees & $\begin{array}{l}\text { HM Longhi-Wagner } \\
3060\end{array}$ & & $\mathrm{c}$ & Sub \\
\hline Eragrostis polytricha Nees & VCS 4480 & & $\mathrm{r}$ & $\mathrm{Am}$ \\
\hline Eragrostis rufescens Schrad. ex Schult. & M Kuhlmann 1383 & & $\mathrm{c}, \mathrm{r}$ & Neo \\
\hline Eragrostis seminuda Trin. & $\begin{array}{l}\text { CAMS } 270 \& \text { M } \\
\text { Godron }\end{array}$ & & $\mathrm{c}$ & $\mathrm{Br}$, Arg, Par \\
\hline Eriochrysis cayennensis P. Beauv. & VCS 2263 & & $\mathrm{~b}$ & Neo \\
\hline Eriochrysis holcoides (Nees) Kuhlm. & CAMS 809 & G3 & $\mathrm{c}$ & AmS, i \\
\hline Eustachys disticophylla (Lag.) Nees & CAMS $175 \&$ VCS & & $\mathrm{b}, \mathrm{r}$ & AmS \\
\hline Gymnopogon foliosus (Willd.) Nees * & VCS 3912 & & $\mathrm{c}$ & Neo \\
\hline Gymnopogon spicatus (Spreng.) Kuntze * & $\begin{array}{l}\text { CAMS } 269 \& \text { M } \\
\text { Godron }\end{array}$ & G2 & $\mathrm{c}$ & Neo \\
\hline Homolepis glutinosa (Sw. ) Zuloaga \& Soderstr. & VCS 3959 & & $\mathrm{c}$ & Neo \\
\hline Hyparrhenia bracteata (Willd.) Stapf & CAMS $9 \&$ VCS & & $\mathrm{r}$ & Af \\
\hline Hypoginium virgatum (Desv.) Dandy & VCS 3228 & G3 & $\mathrm{c}$ & Neo \\
\hline Ichnanthus inconstans (Trin. ex Nees) Döll & CAMS $229 \&$ VCS & & $\mathrm{c}$ & AmS \\
\hline Ichnanthus procurrens (Nees ex Trin.) Swallen & CAMS 857 & G2 & $\mathrm{c}$ & $\mathrm{AmS}$ \\
\hline Leptocoryphium lanatum (Kunth) Nees & VCS 3767 & G2 & $\mathrm{c}$ & Neo \\
\hline Melinis minutiflora P. Beauv. & VCS 3967 & & $\mathrm{c}$ & Sub \\
\hline Otachyrium versicolor (Döll) Henrard & CAMS 1028 & G3 & $\mathrm{b}, \mathrm{c}$ & Neo \\
\hline Panicum cf. sabulorum Lam. & CAMS 738 & & $\mathrm{c}$ & - \\
\hline Panicum cf. trichantum Nees & CAMS 902e & & $\mathrm{c}$ & - \\
\hline Panicum cyanescens Nees ex Trin. & CAMS 79 \& VCS & $\mathrm{G} 2$ & $\mathrm{c}$ & Neo \\
\hline Panicum hebotes Trin. & VCS 7418 & & $\mathrm{c}$ & $\mathrm{AmS}$ \\
\hline Panicum maximum Jacq. & VCS 3658 & & $\mathrm{c}$ & Sub \\
\hline Panicum olyroides Kunth var. hirsutum Henrard & VCS 7329 & & $\mathrm{c}$ & $\mathrm{AmS}$ \\
\hline Panicum pantrichum Hack. & CAMS 796 & & $\mathrm{c}$ & Neo \\
\hline Panicum parvifolium Lam. & CAMS 699 & $\mathrm{G} 2$ & $\mathrm{c}$ & Neo \\
\hline Panicum rude Nees & CAMS 483 \& VCS & & $\mathrm{c}$ & $\mathrm{Br}$ \\
\hline Panicum schwackeanum Mez & $\begin{array}{l}\text { HM Longhi-Wagner } \\
3186\end{array}$ & & $\mathrm{~b}$ & Neo \\
\hline Panicum sellowii Nees & CAMS 412 \& VCS & & $\mathrm{r}$ & $\mathrm{Neo}$ \\
\hline Paspalum ammodes Trin. $*$ & VCS 4526 & & $\mathrm{c}$ & $\mathrm{AmS}$ \\
\hline Paspalum cf. dedeccae Quarin & CAMS 900e & & $\mathrm{c}$ & - \\
\hline Paspalum cf. flaccidum Nees & CAMS $899 \mathrm{e}$ & & $\mathrm{c}$ & - \\
\hline Paspalum cordatum Hack. & CAMS 1035 & G3 & $\mathrm{b}$ & $\mathrm{Br}$ \\
\hline Paspalum dasytrichum Dusén ex Swallen & $\begin{array}{l}\text { CAMS } 608 \& \mathrm{M} \\
\text { Deur }\end{array}$ & & $\mathrm{c}$ & $\mathrm{S}, \mathrm{SE}, \mathrm{LN}$ \\
\hline Paspalum ellipticum Döll & VCS 4653 & G3 & $\mathrm{b}$ & $\mathrm{Br}, \mathrm{Arg}$ \\
\hline Paspalum erianthum Nees ex Trin. * & VCS 4528 & G3 & $\mathrm{c}$ & $\mathrm{Br}$, Uru \\
\hline Paspalum glaucescens Hack. & VCS 3597 & G3 & $\mathrm{c}$ & AmS \\
\hline Paspalum guenoarum Arechav. & VCS 3254 & & $\mathrm{c}$ & AmS \\
\hline Paspalum hyalinum Nees ex Trin. & CAMS 709 & $\mathrm{G} 2$ & $\mathrm{c}$ & $\mathrm{AmS}, \mathrm{LS}$ \\
\hline Paspalum lineare Trin. & VCS 7414 & G2 & $\mathrm{c}$ & Neo \\
\hline Paspalum maculosum Trin. & CAMS 714 & & $\mathrm{~b}$ & AmS \\
\hline Paspalum paniculatum $\mathrm{L}$. & CAMS 718 & & $\mathrm{c}$ & Cosmo \\
\hline Paspalum pectinatum Nees & VCS 4503 & G3 & $\mathrm{r}$ & Neo \\
\hline Paspalum pilosum Lam. & CAMS 858 & & $\mathrm{c}$ & Neo \\
\hline Paspalum plicatulum Michx. & VCS 7365 & & $\mathrm{~b}$ & $\mathrm{Am}$ \\
\hline Paspalum polyphyllum Nees & CAMS 80 \& VCS & G2 & $\mathrm{b}, \mathrm{c}$ & $\mathrm{AmS}$ \\
\hline Paspalum rojasii Hack. & CAMS 206 \& VCS & & $\mathrm{b}, \mathrm{r}$ & $\mathrm{AmS}$ \\
\hline Paspalum urvillei Steud. & VCS 4450 & & $\mathrm{~b}$ & Neo \\
\hline Polypogon elongatus Kunth & $\begin{array}{l}\text { HM Longhi-Wagner } \\
3151\end{array}$ & & $\mathrm{c}$ & $\begin{array}{l}\text { S, SE, Arg, } \\
\text { Uru, LN }\end{array}$ \\
\hline Rhynchelitrum repens (Willd.) C.E. Hubb. & CAMS $81 \&$ VCS & G2 & $\mathrm{c}$ & Sub \\
\hline Rhytachne rottboellioides Desv. & JR Mattos 12885 & & $\mathrm{~b}$ & Af \\
\hline Saccharum villosum Steud. & CAMS $131 \&$ VCS & & $\mathrm{c}$ & S, SE, Par \\
\hline Schizachyrium condensatum (Kunth) Nees & CAMS 67 \& VCS & G3 & $\mathrm{c}$ & $\mathrm{Am}$ \\
\hline Schizachyrium salzmanii (Trin. ex Steud.) Nash & JR Mattos 12910 & & $\mathrm{r}$ & Neo \\
\hline Schizachyrium spicatum (Spreng.) Herter & CAMS 846 & & $\mathrm{c}$ & $\begin{array}{l}\text { S, SE, Arg, } \\
\text { Par, Uru, i }\end{array}$ \\
\hline
\end{tabular}




\begin{tabular}{|c|c|c|c|c|}
\hline DIVISÃO/Família/Espécie & Coletor & Estrutura & Hábitat & $\begin{array}{l}\text { Distribuiçã } \\
\text { o geográfica } \\
\end{array}$ \\
\hline Schizachyrium tenerum Nees * & $\begin{array}{l}\text { CAMS } 410 \& \mathrm{M} \\
\text { Godron }\end{array}$ & G2 & $\mathrm{c}$ & $\mathrm{Am}$ \\
\hline Setaria parviflora (Poir.) Kerguélen & CAMS $207 \&$ VCS & G2 & $\mathrm{b}$ & Cosmo \\
\hline Setaria scabrifolia (Nees) Kunth & CAMS $29 \&$ VCS & & $\mathrm{r}$ & $\mathrm{AmS}$ \\
\hline Sorghastrum scaberrimum (Nees) Herter & VCS 2309 & & $\mathrm{~b}$ & $\mathrm{~S}, \mathrm{SE}, \mathrm{LN}$ \\
\hline Sporobolus eximius (Nees) Ekman & CAMS 706 & G2 & $\mathrm{c}$ & $\mathrm{Br}, \mathrm{Par}, \mathrm{i}$ \\
\hline Sporobolus indicus (L.) R. Br. & $\begin{array}{l}\text { HM Longhi-Wagner } \\
3207\end{array}$ & & $\mathrm{c}$ & $\mathrm{Neo}$ \\
\hline Sporobolus pseudairoides Parodi & VCS 10592 & & $\mathrm{c}$ & Af \\
\hline Steinchisma decipiens (Nees ex Trin.) W.V. Br. & VCS 4454 & & $\mathrm{c}$ & $\mathrm{AmS}$ \\
\hline Trachypogon spicatus (L. f.) Kuntze & VCS 2494 & G3 & $\mathrm{c}$ & $\mathrm{Neo}, \mathrm{Af}$ \\
\hline Urochloa brizantha (Hochst. ex A. Rich.) Webster & VCS 3996 & & $\mathrm{c}$ & Sub \\
\hline Urochloa decumbens (Stapf) Webster & CAMS 730 & & $\mathrm{c}$ & Sub \\
\hline \multicolumn{5}{|l|}{ POLYGALACEAE } \\
\hline Monnina richardiana A. St.-Hil. \& Moq. * & VCS 423 & E2 & $\mathrm{c}$ & $\mathrm{S}, \mathrm{SE}$ \\
\hline Monnina tristaniana A. St.-Hil. \& Moq. & VCS 4584 & & $\mathrm{~b}, \mathrm{c}$ & $\begin{array}{l}\text { S, SE, Arg, } \\
\text { Par, Uru, LN }\end{array}$ \\
\hline Polygala cuspidata DC. & CAMS $92 \&$ VCS & & $\mathrm{b}, \mathrm{c}$ & $\mathrm{Br}, \mathrm{LS}$ \\
\hline Polygala dusenii Norl. * & CAMS $530 \&$ VCS & & $\mathrm{b}, \mathrm{c}$ & S, SE, LN \\
\hline Polygala glochidiata Kunth var. spergulaefolia (A. St.-Hil.) Chodat & VCS 4583 & & $\mathrm{c}$ & $\mathrm{Br}, \mathrm{LS}$ \\
\hline Polygala hebeclada DC. & CAMS $561 \&$ VCS & & $\mathrm{b}$ & $\mathrm{Br}$ \\
\hline Polygala hirsuta A. St.-Hil. * & VCS 2465 & & $\mathrm{c}$ & SP, MG, LS \\
\hline Polygala lancifolia A. St.-Hil. \& Moq. & CMS 337 & & $\mathrm{c}$ & $\mathrm{Br}$, Par \\
\hline Polygala longicaulis Kunth & CAMS 35 \& VCS & & $\mathrm{c}$ & $\mathrm{Br}$ \\
\hline Polygala minima Pohl ex A.W. Benn. & VCS 3910 & & $\mathrm{c}$ & SP, Par, LS \\
\hline Polygala moquiniana A. St.-Hil. ** & CAMS $529 \&$ VCS & & $\mathrm{c}$ & $\mathrm{SP}, \mathrm{PR}, \mathrm{LN}$ \\
\hline Polygala multiceps Mart. ex A.W. Benn. * & CMS 360 & & $\mathrm{c}$ & $\mathrm{Br}, \mathrm{LS}$ \\
\hline Polygala paniculata $\mathrm{L}$. & VCS 6031 & & $\mathrm{c}$ & Neo \\
\hline Polygala pumila Norl. & CAMS 1176 & & $\mathrm{c}$ & $\mathrm{S}, \mathrm{SE}$ \\
\hline Polygala sabulosa A.W. Benn. * & VCS 3952 & & $\mathrm{r}$ & $\mathrm{S}, \mathrm{SE}$ \\
\hline Polygala tenuis DC. * & CAMS $416 \&$ VCS & & $\mathrm{b}, \mathrm{c}$ & $\mathrm{Br}$ \\
\hline Polygala timoutoides Chodat $*$ & VCS 7237 & & $\mathrm{r}$ & Br, Arg, Par \\
\hline \multicolumn{5}{|l|}{ POLYGONACEAE } \\
\hline Polygonum hydropiperoides Michx. & VCS 4032 et al & & $\mathrm{c}$ & $\mathrm{Neo}$ \\
\hline \multicolumn{5}{|l|}{ PONTEDERIACEAE } \\
\hline Pontederia cordata $\mathrm{L}$. & VCS 4662 & & $\mathrm{~b}$ & $\mathrm{Neo}$ \\
\hline \multicolumn{5}{|l|}{ PROTEACEAE } \\
\hline Roupala brasiliensis Klotzsch & VCS 6038 & & $\mathrm{c}$ & $\mathrm{S}, \mathrm{SE}$ \\
\hline Roupala montana Aubl. & CAMS 443 \& VCS & & $\mathrm{c}, \mathrm{r}$ & Neo \\
\hline \multicolumn{5}{|l|}{ RANUNCULACEAE } \\
\hline Clematis dioica $\mathrm{L}$. & CAMS $1173 \mathrm{e}$ & & $\mathrm{c}$ & $\mathrm{AmS}$ \\
\hline \multicolumn{5}{|l|}{ RHAMNACEAE } \\
\hline Rhamnus sphaerosperma Sw. & VCS 3958 & E3 & $\mathrm{b}, \mathrm{c}$ & $\mathrm{Br}$ \\
\hline \multicolumn{5}{|l|}{ ROSACEAE } \\
\hline Prunus myrtifolia (L.) Urb. & VCS 3486 & & $\mathrm{c}$ & Neo \\
\hline Rubus brasiliensis Mart. & CAMS $2 \&$ VCS & & $\mathrm{r}$ & Br, Par, Uru \\
\hline \multicolumn{5}{|l|}{ RUBIACEAE } \\
\hline Alibertia concolor (Cham.) K.Schum. & CAMS $565 \&$ VCS & & $\mathrm{c}, \mathrm{r}$ & $\mathrm{AmS}$ \\
\hline Borreria brachystemonoides Cham. \& Schltdl. & CMS 384 & & $\mathrm{c}$ & $\mathrm{AmS}$ \\
\hline Borreria capitata (Ruiz \& Pav.) DC. & CAMS 574 \& VCS & & $\mathrm{b}, \mathrm{c}, \mathrm{r}$ & Neo \\
\hline Borreria latifolia K. Schum. & CAMS 406 & & $\mathrm{r}$ & $\mathrm{Neo}$ \\
\hline Borreria poaya (A. St.-Hil.) DC. & CAMS $575 \&$ VCS & E1 & $\mathrm{b}, \mathrm{c}, \mathrm{r}$ & $\mathrm{Br}$ \\
\hline Borreria tenella (Kunth) Cham. \& Schltdl. & VCS 4590 & & $\mathrm{c}, \mathrm{r}$ & $\mathrm{Neo}$ \\
\hline Borreria verticillata (L.) G. Mey & CAMS $577 \&$ VCS & & $\mathrm{c}$ & $\mathrm{Neo}$ \\
\hline Coccocypselum campanuliflorum Cham. \& Schltdl. & CAMS 811 & & $\mathrm{c}$ & $\mathrm{Br}$ \\
\hline Coccocypselum condalia Pers. & VCS 4744 & & $\mathrm{c}$ & $\mathrm{Neo}$ \\
\hline Coccocypselum guianensis (Aubl.) K.Schum. & VCS 7168 & & $\mathrm{c}$ & $\mathrm{Neo}$ \\
\hline Coccocypselum lanceolatum (Ruiz \& Pav.) Pers. & CAMS $230 \&$ VCS & & $\mathrm{r}$ & $\mathrm{Neo}$ \\
\hline Declieuxia cordigera Mart. et Zucc. ex Schult. et Schult.. & J. Mattos $15270-$ SP & & $\mathrm{c}$ & $\mathrm{SE}, \mathrm{GO}, \mathrm{DF}$ \\
\hline Declieuxia dusenii Standl. & CAMS $505 \&$ VCS & & $\mathrm{b}, \mathrm{c}$ & $\mathrm{S}, \mathrm{SE} ?$ \\
\hline Declieuxia fruticosa (Willd. ex Roem. et Schult.) Kuntze & CAMS $155 \&$ VCS & & $\mathrm{c}, \mathrm{m}, \mathrm{r}$ & Neo \\
\hline Diodia apiculata (Willd. ex Roem. et Schult.) K. Schum. & CAMS 51 \& VCS & & $\mathrm{r}$ & Neo \\
\hline Emmeorhiza umbellata (Spreng.) K. Schum. & VCS 3924 & & $\mathrm{c}$ & $\mathrm{AmS}$ \\
\hline Galianthe angustifolia (Cham. \& Schltdl.) E.L. Cabral & CAMS 820 & & $\mathrm{c}$ & $\mathrm{AmS}$ \\
\hline
\end{tabular}




\begin{tabular}{|c|c|c|c|c|}
\hline DIVISÃO/Família/Espécie & Coletor & Estrutura & Hábitat & $\begin{array}{l}\text { Distribuiçã } \\
\text { o geográfica }\end{array}$ \\
\hline Galianthe eupatorioides (Cham. \& Schltdl.) E.L. Cabral * & VCS 3269 & & $\mathrm{c}$ & $\mathrm{S}, \mathrm{SE}$ \\
\hline Galianthe souzae E.L. Cabral \& Bacigalupo ** \#\#\# & CAMS $473 \&$ VCS & & $\mathrm{c}$ & $\begin{array}{l}\text { Endêmica } \\
\text { Itararé }\end{array}$ \\
\hline Galianthe thalictroides (Cham. \& Schltdl.) E.L. Cabral * & KD Barreto 3165 & & $\mathrm{r}$ & S, SE, Par \\
\hline Galianthe valerianoides (Cham. \& Schltdl.) E.L. Cabral & CAMS 761 & & $\mathrm{~b}, \mathrm{c}$ & $\begin{array}{l}\text { S, SE, Arg, } \\
\text { Uru }\end{array}$ \\
\hline Galium cf. nigroramosum (Ehrend.) Dempster & VCS 4267 & & $\mathrm{c}$ & - \\
\hline Galium hypocarpium (L.) Endl. ex Griseb. & CMS 541 & & $\mathrm{c}$ & Neo \\
\hline Galium megapotamicum Spreng. & VCS 4664 & & $\mathrm{c}, \mathrm{r}$ & $\begin{array}{l}\text { S, SE, Arg, } \\
\text { Uru }\end{array}$ \\
\hline Galium sellowianum (Cham.) Walp. & VCS 3729 & E2 & $\mathrm{c}$ & S, SE \\
\hline Palicourea rigida Humb., Bonpl. \& Kunth & VCS 4627 & & $\mathrm{~b}, \mathrm{c}, \mathrm{r}$ & $\mathrm{AmS}$ \\
\hline Posoqueria latifolia (Rudge) Roem. et Schult. & VCS 4277 et al & & $\mathrm{m}$ & Neo \\
\hline Psychotria leiocarpa Cham. \& Schltdl. & $\begin{array}{l}\text { CAMS } 280 \& \mathrm{M} \\
\text { Godron }\end{array}$ & & $\mathrm{r}$ & S, SE \\
\hline Psychotria stachyoides Benth. & CMS 376 & & $\mathrm{c}$ & S, SE \\
\hline Psychotria suterella Müll. Arg. & CAMS $262 \&$ VCS & & $\mathrm{m}$ & S, SE \\
\hline Psychotria vellosiana Benth. & CMS 494 & & $\mathrm{~m}, \mathrm{r}$ & $\mathrm{AmS}$ \\
\hline Rubiaceae sp. 1 & VCS 7021 & & & - \\
\hline \multicolumn{5}{|l|}{ SALICACEAE } \\
\hline Casearia sylvestris $\mathrm{Sw}$. & CAMS $462 \&$ VCS & & $\mathrm{c}$ & Neo \\
\hline \multicolumn{5}{|l|}{ SANTALACEAE } \\
\hline Thesium brasiliense A. DC. & CAMS $1167 \mathrm{e}$ & & $\mathrm{c}$ & $\mathrm{S}, \mathrm{SE}$ \\
\hline \multicolumn{5}{|l|}{ SAPINDACEAE } \\
\hline Cupania vernalis Cambess. & CAMS $140 \&$ VCS & & $\mathrm{r}$ & $\mathrm{AmS}$ \\
\hline Serjania erecta Radlk. & CAMS 425 \& VCS & & $\mathrm{b}, \mathrm{r}$ & $\mathrm{AmS}$ \\
\hline Serjania gracilis Radlk. & CAMS $209 \&$ VCS & & $\mathrm{c}, \mathrm{m}$ & $\mathrm{S}, \mathrm{SE}$ \\
\hline Serjania reticulata Cambess. & CAMS $208 \&$ VCS & & $\mathrm{m}, \mathrm{r}$ & $\mathrm{AmS}$ \\
\hline \multicolumn{5}{|l|}{ SAPOTACEAE } \\
\hline Pradosia brevipes (Pierre) Penn. & $\begin{array}{l}\text { CAMS } 283 \& \mathrm{M} \\
\text { Grodon }\end{array}$ & & $\mathrm{c}$ & Br, Par, LS \\
\hline Sapotaceae sp. 1 & CAMS 210 \& VCS & & $\mathrm{m}$ & - \\
\hline \multicolumn{5}{|l|}{ SCROPHULARIACEAE } \\
\hline Buddleja elegans Cham. \& Schltdl. & CAMS $516 \&$ VCS & & $\mathrm{c}$ & S, SE \\
\hline Buddleja stachyoides Cham. \& Schltdl. & CAMS $457 \&$ VCS & & $\mathrm{c}$ & $\mathrm{AmS}$ \\
\hline Verbascum virgatum Stokes & CAMS $635 \&$ VCS & & $\mathrm{b}$ & Sub \\
\hline \multicolumn{5}{|l|}{ SMILACACEAE } \\
\hline Smilax elastica Griseb. & CAMS $145 \&$ VCS & & $\mathrm{c}, \mathrm{r}$ & $\mathrm{Br}$ \\
\hline Smilax fluminensis Steud. & CAMS 48 \& VCS & & $\mathrm{c}, \mathrm{r}$ & $\mathrm{AmS}$ \\
\hline \multicolumn{5}{|l|}{ SOLANACEAE } \\
\hline Athenaea picta (Mart.) Sendtn. & VCS 4425 & & $\mathrm{~b}$ & S, SE \\
\hline Brunfelsia brasiliensis (Spreng.) L.B.Sm. \& Downs & VCS 2415 & & $\mathrm{c}$ & $\mathrm{S}, \mathrm{SE}$ \\
\hline Calibrachoa micrantha (R.E.Fr.) Stehmann \& Semir & VCS 4058 & & $\mathrm{~b}, \mathrm{c}, \mathrm{r}$ & S, SE, LN \\
\hline Petunia paranaensis Dusén & CAMS 95 \& VCS & & $\mathrm{c}$ & S, SE, LN \\
\hline Petunia rupestris Dusén & VCS 6036 & & $\mathrm{c}$ & S, SE, LN, i \\
\hline Solanum aculeatissimum Jacq. & CAMS 1084 & & $\mathrm{~b}, \mathrm{c}$ & Pan \\
\hline Solanum americanum Mill. & CAMS 1078 & & $\mathrm{~b}, \mathrm{c}$ & Neo \\
\hline Solanum argenteum Dunal & $\begin{array}{l}\text { CAMS } 683 \& \text { M } \\
\text { Deur }\end{array}$ & & $\mathrm{c}$ & Neo \\
\hline Solanum cf. swartzianum Roem. \& Schult. & CAMS 683e & & $\mathrm{c}$ & - \\
\hline Solanum erianthum D. Don & CAMS $1183 \mathrm{e}$ & & $\mathrm{c}$ & Pan \\
\hline Solanum inaequale Vell. & CAMS 1135 & & c & S, SE, Par \\
\hline Solanum lycocarpum A. St.-Hil. & VCS 4502 & & $\mathrm{c}, \mathrm{r}$ & $\mathrm{Br}$, Par \\
\hline Solanum mauritianum Scop. & VCS 2322 & & $\mathrm{~b}, \mathrm{c}, \mathrm{m}$ & Neo \\
\hline Solanum pseudocapsicum L. & CAMS 1074 & & $\mathrm{~b}$ & Neo \\
\hline Solanum sisymbriifolium Lam. & CAMS $511 \&$ VCS & & $\mathrm{c}$ & Neo \\
\hline Solanum sp. 2 & VCS 4612 & & $\mathrm{~b}$ & - \\
\hline Solanum variabile Mart. & CMS 493 & & $\mathrm{r}$ & S, SE, Par \\
\hline \multicolumn{5}{|l|}{ STYRACACEAE } \\
\hline Styrax acuminatum Pohl & VCS 4638 et al & & $\mathrm{r}$ & S, SE \\
\hline Styrax ferrugineus Nees \& Mart. & CAMS 169 \& VCS & & $\mathrm{c}, \mathrm{r}$ & $\mathrm{AmS}$ \\
\hline \multicolumn{5}{|l|}{ SYMPLOCACEAE } \\
\hline Symplocos crenata (Vell.) Mattos & CAMS $439 \&$ VCS & & $\mathrm{c}, \mathrm{r}$ & $\mathrm{Br}$ \\
\hline Symplocos lanceolata (Mart.) A. DC. & CAMS $528 \&$ VCS & E5 & $\mathrm{c}$ & $\mathrm{Br}$ \\
\hline
\end{tabular}




\begin{tabular}{|c|c|c|c|c|}
\hline DIVISÃO/Família/Espécie & Coletor & Estrutura & Hábitat & $\begin{array}{l}\text { Distribuiçã } \\
\text { o geográfica }\end{array}$ \\
\hline Symplocos lanceolata (Mart.) A. DC. f. intermedia Brand & CAMS $179 \&$ VCS & & $\mathrm{b}, \mathrm{c}$ & $\mathrm{S}, \mathrm{SE}$ \\
\hline Symplocos tenuifolia Brand. & VCS 2358 & & $\mathrm{~m}$ & $\mathrm{~S}, \mathrm{SE}$ \\
\hline \multicolumn{5}{|l|}{ THEACEAE } \\
\hline Gordonia fruticosa (Schrad.) Kobuski & VCS 6100 & & $\mathrm{c}$ & $\mathrm{Neo}$ \\
\hline \multicolumn{5}{|l|}{ THYMELAEACEAE } \\
\hline Daphnopsis racemosa Griseb. & VCS 4021 & & $\mathrm{~b}$ & $\mathrm{Br}, \mathrm{Arg}, \mathrm{Par}$ \\
\hline \multicolumn{5}{|l|}{ TURNERACEAE } \\
\hline Piriqueta taubatensis (Urb.) Arbo * & VCS 7267 & & $\mathrm{r}$ & $\mathrm{AmS}$ \\
\hline Turnera oblongifolia Cambess. & CAMS 835 & E2 & $\mathrm{c}$ & $\mathrm{Br}$ \\
\hline \multicolumn{5}{|l|}{ URTICACEAE } \\
\hline Cecropia pachystachya Trécul & VCS 3549 & & $\mathrm{c}$ & $\mathrm{Br}$ \\
\hline \multicolumn{5}{|l|}{ VERBENACEAE } \\
\hline Lantana camara $\mathrm{L}$. & VCS 4096 & & $\mathrm{c}, \mathrm{r}$ & $\mathrm{Neo}$ \\
\hline Lantana lundiana Schauer & VCS 6255 & & $\mathrm{r}$ & SE, LS \\
\hline Lantana trifolia Cham. & CAMS $45 \&$ VCS & & $\mathrm{r}$ & Neo \\
\hline Lippia corymbosa Cham. & CMS 380 & & $\mathrm{c}$ & $\mathrm{Br}$ \\
\hline Lippia lasiocalycina Cham. & CMS 315 & & $\mathrm{c}, \mathrm{r}$ & $\mathrm{AmS}$ \\
\hline Lippia lupulina Cham. & CAMS 850 & & $\mathrm{~b}, \mathrm{c}$ & $\mathrm{AmS}$ \\
\hline Lippia pumila Cham. & VCS 4261 & & $\mathrm{c}$ & $\mathrm{Br}$ \\
\hline Lippia salviifolia Cham. & $\begin{array}{l}\text { CAMS } 403 \& \text { M } \\
\text { Godron }\end{array}$ & & $\mathrm{r}$ & $\mathrm{Br}, \mathrm{Bol}$ \\
\hline Lippia schomburgkiana Cham. & VCS 3969 & & $\mathrm{c}$ & $\mathrm{AmS}$ \\
\hline Lippia sidoides Cham. & CAMS 861 & & $\mathrm{c}$ & Br, Arg, Par \\
\hline Lippia velutina Schauer & VCS 2192 & & $\mathrm{r}$ & $\mathrm{Br}, \mathrm{Bol}$ \\
\hline Stachytarpheta cayennensis Cham. & CAMS $50 \&$ VCS & & $\mathrm{r}$ & Neo, Af \\
\hline Verbena hirta Spreng. & CAMS 493 \& VCS & & $\mathrm{b}, \mathrm{c}, \mathrm{r}$ & S, SE, Arg \\
\hline Verbena pinnatisecta Schauer & VCS 7369 & & $\mathrm{c}$ & S, SE, LN \\
\hline Verbena rigida Spreng. & CAMS $539 \&$ VCS & & $\mathrm{c}$ & Neo \\
\hline Verbena thymoides Cham. & CAMS $417 \&$ VCS & & $\mathrm{b}, \mathrm{c}$ & $\begin{array}{l}\text { S, SE, Arg, } \\
\text { Par, Uru }\end{array}$ \\
\hline \multicolumn{5}{|l|}{ VIOLACEAE } \\
\hline Hybanthus parviflorus (Mutis ex L.f.) Baill. & VCS 4170 & & $\mathrm{c}, \mathrm{r}$ & $\mathrm{AmS}$ \\
\hline \multicolumn{5}{|l|}{ VITACEAE } \\
\hline Cissus erosa Rich. & $\begin{array}{l}\text { CAMS } 402 \& \text { M } \\
\text { Godron }\end{array}$ & & $\mathrm{b}, \mathrm{r}$ & $\mathrm{NeO}$ \\
\hline Cissus sp. 1 & CMS 344 & & $\mathrm{r}$ & - \\
\hline \multicolumn{5}{|l|}{ VOCHYSIACEAE } \\
\hline Qualea cordata Spreng. & VCS 4575 & & $\mathrm{c}, \mathrm{r}$ & $\mathrm{AmS}$ \\
\hline Qualea grandiflora Mart. & CAMS $628 \&$ VCS & & $\mathrm{r}$ & $\mathrm{AmS}$ \\
\hline Qualea selloi Warm. & VCS 4741 & & $\mathrm{c}$ & $\mathrm{Br}$ \\
\hline Vochysia tucanorum Mart. & CAMS $163 \&$ VCS & & $\mathrm{r}$ & $\mathrm{AmS}$ \\
\hline \multicolumn{5}{|l|}{ WINTERACEAE } \\
\hline Drimys brasiliensis Miers & VCS 4056 & & $\mathrm{c}$ & $\mathrm{AmS}$ \\
\hline \multicolumn{5}{|l|}{ XYRIDACEAE } \\
\hline Abolboda pulchella Humb. \& Bonpl. & VCS 7322 & & $\mathrm{~b}$ & $\mathrm{AmS}$ \\
\hline Xyris asperula Mart. ${ }^{*}$ & CAMS 807 & & $\mathrm{c}$ & $\mathrm{Br}$ \\
\hline Xyris augusto-coburgii Szyszyl. ${ }^{\#}$ & CAMS 743 & & $\mathrm{c}$ & SE, LS \\
\hline Xyris filifolia L.A. Nilsson & CAMS $455 \&$ VCS & & $\mathrm{c}$ & Neo, LS \\
\hline Xyris hilariana Malme & VCS 2268 & & $\mathrm{~b}$ & $\mathrm{Br}, \mathrm{i}$ \\
\hline Xyris hymenachne Mart. & CAMS 742 & & $\mathrm{c}$ & $\mathrm{AmS}$ \\
\hline Xyris jupicai Rich. & VCS 6128 & & $\mathrm{~b}$ & $\mathrm{Am}$ \\
\hline Xyris laxifolia Mart. & CAMS $102 \&$ VCS & & $\mathrm{b}, \mathrm{c}$ & Neo \\
\hline Xyris rigida Kunth & VCS 2479 & & $\mathrm{~b}$ & $\mathrm{~S}, \mathrm{SE}, \mathrm{i}$ \\
\hline Xyris savanensis Miq. & CAMS $642 \&$ VCS & & $\mathrm{b}, \mathrm{c}$ & $\mathrm{AmS}$ \\
\hline Xyris schizachne Mart. & VCS 3577 & & $\mathrm{c}$ & S, SE, Par \\
\hline Xyris tenella Kunth * & VCS 4826 & & $\mathrm{c}$ & $\mathrm{AmS}$ \\
\hline Xyris tortula Mart. & VCS 3693 & & $\mathrm{~b}, \mathrm{c}$ & $\mathrm{Br}$ \\
\hline Xyris uninervis Malme $* *$ & VCS 8869 & & $\mathrm{~b}$ & SP \\
\hline Xyris vacillans Malme $*$ & VCS 2257 & & $\mathrm{~b}, \mathrm{c}$ & $\mathrm{S}, \mathrm{SE}$ \\
\hline Xyris wawrae Heimerl $* *$ & CAMS $671 \&$ VCS & & $\mathrm{b}$ & S, SE, LS \\
\hline \multicolumn{5}{|l|}{ MAGNOLIOPSIDA não identificadas } \\
\hline Magnoliopsida sp. 2 & VCS 3638 & & $\mathrm{c}$ & - \\
\hline Magnoliopsida sp. 5 & VCS 4289 & & $\mathrm{c}$ & - \\
\hline
\end{tabular}


Anexo 2. Espécies vulneráveis e em perigo presentes na região dos campos de Itararé conforme a lista de espécies ameaçadas para o estado de São Paulo (São Paulo 2004).

\begin{tabular}{|c|c|c|c|}
\hline Famílias & Espécies vulneráveis & Famílias & Espécies vulneráveis \\
\hline Dicksoniaceae & Dicksonia sellowiana (Presley) Hook. & Poaceae & Axonopus marginatus (Trin.) Chase \\
\hline Amaranthaceae & Pfaffia gnaphalioides (L. f.) Mart. & Poaceae & $\begin{array}{l}\text { Axonopus pellitus (Nees ex Trin.) Hitchc. \& } \\
\text { Chase }\end{array}$ \\
\hline Amaranthaceae & Pfaffia jubata Moq. & Poaceae & Axonopus siccus (Nees) Kuhlm. \\
\hline Amaryllidaceae & Zephyranthes candida (Lindl.) Herb. & Poaceae & Ctenium polystachyum Balansa \\
\hline Annonaceae & Annona cornifolia A. St.-Hil. & Poaceae & Gymnopogon foliosus (Willd.) Nees \\
\hline Apiaceae & Eryngium marginatum Pohl ex Urb. & Poaceae & Gymnopogon spicatus (Spreng.) Kuntze \\
\hline Apiaceae & $\begin{array}{l}\text { Eryngium subinerme (H.Wolff) Mathias \& } \\
\text { Constance }\end{array}$ & Poaceae & Paspalum ammodes Trin. \\
\hline Apocynaceae & Aspidosperma tomentosum Mart. & Poaceae & Paspalum erianthum Nees ex Trin. \\
\hline Apocynaceae & Ditassa acerosa Mart. & Poaceae & Schizachyrium tenerum Nees \\
\hline Apocynaceae & Forsteronia velloziana (A. DC.) Woodson & Polygalaceae & Monnina richardiana A. St.-Hil. \& Moq. \\
\hline Apocynaceae & Hemipogon setaceus Decne. & Polygalaceae & Polygala dusenii Norl. \\
\hline Apocynaceae & $\begin{array}{l}\text { Macrosiphonia virescens (A. St.-Hil.) Müll. } \\
\text { Arg. }\end{array}$ & Polygalaceae & Polygala hirsuta A. St.-Hil. \\
\hline Apocynaceae & $\begin{array}{l}\text { Mandevilla coccinea (Hook. \& Arn.) } \\
\text { Woodson }\end{array}$ & Polygalaceae & Polygala multiceps Mart. ex A.W. Benn. \\
\hline Apocynaceae & $\begin{array}{l}\text { Mandevilla pohliana (Mart. ex Stadelm.) A.H. } \\
\text { Gentry }\end{array}$ & Polygalaceae & Polygala sabulosa A.W. Benn. \\
\hline Apocynaceae & Mandevilla tenuifolia (J.C. Mikan) Woodson & Polygalaceae & Polygala tenuis DC. \\
\hline Apocynaceae & Oxypetalum aequaliflorum E. Fourn. & Polygalaceae & Polygala timoutoides Chodat \\
\hline Asteraceae & Gyptis pinnatifida Cass. & Rubiaceae & $\begin{array}{l}\text { Galianthe eupatorioides (Cham. \& Schltdl.) } \\
\text { E.L. Cabral }\end{array}$ \\
\hline Asteraceae & Stevia leptophylla Sch. Bip. ex Baker & Rubiaceae & $\begin{array}{l}\text { Galianthe thalictroides (Cham. \& Schltdl.) E.L. } \\
\text { Cabral }\end{array}$ \\
\hline Bromeliaceae & Tillandsia mallemontii Glaz. ex Mez & Turneraceae & Piriqueta taubatensis (Urb.) Arbo \\
\hline Campanulaceae & Siphocampylus lycioides (Cham.) G. Don & Xyridaceae & Xyris asperula Mart. \\
\hline Clusiaceae & Kielmeyera coriacea Mart. \& Zucc. & Xyridaceae & Xyris tenella Kunth \\
\hline Clusiaceae & $\begin{array}{l}\text { Kielmeyera variabilis Mart. \& Zucc. ssp. } \\
\text { paranaensis (Saddi) Bittrich }\end{array}$ & Xyridaceae & Xyris vacillans Malme \\
\hline Convolvulaceae & Evolvulus serpylloides Meisn. & Família & Espécies em perigo \\
\hline Ericaceae & Agarista pulchella Cham. ex G. Don & Alliaceae & Nothoscordum aff. bonariense (Pers.) Beauv. \\
\hline Fabaceae & Bauhinia longifolia (Bong.) Steud. & Apiaceae & Eryngium eriophorum Cham. \& Schltdl. \\
\hline Fabaceae & Centrosema bracteosum Benth. & Asteraceae & $\begin{array}{l}\text { Chromolaena arrayana (Gardn.) R.M. King \& } \\
\text { H. Rob. }\end{array}$ \\
\hline Fabaceae & $\begin{array}{l}\text { Chamaecrista punctata (Vogel) H.S. Irwin \& } \\
\text { Barneby }\end{array}$ & Asteraceae & $\begin{array}{l}\text { Disynaphia ericoides (DC.) R.M. King \& H. } \\
\text { Rob. }\end{array}$ \\
\hline Fabaceae & Clitoria laurifolia Poir. & Cactaceae & $\begin{array}{l}\text { Rhipsalis dissimilis (G. Lindb.) K. Schum. ex } \\
\text { Mart. }\end{array}$ \\
\hline Fabaceae & Copaifera langsdorfii (Desf.) Kuntze & Cunoniaceae & Lamanonia cuneata (Cambess.) Kuntze \\
\hline Fabaceae & Dalbergia miscolobium Benth. & Gesneriaceae & Sinningia canescens (Mart.) Wiehler \\
\hline Fabaceae & Rhynchosia corylifolia Mart. ex Benth. & Lentibulariaceae & Genlisea aurea A. St.-Hil. \\
\hline Fabaceae & Tephrosia rufescens Benth. & Lentibulariaceae & Genlisea repens Benj. \\
\hline Hypericaceae & Hypericum ternum A. St.-Hil. & Lentibulariaceae & Utricularia nigrescens Sylvén \\
\hline Iridaceae & Calydorea campestris (Klatt) Baker & Malpighiaceae & Byrsonima brachybotrya Nied. \\
\hline Iridaceae & Sisyrinchium restioides Spreng. & Melastomataceae & Lavoisiera phyllocalycina Cogn. \\
\hline Iridaceae & Trimezia spathata (Klatt) Baker & Melastomataceae & Lavoisiera pulchella Cham. \\
\hline Lamiaceae & Hyptis lantanifolia Poit. & Orchidaceae & Zygopetalum sellowii Rchb. f. \\
\hline Lythraceae & Cuphea linarioides Cham. \& Schltdl. & Orobanchaceae & Buchnera longifolia Kunth \\
\hline Malpighiaceae & Aspicarpa sericea (A. St.-Hil.) Nied. & Poaceae & Agenium leptocladum (Hack.) Clayton \\
\hline Malvaceae & Pavonia reticulata Garcke & Poaceae & Aristida filifolia (Arechav.) Herter \\
\hline Melastomataceae & Lavoisiera bergii Cogn. & Poaceae & Eragrostis neesii Trin. \\
\hline Melastomataceae & Microlicia humilis Naudin & Polygalaceae & Polygala moquiniana A. St.-Hil. \\
\hline Melastomataceae & Tibouchina ursina (Cham.) Cogn. & Rubiaceae & Galianthe souzae E.L. Cabral \& Bacigalupo \\
\hline Melastomataceae & Trembleya phlogiformis DC. & Xyridaceae & Xyris uninervis Malme \\
\hline Myrtaceae & Eugenia dysenterica DC. & Xyridaceae & Xyris wawrae Heimerl \\
\hline Orchidaceae & $\begin{array}{l}\text { Cyanaeorchis arundinae (Rchb. f.) Barb. } \\
\text { Rodr. }\end{array}$ & & \\
\hline Orchidaceae & Habenaria edwallii Cogn. & & \\
\hline Orobanchaceae & Buchnera juncea Cham. \& Schltdl. & & \\
\hline Plantaginaceae & Plantago guilleminiana Decne. & & \\
\hline
\end{tabular}




\title{
Capítulo 3. Estrutura dos campos e suas relações com o ambiente em Itararé, SP.
}

RESUMO - (Estrutura dos campos e suas relações com o ambiente em Itararé, SP). A estrutura ecológica dos campos na região sul de Itararé, sudoeste do estado de São Paulo, Brasil, foi estudada em uma área de 32.697 ha. Esses fragmentos de campo ainda estão relativamente preservados. O objetivo deste trabalho é diferenciar os tipos de campos existentes na região de Itararé e caracterizar suas relações com variáveis ecológicas. Foi empregada a estratégia de amostragem estratificada aleatória. O critério de estratificação da paisagem foi produzido por meio da interseção do mapa morfopedológico com zonas de influência microclimáticas. A composição florística e sua abundância/cobertura, junto com descritores sobre o meio físico e a estrutura da vegetação, foram obtidos em 115 levantamentos distribuídos pelas unidades de amostragem. Através da aplicação de métodos de estatística multivariada (análise de agrupamentos, de espécies indicadoras e ordenações) foram identificados 4 tipos de campos com suas respectivas espécies indicadoras. $\mathrm{O}$ gradiente mais importante presente na matriz de dados está relacionado com o fator umidade.

Palavras-chave: variáveis abióticas, análise multivariada, classificação de vegetação, unidades morfopedológicas, espécies indicadoras

\begin{abstract}
Grasslands structure and relations with environment in Itararé, SP). The ecological structure of the grassland in the South region of Itararé, located in southwest of São Paulo state, Brazil, was studied over an area of $32.697 \mathrm{ha}$. These grassland fragments are still relatively well preserved. The goal of this paper is to distinguish the types of grassland present in the Itararé region and to characterize their relationship with ecological variables. A stratified random sampling strategy was used and the landscape stratification criterion was produced by an intersection of the morphopedologic map with a microclimatic zones layer. Species composition and cover/abundance, together with structural and abiotic parameters were recorded in 115 relevés distributed throughout the sampling units. By the application of multivariate statistical analysis methods - such as cluster analysis, indicator species analyses, and ordination techniques - four grasslands vegetation types were identified with its diagnostic species. The most important ecological gradient present in the data matrix is related with humidity.
\end{abstract}

Key words: abiotic variables, multivariate statistics, vegetation classification; morphopedologic units, indicator species

\section{Introdução}

A expressão espacial da flora na vegetação (Miranda 1980) usualmente não é aleatória. A identificação destes padrões de distribuição e a determinação das variáveis ecológicas que governam a composição florística das comunidades vegetais é a problemática focalizada por este trabalho.

A investigação das relações existentes entre a vegetação e as variáveis ecológicas traduz o significado da forte interação dialética entre a dinâmica vegetal e a do meio físico. Como a vegetação é um espelho das condições ambientais, sua avaliação permite identificar os elementos principais do ambiente. Além disso, quando da generalização dos 
resultados obtidos, a determinação das condições ecológicas de uma área é viável a partir do conhecimento de sua vegetação (Miranda 1980). Assim um dos interesses da classificação ecológica de uma área é a possibilidade de um trânsito em ambos os sentidos entre a vegetação e o meio físico.

Esse tipo de estudo fitoecológico exige uma dupla qualificação da paisagem em termos de vegetação e meio físico, demandando uma abordagem interdisciplinar com conhecimentos sobre florística, estrutura da vegetação, fisiografia, geoprocessamento e tratamentos numéricos globais.

Ainda são poucos os trabalhos sobre os campos que adotaram uma visão dessa natureza, abordando as relações ecológicas entre a vegetação e variáveis abióticas ou antrópicas (Meirelles 1990, Girardi-Deiro et al. 1992, Pillar et al. 1992, Vitta 1995, Boldrini \& Eggers 1996, Boldrini et al. 1998; Conceição 1998, Pinder \& Rosso 1998, Garcia 2003, Overbeck et al. 2006).

Em Itararé, a presença de remanescentes de campos conjugada a ações de pesquisas (capítulos 1 e 2), envolvendo o Departamento de Biologia da Escola Superior de Agricultura "Luiz de Queiroz" da Universidade de São Paulo, o Departamento de Geologia da Universidade Federal do Paraná e o Departamento de Ecologia Geral do Instituto de Biociências da Universidade de São Paulo, ao longo das duas últimas décadas, gerou uma série de informações de base que tornam possível a realização de um projeto sobre composição e estrutura dos campos de Itararé, São Paulo, avaliando os padrões de distribuição das espécies e suas relações com variáveis ecológicas.

\section{Objetivo}

A região de Itararé é uma das últimas porções do estado de São Paulo onde ainda subsistem frações significativas de campos naturais. Esta pesquisa busca caracterizar a ecologia destes campos, sendo que o objetivo geral pode ser subdividido em:

1. definir e caracterizar as comunidades vegetais que constituem os campos;

2. determinar as variáveis ecológicas que regem a composição taxonômica e a distribuição espacial dessas comunidades vegetais. 


\section{Material}

\section{1 Área de estudo}

A área selecionada (32.697 ha) está situada na porção sul do município de Itararé, na parte sudoeste do estado de São Paulo (Figura 1). Seu limite segue a ocorrência dos campos de planalto e seus gradientes para campos-cerrados e cerrados, a partir da cota $800 \mathrm{~m}$, até as escarpas que marcam o contato entre a Bacia Sedimentar do Paraná e o Planalto Cristalino Ocidental, na divisa sul do município com Bom Sucesso de Itararé. Os capítulos 1 e 2 apresentam descrições, respectivamente, da paisagem dessa região em seus aspectos físiográficos, de ocupação humana, da florística e da fitogeografia dos campos de planalto da região de Itararé, SP.

\section{Método}

\subsection{Mapeamento do uso das terras}

Com a finalidade de facilitar a localização dos campos de planalto na área de estudo e determinar sua área, o uso das terras na área de estudo foi mapeado através de interpretação analógica de uma imagem de satélite digital (LANDSAT 1990) e com o auxílio de fotos aéreas (Terrafoto 1981). A extensão e a localização desses remanescentes foi atualizada por meio da aplicação do método de classificação não supervisionada ISODATA (Niblack 1986) aplicado a uma imagem recente (CBERS 2005). Para reduzir a confusão na classificação entre as áreas de campo e os talhões de florestamento recém-cortados ou em fase inicial de desenvolvimento, as áreas identificadas como antropizadas (florestamentos, agricultura e pastagem cultivada) pela classificação da imagem de 1990 foram excluídas da imagem de 2005 usando-se uma máscara.

\subsection{Plano de amostragem e campanha de levantamento}

$\mathrm{Na}$ impossibilidade de percorrer toda a área procurando esclarecer a repartição espacial da vegetação, foi necessário amostrar as fisionomias existentes através de uma estratégia capaz de assegurar um caráter estocástico necessário à elaboração de inferências.

Um exame da base cartográfica e dos documentos disponíveis sobre a região de Itararé permitiu formar um panorama da repartição espacial de algumas variáveis ecológicas consideradas significativas a priori (formações vegetais, topografia e geologia). Mesmo sendo informações gerais e preliminares, essa análise da heterogeneidade ambiental 
indicou a estratégia de amostragem estratificada-aleatória como a mais conveniente para lidar com a diversidade de fisionomias existentes e a extensão da área.

Com esse método de amostragem, onde o número de levantamentos é fixo por estrato, assegurou-se uma comparação qualitativa entre as unidades naturais identificáveis em Itararé com diferentes extensões. Neste procedimento, um conjunto heterogêneo é dividido em estratos mais homogêneos, praticamente exclusivos e coletivamente exaustivos, segundo a orientação de um critério o mais abrangente possível em relação às variáveis ecológicas. Para cada um desses estratos, obtêm-se amostras randômicas (Frontier 1983).

O setor sul de Itararé particulariza-se pela existência de uma longa superfície levemente inclinada, da cota 1.100 até $600 \mathrm{~m}$. Esse clinoplano é recoberto por um gradiente de vegetação, disposto no sentido sul-norte, de campos de planalto até cerrados stricto sensu (vide descrição detalhada da região no capítulo 1 e 2). Em função dessas características fisiográficas e fitofisionômicas, a hipótese inicial sobre a natureza desse gradiente de vegetação era de que as macro-variáveis ecológicas, clima e relevo, tinham forte influência na distribuição das espécies entre os diferentes tipos de formações.

O reconhecimento de campo e a análise dos dados climáticos (capítulo 1) indicaram a existência de um gradiente de umidade passando de locais mais secos, nas cotas mais baixas ao norte, para áreas mais úmidas, na região mais elevada no limite sul da área de estudo, próximo à escarpa da Formação Furnas. Essa maior umidade está relacionada com o efeito orográfico gerado pela escarpa e a maior altitude da parte sul do clinoplano. Desse modo, foram definidas duas zonas de influência microclimática, traçando-se duas faixas de largura constantes e análogas ao contorno da escarpa (Figura 2), a primeira a $2 \mathrm{~km}$ de distância da escarpa e a segunda a $6 \mathrm{~km}$. Denominadas de campos altos e campos de planalto, cada uma delas representaria um extremo dessa variação de umidade ao longo do eixo norte-sul da área de estudo.

Para a variável geomorfológica utilizou-se a abordagem morfopedológica (Tricart 1994) em Itararé (capítulo 1), capaz de sintetizar a heterogeneidade fisiográfica em unidades cartográficas homogêneas em termos de seu material de origem, modelado, morfogênese e pedogênese.

A estratificação da paisagem da região de Itararé foi gerada articulando-se os fatores 
ambientais, clima e morfopedologia num critério climato-morfopedológico. A interseção da carta morfopedológica (capítulo 1) com as duas zonas de influência microclimática gerou o plano de amostragem (Figura 3), onde as unidades morfopedológicas foram divididas em duas, uma próxima e a outra distante da escarpa, totalizando uma superfície total de 16.870 ha até o limite sul da segunda faixa climática, totalizando 13 estratos. O número de levantamentos para cada uma desses estratos (Tabela 1) foi aproximadamente 10.

O tamanho da amostra foi escolhido através de nove levantamentos de área mínima, relacionando o número de espécies com diferentes tamanhos de amostras. Desse modo, a amostragem da vegetação nos campos de planalto de Itararé seguiu um esquema combinando 3 técnicas (Figura 4) para obter-se uma suficiência amostral adequada: uma parcela correspondendo a um quadrado com $4 \mathrm{~m}^{2}$; uma espiral com 2 círculos em torno da parcelas, a $2 \mathrm{~m}$ e a $6 \mathrm{~m}$ do limite da parcela (área aproximada $220 \mathrm{~m}^{2}$ ) e um passeio, ou seja, um percurso livre pelo agrupamento amostrado.

Em cada parcela, a estimativa visual de abundância e cobertura foi feita empregando a escala de Braun-Blanquet (Braun-Blanquet 1979) com sete classes: "r" para espécies raras; "+" para esparsas; "1" para espécies abundantes com menos de $5 \%$ de cobertura; "2" para espécies com cobertura de $5 \%$ a $25 \%$; "3" para aquelas com cobertura entre $25 \%$ e $50 \%$; "4" para as que apresentaram cobertura entre $50 \%$ e $75 \%$; e "5" para espécies com mais de $75 \%$ de cobertura. Na espiral e no passeio, registrou-se a presença de outras espécies, além das identificadas na parcela.

A localização aproximada das amostras foi determinada aleatoriamente sorteando-se uma quadrícula em uma grade disposta sobre cada estrato amostral. Utilizou-se o mapeamento do uso das terras previamente executado e as fotos aéreas (Terrafoto 1981) para confirmar a existência de cobertura nativa no local sorteado. O local preciso no campo foi determinado de modo a representar a fisionomia dominante da estação ecológica.

Assim, em 71 dias de trabalho de campo, no período de 14/02/1993 a 04/07/1993, foram executados 115 levantamentos fitoecológicos (Figura 3).

Utilizou-se um formulário codificado de modo a facilitar a informatização e tratamento dos dados, bem como a uniformidade na descrição da paisagem (Anexo 1). Foram escolhidos 41 descritores qualitativos, sendo 12 para identificação e descrição geral do ponto amostrado, 24 para caracterização do meio físico, 4 para a vegetação, 8 para 
atividades antrópicas e duas tabelas, uma descritiva da estrutura da vegetação e a outra para a análise fitossociológica. Nessa última tabela, os descritores sobre a composição e estrutura da comunidade foram: nome da espécie, seu valor de cobertura, estado fenológico e posição no estrato vertical.

A identificação das espécies, quando possível, foi feita em campo por um taxonomista experiente com o auxílio da lista florística dos campos de Itararé (capítulo 2). Mesmo assim foram necessárias 8.200 coletas de material estéril que ficaram depositadas temporariamente no herbário ESA da Escola Superior de Agricultura "Luiz de Queiroz", da USP. Sua identificação foi feita por comparação com material fértil, por especialistas em levantamento florístico e taxonomistas especializados em algumas famílias muito diversas, como Poaceae, Cyperaceae, Asteraceae, entre outras.

Em 45 desses 115 levantamentos foram coletadas amostras de solo para a realização de análises químicas, objetivando a caracterização do mapeamento morfopedológico (capítulo 1), por meio do método IAC adaptado (van Raij et al. 2001), efetuado pelo Departamento de Ciência do Solo da ESALQ-USP. Os seguintes atributos foram estimados: $\mathrm{pH}$ (acidez ativa) pelos métodos: a. $\mathrm{H}_{2} \mathrm{O}$ deionizado, b. $\mathrm{KCl}(1 \mathrm{~N})$ e c. $\mathrm{CaCl}_{2}$ (0,01 M); matéria orgânica pelo método Walkey-Black (titulometria); fósforo, potássio, cálcio e magnésio pelo método de extração via resina trocadora de íons; alumínio trocável por titulometria $(\mathrm{KCl} 1 \mathrm{~N})$; e $\mathrm{H}^{+} \mathrm{Al}$ (acidez potencial) por titulometria (solução de acetato de cálcio $1 \mathrm{~N}$ a $\mathrm{pH} 7,0$ ). A partir destes foram determinados os valores da soma de bases, da capacidade de troca de cátions, saturação por bases e por alumínio ( $\mathrm{SB}, \mathrm{T}, \mathrm{V}$ e m), totalizando 14 descritores quantitativos para os solos.

\subsection{Tratamento dos dados}

O tratamento dos dados seguiu um processo com 5 grandes etapas (Figura 5): entrada dos dados, pré-processamento dos dados, análise primária exploratória, análise secundária e apresentação dos resultados.

\subsubsection{Pré-processamento dos dados}

O pré-processamento seguiu um procedimento com as seguintes etapas (Figura 5): seleção de caracteres, descritores e transformações escalares.

Os valores de cobertura atribuídos em campo foram transformados conforme van der Maarel (1979), atribuindo-se os valores 1, 2, 3, 5, 7, 8 e 9 respectivamente às classes de 
Braun-Blanquet (1979): r, +, 1, 2, 3, 4 e 5. Essa transformação diminui o peso excessivo das espécies abundantes e permite que as espécies com menor grau de cobertura possam ser consideradas na análise de padrões.

As espécies com freqüência igual ou menor a quatro dentre as 115 parcelas foram eliminadas. Esta exclusão, no caso dos dados binários para as parcelas, espirais e passeios, restringiu-se às espécies com freqüência igual ou menor a dois. Antes de uma espécie ser eliminada foi verificado se metade ou mais de suas ocorrências recaiam em uma mesma unidade morfopedológica, evitando-se a remoção de espécies exclusivas de um determinado estrato amostral.

A cobertura, segunda a escala de van der Maarel (1979), e a freqüência média para cada espécie foram calculadas em cada unidade morfopedológica. Para a apresentação sintética dos dados, estes valores foram relativizados obtendo-se um valor de cobertura relativo (vcr) e um valor de freqüência relativo (vfr), segundo:

$\mathrm{vcr}_{\mathrm{i}}=\left(\mathrm{vcm}_{\mathrm{i}} / \Sigma \mathrm{vcm}_{\text {upm }}\right) \cdot 100$ e $\quad \mathrm{vfr}_{\mathrm{i}}=\left(\mathrm{vfm}_{\mathrm{i}} / \Sigma \mathrm{vfm}_{\text {upm }}\right) \cdot 100$

Onde:

$\mathrm{vcr}_{\mathrm{i}}=$ valor de cobertura relativo da espécie i na unidade amostral;

$\mathrm{vcm}_{\mathrm{i}}=$ valor de cobertura médio da espécie i na unidade amostral;

$\Sigma \mathrm{vcm}_{\text {upm }}=$ somatória dos valores de cobertura médios das espécies no estrato amostral (unidade morfopedológica / faixa microclimática);

$\operatorname{vfr}_{\mathrm{i}}=$ valor de freqüência relativo da espécie i na unidade amostral;

$\mathrm{vfm}_{\mathrm{i}}=$ valor de freqüência médio da espécie i na unidade amostral;

$\Sigma \operatorname{vfm}_{\text {upm }}=$ somatória dos valores de freqüência médios das espécies na unidade morfopedológica.

A distribuição da freqüência de valores de cada um dos 50 descritores ambientais foi examinada visualmente ou estatisticamente, em alguns casos específicos. $\mathrm{Na}$ maior parte dos casos, a escala empregada dos descritores qualitativos foi revista (Tabela 2) por estar excessivamente subdividida.

Quatorze descritores não foram empregados nas análises multivariadas por apresentarem distribuição distante da normal e simultaneamente o mesmo valor em mais de 90 \% das parcelas. Por exemplo, o descritor "artificialização" apresentou valor nulo (ausência de artificialização) em 113 das 115 parcelas e valor 1 (leve artificialização) nas 
outras duas parcelas.

As 30 variáveis ambientais selecionadas para os tratamentos numéricos globais foram transformadas pela técnica "ranging” (Sneath \& Sokal 1973), numa escala de 0 a 1, para os valores mínimos e máximos respectivamente, mantendo a diferença relativa entre os valores. Esta transformação elimina distorções, devido à escolha arbitrária das unidades de medida. A transformação foi feita pela rotina Matriz do programa FITOPAC 1.5 (Shepherd 1996). Os descritores quantitativos para o solo das 45 parcelas também sofreram a mesma transformação.

A matriz "parcelas x abundância/cobertura dos estratos verticais dominantes" foi feita inicialmente separando graminóides $(\mathrm{G})$, dicotiledôneas herbáceas (D), arbustivas/arbóreas (A), e pteridófitas (P) a partir dos dados de campo. Como os valores médios de altura para cada estrato foram anotados, foi possível, a partir da curva de distribuição de altura, redefinir os limites das 18 classes iniciais (Anexo 1) em 15 estratos: G20 ( $\leq 20 \mathrm{~cm}), \mathrm{G} 40$ (entre 20 e $40 \mathrm{~cm}$ ), G60 (entre 40 e $60 \mathrm{~cm}$ ), G80 (entre 60 e $80 \mathrm{~cm}$ ), G100 (entre 80 e 100 cm), Gm100 (> $100 \mathrm{~cm}), \mathrm{D} 30$ ( $\leq 30 \mathrm{~cm})$, D60 (entre 30 e $60 \mathrm{~cm})$, D90 (entre 60 e $90 \mathrm{~cm})$, Dm90 (> $90 \mathrm{~cm}), \mathrm{A} 60(<60 \mathrm{~cm}), \mathrm{A} 120$ (entre 60 e $120 \mathrm{~cm})$, A180 (entre 120 e $180 \mathrm{~cm})$, $\operatorname{Am} 180(>180 \mathrm{~cm}), \mathrm{P}(\leq 100 \mathrm{~cm})$.

Deste modo, foram construídas as seguintes matrizes: "parcelas $\mathrm{x}$ abundância/cobertura de espécies", "parcelas + espirais x presença ou ausência de espécies", "parcelas + espirais + passeios x presença ou ausência de espécies", "parcelas x variáveis ambientais", "parcelas $\mathrm{x}$ variáveis ambientais + solo" e "parcelas $\mathrm{x}$ abundância/cobertura de estratos verticais dominantes".

\subsubsection{Análise exploratória}

A primeira análise exploratória primária (Figura 5) empregada foi a de agrupamentos, utilizando-se o programa PCOrd 4.14 (McCune \& Melford 1999).

Um agrupamento prévio foi feito utilizando-se o coeficiente geral de similaridade de Gower (Legendre \& Legendre 1998) indicado para combinação de tipos diferentes de descritores (binário, qualitativo, semi-quantitativo e quantitativo), porém os resultados gerados foram semelhantes aos obtidos com distância Euclidiana Quadrada, provavelmente porque a maioria das variáveis categóricas foi subdividida em mais de três classes de valores. 
Optou-se, no caso dos dados quantitativos das parcelas, pela distância Euclidiana (McCune \& Grace 2002). Já para os dados binários das matrizes, com os dados de espiral e de passeio, o índice de similaridade de Sørensen (Podani 2000), que valoriza as espécies com ocorrência comum, foi utilizado para calcular a semelhança entre a composição florística dos 115 levantamentos. O método de aglomeração escolhido para a formação dos agrupamentos foi o $\beta$ flexível que por ser essencialmente combinatório permite o usuário controlar o grau de encadeamento/agrupamento (McCune \& Grace 2002, com valor $\beta=$ $0,25)$.

A definição dos grupos foi feita pela aplicação de uma análise secundária (Figura 5), a de espécies indicadoras (Dufrêne \& Legendre 1997). Este procedimento calcula a distribuição de abundância de cada espécie entre os grupos definidos pela análise de agrupamento. Os valores indicadores gerados para as espécies são testados quanto a sua significância estatística usando a técnica de permutação de Monte Carlo. Para cada nível de corte no dendrograma, a partir de 13 até 2 grupos, foi calculada a probabilidade de cada espécie estar correlacionada com um dos grupos definidos pelo nível de corte. A significância estatística dos valores de correlação das espécies, com cada um dos grupos, foi calculada por um teste de permutação de Monte Carlo (Manly 1991) com 1.000 repetições. Foram consideradas espécies indicadoras aquelas com $P \leq 0,05$. O critério objetivo para o corte do dendrograma foi determinar o número de grupos com o menor valor de $P$ médio para todas as espécies. Secundariamente, usou-se a informação remanescente após o corte aplicado ao dendrograma, conforme medido pela função objetivo de Wishart (McCune \& Grace 2002), avaliando o balanço entre um número de grupos coerente e uma boa homogeneidade interna dos dados.

Escolhido o nível de corte no dendrograma, as espécies com $P \leq 0,05$ foram consideradas indicadoras, para aquele grupo onde o seu valor de indicadora foi maior.

A segunda etapa da análise exploratória primária tratou da aplicação de técnicas de ordenação usando além do PC-Ord, o aplicativo MVSP (Kovach 2005). Esses métodos fazem parte da análise de gradientes, na qual a variação da composição de espécies é relacionada à variação de fatores ambientais, usualmente representada por gradientes ambientais (Kent \& Coker 1992).

Para avaliar o grau de correlação entre a abundância das espécies e as unidades 
morfopedológicas, foi empregada uma análise de correspondência corrigida (DCA - Hill \& Gauch 1980). A ordenação simultânea dos gradientes ambientais e vegetacionais foi feita por análise de correspondência canônica (CCA - Ter Braak 1986).

O DCA assume uma relação linear entre variáveis ambientais e abundância de espécies enquanto o CCA assume uma curva Gaussiana para a distribuição de abundância ao longo de um gradiente. Esta última técnica requer que as variáveis estejam normalmente distribuídas e que o número de variáveis utilizadas na análise seja bem menor do que o número de unidades amostrais. Por isto uma análise de componentes principais (PCA Podani 2000) por correlação foi feita, utilizando-se o programa Past (Hammer et al. 2001), com a finalidade de eliminar descritores com contribuição baixa para os 2 primeiros eixos de ordenação e com grande colineariedade com outras variáveis, mantendo-se aqueles que contribuíram com a maior variação.

Para o CCA calcularam-se os autovalores, a variância explicada por cada eixo de ordenação e a correlação de Pearson entre as espécies e o ambiente. Um teste de permutação de Monte Carlo com 1.000 simulações foi realizado para testar a ausência de relação entre as matrizes de abundância de espécies e a de variáveis ambientais.

A análise de DCA foi feita a partir da matriz "parcelas (115 levantamentos) $\mathrm{x}$ abundância/cobertura de espécies" e "parcelas (115 levantamentos) x abundância/cobertura dos estratos verticais dominantes", cujos resultados não foram apresentados devido a ausência de padrões nítidos. A CCA foi realizada com as matrizes "parcelas (115 levantamentos) x abundância/cobertura de espécies" e "parcelas (45 levantamentos) x variáveis ambientais + solo".

Os grupos definidos pela análise de espécies indicadoras foram discriminados nos diagramas de ordenação para a avaliação a posteriori da relação entre a distribuição das espécies e as unidades morfopedológicas.

\section{Resultados e discussão}

\subsection{Mapeamento do uso das terras}

Os remanescentes dos campos de planalto de Itararé identificados na área de estudo em 1990 correspondiam a 8.562 ha (Figura 6) dispostos principalmente ao longo dos eixos de drenagem e imersos em uma matriz essencialmente composta por florestamentos de 
pínus (7.652 ha) e eucaliptos (10.269 ha), com exceção de área com agricultura de grãos no extremo nordeste (região da Fazenda Santa Andréia) e de batata na Estação Experimental do Instituto Agronômico (IAC), na extremidade sul (total 2.577 ha). Em termos de formações nativas, além dos campos, foram mapeadas matas (floresta ombrófila mista) dispersas por toda a área (1.081 ha) e manchas de cerrado e cerradão (463 ha), sendo que as maiores estavam localizadas na extremidade nordeste.

Na classificação não supervisionada da imagem 2005, a área de campo reduziu-se para 5.766 ha. Essa diferença de 2.764 ha pode ser discriminada em 94 ha de solo nu e 2.671 de não-campo. Boa parte dos locais, classificados nessa classe não-campo, apresentam na sua assinatura espectral uma clara indicação de aumento de fitomassa. Esse fato estaria de acordo com as observações de campo e o conhecimento local de que, com a eliminação do fogo como prática de cultivo para renovação das pastagens nativas depois da implementação dos florestamentos, inicia-se um processo de sucessão secundária. $O$ primeiro estágio corresponderia a uma comunidade dominada pela vassourinha (Baccharis dracunculifolia DC.) que após um período aproximado de dez anos passaria a ser substituído por uma fisionomia mais densa, com indivíduos arbustivos maiores e com acúmulo de fitomassa, tanto que passa a ser localmente denominada macega.

Apesar de minimizado pelo mascaramento das áreas já antropizadas em 1990, essa classificação não supervisionada ainda apresentou problemas, especialmente nas bordas da máscara. As principais fontes desses erros de omissão e comissão são: a semelhança entre a assinatura espectral da fisionomia herbácea dos campos com os talhões de florestamento recém cortados ou nos estágios iniciais de desenvolvimento; e a própria dificuldade de classificação dos fragmentos de campos muito pequenos e inseridos em uma matriz de florestamento (Figura 6).

\subsection{Seleção de caracteres e descritores}

Uma das principais dificuldades para a caracterização da composição e estrutura das comunidades campestres em Itararé foi a identificação do material estéril, particularmente das famílias Poaceae e Cyperaceae, que teria sido impossível sem a preparação da lista florística (capítulo 2).

O quadro sinóptico dos campos de Itararé (Anexo 2) apresenta os valores de cobertura e freqüência relativa das 354 espécies presentes nas parcelas. $\mathrm{O}$ resultado da 
seleção de caracteres com a exclusão das espécies raras (Figura 7) reduziu esse número de espécies, definindo a matriz "parcelas x abundância/cobertura de espécies" com 112 espécies por 115 levantamentos. No caso dos levantamentos com amostras de solo, a matriz "parcelas (45 levantamentos) x variáveis ambientais + solo", a redução foi de 72 espécies para 54 espécies. Já as matrizes "parcelas + espirais x presença ou ausência de espécies", "parcelas + espirais + passeios x presença ou ausência de espécies" sofreram diminuições de respectivamente, 509 e 567 para 314 e 367 espécies.

Entre os caracteres espécie, fenologia e estrutura, as espécies mostraram-se como o melhor carácter a ser explorado nas análises exploratórias primárias (Figura 7).

Análises preliminares também indicaram que os padrões de distribuição das espécies nos campos de Itararé não reconheciam os estratos amostrais gerados pela combinação das unidades morfopedológicas com as faixas climáticas. Desse modo, a divisão de cada unidade morfopedológica em duas foi descartada e os estratos amostrais passaram a ser as unidades morfopedológicas.

\subsection{Análise dos agrupamentos.}

A partir do resultado do agrupamento das parcelas, a análise de espécies indicadoras apontou, de forma objetiva, o nível de corte com 4 grupos como aquele com a menor probabilidade média para as espécies. Os quatro grupos formados também tiveram o maior número de espécies indicadoras (Anexo 2), isto é, aquelas com $P$ significativo $(P \leq 0,05)$.

A visualização desses 4 grupos no dendrograma das 115 parcelas (dados de cobertura - Figura 8), identificados de acordo com as suas respectivas unidades morfopedológicas, indica uma baixa associação dos grupos com a morfopedologia.

A natureza desses 4 grupos foi avaliada com auxílio do mapeamento morfopedológico (Figura 9), do modelo numérico de terreno (capítulo 1) e das imagens de satélite. Pode-se descrever os grupos de levantamento em termos fisiográficos da seguinte forma: grupo 1 relaciona-se com áreas aplainadas e úmidas, como as que caracterizam os "entalhes fluviais" e as "vertentes suaves e fundos de vale"; grupo 2, com áreas aplainadas porém secas como as que caracterizam os "interflúvios e altas vertentes", os "espigões inclinados", as "vertentes superiores e topos" e alguns levantamentos localizados nas "vertentes ravinadas"; grupo 3, com setores de baixa umidade porém mais dissecados e com declividade elevada como os presentes nas "vertentes ravinadas"; grupo 4, o menor de 
todos, com locais úmidos nos fundos de vales das unidades "vertentes ravinadas", "vertentes suaves e fundos de vale".

Os dendrogramas gerados a partir dos dados de presença-ausência para espiral e passeio (Figura 10 e Figura 11) indicam mais claramente a associação dos levantamentos realizados com as unidades morfopedológicas e conseqüentemente com o relevo. Adotando-se arbitrariamente o mesmo nível de corte sugerido pela análise de espécies indicadoras para os dados de cobertura das parcelas, é possível relacionar os 4 grupos formados nos dendrogramas para espiral e passeio com a sua posição relativa em uma colina. O grupo A é formado pelos levantamentos nas unidades morfopedológicas posicionadas nas áreas mais aplainadas e úmidas da unidade "vertentes suaves e nos fundos de vale". Os levantamentos no grupo B estão associados com a parte superior das encostas e estão presentes nas unidades: "vertente superior e topo", "borda da escarpa" e em alguns pontos na unidade "interflúvios e altas vertentes". Já o grupo C caracteriza-se por levantamentos localizados principalmente nos interflúvios enquanto que no $D$ concentraram-se locais com declives mais íngremes e com maior grau de dissecação, típico das unidades: "borda da escarpa", "vertente ravinada" e em pontos isolados dos "entalhes fluviais abertos". Como o dado binário não leva em conta a abundância das espécies, aquelas raras mas fortemente associadas a uma determinada unidade morfopedológica contribuíram para tornar a relação entre os grupos e as classes morfopedológicas mais nítida.

\subsection{Ordenações}

O tratamento sobre as ordenações foi subdividido em um quadro "115" com os resultados do DCA e CCA para os dados de cobertura e descritores ambientais categóricos para 115 parcelas e um quadro " 45 " com os resultados do CCA para os dados de cobertura, descritores ambientais categóricos e quantitativos para 45 parcelas.

\subsubsection{Quadro 115}

$\mathrm{Na}$ ordenação indireta das 115 parcelas por DCA, o primeiro eixo apresentou um autovalor intermediário (eixo $1=0,658$ ) e os subseqüentes valores pequenos (eixo $2=$ 0,350 e eixo $3=0,273$ ), indicando a existência de um gradiente médio no primeiro eixo e gradientes curtos no segundo e terceiro. Em outras palavras, a substituição de espécies entre os dois extremos é pequena e predomina a variação na abundância das espécies. 
O primeiro eixo (Figura 12a) separou os grupos 1 e 4 dos grupos 3 e 2, ainda que para o último diversas parcelas tenham se localizado em posição intermediária. Ao locar a correlação das variáveis com os eixos gerados pela ordenação simultânea das parcelas em função das espécies, a variável que mais contribuiu para o eixo principal de ordenação nos dois casos é a "umidade" seguida pela variável "valor da cor do solo" no segundo eixo. A variável "umidade" apresentou valores de correlação positiva elevados com as parcelas e espécies do grupo 4 (Figura 12b). No segundo eixo somente o terceiro grupo foi razoavelmente discriminado. O fato do gradiente de umidade ao longo do clinoplano da Ventania (capítulo 1) possuir um caráter linear, aumentado na direção das maiores elevações próximas a Escarpa Devoniana no sul da área de estudo, está associado ao desempenho adequado do DCA no ordenamento das parcelas e das espécies indicadoras.

Os três primeiros eixos explicaram 7,6 \% (eixo 1), 4,0\% (eixo 2) e 3,1\% (eixo 3) da variância global dos dados (total acumulado: 14,7 \%), o que indica a presença de ruído ou que as variáveis empregadas não explicaram a variância remanescente. $\mathrm{Na}$ ordenação simultânea de parcelas e espécies, há baixa correspondência entre a abundância das espécies e as parcelas, não sendo possível condensar esta variação em alguns poucos eixos.

Mesmo assim, esses padrões concordaram fortemente com as diferenças encontradas entre os grupos. As 14 espécies indicadoras do grupo 4 correlacionaram-se positivamente com o eixo 1, dispondo-se no lado esquerdo do gráfico "biplote" (Figura 12b), assim como as dos grupos 2 e 3. Isso é esperado porque se os grupos foram definidos em função destas espécies diagnóstico, a indeterminação causada pelas outras espécies na ordenação das parcelas foi removida.

A DCA é sensível a "outliers" e descontinuidades nos dados (Palmer 1993) e produz uma ordenação das unidades amostrais mais robusta do que a ordenação das variáveis (McGarigal et al. 2000). A baixa percentagem de síntese da variação pelos dois primeiros eixos não conflita com o caráter exploratório da análise. Notou-se ao plotar as parcelas em relação aos eixos 2 × 4, 5 × 6 e 7 × 8, a repetição do mesmo padrão dos eixos 1 e 2 (Figura 12).

A análise de correspondência corrigida (DCA) é pouco utilizada na ordenação com variáveis ambientais, sendo mais apropriada para este fim a análise de correspondência canônica (CCA), desde que para esta última todas os pressupostos exigidos sejam 
satisfeitos.

A análise de correspondência canônica foi feita para correlacionar as parcelas e espécies ao gradiente revelado pelo DCA e aos padrões obtidos nos agrupamentos. Os autovalores da CCA (Figura 13) para os três primeiros eixos de ordenação foram de 0,452 (eixo 1), 0,213 (eixo 2) e 0,131 (eixo 3), considerados baixos (<0,5 sensu Ter Braak 1995), indicando a existência de gradientes curtos nos eixos, onde há poucas substituições de espécies entre os dois extremos e predominância da variação na abundância das espécies.

Estes três primeiros eixos explicaram 5,2 \% (eixo 1), 2,4\% (eixo 2) e 1,5\% (eixo 3) da variância global dos dados (total acumulado: 9,2 \%), também indicando a presença de muito "ruído", ou variância remanescente não explicada pelas variáveis ambientais empregadas. Essa indeterminação elevada é uma característica comum em dados de vegetação e não prejudica a significância das relações espécie-ambiente (Ter Braak 1987).

De fato, o primeiro eixo de ordenação apresentou uma correlação espécie-ambiente $(0,850)$ altamente significativa, segundo o teste de permutação de Monte Carlo $(P<0,01)$.

Os eixos 2 e 3 produziram correlações mais baixas, 0,797 e 0,753 , que não foram significativas.

As variáveis ambientais mais fortemente correlacionadas com o primeiro eixo (Tabela 3) foram, em ordem decrescente, umidade $(-0,750)$, croma da cor do solo $(0,556)$ e matiz da cor do solo $(-0,537)$.

As correlações ponderadas mostraram também inter-relações fortes entre altitude e declividade; valor da cor do solo e declividade; valor da cor do solo e altitude; textura e pegajosidade; e matiz e croma da cor do solo (Tabela 3).

Ainda que não tão nítido como na análise de correspondência corrigida (DCA) os grupos foram separados no primeiro eixo (Figura 13) e a variável umidade também foi a mais correlacionada com o eixo principal.

As espécies indicadoras (Anexo 2) associadas com o grupo 4 dos levantamentos são características dos campos úmidos, como por exemplo, as compostas: Calea marginata, Baccharis trimera; gramíneas: Paspalum ellipticum, Paspalum cordatum, Panicum parvifolium, Otachyrium versicolor e pteridófitas: Thelypteris rivularioides, Trichipteris villosa.

As espécies correlacionadas com a extremidade do primeiro eixo são características 
de locais mais secos, exemplificando, gramíneas: Aristida megapotamica, Axonopus marginatus, Paspalum erianthum, Paspalum pectinatum, Eriochrysis holcoides e dicotiledôneas: Eryngium canalicutum, Eryngium junceum, Oligandra lycopodioides, Campomanesisa pubescens.

\subsubsection{Quadro 45}

A partir do resultado da análise de agrupamento para as 45 parcelas desse quadro, a técnica de espécies indicadoras selecionou, de forma objetiva, o nível de corte com 3 grupos, por ter a menor probabilidade média para as espécies presentes. Esses 3 grupos foram utilizados nas análises subseqüentes.

A análise de correspondência canônica (CCA) com as 45 parcelas nas quais foram feitas as análises de solo não revelou padrões tão nítidos tanto na ordenação das parcelas como das espécies indicadoras (Figura 14).

Foi verificado o mesmo padrão de gradientes curtos nos quais as mudanças na abundância relativa de espécies são mais importantes do que as mudanças na composição das espécies. Todos os autovalores gerados tiveram valores menores do que $0,5(0,268$ para o eixo 1, 0,170 para o eixo 2 e 0,120 para o eixo 3). Os três eixos explicaram 14,6 \% da variação total (7,0 \% do eixo $1,4,4 \%$ do eixo 2 e $3,1 \%$ do eixo 3$)$.

O primeiro eixo de ordenação apresentou correlação significativa com as variáveis ambientais ( $\mathrm{r}=0,861, P<0,01$, no teste de permutação de Monte Carlo). Como na análise de correlação com todas as parcelas, o $2^{\circ}$ e $3^{\circ}$ eixos também não estiveram significativamente correlacionados, apesar dos altos valores obtidos: 0,811 e 0,793 respectivamente.

Altitude, acidez potencial $\left(\mathrm{H}^{+} \mathrm{Al}^{-}\right)$, valor da cor do solo, saturação por bases (V) e pendente foram as variáveis ambientais mais correlacionadas com o primeiro eixo (Tabela 4).

Como a seleção das 45 parcelas foi feita com a finalidade de subsidiar o mapeamento morfopedológico e não de correlacionar a abundância e ocorrência das espécies com variáveis ambientais, alguns estratos amostrais estão sub ou super representados nesse subconjunto dos levantamentos. A análise da matriz de dados 45 "levs x sps" revela que várias das espécies indicadoras estavam pobremente representadas. Por exemplo, das 14 espécies do grupo 4 presentes nas 115 parcelas, apenas 3 ocorreram dentre estas 45 parcelas 
e nenhuma delas foi selecionada como indicadora. O mesmo ocorreu com os outros grupos. Ainda assim, os escores finais destas espécies em relação aos eixos 1 e 2 mostraram alguma congruência com os valores obtidos na análise anterior. Essa sub amostragem fez com que o centro dos dois primeiros eixos de ordenação da Figura 14 se deslocassem para a esquerda em relação a CCA executada para as 115 parcelas (Figura 13). Desse modo, espécies que apresentavam uma baixa correlação negativa com a variável umidade na primeira CCA passaram a ter uma correlação positiva.

\subsection{Composição e estrutura da comunidade}

No setor sul de Itararé, há dois tipos básicos de gradiente de vegetação: um suave e longo disposto no sentido norte-sul ao longo do clinoplano, com transições suaves de um cerrado stricto sensu, ao redor da cota 600, para o campo geral próximo à borda da escarpa no limite sul da área de estudo; e outro local, mais curto e abrupto presente nas vertentes, indo dos topos aplainados até os fundos de vale. Esses gradientes locais são influenciados basicamente pelo modelado do terreno com as comunidades dispostas nos fundos de vale, nas porções inferiores, médias e superiores das vertentes e nos interflúvios aplainados.

Parte da indeterminação verificada nas análises deve estar relacionada à existência desses gradientes locais não captados pelo plano de amostragem adotado.

Um complicador adicional para a distinção desses gradientes locais é o intenso aplainamento do relevo em alguns locais da área de estudo. Por exemplo, na região central a distinção entre vales e vertentes mostrou-se tão complexa na escala de semi-detalhe que esse setor foi mapeado em uma única subunidade "vertentes suaves e fundos de vale". Já nas "vertentes ravinadas", na escala de semi-detalhe utilizada no mapeamento, não foi possível distinguir os interflúvios, encostas e entalhes fluviais (Figura 3). O refinamento desse mapeamento em uma escala maior seria capaz de captar os gradientes locais da vegetação posicionados ao longo das vertentes.

O conjunto de análises empregadas na exploração dos dados coletados permitiu formar um retrato sinóptico da estrutura dos campos e suas relações com o ambiente, possibilitando a formação de novas hipóteses, como por exemplo, o papel dos gradientes locais e seus principais condicionantes na estruturação das fitocomunidades em Itararé, SP. 


\section{Conclusões}

As unidades morfopedológicas mapeadas na escala de semi-detalhe distinguiram o macro-gradiente de vegetação existente, mas não foram sensíveis ao gradiente em escala local. Portanto, o mapeamento morfopedológico pode ser uma estratégia adequada para delimitar porções relativamente homogêneas em áreas com maior heterogeneidade ambiental inter-classes do que a apresentada pela área de estudo na região sul de Itararé.

A influência climática no controle do gradiente de vegetação disposto no sentido sulnorte ao longo da superfície inclinada da Ventania (capítulo 1) foi demonstrada pelas análises de ordenamento que indicaram a importância da umidade.

Quatro grupos de campos foram distinguidos quanto a sua composição e abundância de espécies. Desses 4, o grupo relacionado às condições ambientais de maior umidade, como os "entalhes fluviais em V", pode ser nitidamente discriminado nos diversos tratamentos adotados.

A maioria das espécies não se mostrou significativamente correlacionada, na escala de semi-detalhe, com os grupos de levantamento identificados ou com as variáveis ambientais utilizadas na análise. Tratam-se de espécies com nicho amplo e de comunidades abertas, sensu Ricklefs (1990), ou seja, sem ecótonos claros e sem substituição abrupta de espécies.

\section{Agradecimentos}

Aos Drs.Valério de P. Pillar, do Departamento de Ecologia do IB-UFRGS, Michel Godron da Université de Montpelier; Jean François Duranton, Michel Lecoq do CIRADPRIFAS pelo apoio em diversas fases desse trabalho.

\section{Referências bibliográficas}

BOLDRINI, I.I.; EGGERS, L. Vegetação campestre do sul do Brasil: dinâmica de espécies à exclusão do gado. Acta Botânica Brasílica, Porto Alegre, v. 10, n. 1, p. 37-50, 1996.

BOLDRINI, I.I.; MIOTTO, S.T.S.; LONGHI-WAGNER, H.M.; PILLAR, V.D.P.; MARZALL, K. Aspectos florísticos e ecológicos da vegetação do Morro da Polícia, Porto Alegre, RS, Brasil. Acta Botânica Brasílica, Porto Alegre, v. 12, n. 1, p. 89$100,1998$. 
BRAUN-BLANQUET, J. Fitosociologia. Barcelona: Editora Omega, 1979.

CBERS-2: Imagem de satélite. São José dos Campos: INPE, 2005. Bandas 2- 3-4, sensor CCD, órbita 157 , ponto $127,03 / 09 / 2005$.

CONCEIÇÃO, A.A. Ecologia da vegetação em afloramentos rochosos na Chapada Diamantina, Bahia, Brasil. São Paulo: IB-USP, 2003. Tese - Doutorado em Botânica.

CONCEIÇÃO, A.A. Estudo da vegetação rupestre no morro do Pai Inácio, Chapada Diamantina, Palmeiras, Bahia, Brasil. São Paulo: IB-USP, 1998. DissertaçãoMestrado em Botânica.

DUFRENE, M.; LEGENDRE, P. Species assemblages and indicator species: the need for a flexible asymmetrical approach. Ecological Monographs, Durham, v. 67, n. 3, p. 34$366,1997$.

FRONTIER, S. Stratégies d échantillonnage em écologie. Paris: Masson, 1983. p. 494. (Colletion d'Écologie, n. 17).

GARCIA, R.J.F. Estudo florístico dos campos alto-montanos e matas nebulares do Parque Estadual da Serra do Mar - Núcleo Curucutu, São Paulo, SP, Brasil. São Paulo: IB-USP, 2003. Tese - Doutorado em Botânica.

GIRARDI-DEIRO, A.M.; GONÇALVES, J.O.N.; GONZAGA, S.S. Campos naturais ocorrentes nos diferentes tipos de solo no município de Bagé, RS. 2: físionomia e composição florística. Iheringia: Série Botânica, Porto Alegre, v. 42, p. 55-79, 1992.

HAMMER, Ø.; HARPER, D.A.T.; RYAN, P.D. PAST - Paleontological Statistics Software Package for Education and Data Analysis. Palaeontologia Electronica, v. 4, n. 1, p. 9, 2001. Disponível em <http://palaeo-electronica.org/2001_1/past/issue1 01.htm> Acesso em: 18 jun. 2006.

HILL, M.O.; GAUCH JR, H.G. Detrended correspondence analysis; an improved ordination technique. Vegetatio, Dordrecht, v. 42, p. 47-58, 1980.

KENT, M.; COKER, P. Vegetation description and analysis. A practical approach. Chichester: John Wiley, 1992. p. 363.

KOVACH, W.L. MVSP - A MultiVariate Statistical Package for Windows, ver. 3.1. Pentraeth: Kovach Computing Services, 2005.

LANDSAT: Imagem de satélite. São José dos Campos: INPE, 1990. Bandas 1-2-3-4-5, 
sensor TM-5, órbita 221, ponto 77B, 16/09/1990.

LEGENDRE, P.; LEGENDRE, L. Numerical ecology. Amsterdam: Elsevier, 1998.

MANLY, B.F.J. Randomization and Monte Carlo methods in biology. London: Chapman \& Hall, 1991. p. 281.

McCUNE, B.; GRACE, J.B. Analysis of ecological communities. Gleneden Beach: MjM Softwares Design, 2002.

McCUNE, B.; MELFORD, M. J. PC-ORD. Multivariate analysis of ecological data. Version 4. Gleneden Beach: MjM Software Design, 1999.

MCGARIGAL, K.; CUSHMAN, S.; STAFFORD, S. Multivariate statistics for wildlife and ecology research. Nova Cork: Springer, 2000.

MEIRELLES, S. T. Ecologia da vegetação de afloramentos rochosos do litoral da região sudeste. Campinas: Universidade Estadual de Campinas, 1990. DissertaçãoMestrado.

MIRANDA, E.E. de. Essai sur les desequilibre ecologiques et agricoles en zone tropicale-semi-aride; les cas de la region de Maradi au Niger. Montpellier, Université des Sciences et Techniques du Languedoc, 1980. p. 231. Tese - Doutorado em Ecologia.

NIBLACK, W. An introduction to digital image processing. Englewood Cliffs: Prentice Hall, 1986.

OVERBECK, G.E.; MÜLlER, S.C.; PILlAR, V.D.; PFADENHAUER, J. Floristic composition, environmental variation and species distribution patterns in burned grassland in southern Brazil. Brazilian Journal of Biology, São Carlos, v. 67, n. 2, 2006. No prelo.

PALMER, M.J. Putting things in even better order: the advantages of canonical correspondence analysis. Ecology, New York, v. 74, n. 8, p. 2215-2230, 1993.

PILLAR, V.D.; JACQUES, A.V.A.; BOLDRINI, I.B. Fatores de ambiente relacionados à variação da vegetação de um campo natural. Pesqu. Agropec. Bras., Brasília,v. 27, p. 1089-1101, 1992.

PINDER, L.; ROSSO, S. Classification and ordination of plant formations in the Pantanal of Brazil. Plant Ecology, Dordrecht, v. 136, p. 151-165, 1998.

PODANI, J. Introduction to the exploration of multivariate biological data. Leiden: 
Backhuys, 2000.

RICKLEFS, R.E. Ecology. 3ed. San Francisco: W.H. Freeman, 1990.

SHEPHERD, G. J. Fitopac 1.5. Campinas: Universidade Estadual de Campinas, 1996.

SNEATH, P.H.A.; SOKAL, R.R. Numerical taxonomy. San Francisco: W.H. Freeman, 1973.

TER BRAAK, C.J.F. Canonical correspondence analysis: a new eigenvector technique for multivariate direct gradient analysis. Ecology, New York, v. 67, n. 5, p. 1167-1179, 1986.

TER BRAAK, C.J.F. Ordination. In: JONGMAN, R.H.G.; TER BRAAK, C.J.F.; VAN TONGEREN, O.F.R. (Ed.) Data analysis in community and landascape ecology. Cambridge: Cambridge University Press, 1995. p. 91-173.

TER BRAAK, C.J.F. The analysis of vegetation-environment relationships by canonical correspondence analysis. Vegetatio, Dordrecht, v. 69, p. 69-77, 1987.

TERRA FOTO S.A. Projeto Litoral Sul - CESP: fotos aéreas. São Paulo, 1981. 38 fotos aéreas. Escala 1:35.000. Obra 407.

TRICART, J. Écogéographie des espaces ruraux. Paris: Nathan, 1994. 183 p.

VAN DER MAAREL, E. Transformation of cover abundance values in phytossociological and its effects on community similarity. Vegetatio, Dordrecht, v. 39, n. 2, p. 97-114, 1979.

VAN RAIJ, B.; ANDRADE, J.C.; CANTARELLA, H.; QUAGGIO, J.A. Análise química para avaliação da fertilidade de solos tropicais. Campinas: Instituto Agronômico, 2001. p. 285.

VITTA, F.A. Composição florística e ecologia de comunidades campestres na Serra do Cipó, Minas Gerais. São Paulo: IB-USP, 1995. Dissertação-Mestrado. 


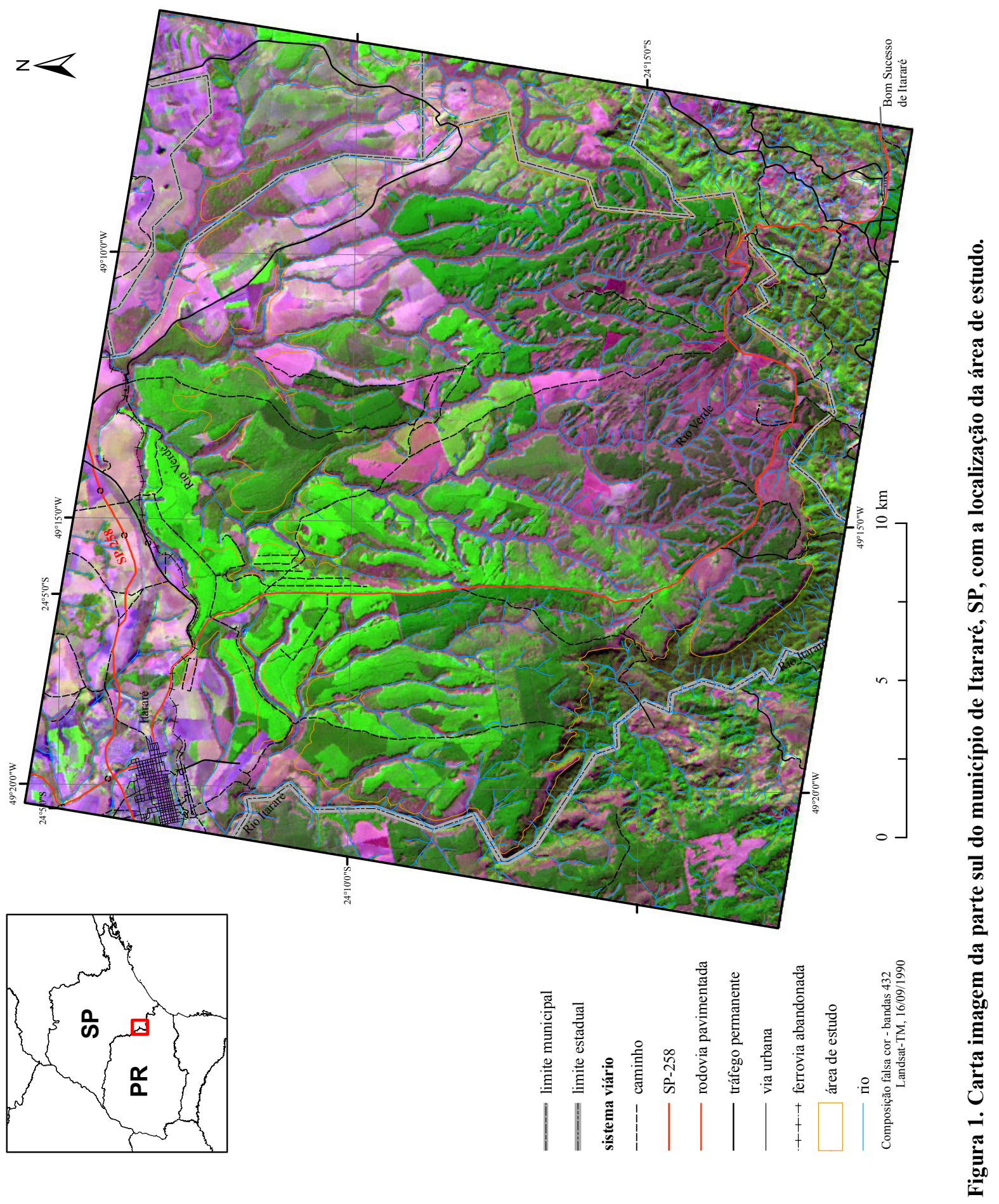


ก

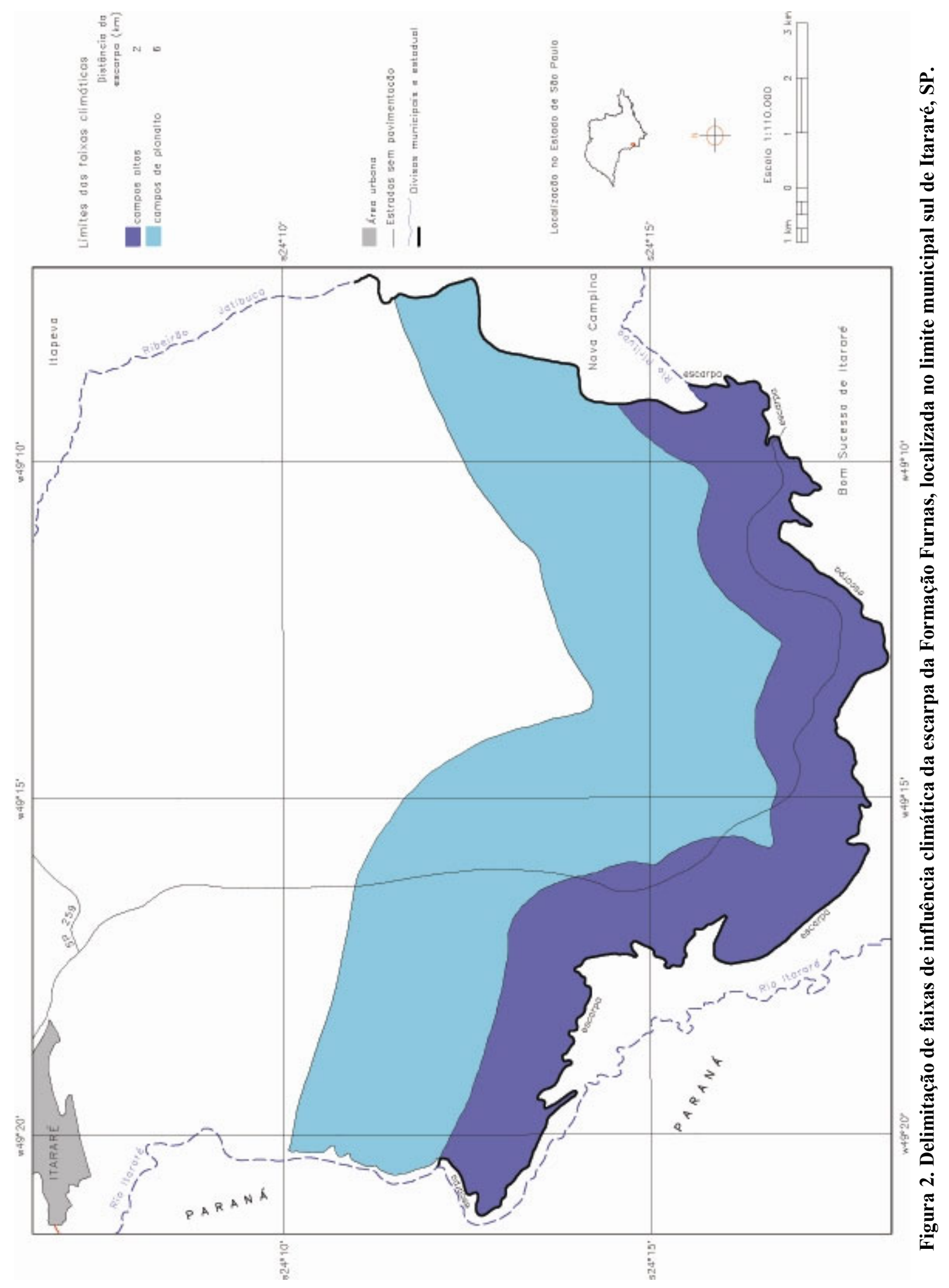



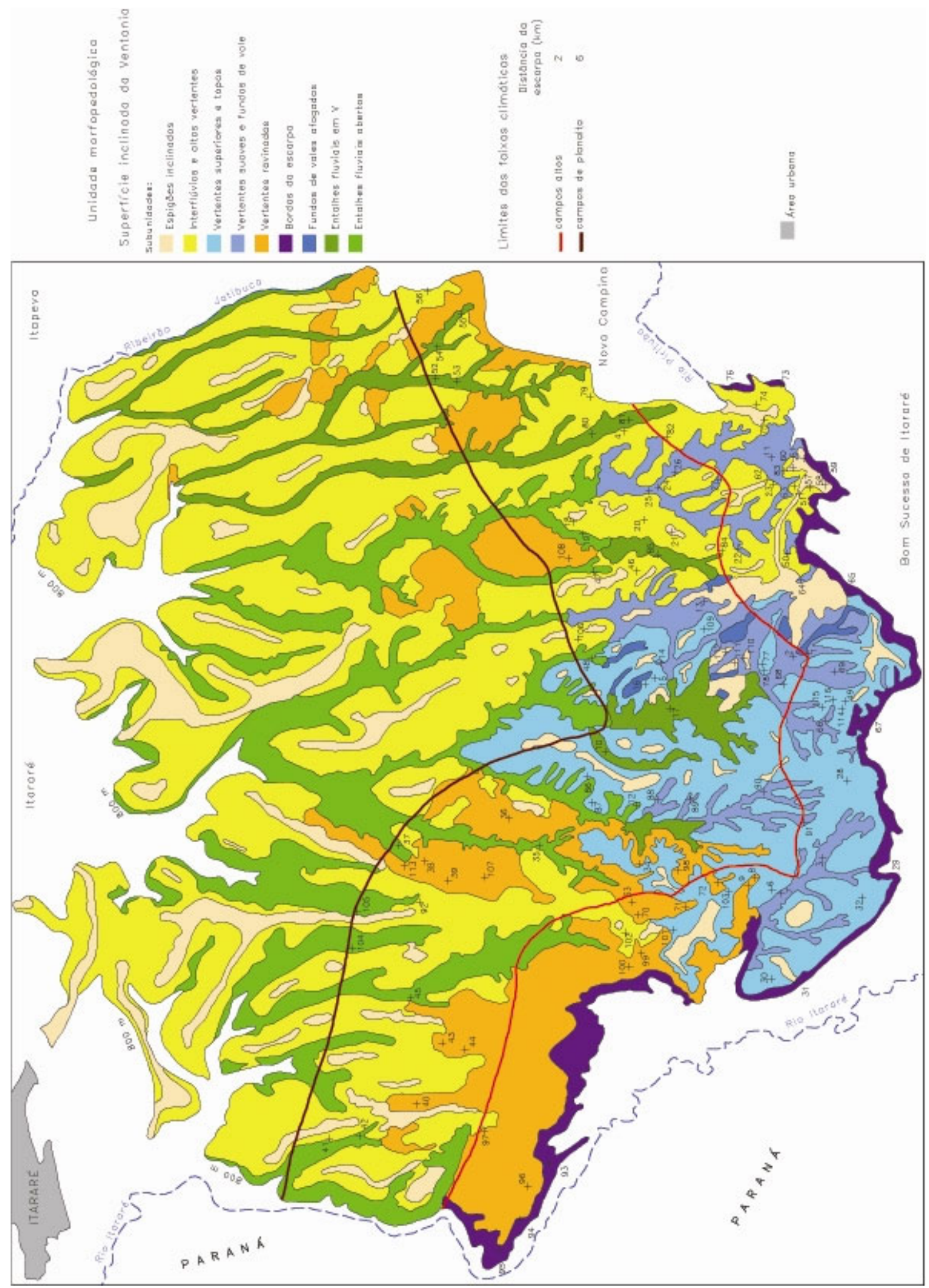

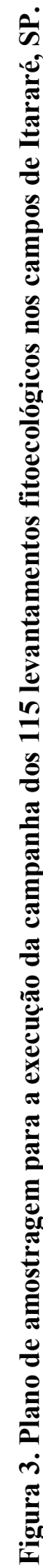




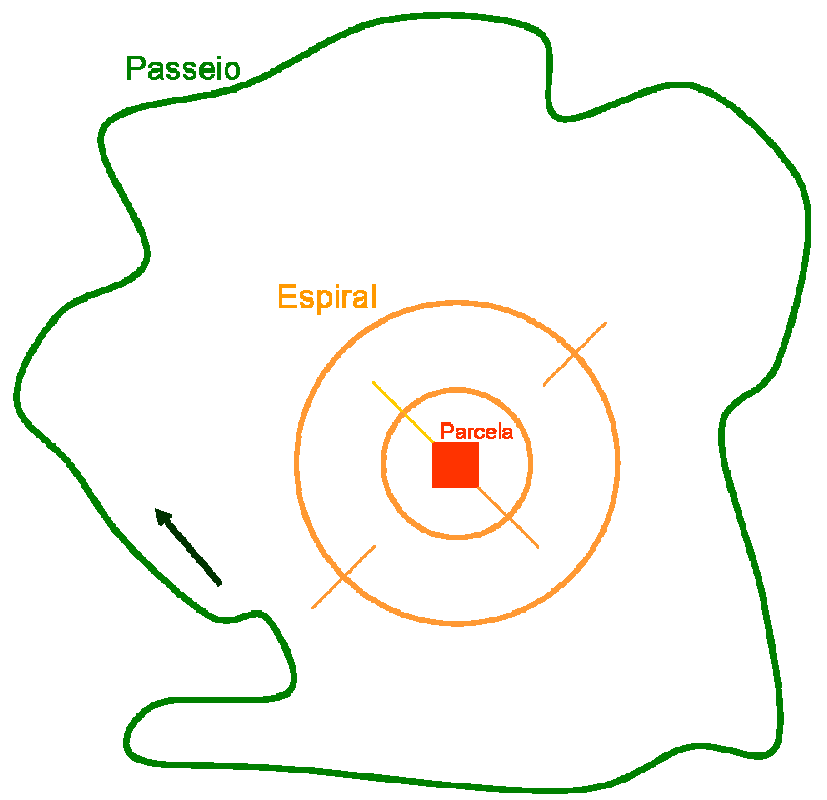

Figura 4 Esquema dos levantamentos fitoecológicos realizados nos campos de planalto de Itararé, SP onde a parcela corresponde a um quadrado de $2 \mathrm{~m}$; a espiral, a 2 círculos em torno da parcela e o passeio, a um percurso livre pelo agrupamento. 


\section{Entrada dos dados}

1. Digitação, homogeneização dos dados e construção das matrizes

2. Definição do agrupamento de levantamentos por estrato amostral

1. Seleção de descritores e caracteres
a. cálculo de estatísticas descritivas
b. eliminação de descritores com baixo poder de discriminação
c. avaliação de descritores qualitativos: eliminação, fusão ou divisão e modificação de classes
d. eliminação de espécies raras

2. Transformações escalares

a. dados de cobertura conforme Van de Maarel (1979) e relativização geral McCune \& Grace (2002)

b. dados ambientais por "ranguing"- Sneath \& Sokal (1973)

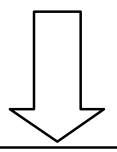

\section{Análise exploratória}

1. Agrupamento - distância euclidiana e método de aglomeração $\beta$ flexível (Legendre \& Legendre 1998)

2. Análise de correspondência $=>$ DCA (Hill \& Gauch 1980)

3. Análise de correspondência canônica $=>$ CCA (Ter Braak 1986)

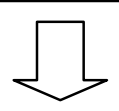

\section{Análise secundária}

1. Análise de espécies indicadoras (Dufrene \& Legendre 1997)

2. Teste de hipóteses - aleatorização

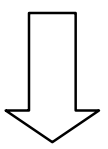

\section{Apresentação dos resultados}

1. Tabela sinóptica sobre a vegetação

2. Dendrogramas

3. Diagramas de Ordenação

4. Espécies indicadoras

Figura 5. Fluxograma do tratamento dos dados fitoecológicos dos campos de Itararé, SP. 
ป

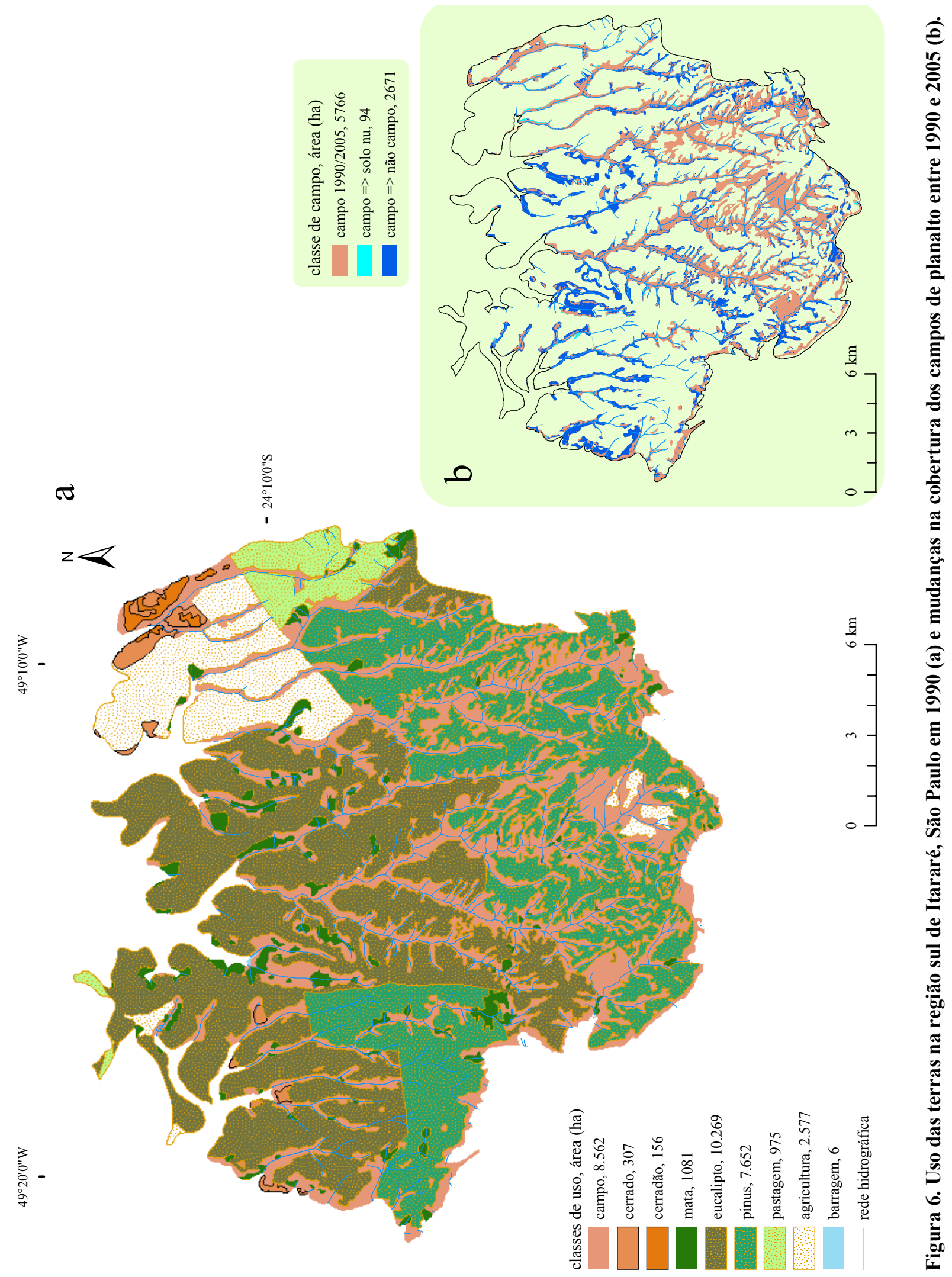




$$
\begin{array}{r}
\text { lev. - levantamento } \\
\text { esp. - espécie } \\
\text { * vide Tabela } 2
\end{array}
$$

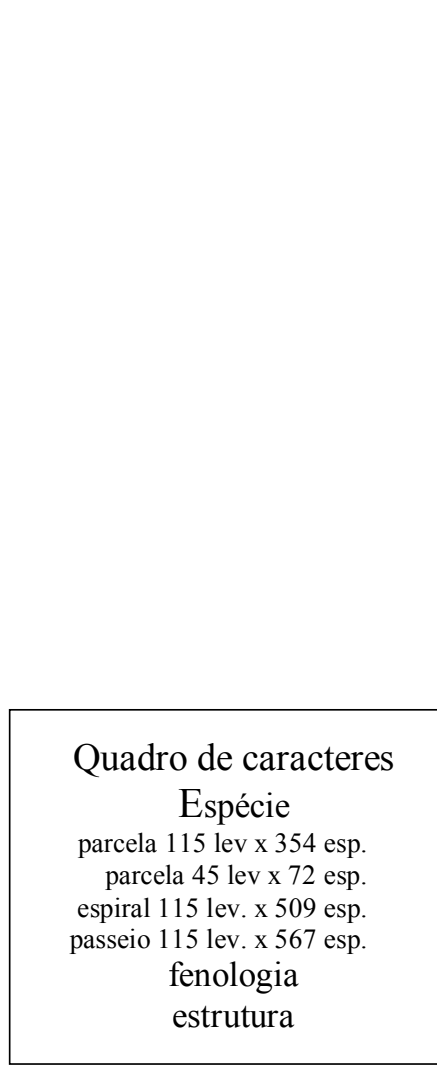

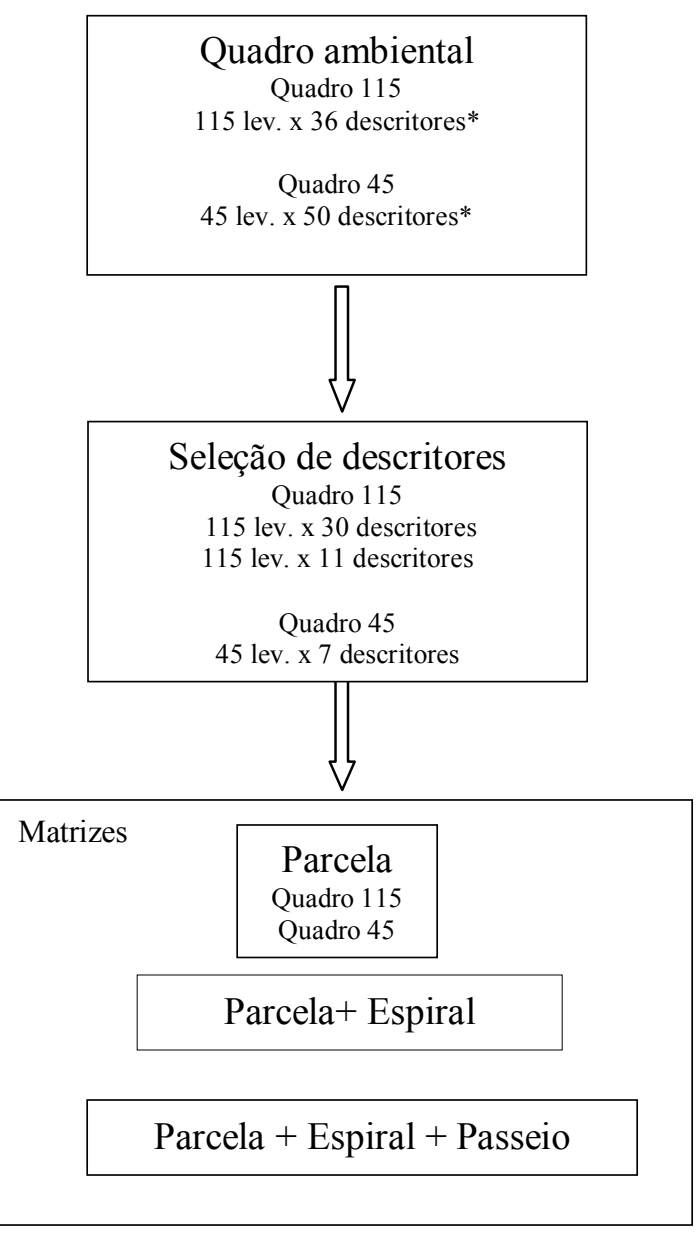

Figura 7. Seleção de caracteres e de descritores no pré-processamento dos dados fitoecológicos levantados para os campos de Itararé, SP. 


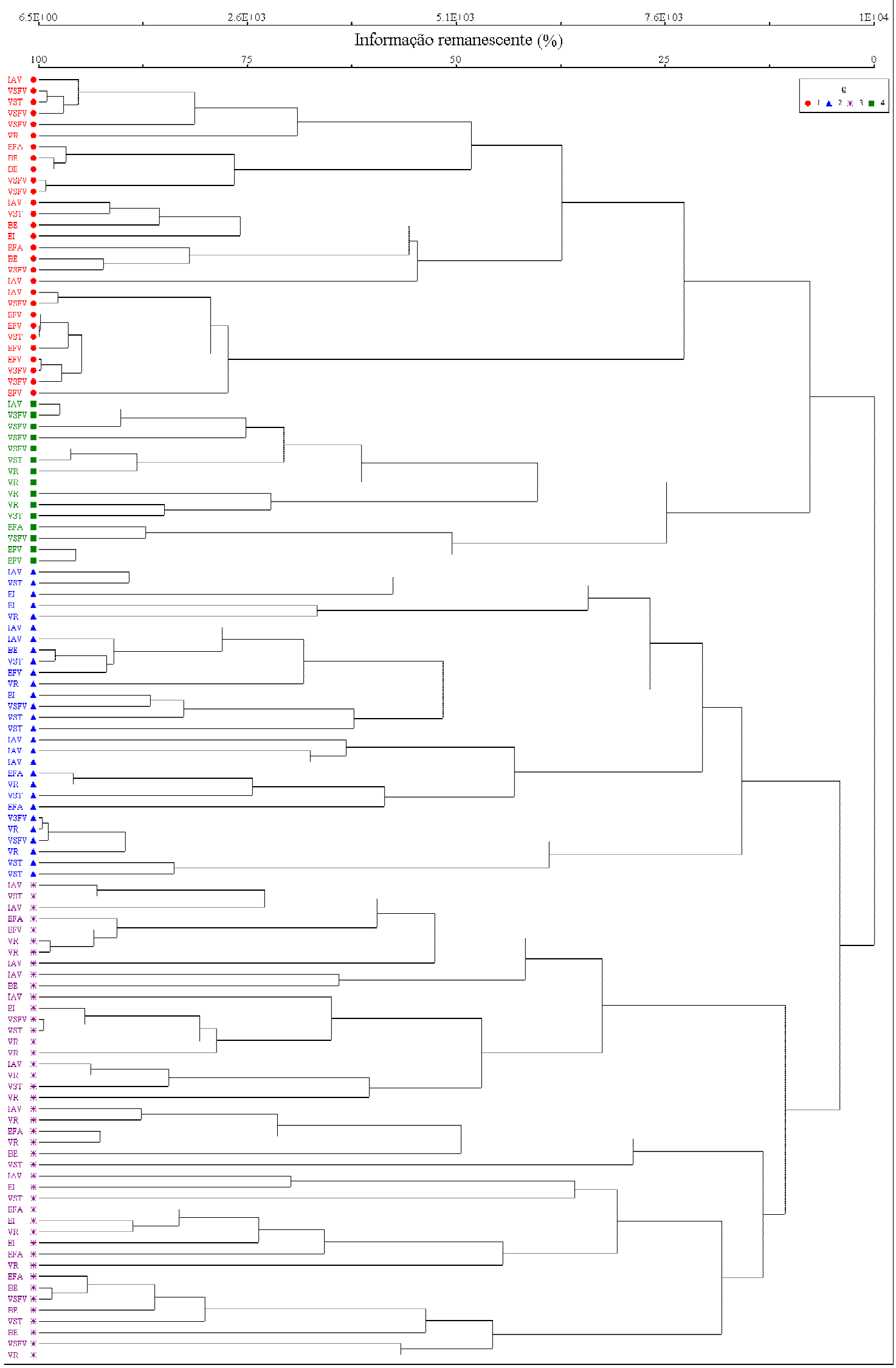

Figura 8. Dendrograma dos 115 levantamentos dos campos de Itararé, a partir de dados de cobertura (parcela; distância euclidiana; método de aglomeração $\beta$ flexível, $\beta=-0.25$; colorido conforme os grupos de levantamentos sugeridos pela análise de espécies indicadoras). 


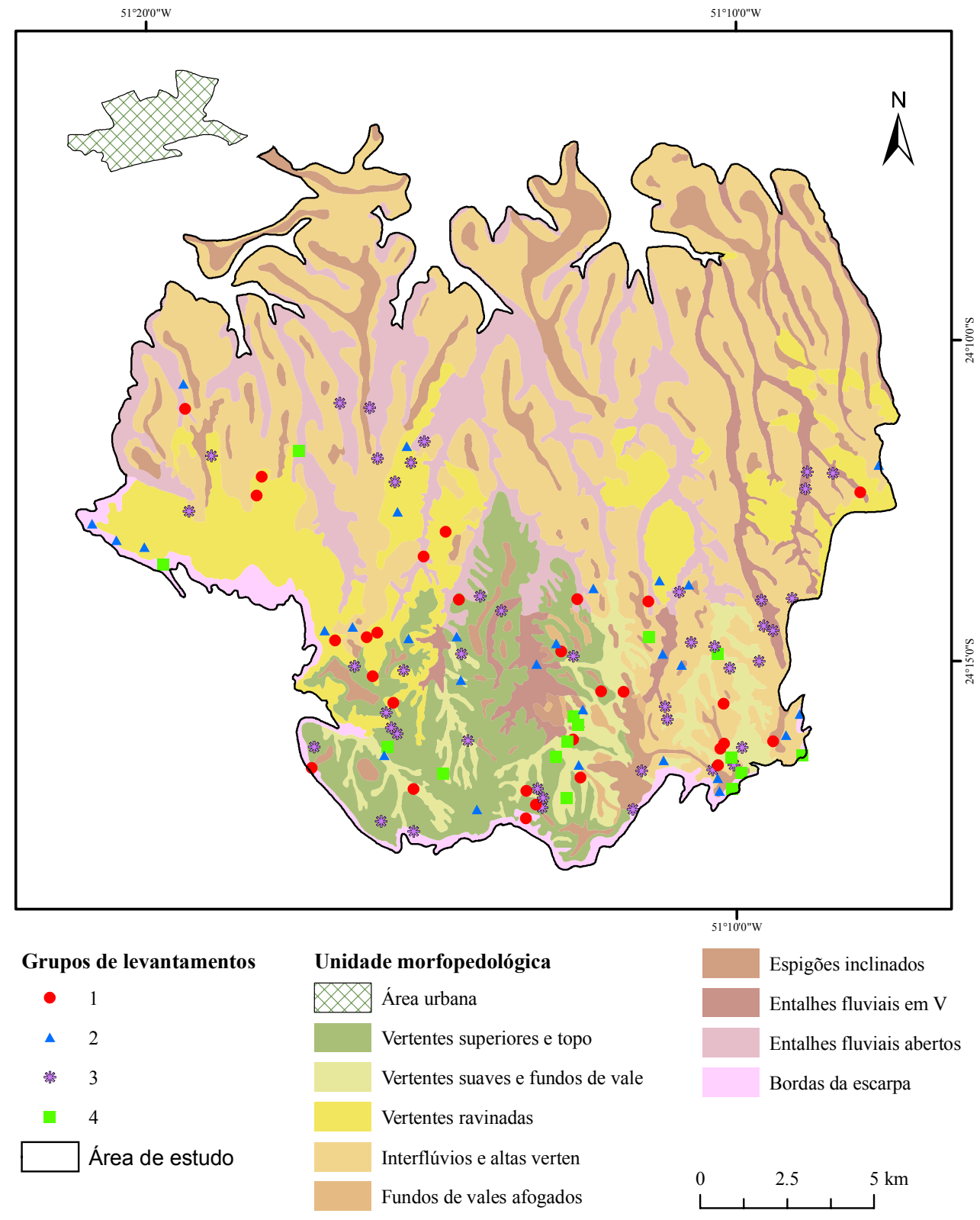

Figura 9. Agrupamento dos levantamentos sugerido pela análise de indicadores, dispostos sobre as unidades morfopedológicas. 


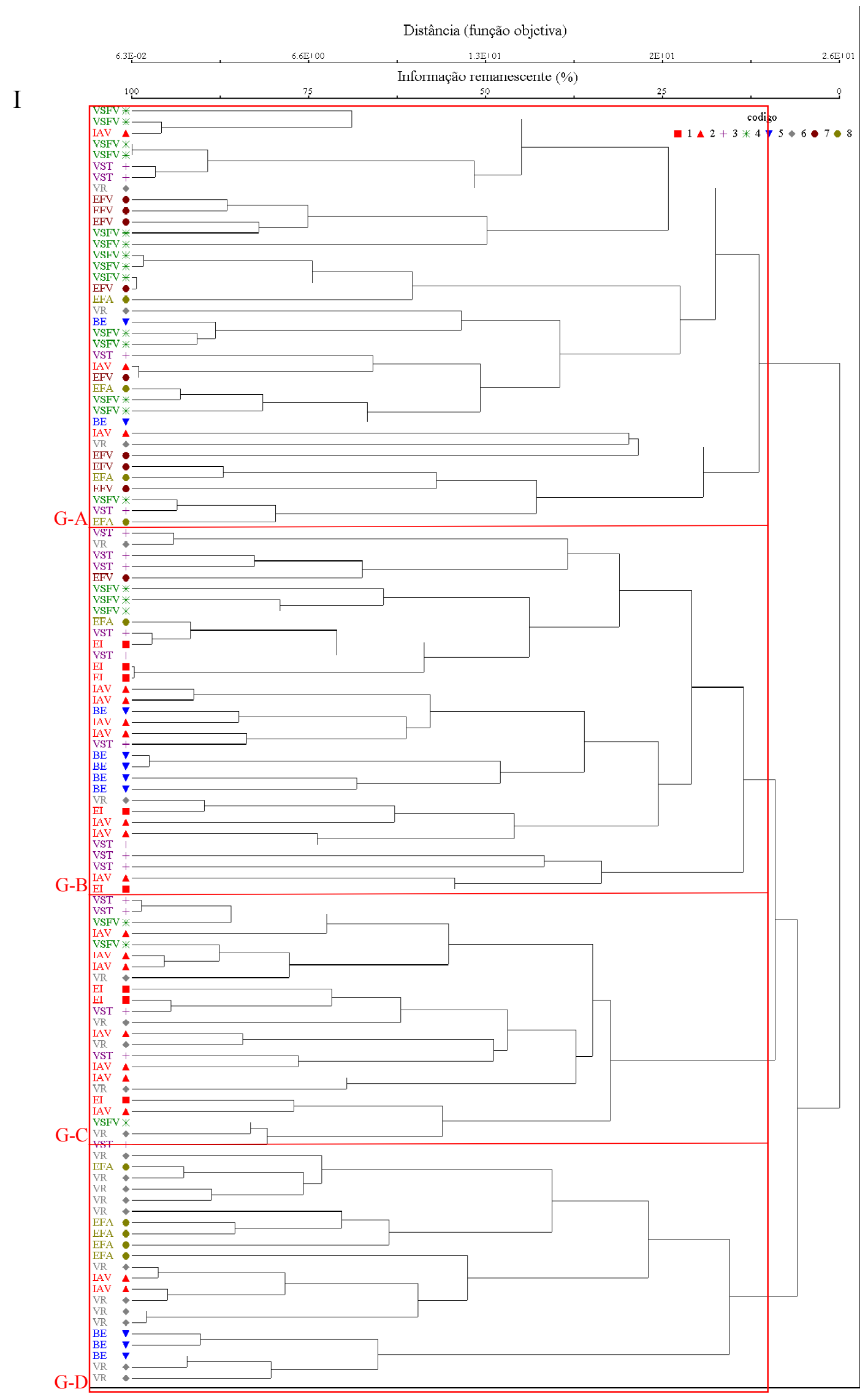

Figura 10. Dendrograma dos 115 levantamentos dos campos de Itararé, a partir de dados binários (parcela + espiral; distância de Sørensen, método de aglomeração $\beta$ flexível, $\beta$ = - $\mathbf{0 . 2 5}$; coloridos conforme as unidades morfopedológicas - vide códigos na Tabela 1 ). 


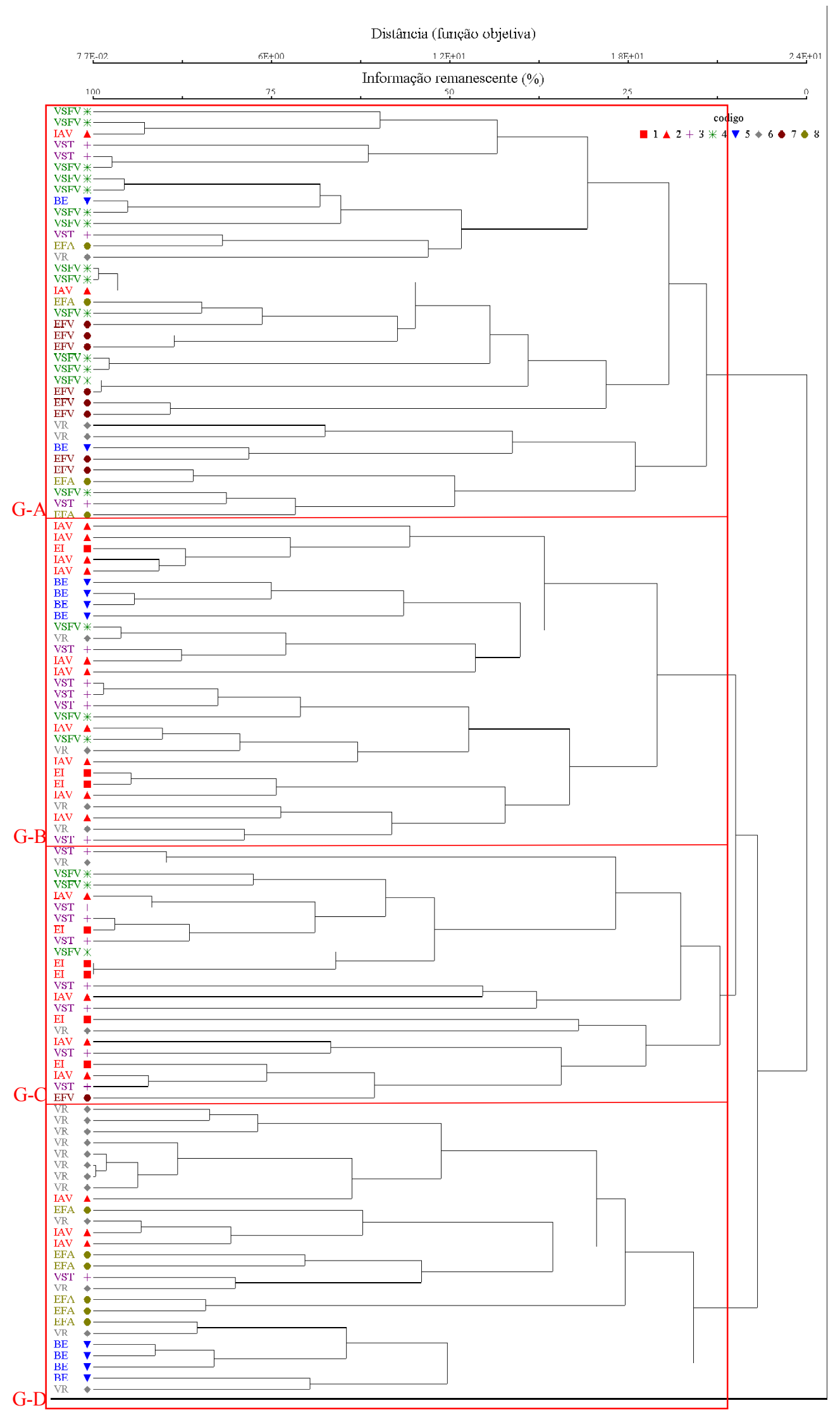

Figura 11. Dendrograma dos 115 levantamentos dos campos de Itararé, a partir de dados binários (parcela + espiral + passeio; distância de Sørensen; método aglomeração $\beta$ flexível, $\beta=\mathbf{- 0 . 2 5}$; coloridos conforme as unidades morfopedológicas - vide códigos na Tabela 1). 

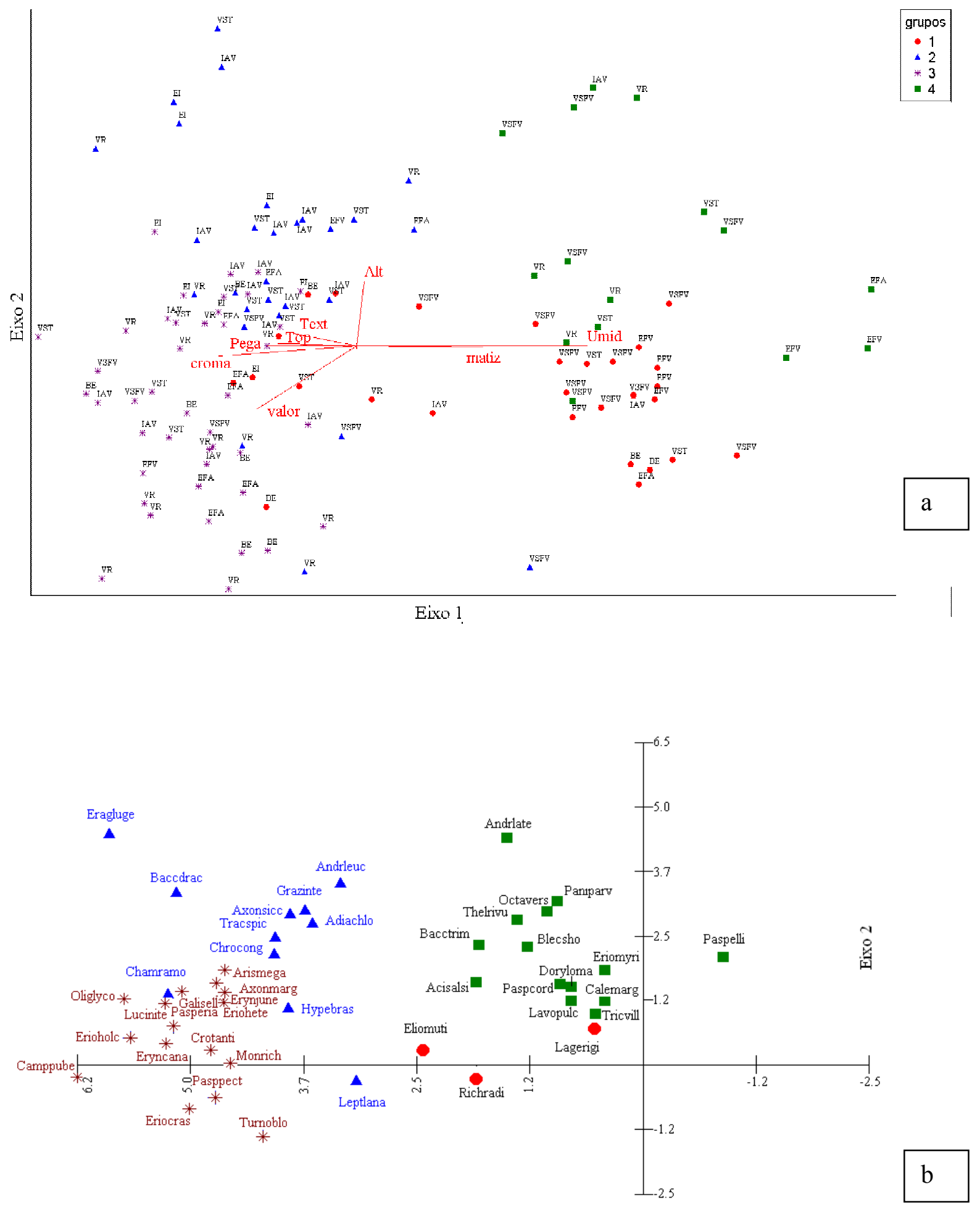

Eixo 1

Figura 12. Análise de correspondência corrigida (DCA) para os campos de Itararé: diagrama de ordenação das 115 parcelas e sua correlação com (a) 30 variáveis utilizadas - vetores e (b) espécies indicadoras, baseados na distribuição da cobertura e nos grupos de levantamentos definidos pela análise de espécies indicadoras, apresentados na Figura 8 (códigos das unidades morfopedológicas na Tabela 1, das espécies no Anexo 2 e dos descritores ambientais na Tabela 2). 

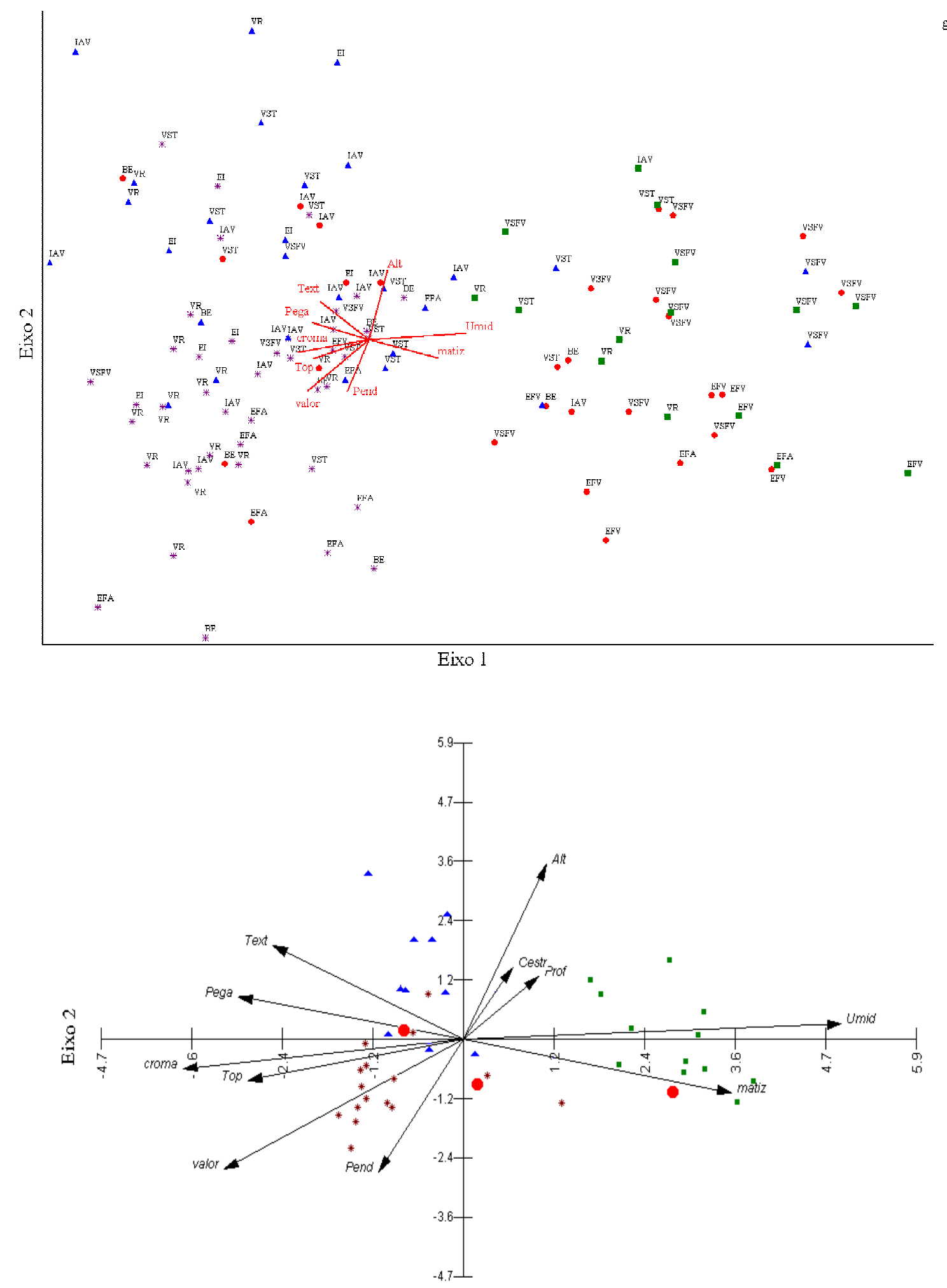

Eixo 1

Figura 13. Análise de correspondência canônica (CCA) para os campos de Itararé: diagrama de ordenação das (a) 115 parcelas e das (b) espécies indicadoras, baseados na distribuição da cobertura, sua correlação com as 11 variáveis ambientais-vetores e nos grupos de levantamentos definidos pela análise de espécies indicadoras, apresentados na Figura 8 

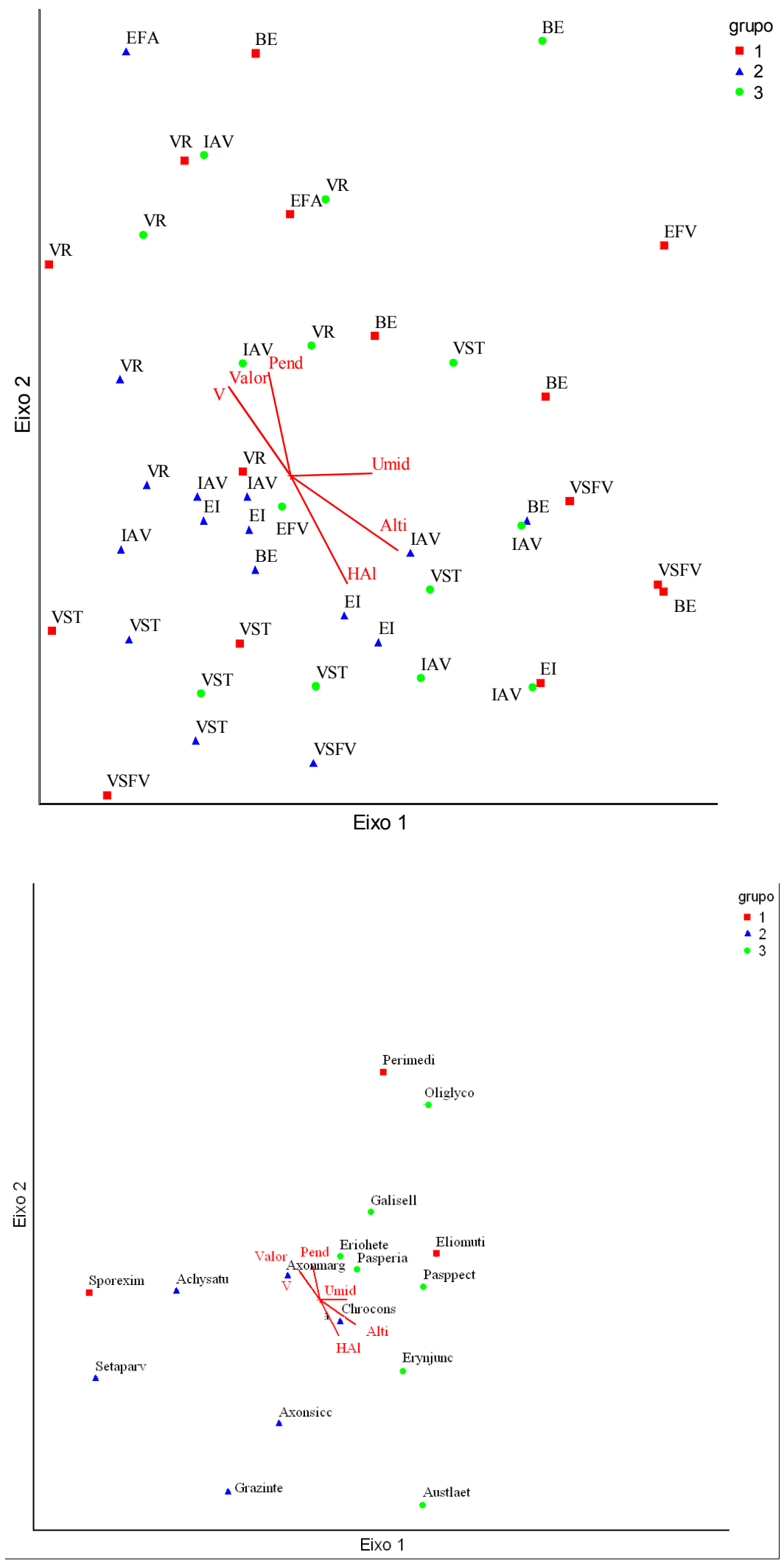

Figura 14. Análise de correspondência canônica (CCA) para os campos de Itararé: diagrama de ordenação das 45 parcelas (a) e das espécies indicadoras (b), baseados na distribuição da cobertura, sua correlação com as 7 variáveis ambientais-vetores e nos grupos de levantamentos definidos pela análise de espécies indicadoras (códigos das unidades 
Tabela 1. Estratos amostrais utilizados no levantamento fitoecológico dos campos de Itararé, SP.

\begin{tabular}{llr}
\hline \multicolumn{1}{c}{ Código } & \multicolumn{1}{c}{$\begin{array}{c}\text { Estrato amostral } \\
\text { (morfopedologia / faixas microclimáticas) }\end{array}$} & $\begin{array}{r}\text { n. de } \\
\text { amostras }\end{array}$ \\
\hline IAV-A & Interflúvios e altas vertentes / campos de planalto & 9 \\
\hline IAV-B & Interflúvios e altas vertentes / campos do alto & 10 \\
\hline BE & Bordas da escarpa / campos do alto & 10 \\
\hline EFA & Entalhes fluviais abertos / campos do planalto & 10 \\
\hline EFV & Entalhes fluviais em V / campos do planalto & 9 \\
\hline EI-A & Espigões inclinados / campos de planalto & 4 \\
\hline EI-B & Espigões inclinados / campos do alto & 4 \\
\hline VSFV-A & Vertentes suaves e fundos de vale / campos de planalto & 10 \\
\hline VSFV-B & Vertentes suaves e fundos de vale / campo do alto & 10 \\
\hline VR-A & Vertentes ravinadas / campos de planalto & 11 \\
\hline VR-B & Vertentes ravinadas / campos do alto & 10 \\
\hline VS-A & Vertentes superiores e topos / campos de planalto & 8 \\
\hline VS-B & Vertentes superiores e topos / campos do alto & 10 \\
\hline
\end{tabular}

Vide capítulo 1 para descrição detalhada das unidades morfopedológicas

Tabela 2. Descritores ambientais utilizados na análise dos campos de Itararé, SP (tipo: C categórica, Q - quantitativo (solo); parcelas: número de parcelas na qual houve mensuração da variável; escala inicial: número de classes categóricas inicialmente utilizadas; escala redefinida : número de classes categóricas redefinidas após análise de distribuição de freqüência das classes de escalas iniciais; D: descritor descartado). Células mescladas dessa tabela correspondem a fusão de descritores.

\begin{tabular}{|c|c|c|c|c|c|}
\hline Descritor & Código & Tipo & Parcelas & $\begin{array}{l}\text { Escala } \\
\text { inicial }\end{array}$ & $\begin{array}{l}\text { Escala } \\
\text { redefinida }\end{array}$ \\
\hline \multicolumn{6}{|l|}{ Meio Fisíco } \\
\hline Situação topográfica & TOPO & $\mathrm{C}$ & 115 & 15 & 13 \\
\hline Declividade & PEND & Q & 115 & & \\
\hline Altitude & ALTI & Q & 115 & & \\
\hline Exposição & EXP & $\mathrm{C}$ & 115 & 9 & 9 \\
\hline Cobertura da superfície - solo nu e livre & NU + LIVRE & Q & 115 & & \\
\hline Cobertura da superfície - serrapilheira & SERR & Q & 115 & & \\
\hline Natureza da rocha & $\mathrm{D}$ & & 115 & & \\
\hline Efervescência da rocha & $\mathrm{D}$ & & 115 & & \\
\hline Profundidade do solo & PROF & Q & 115 & & \\
\hline Textura do solo & TEXT & $\mathrm{C}$ & 115 & 13 & \\
\hline Fração grosseira do solo & FGROSS & $\mathrm{C}$ & 115 & 4 & 2 \\
\hline Coesão estrutural do solo & \multirow{3}{*}{ CESTR } & \multirow{3}{*}{$\mathrm{C}$} & \multirow{3}{*}{115} & 7 & \multirow{3}{*}{9} \\
\hline Tamanho estrutural do solo & & & & 4 & \\
\hline Tipo estrutural do solo & & & & 3 & \\
\hline Consistência seca do solo & CONSI & $\mathrm{C}$ & 115 & 6 & \\
\hline Consistência úmida do solo & $\mathrm{D}$ & & 115 & & \\
\hline Porosidade do solo - Quantidade & \multirow{2}{*}{ POROS } & \multirow{2}{*}{$\mathrm{C}$} & \multirow{2}{*}{115} & 6 & \multirow{2}{*}{5} \\
\hline Porosidade do solo - Tamanho & & & & 6 & \\
\hline Cor do solo seco - Matiz & MATIZ & $\mathrm{C}$ & 115 & 6 & 6 \\
\hline Cor do solo seco - Valor & VALOR & $\mathrm{C}$ & 115 & 9 & 9 \\
\hline Cor do solo seco - Croma & CROMA & $\mathrm{C}$ & 115 & 6 & 6 \\
\hline Cor do solo úmido & $\mathrm{D}$ & & 115 & & \\
\hline Plasticidade do solo & PLASTI & $\mathrm{C}$ & 115 & 4 & \\
\hline Pegajosidade do solo & PEGA & $\mathrm{C}$ & 115 & 4 & \\
\hline $\mathrm{pH} \mathrm{H}_{2} \mathrm{O}$ & pHA & $\mathrm{Q}$ & 45 & & \\
\hline $\mathrm{pH} \mathrm{KCl}$ & pHK & $\mathrm{Q}$ & 45 & & \\
\hline $\mathrm{pH} \mathrm{CaCl}_{2}$ & $\mathrm{pHC}$ & $\mathrm{Q}$ & 45 & & \\
\hline Matéria orgânica & MOr & $\mathrm{Q}$ & 45 & & \\
\hline Fósforo - $\mathrm{P}^{+}$ & $\mathrm{P}$ & $\mathrm{Q}$ & 45 & & \\
\hline Potássio - $\mathrm{K}^{+}$ & $\mathrm{K}$ & $\mathrm{Q}$ & 45 & & \\
\hline Cálcio - $\mathrm{Ca}^{+2}$ & $\mathrm{Ca}$ & $\mathrm{Q}$ & 45 & & \\
\hline Magnésio $-\mathrm{Mg}^{+2}$ & $\mathrm{Mg}$ & Q & 45 & & \\
\hline Alumínio - $\mathrm{Al}^{+3}$ & $\mathrm{Al}$ & Q & 45 & & \\
\hline
\end{tabular}




\begin{tabular}{|l|l|l|l|l|l|}
\hline Descritor & Código & Tipo & Parcelas & $\begin{array}{c}\text { Escala } \\
\text { inicial }\end{array}$ & $\begin{array}{c}\text { Escala } \\
\text { redefinida }\end{array}$ \\
\hline Acidez potencial - H ${ }^{+}$Al & HAl & Q & 45 & & \\
\hline Soma de bases & SB & Q & 45 & & \\
\hline Capacidade de troca de cátions & T & Q & 45 & & \\
\hline Saturação por bases & V & Q & 45 & & \\
\hline Saturação por alumínio & m & Q & 45 & & \\
\hline Morfogênese atual & MORFOG & C & 115 & 7 & \\
\hline Tipo de morfogênese & D & & 115 & & \\
\hline Erosão & EROS & C & 115 & 5 & \\
\hline Umidade aparente da estação & UMID & C & 115 & 5 & \\
\hline Submersão & SUBM & C & 115 & 5 & \\
\hline Drenagem externa & DEXT & C & 115 & 6 & \\
\hline Drenagem interna & DINT & C & 115 & 6 & \\
\hline Vegetação & & & & & \\
\hline Regularidade da estrutura & REG & C & 115 & 4 & \\
\hline Fitodinâmica & FITOD & C & 115 & 8 & 5 \\
\hline Velocidade da fitodinâmica & VFITOD & C & 115 & 6 & \\
\hline Tipo de ecótono & D & & 115 & & \\
\hline Influência humana & & & & & \\
\hline Indicação de pastejo & PAST & C & 115 & 4 & 3 \\
\hline Indicação de sobrepastejo & D & & 115 & & \\
\hline Composição provável do rebanho & D & & 115 & & \\
\hline Atividade agrícola na área & AGR & C & 115 & 6 & 4 \\
\hline Destruição parcial da vegetação & DVEG & C & 115 & 3 & \\
\hline Existência de habitações & HAB & C & 115 & 4 & \\
\hline Grau de artificializção & D & & 115 & & \\
\hline Natureza da artificialização & D & & 115 & & \\
\hline
\end{tabular}




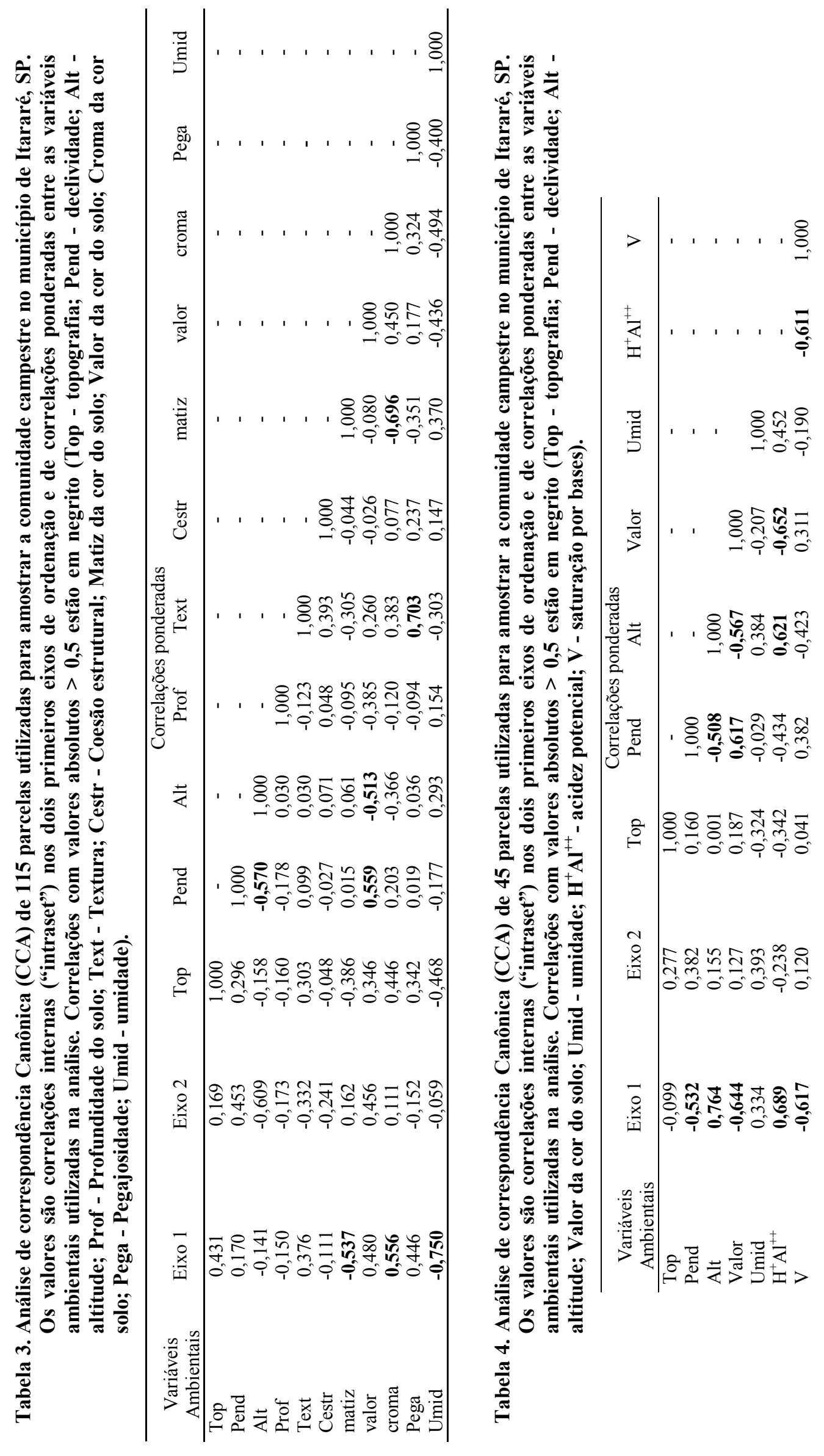


Anexo 1. Modelo da ficha de coleta de dados.

\section{FORMULÁRIO PARA LEVANTAMENTOS FITOECOLÓGICO}

\section{I - DADOS DE IDENTIFICAÇÃO}

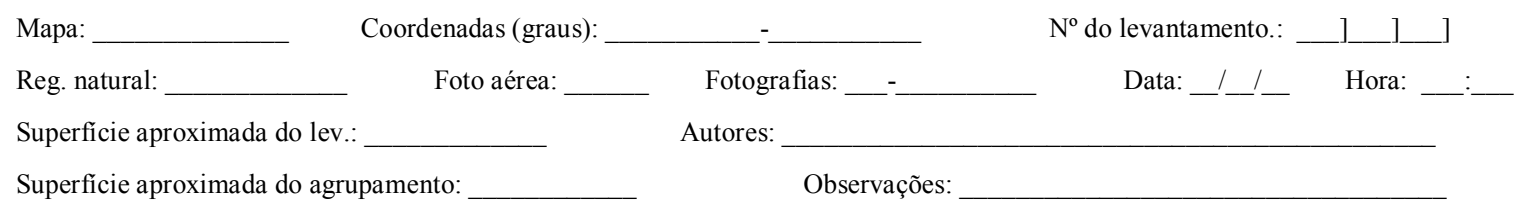

\section{II - DADOS SOBRE O MEIO FISÍCO}
A. SITUAÇÃO TOPOGRÁFICA:
B. PENDENTE:
C. Altitude (m):
D. EXPOSIÇÃO:
E. SUPERFICIE COBERTA EM \% POR: 1. 2. 3.
4. 5. $6 . \quad 7 . \quad 8$
F. NATUREZA DA ROCHA G. COLETA DA ROCHA:
H. EFERVESCÊNCIA DO HCL:
I. COLETA DE SOLO:
J. PROFUNDIDADE DO SOLO:
K. TEXTURA DO SOLO:
L. FRAÇÃO GROSSEIRA DO SOLO:
M. ESTRUTURA:
N1. CONSISTÊNCIA SECA:
N2. CONSISTÊNCIA ÚMIDA:
O1. QUANTIDADE DE POROS:
P1. COR DO SOLO SECA:
Q. PLASTICIDADE:
O2. TAMANHO DOS POROS:
S. MORFOGÊNESE ATUAL:
P2. COR DO SOLO ÚMIDA:
U. EROSÃO:
R. PEGAJOSIDADE
X. SUBMERSÃO:
T. TIPO DAS AÇÕES MORFOGÉNETICAS:
Z. DRENAGEM INTERNA:
V. UMIDADE APARENTE DA ESTAÇÃO:
Y. DRENAGEM EXTERNA:
W. ALTURA DA CAMADA DE SUBMERSÃO:

Observações:

\section{III- DADOS SOBRE A VEGETAÇÃO}
A. REGULARIDADE DA ESTRUTURA:
B. FITODINÂMICA:
C. VELOCIDADE DA FITODINÂMICA:
D. TIPOS DE ECOTONOS: 1.

2. -3.

3. - -

4. - - 5

Observações:

\section{IV - DADOS SOBRE A INFLUÊNCIA DO HOMEM SOBRE A VEGETAÇÃO E O MEIO}
A. INDICAÇÃO DE PASTEJO:
C. COMPOSIÇÃO PROVÁVEL DO REBANHO:
E. DESTRUIÇÃO PARCIAL DA VEGETAÇÃO:
G. GRAU DE ARTIFICIALIZAÇÃO:

Observações:
B. INDICAÇÃO DE SOBREPASTEJO:

D. ATIVIDADE AGRÍCOLA NA ÁREA:

F. EXISTÊNCIA DE HABITAÇÕES:

H. NATUREZA DA ARTIFICIALIZAÇÃO: 


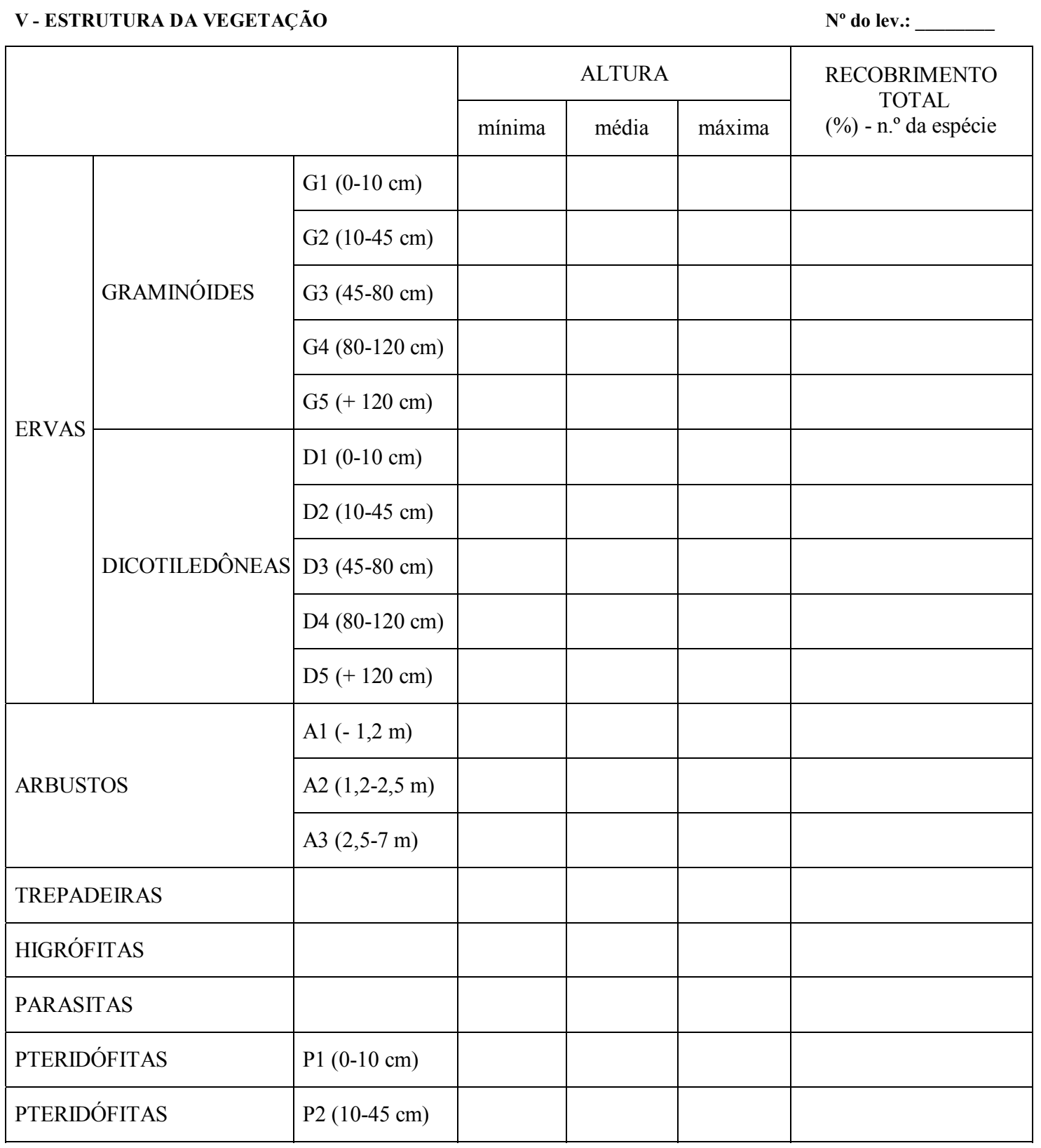


VI - ANÁLISE FITOSSOCIOLÓGICA

\begin{tabular}{|c|c|c|c|c|c|c|c|c|c|}
\hline N. & NOME DA ESPÉCIE & BRBL & FEN & ESTR & N. & NOME DA ESPÉCIE & BRBL & FEN & ESTR \\
\hline 1 & & & & & 38 & & & & \\
\hline 2 & & & & & 39 & & & & \\
\hline 3 & & & & & 40 & & & & \\
\hline 4 & & & & & 41 & & & & \\
\hline 5 & & & & & 42 & & & & \\
\hline 6 & & & & & 43 & & & & \\
\hline 7 & & & & & 44 & & & & \\
\hline 8 & & & & & 45 & & & & \\
\hline 9 & & & & & 46 & & & & \\
\hline 10 & & & & & 47 & & & & \\
\hline 11 & & & & & 48 & & & & \\
\hline 12 & & & & & 49 & & & & \\
\hline 13 & & & & & 50 & & & & \\
\hline 14 & & & & & 51 & & & & \\
\hline 15 & & & & & 52 & & & & \\
\hline 16 & & & & & 53 & & & & \\
\hline 17 & & & & & 54 & & & & \\
\hline 18 & & & & & 55 & & & & \\
\hline 19 & & & & & 56 & & & & \\
\hline 20 & & & & & 57 & & & & \\
\hline 21 & & & & & 58 & & & & \\
\hline 22 & & & & & 59 & & & & \\
\hline 23 & & & & & 60 & & & & \\
\hline 24 & & & & & 61 & & & & \\
\hline 25 & & & & & 62 & & & & \\
\hline 26 & & & & & 63 & & & & \\
\hline 27 & & & & & 64 & & & & \\
\hline 28 & & & & & 65 & & & & \\
\hline 29 & & & & & 66 & & & & \\
\hline 30 & & & & & 67 & & & & \\
\hline 31 & & & & & 68 & & & & \\
\hline 32 & & & & & 69 & & & & \\
\hline 33 & & & & & 70 & & & & \\
\hline 34 & & & & & 71 & & & & \\
\hline 35 & & & & & 72 & & & & \\
\hline 36 & & & & & 73 & & & & \\
\hline 37 & & & & & 74 & & & & \\
\hline
\end{tabular}

BRBL - Coeficiente de abundância/dominância de Braun-Blanquet

1. um ou poucos indivíduos

2. ocasional e cobertura $<5 \%$

3. abundante e cobertura $<5 \%$

4. abundante e cobertura $5-25 \%$

muito abundante e cobertura $<5 \%$

5. cobertura $25-50 \%$

6. cobertura $50-75 \%$

7. cobertura $+75 \%$
FEN - Fenologia

1. germinação ou brotação

2. crescimento

3. floração

4. frutificação

5. senescência

6. floração/frutificação

ESTR. - Estratificação vertical

\begin{tabular}{|l|l|l|l|l|}
\hline G1 $(0-10 \mathrm{~cm})$ & D1 $(0-10 \mathrm{~cm})$ & A1 $(-1,2 \mathrm{~m})$ & P3 $(45-80 \mathrm{~cm})$ & RUPIC \\
\hline G2 $(10-45 \mathrm{~cm})$ & D2 $(10-45 \mathrm{~cm})$ & A2 $(1,2-2,5 \mathrm{~m})$ & P4 $(80-120 \mathrm{~cm})$ & \\
\hline G3 $(45-80 \mathrm{~cm})$ & D3 $(45-80 \mathrm{~cm})$ & A3 $(2,5-7 \mathrm{~m})$ & TREP & \\
\hline G4 $(80-120 \mathrm{~cm})$ & D4 $(80-120 \mathrm{~cm})$ & P1 $(0-10 \mathrm{~cm})$ & HIGR & \\
\hline G5 $(+120 \mathrm{~cm})$ & D5 $(+120 \mathrm{~cm})$ & P2 $(10-45 \mathrm{~cm})$ & PARAS & \\
\hline
\end{tabular}




\section{CÓDIGO PARA PREENCHIMENTO DO FORMULÁRIO DE LEVANTAMENTO FITOECOLÓGICO}

\section{I - DADOS DE IDENTIFICAÇ̃̃O}

$\begin{array}{lllll}\text { Mapa: } & \text { 1. Itararé } & \text { 2. Engenheiro Maia } & \text { 3. Ouro Verde } & \text { 4. Barra do Chapéu } \\ \text { Região: } & \text { 1. campo de Baccharis trimera } & \text { 2. campo de Lagenocarpus } & \text { 3. campo de Trembleya } & \text { 4. campo úmido } \\ & \text { 5. campo limpo } & \text { 6. campo sujo }\end{array}$

\section{II - DADOS SOBRE O MEIO FISÍCO}

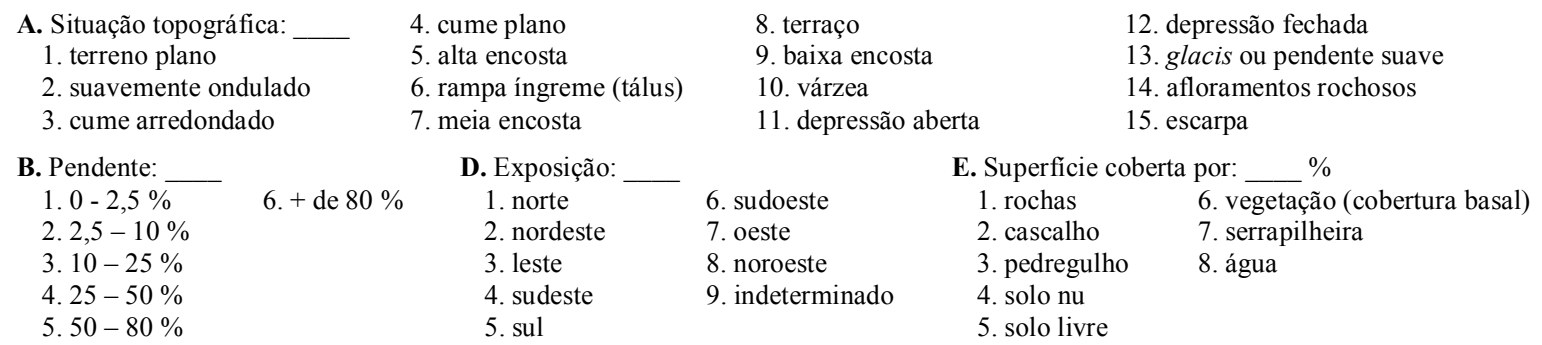

F. Natureza da rocha: 1. Arenito Furnas, mapa geológico

2. Arenito Furnas, afloramento rochoso
G. Coleta da rocha:
1. $\operatorname{sim}$ 2. não
H. Efervescência do $\mathrm{HCl}$ :
1. $\operatorname{sim}$ 2. não 3 . rocha ausente
I. Coleta do solo:
1. superficial
2. profunda
3. não coletado
J. Profundidade do solo $(\mathrm{cm})$ :
1. $0-5$
2. $5-10$
3. $10-25$
4. $25-50$
K. Textura do solo:
3. silte
1. areia
4. franco-arenosa
5. franco-siltosa
6. franca
7. franco-argiloarenosa
8. franco-argilosiltosa 5. + de 50
9. franco-argilosa
10. argilosiltosa
11. argiloarenosa
12. argila
13. Muito argilosa

L. Fração grosseira do solo $(\mathrm{cm})$ :

M1. Coesão estrutural:

1. grão simples

2. maciça > grão simples

2,5. grão simples fraca

3. maciça

4. fraca

5. moderada

6. forte
1. solta 2. macia

1. solta 2. muito friável

3. friável

O

2. Tamanho dos poros:

01. Quantidade de poros:
1. sem poros visíveis
2. poucos poros
3. poros comuns

\section{4. muitos poros}

5. muitos e poucos poros

6. muitos e comuns poros vide tabela Munsell (Munsell, 1975)

P1. Cor do solo seca:

4. dura
2. casc

.

1. infinitesimal

. muito pequena

3. pequena

4. média 1. não plástica

2. ligeiramente plástica

5. muito dura

6. extremamente dura

Q. Plasticidade:

1. não pegajosa

2. ligeiramente pegajosa

3. cascalho fino $0,2-2$

4. nula

R. Pegajosidade:

T. Tipo da morfogênese:

U. Erosão:

S. Morfogênese atual:

1. nula

5. forte

1. nula

2. muito fraca

3. fraca

6. muito forte

7. variável

2. hídrica

3. eólica

4. média

4. antrópica

1. não aparente

2. laminar fraca

3. laminar forte

4. sulcos fracos

Y. Drenagem externa:

\begin{tabular}{|c|c|}
\hline \\
\hline 1. nula & 6. fluxo superficial \\
\hline 2. lenta & \\
\hline 3. médi & \\
\hline 4. rápid & \\
\hline 5. muitc & \\
\hline
\end{tabular}

5. muito rápida
M3. Tipo estrutural:

estrutura

granular

3. blocos subangulares
X. Submersão:

1. aparentemente nunca inundada

2. inundável acidentalmente

3. submersa periodicamente - 6 meses

4. submersa periodicamente +6 meses

5. sempre submersa
5. muito firme

6. extremamente firme 


\section{CÓDIGO PARA PREENCHIMENTO DO FORMULÁRIO DE LEVANTAMENTO FITOECOLÓGICO}

\section{III - DADOS SOBRE A VEGETAÇÃO}

A. Regularidade da estrutura: 1. estrutura vertical e horizontal regulares 2. estrutura vertical irregular e horizontal regular 3. estrutura vertical regular e horizontal irregular 4. estrutura vertical e horizontal irregulares

C. Velocidade da fitodinâmica: 1. nula

2. muito lenta

3. lenta

4. média

5. rápida

6. muito rápida
B. Fitodinâmica:

1. indeterminada

2. progressiva - formação arbustiva

3. regressiva

4. transgressiva - invasão de gramíneas

D. Tipo de ecotono:

1. campo limpo

2. campo sujo

3. campo rupestre

4. campo de Baccharis

5. campo de Xyris

6. campo de Lagenocarpus

7. campo de Trembleya
5. transgressiva - invasão de eucaliptos

6. transgressiva - invasão de pinheiros

7. complexa - tipo 6 e 2

8. nula

8. capão de mata

9. mata de encosta

10. mata de galeria

11. pastagem

12. florestamento de Pinus

13. florestamento de Eucalipto

14. agricultura

\section{IV - DADOS SOBRE A INFLUÊNCIA DO HOMEM SOBRE A VEGETAÇÃO E O MEIO}

A. Indicação de pastejo:

1. presença de esterco e veredas

2. estrato herbáceo pastejado

3. estrato herbáceo e arbustivo pastejado

4. ausência aparente de pastagem

D. Atividade agrícola na área:

1. cultivo há menos de 2 anos

2. cultivo entre 2 e 5 anos

3. cultivo entre 5 e 10 anos

4. cultivo há mais de 10 anos

5. raro ou nulo

6. indeterminado

G. Grau de artificialização:

1. vegetação em clímax

2. artificialidade muito fraca

3. artificialidade fraca

4. artificialidade média

5. artificialidade forte
B. Indicação de sobrepastejo:

1. muito forte

2. forte

3. regular

4. fraca

5. ausência

E. Destruição parcial da vegetação: 1. fogo

2. coleta de lenha, carvão, etc.

3. rara ou nula

H. Natureza da artificialização:

1. pastagem

2. florestamento

3. agricultura extensiva

4. agricultura intensiva

5. nulo
C. Composição provável do rebanho:

1. bovino

2. misto

3. área livre de pastejo

F. Existência de habitações:

1. a mais de $0,5 \mathrm{~km}$

2. entre 0,5 e $1 \mathrm{~km}$

3. entre 1 e $2 \mathrm{~km}$

4. a mais de $2 \mathrm{~km}$ 


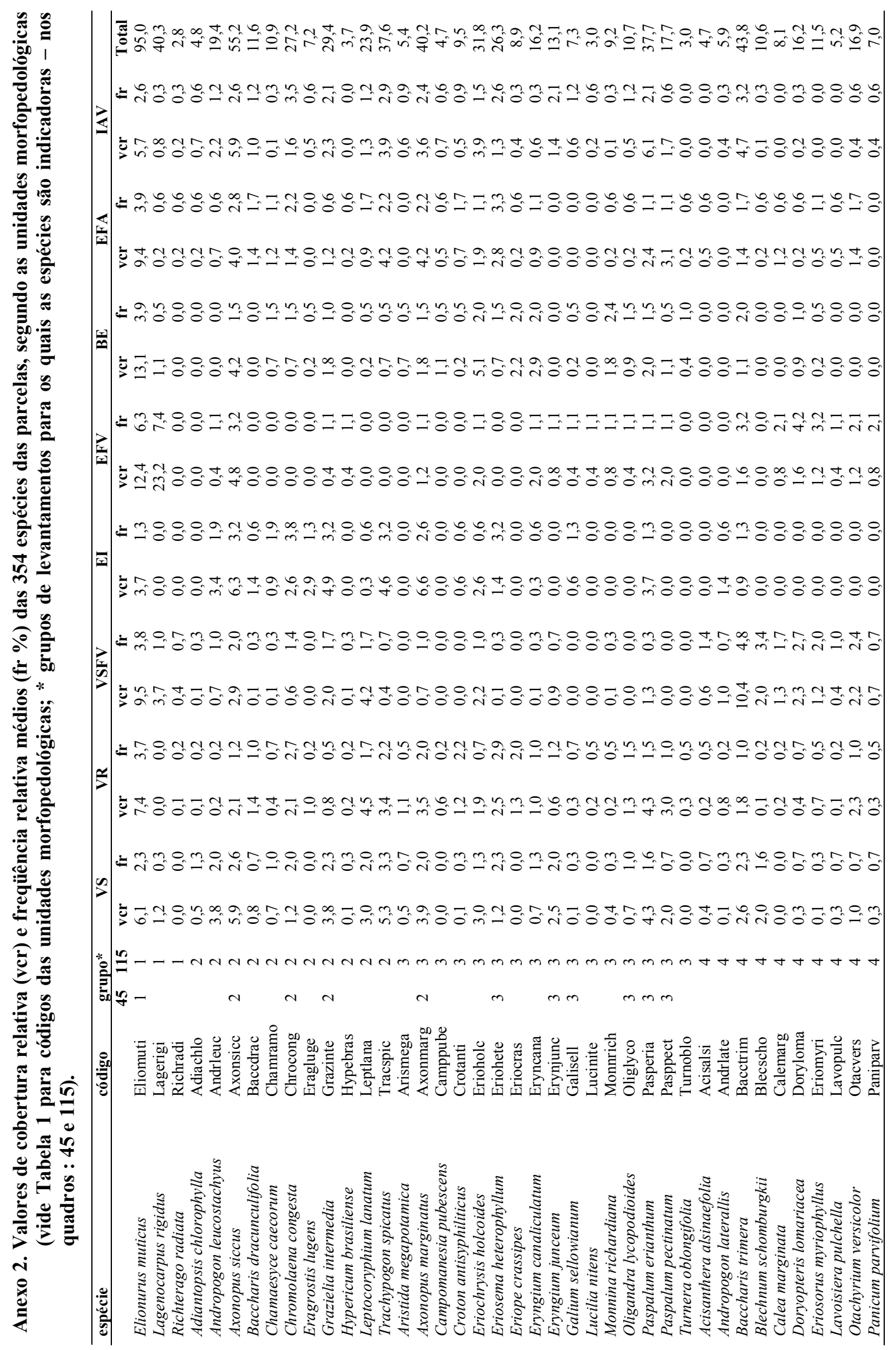




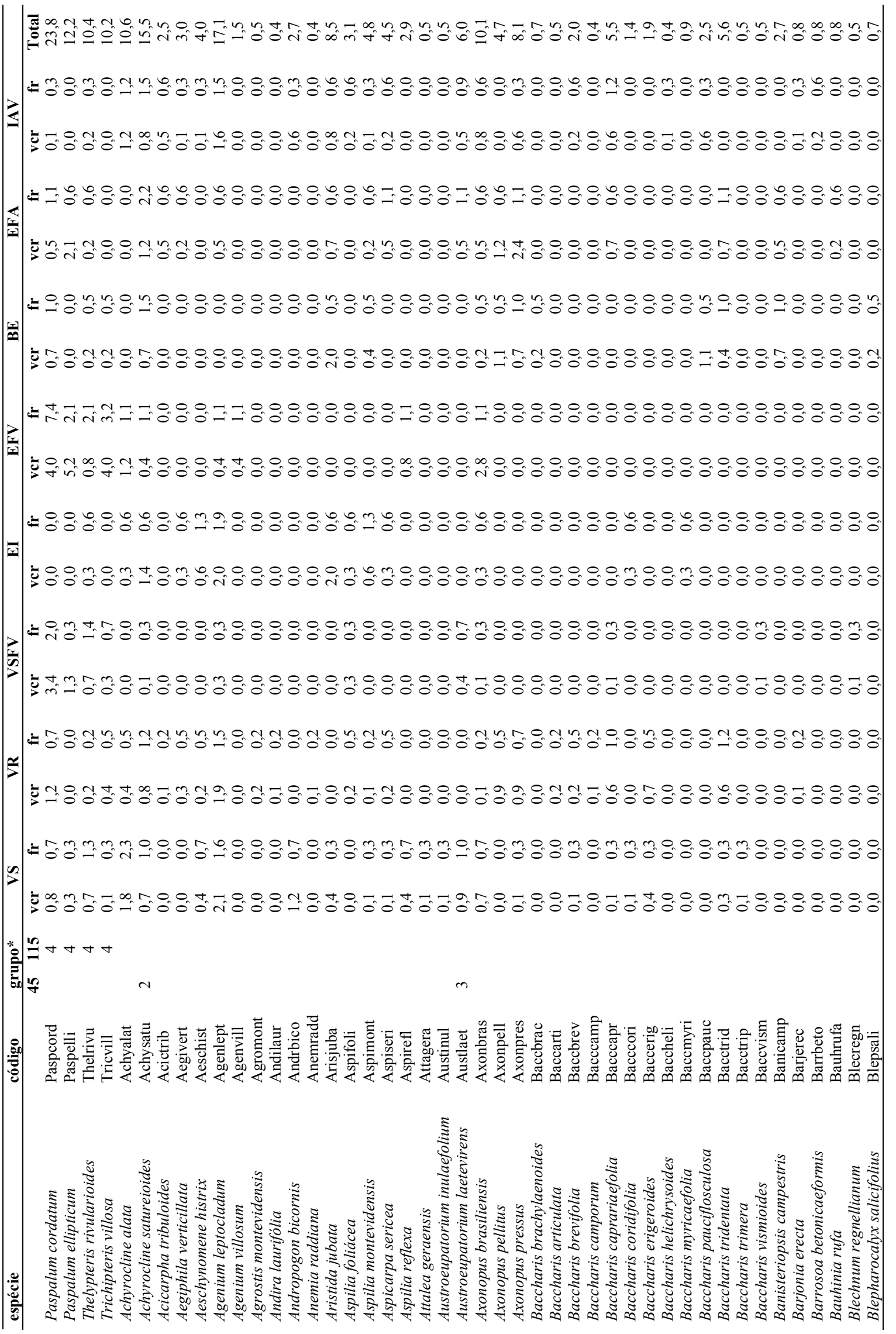




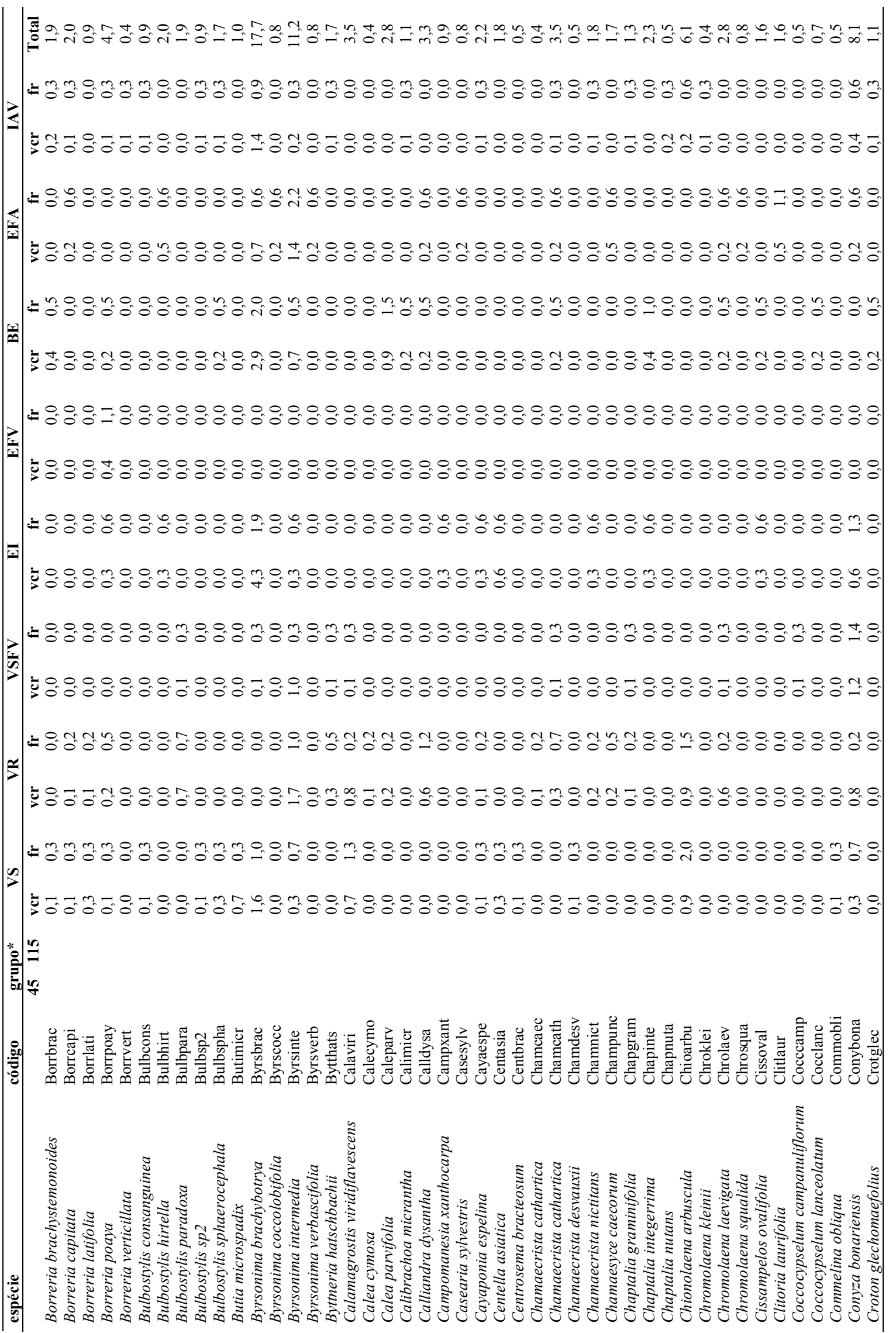




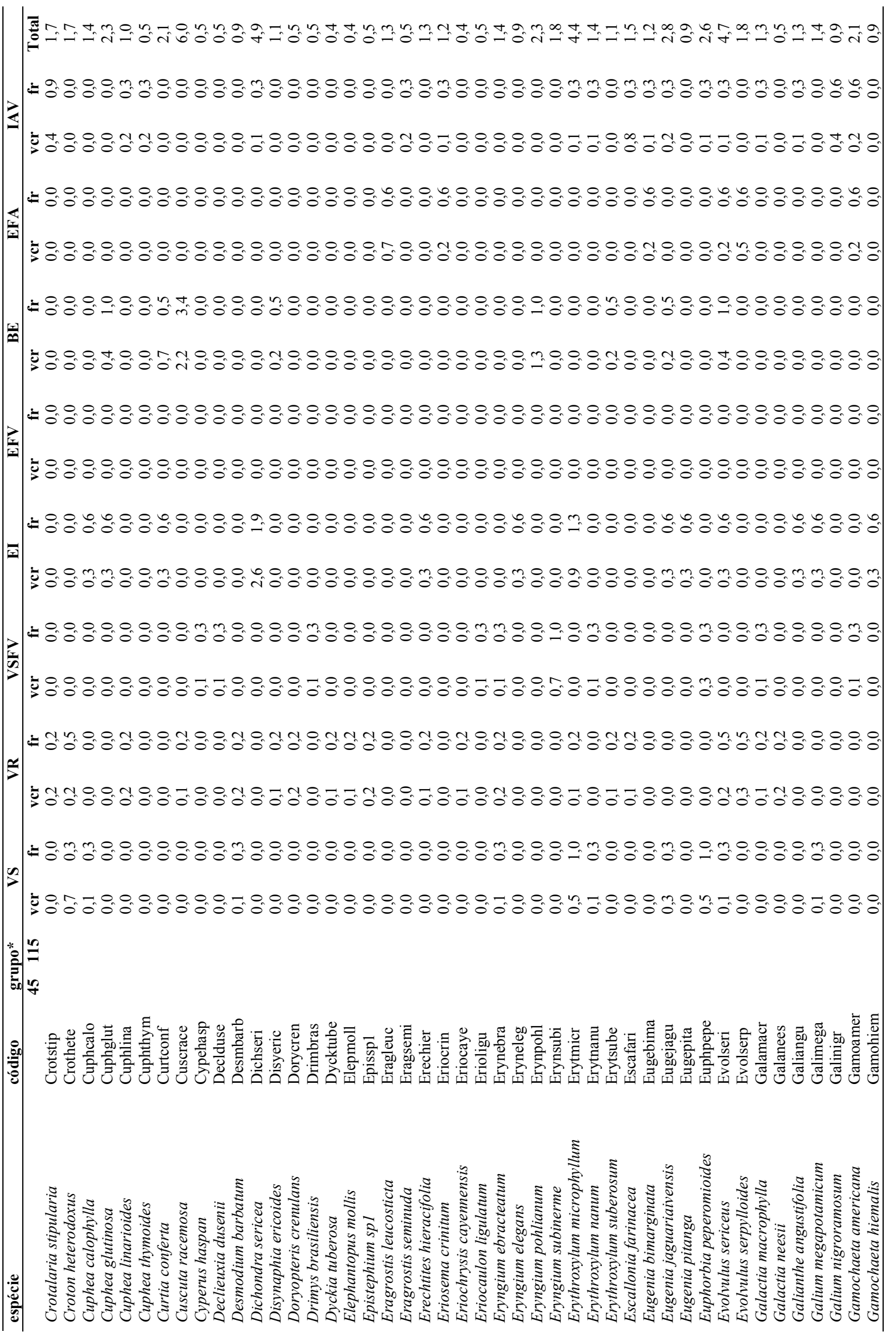




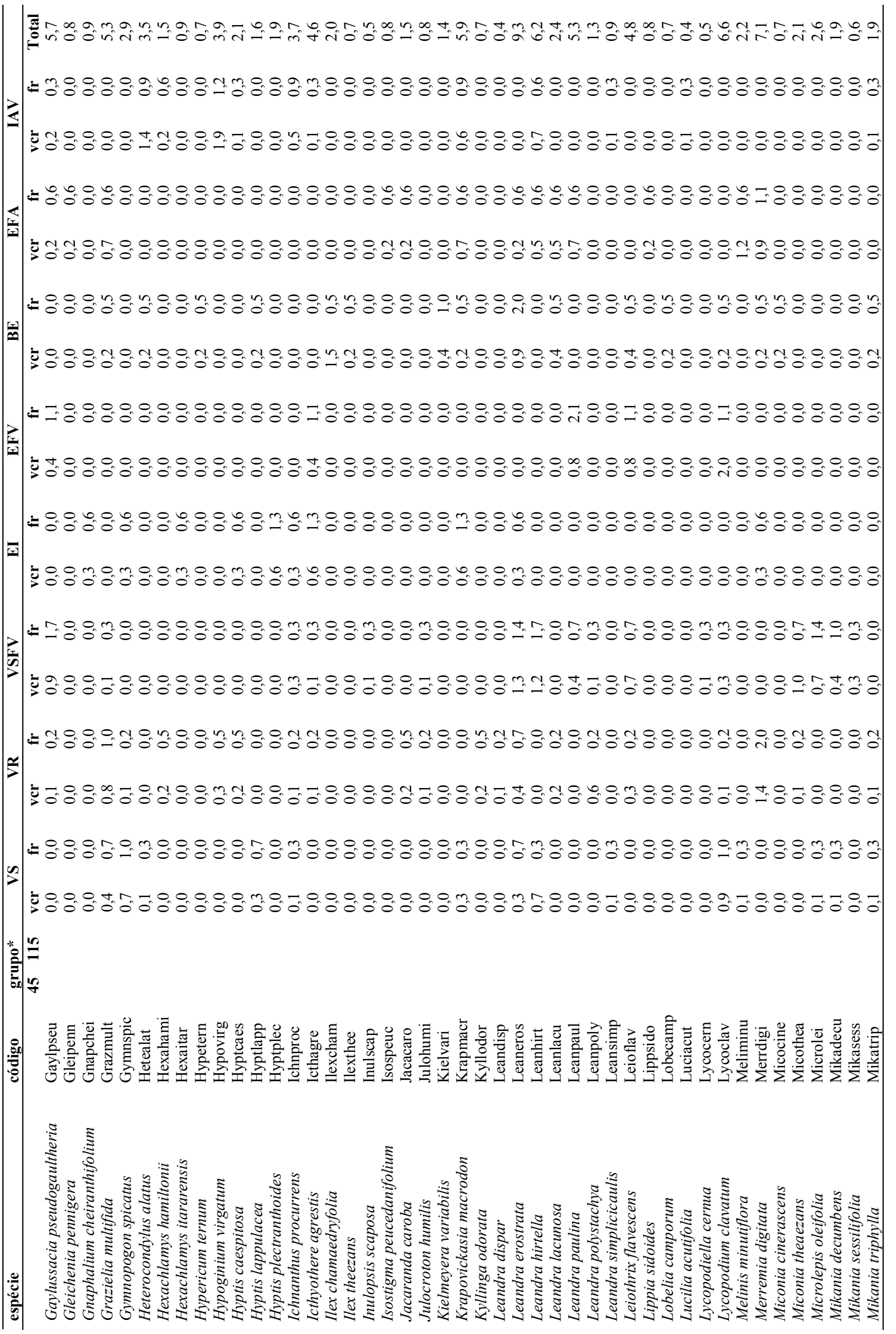




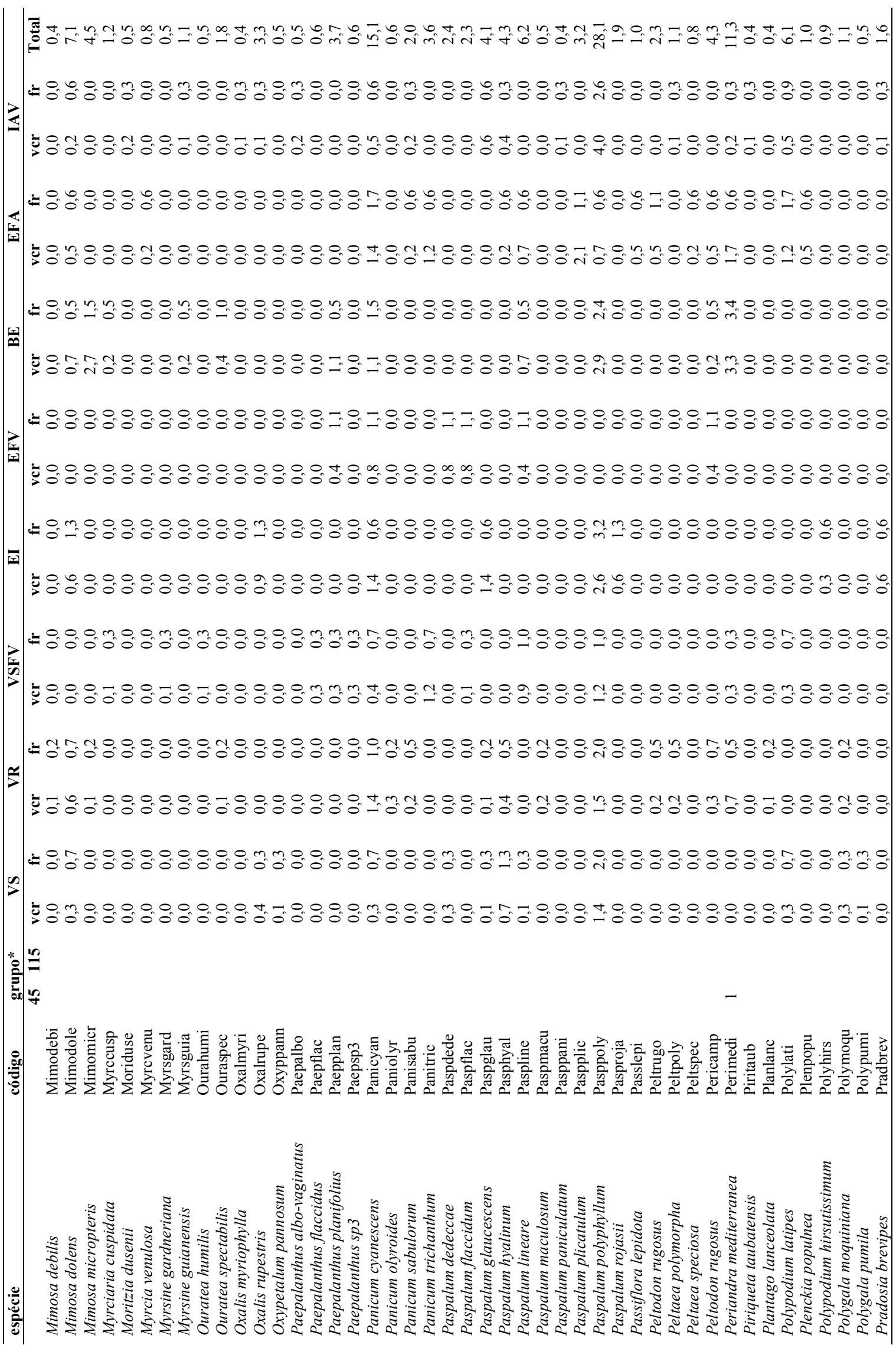




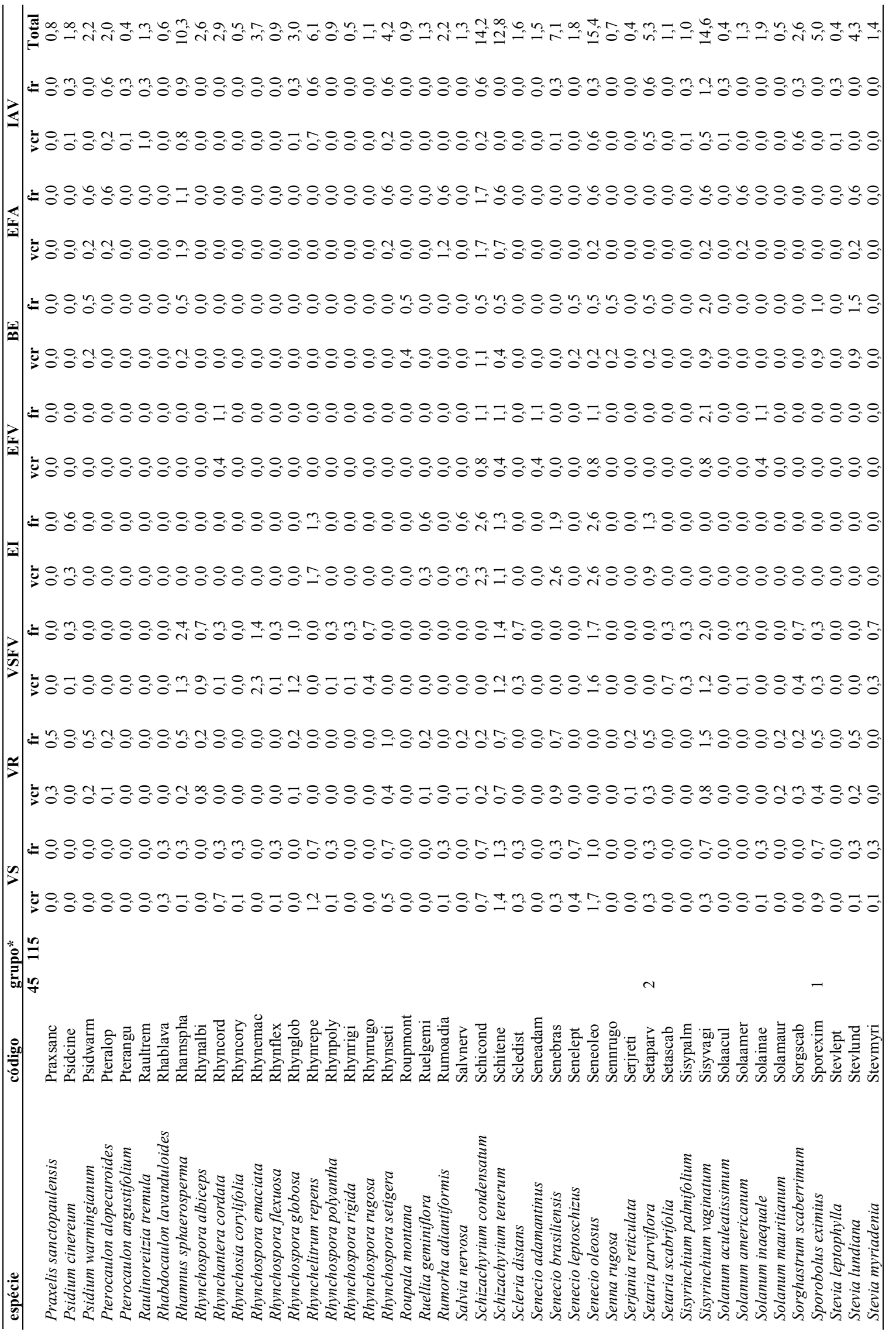




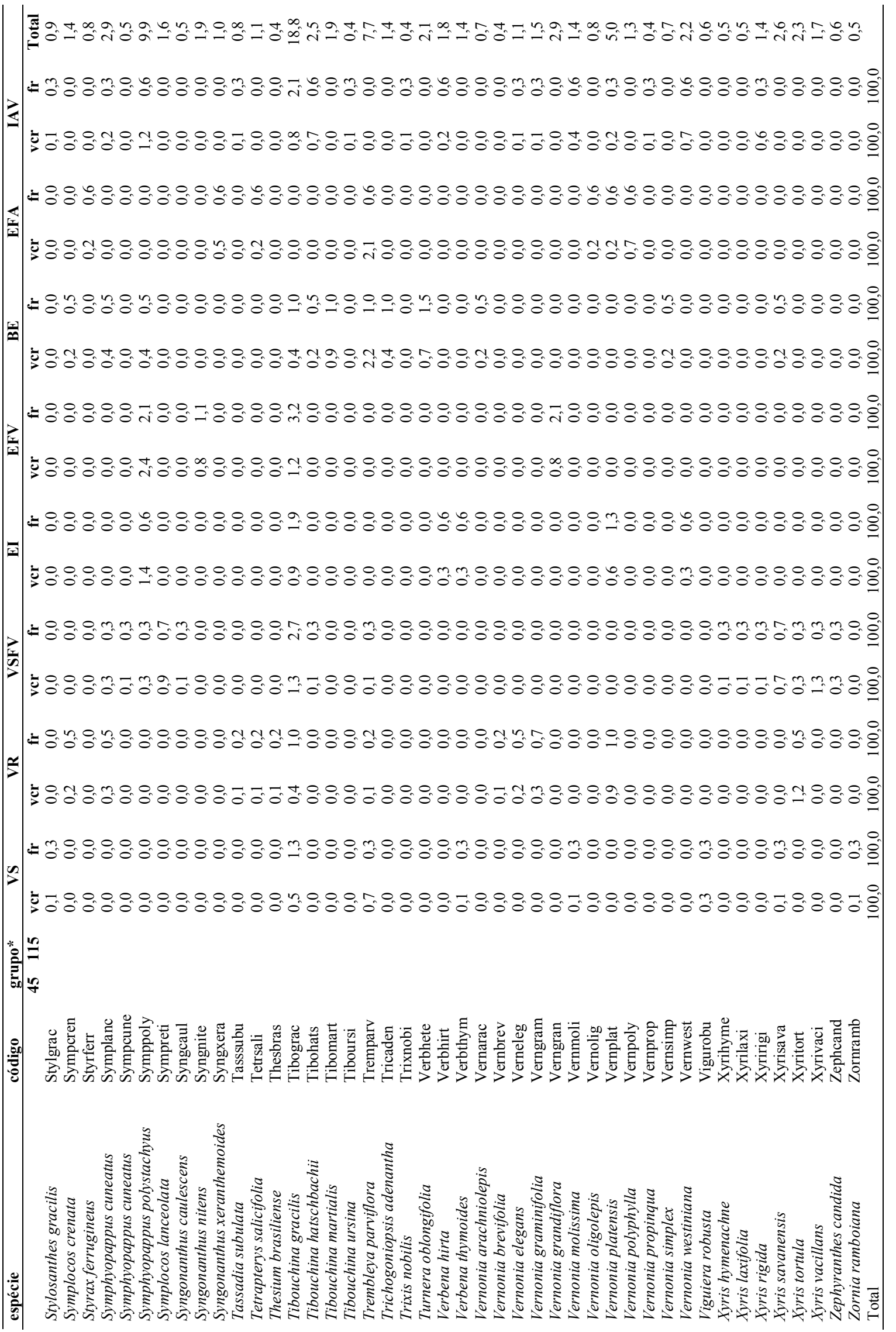




\section{Conclusões gerais}

A cartografia da ocupação das terras e da morfopedologia tem um potencial de formular uma visão sintética sobre o meio físico, a cobertura vegetal e a natureza da presença humana em um dado território. Seu baixo custo e flexibilidade fazem destes métodos opções para ampliar o leque de recursos técnicos disponíveis ao processo de ordenamento territorial.

A flora dos campos gerais de Itararé se caracteriza por uma riqueza elevada (514 espécies), com 27 novas ocorrências para o estado de São Paulo, 71 espécies consideradas vulneráveis e 22 em perigo de extinção.

As 47 listas florísticas de campos da região centro-sul do Brasil analisadas foram agrupadas em termos florísticos em um arranjo com 7 diferentes tipos de campos (campos da Chapada Diamantina - BA; campos úmido - SP, GO, DF e RS; campos alto-montanos - SP e RJ; campos de planalto - SP, PR, SC e RS; campos cerrados do Brasil Central - DF; campos cerrados do Brasil Centro-Sul - GO, SP e MG; e campos sulinos- RS). As principais variáveis climáticas relacionadas com os padrões de distribuição das espécies nessas 47 áreas foram a sazonalidade térmica, a umidade, a intensidade e duração da estiagem.

A escala de semi-detalhe do mapeamento morfopedológico distinguiu o macrogradiente de vegetação, mas não os gradientes em escala local.

A análise da composição e abundância das espécies sugere a existência de quatro grupos de campos na região de Itararé. Demonstrou-se a influência da variável umidade sobre o gradiente de vegetação ao longo da região sul de Itararé.

O mapeamento morfopedológico pode ser usado como critério de estratificação na estratégia de amostragem estratificada aleatória em áreas com uma nítida heterogeneidade ambiental inter-classes.

Além de permitir um aprofundamento dos temas desenvolvidos neste trabalho, a base de dados sobre a composição florística de campos da região Centro-Sul do Brasil (capítulo 2) e sobre a vegetação dos campos de Itararé (capítulo 3) propicia perspectivas de novos estudos. Algumas destas possibilidades são:

1. a base de dados sobre a composição florística de diferentes localidades de campos em diversas regiões brasileiras (capítulo 2) pode ser usada como um objeto de conservação para alimentar a formulação de exercícios de planejamento sistemático da conservação para o bioma campo sulino;

2. a base de dados fitoecológica aqui apresentada foi levantada há 15 anos e reflete um cenário local anterior à implementação dos grandes florestamentos no setor sul de Itararé; decorridos vinte anos da eliminação do uso do fogo, estaria ocorrendo um processo de 
sucessão secundária nessas áreas de campo? Qual seria o efeito da fragmentação dos campos pelos talhões de eucaliptos e pínus?

3. avaliar qual seria o efeito de reclassificar o mapeamento morfopedológico em um número menor de classes, fundindo aquelas sem uma relação explícita com os gradientes ambientais como por exemplo "interflúvios e altas vertentes" com "espigões inclinados";

4. explorar outros tratamentos numéricos, como por exemplo o cálculo da informação ecológica de um perfil ecológico e aprofundar a análise dos descritores ambientais categóricos, dos dados de estrutura levantados nas parcelas e dos dados binários da amostragem em espiral;

5. usar parâmetros ecológicos agregados como riqueza, contribuição para riqueza total e diversidade, gerados a partir da base de dados sobre a distribuição das espécies, em uma análise de caráter mais regional sobre a estrutura dos campos, utilizando técnicas de ordenação e descritores ambientais para solos, clima e estrutura da paisagem.

A consecução deste projeto gerou uma base de conhecimento sobre a flora e ecologia dos campos gerais da região sul de Itararé, focalizando aspectos como sua composição, estrutura e relações com variáveis ambientais. Essas informações podem subsidiar técnicocientificamente o esforço de conservação desses últimos remanescentes dos campos gerais nos estados de São Paulo e Paraná. 